Marquette University

e-Publications@Marquette

Civil and Environmental Engineering Faculty

Research and Publications

Engineering, College of

9-1-2016

Influent Wastewater Microbiota and Temperature Influence Anaerobic Membrane Bioreactor Microbial Community

Matthew Seib

Marquette University, matthew.seib@marquette.edu

K.J. Berg

Marquette University

Daniel Zitomer

Marquette University, daniel.zitomer@marquette.edu

Accepted version. Bioresource Technology, Vol. 216 (September 2016): 446-452. DOI. (C) 2016

Elsevier Ltd. Used with permission. 


\title{
Influent Wastewater Microbiota and Temperature Influence Anaerobic Membrane Bioreactor Microbial Community
}

\author{
M.D. Seib \\ Department of Civil, Construction and \\ Environmental Engineering, \\ Marquette University, \\ Milwaukee, WI \\ K.J. Berg \\ Department of Civil, Construction and \\ Environmental Engineering, \\ Marquette University, \\ Milwaukee, WI \\ D.H. Zitomer \\ Department of Civil, Construction and \\ Environmental Engineering, \\ Marquette University, \\ Milwaukee, WI
}


Abstract: Sustainable municipal wastewater recovery scenarios highlight benefits of anaerobic membrane bioreactors (AnMBRs). However, influences of continuous seeding by influent wastewater and temperature on attached-growth AnMBRs are not well understood. In this study, four bench-scale AnMBR operated at 10 and $25^{\circ} \mathrm{C}$ were fed synthetic (SPE) and then real (PE) primary effluent municipal wastewater. Illumina sequencing revealed different bacterial communities in each AnMBR in response to temperature and bioreactor configuration, whereas differences were not observed in archaeal communities. Activity assays revealed hydrogenotrophic methanogenesis was the dominant methanogenic pathway at $10{ }^{\circ} \mathrm{C}$. The significant relative abundance of Methanosaeta at $10^{\circ} \mathrm{C}$ concomitant with low acetoclastic methanogenic activity may indicate possible Methanosaeta-Geobacter direct interspecies electron transfer. When AnMBR feed was changed to PE, continual seeding with wastewater microbiota caused AnMBR microbial communities to shift, becoming more similar to PE microbiota. Therefore, influent wastewater microbiota, temperature and reactor configuration influenced the AnMBR microbial community. Keywords: Anaerobic digestion, Illumina, Microbial community

\section{Introduction}

Sustainable municipal wastewater recovery scenarios have highlighted anaerobic biotechnology with special attention being given to the anaerobic membrane bioreactor (AnMBR) (McCarty et al., 2011). AnMBR configurations have successfully achieved effluent with $<40 \mathrm{mg} / \mathrm{L}$ chemical oxygen demand (COD) from dilute or municipal wastewaters at temperatures as low as $6{ }^{\circ} \mathrm{C}$ (Seib et al., 2016a and Smith et al., 2015). These results indicate that historical anaerobic biotechnology challenges including poor operation at low temperature with low strength wastewater, and high effluent organic concentration can be overcome (Lettinga et al., 2001).

While AnMBR technology shows great promise, remaining challenges require further investigation including high energy requirements for membrane operation (Seib et al., 2016a) and post treatment for nutrient and dissolved methane removal (McCarty et al., 2011), as well as lack of fundamental understanding of microbial communities responsible for system function (Smith et al., 2015). Microbial community composition is of particular interest since anaerobic bioprocesses historically have been operated as "black boxes" without accounting for the relationship between microbiology and process function (McKeown et al., 2012).

In engineered microbial systems, community structure and diversity are considered important factors to achieve process stability (Briones and

Bioresource Technology, Vol 216 (September 2016): pg. 446-452. DOI. This article is @ Elsevier and permission has been granted for this version to appear in e-Publications@Marquette. Elsevier does not grant permission for this article to be further copied/distributed or hosted elsewhere without the express permission from Elsevier. 
Raskin, 2003 and Falk et al., 2009). Highly diverse communities which contain many unique members within different trophic groups (i.e. fermenting bacteria, syntrophic bacteria, methanogens, etc.) are functionally redundant which is important to maintain system function in the event of environmental stress (i.e. pH change, substrate change, toxicity, etc.) (Briones and Raskin, 2003 and Fernandez et al., 2000). Traditional characterizations of community diversity have included richness, evenness, and Shannon-Weaver index, which are broad measures indicating the number of unique members along with general distribution of members within the community (Stirling and Wilsey, 2001). Communities with higher richness and Shannon-Weaver index values are more diverse (Stirling and Wilsey, 2001). A high evenness score indicates unique community members are evenly distributed, which is beneficial for functional redundancy (Fernandez et al., 2000). Additionally, ordination techniques including nonmetric multi-dimensional scaling (NMDS) and principal component analysis (PCA) have been useful to compare microbial community differences in separate systems (Bialek et al., 2011 and Bocher et al., 2015).

Increased knowledge of key microbial players is important to understand the potential and limitations of microbially driven processes such as hydrolysis, fermentation, and methanogenesis (McKeown et al., 2012). Links between microbial community composition and function could be used to match inoculum biomass to specific operating conditions including temperature or waste type (McKeown et al., 2012). This information could also be used to warn of impending process upset by identifying adverse shifts in the microbial community before function significantly deteriorates (Collins et al., 2006).

While the importance of microorganisms in biological systems is evident, the body of knowledge describing microbial consortia in anaerobic wastewater reclamation systems is underdeveloped. To date, the majority of studies have focused on microbial communities in anaerobic digesters treating high strength waste. Less attention has been given to microbial community composition in anaerobic systems reclaiming dilute wastes such as municipal wastewater. However, previous studies have shown that microbial communities in otherwise similar conditions will vary due to selective pressures such as temperature and bioreactor configuration (Bialek 
et al., 2011 and O’Reilly et al., 2009), bacterial communities are typically more even and diverse than archaeal communities in anaerobic systems (Rivière et al., 2009), and hydrogenotrophic methanogenesis becomes the dominant methanogenic pathway at psychrophilic temperatures (McKeown et al., 2009, O'Reilly et al., 2009 and Siggins et al., 2011).

While several examples of low/ambient temperature AnMBRs have been previously described, only two studies have investigated the microbial community composition within the bioreactor (Smith et al., 2013 and Smith et al., 2015). Both studies evaluated completely mixed submerged AnMBRs with gas sparging treating synthetic municipal wastewater, and concluded that biofilm formation on membranes was important to achieve high organic removal. Possible benefits of biofilms such as faster interspecies hydrogen transfer and enhanced syntrophism have already been described (Lettinga et al., 2001). The results of Smith et al. (2015) coupled with existing understanding of the benefits of biofilms highlights the need for further investigation of biofilm microbial consortia in AnMBRs and suggests that reactors relying on biofilm technology such as the fluidized bed reactor (FBR) or downflow floating filter reactor (DFF) may offer advantages over flocculant biomass (Seib et al., 2016b).

The impact of continuous inoculation of anaerobic bioreactors by wastewater microbiota also merits investigation. Municipal wastewater is microbially complex (McLellan et al., 2011) and temporal effects of wastewater microbiota on engineered process microbial community composition have been observed in the aerobic activated sludge process (Lee et al., 2015). Regarding anaerobic systems, no studies have been found which considered the effect of wastewater continuous inoculation on bioreactor anaerobic microbial community.

The objective of this study was to assess AnMBR configurations using different biofilm technologies while treating synthetic and real municipal primary effluent wastewater at low and moderate temperatures. Lab-scale reactors were operated to evaluate treatment performance and bioreactor microbial community composition at common wastewater temperatures (10 and $25^{\circ} \mathrm{C}$ ). To our knowledge no study currently exists that examines the microbial community structure within AnMBRs utilizing biofilm technology 
while treating dilute primary effluent municipal wastewater at low temperatures.

\section{Methods}

\subsection{AnMBR configurations}

Two different AnMBR configurations utilizing different biofilm technologies and membrane types were used as previously described (Seib et al., 2016b). The first configuration was a downflow floating filter (DFF) bioreactor (2.3 L working volume) combined with a polymeric tubular membrane (1 L working volume). The DFF bioreactor contained buoyant plastic media to support biofilm formation (Aqwise, Herzliya, Israel). The polymeric membrane (polyvinylidene fluoride) had a nominal molecular weight cutoff of $100 \mathrm{kDa}(\sim 0.018 \mu \mathrm{m}$ nominal pore size) (FP100, PCI Membranes, Fareham, UK). The second configuration was a fluidized bed reactor (FBR) (2.3 L working volume) combined with a ceramic membrane ( $1 \mathrm{~L}$ working volume). The FBR contained $0.6 \mathrm{~mm} \times 1.7 \mathrm{~mm}(12 \times 30 \mathrm{mesh})$ coconut-based granular activated carbon (GAC) (TIGG 5DC 1230, TIGG Corp, Oakdale, PA). The ceramic membrane was composed of aluminum oxide with a $0.05 \mu \mathrm{m}$ nominal pore size (Type 1/16, Atech Innovations, Gladbeck, Germany).

\subsection{Bioreactor inoculation and operational parameters}

Each AnMBR configuration was duplicated and individual reactors were operated at different temperatures (10 and $25^{\circ} \mathrm{C}$ ), yielding a total of four systems (FBR10, FBR25, DFF10, DFF25). All AnMBRs were seeded with $2 \mathrm{~g}$ VSS/L of a mix of methanogenic biomass from five different sources as previously described (Seib et al., 2016b). For the first 320 days, all AnMBRs were fed synthetic primary effluent wastewater (SPE) as previously described (Seib et al., 2016b). After day 320, the feed to all AnMBRs was changed to real primary effluent wastewater (PE). PE was collected weekly from a local water reclamation facility (South Shore Water Reclamation Facility, Oak Creek, WI, USA) and stored at $4{ }^{\circ} \mathrm{C}$ before use (Table 1). After an initial startup period (day 1-79), total system hydraulic residence time (HRT) in all AnMBRs was $9 \mathrm{~h}$ from day 80 to 145 . On day 146, HRT was adjusted to the

Bioresource Technology, Vol 216 (September 2016): pg. 446-452. DOI. This article is @ Elsevier and permission has been granted for this version to appear in e-Publications@Marquette. Elsevier does not grant permission for this article to be further copied/distributed or hosted elsewhere without the express permission from Elsevier. 
minimum time necessary to achieve $<10 \mathrm{mg} / \mathrm{L} \mathrm{BOD}_{5}$ in AnMBR permeate in each system. Membranes were operated with flux ranging from 5.9 to $7.4 \mathrm{~L} / \mathrm{m}^{2} \mathrm{~h}$ and chemically cleaned using $\mathrm{NaClO}$ and $\mathrm{HNO}_{3}$ solutions when transmembrane pressure increased above 0.5 bar (Seib et al., 2016b).

Table 1. Average influent and effluent parameters during SPE and PE operation.

\begin{tabular}{|c|c|c|c|c|c|c|c|c|c|c|}
\hline \multirow{3}{*}{$\begin{array}{c}\text { Paramet } \\
\text { er }\end{array}$} & \multicolumn{2}{|c|}{ Influent } & \multicolumn{8}{|c|}{ Effluent } \\
\hline & \multirow[b]{2}{*}{ SPE } & \multirow[b]{2}{*}{ PE } & \multicolumn{4}{|c|}{ Treating SPE influent } & \multicolumn{4}{|c|}{ Treating PE influent } \\
\hline & & & FBR25 & FBR10 & DFF25 & DFF10 & FBR25 & FBR10 & DFF25 & DFF10 \\
\hline $\mathrm{BOD}_{5}$ & $\begin{array}{l}235 \pm 3 \\
5\end{array}$ & $160 \pm 60$ & $3 \pm 1$ & $8 \pm 4$ & $6 \pm 3$ & $8 \pm 7$ & $6 \pm 3$ & $6 \pm 4$ & $10 \pm 7$ & $10 \pm 9$ \\
\hline TCOD & $\begin{array}{l}480 \pm 5 \\
0\end{array}$ & $\begin{array}{l}310 \pm 11 \\
0\end{array}$ & $14 \pm 7$ & $25 \pm 15$ & $25 \pm 10$ & $25 \pm 13$ & $29 \pm 12$ & $29 \pm 16$ & $44 \pm 16$ & $42 \pm 19$ \\
\hline $\mathrm{NH}_{3}-\mathrm{N}$ & $\begin{array}{l}17 \pm 1 \\
5\end{array}$ & $21 \pm 7.6$ & $31 \pm 2$ & $31 \pm 1$ & $29 \pm 1$ & $31 \pm 2$ & $25 \pm 6$ & $25 \pm 6$ & $25 \pm 5$ & $25 \pm 6$ \\
\hline TKN & $\begin{array}{l}43 \pm 2 \\
8\end{array}$ & $34 \pm 6.7$ & $36 \pm 2$ & $37 \pm 2$ & $35 \pm 1$ & $37 \pm 2$ & $29 \pm 4$ & $29 \pm 5$ & $28 \pm 4$ & $29 \pm 6$ \\
\hline $\mathrm{PO}_{4}{ }^{-3}-\mathrm{P}$ & $\begin{array}{l}2.3 \pm 0 \\
3\end{array}$ & $3.8 \pm 1.7$ & $\begin{array}{l}3.9 \pm 0 . \\
3\end{array}$ & $\begin{array}{l}3.9 \pm 0 \\
3\end{array}$ & $\begin{array}{l}3.1 \pm 0 . \\
4\end{array}$ & $\begin{array}{l}3.7 \pm 0 \\
4\end{array}$ & $\begin{array}{l}4.3 \pm 1 . \\
6\end{array}$ & $\begin{array}{l}4.0 \pm 1 . \\
4\end{array}$ & $\begin{array}{l}3.6 \pm 1 \\
4\end{array}$ & $\begin{array}{l}3.8 \pm 1 . \\
7\end{array}$ \\
\hline Total P & $\begin{array}{l}5.0 \pm 0 . \\
4\end{array}$ & $5.1 \pm 1.7$ & $\begin{array}{l}3.9 \pm 0 \\
3\end{array}$ & $\begin{array}{l}4.2 \pm 0 \\
4\end{array}$ & $\begin{array}{l}3.4 \pm 0 . \\
5\end{array}$ & $\begin{array}{l}3.8 \pm 0 \\
3\end{array}$ & $\begin{array}{l}4.4 \pm 1 \\
6\end{array}$ & $\begin{array}{l}4.2 \pm 1 \\
4\end{array}$ & $\begin{array}{l}3.8 \pm 1 . \\
2\end{array}$ & $\begin{array}{l}3.9 \pm 1 . \\
6\end{array}$ \\
\hline $\mathrm{TSS}^{\underline{a}}$ & $\begin{array}{l}120 \pm 4 \\
0\end{array}$ & $106 \pm 40$ & $\mathrm{BD}$ & $\mathrm{BD}$ & $\mathrm{BD}$ & $\mathrm{BD}$ & $\mathrm{BD}$ & $\mathrm{BD}$ & BD & $\mathrm{BD}$ \\
\hline VSSa & $\begin{array}{l}115 \pm 4 \\
0\end{array}$ & $77 \pm 25$ & $\mathrm{BD}$ & $\mathrm{BD}$ & $\mathrm{BD}$ & $\mathrm{BD}$ & $\mathrm{BD}$ & $\mathrm{BD}$ & BD & BD \\
\hline
\end{tabular}

${ }^{\mathrm{a} B D}$ indicates result below method detection limit.

\subsection{Analytical procedures}

Influent and permeate $\mathrm{BOD}_{5}, \mathrm{TCOD}, \mathrm{NH}_{3}-\mathrm{N}, \mathrm{TKN}, \mathrm{PO}_{4}^{-3}, \mathrm{TP}, \mathrm{TSS}$, and VSS concentrations were determined using standard methods (APHA et al., 1999). Bioreactor bulk liquid volatile fatty acid (VFA) concentrations were determined by gas chromatography with a flame ionization detector (FID) (Agilent 7890A, Santa Clara, CA, USA). Methane concentration in biogas was determined using gas chromatography with a thermal conductivity detector (TCD) (Agilent 7890A, Santa Clara, CA, USA).

\subsection{DNA extraction}

Biomass was collected for DNA analysis from each reactor on days $180,200,230,250$, and 355 and from the PE feed on day 355. Biomass

Bioresource Technology, Vol 216 (September 2016): pg. 446-452. DOI. This article is @ Elsevier and permission has been granted for this version to appear in e-Publications@Marquette. Elsevier does not grant permission for this article to be further copied/distributed or hosted elsewhere without the express permission from Elsevier. 
$(\sim 0.5 \mathrm{~g})$ from each reactor was removed from the biocarrier and placed in $2 \mathrm{~mL}$ centrifuge tubes. Lysis buffer (120 mM phosphate buffer, $\mathrm{pH} 8.0,5 \%$ sodium dodecylsulfate) was added to each sample and cells were lysed by performing three freeze-thaw cycles followed by a 90 min incubation at $70{ }^{\circ} \mathrm{C}$. DNA was extracted using a FastDNA Spin Kit (MP Biomedicals, Santa Ana, CA, USA), and then stored at $-20^{\circ} \mathrm{C}$ until use.

\subsection{DNA sequencing}

PCR amplification using universal primers for the V4 variable region of 16 s rRNA (515F and 806R) was performed using the HotStarTaq Plus Master Mix Kit (Qiagen, Valencia, CA, USA). PCR consisted of the following steps: $94{ }^{\circ} \mathrm{C}$ for $3 \mathrm{~min}$ followed by 28 cycles of $94^{\circ} \mathrm{C}$ for $30 \mathrm{~s}, 53^{\circ} \mathrm{C}$ for $40 \mathrm{~s}$ and $72{ }^{\circ} \mathrm{C}$ for $1 \mathrm{~min}$, followed by a final elongation step at $72{ }^{\circ} \mathrm{C}$ for $5 \mathrm{~min}$. Ampure XP beads (Beckman Coulter, Indianapolis, IN, USA) were used to purify PCR products. Purified PCR products were used to prepare a DNA library using the Illumina TruSeq DNA library preparation protocol. Sequencing was performed by a commercial laboratory (MR DNA, Shallowater, TX, USA) using an Illumina MiSeq v3 300 base pair sequencing platform (Illumina, San Diego, CA, USA) following manufacturer guidelines. Barcodes and primers were removed from Q25 filtered sequences and processed as previously described (Dowd et al., 2008). Briefly, data were refined by removing sequences $<200 \mathrm{bp}$, sequences with ambiguous base calls, and sequences with homopolymers $>6 \mathrm{bp}$. Denoised sequences were clustered into operational taxonomic units (OTUs) having $97 \%$ similarity. Singleton sequences and chimeras were removed. BLASTn was used to taxonomically classify OTUs against a curated database derived from GreenGenes, RDPII, and NCBI (CME, 2015, DeSantis et al., 2006 and NCBI, 2015).

\subsection{Microbial community analysis}

Inter-AnMBR comparisons of richness (S), Shannon-Weaver diversity $(H)$, and evenness $(E)$ indices were performed using Illumina sequence results. Richness was calculated as the number of unique OTUs identified at the genus level from Illumina sequencing. Shannon-Weaver diversity index was determined as follows: $H=-\Sigma p_{i} \log \left(p_{i}\right)$, where $p_{i}$ is the relative 
abundance of genus $i$ of the $n$ genera detected in a sample ( $i=1$ to $n$ ) (Falk et al., 2009). Evenness was calculated as follows: $E=H / \ln (S)$ (Falk et al., 2009).

Ordination techniques including non-metric multi-dimensional scaling (NMDS) and principal component analysis (PCA) were used to compare AnMBR microbial communities. Using Ilumina sequencing data, NMDS using a Bray-Curtis similarity distance matrix was performed in $\mathrm{R}$ (version 3.2.0 (20015-04-16)) using the VEGAN and MASS packages. NMDS is considered well suited for environmental data because it does not assume a linear distribution (as in PCA) and is unaffected by null values among samples (Ramette, 2007). PCA was also performed using R. Sequencing results were also used to calculate Pearson's correlation coefficients comparing AnMBR and PE microbial communities.

\subsection{Methanogenic activity}

Specific methanogenic activity (SMA) assays were performed using acetate and $\mathrm{H}_{2} / \mathrm{CO}_{2}$ while AnMBRs were fed SPE (day 300) and PE (day 355) at $10^{\circ} \mathrm{C}$. Biocarrier was removed from each AnMBR, placed in a serum bottle with basal nutrient medium and agitated in an anaerobic glove box to remove biomass from the biocarrier. Biocarrier was then removed and biomass was placed in $160 \mathrm{~mL}$ serum bottles, sparged with $\mathrm{O}_{2}$-free gas (7:3 $\mathrm{v} / \mathrm{v} \mathrm{N}_{2} / \mathrm{CO}_{2}$ ), sealed with butyl rubber stoppers, and allowed to endogenously produce biogas for two days at $10^{\circ} \mathrm{C}$. Produced biogas was then removed and substrate (either acetate or $\mathrm{H}_{2} / \mathrm{CO}_{2}$ ) was added. SMA using acetate was performed for 40 days as described by Bocher et al. (2015) using biomass concentration of 1.5 to $1.8 \mathrm{~g} \mathrm{VS} / \mathrm{L}$ and $10 \mathrm{~g} / \mathrm{L}$ calcium acetate at $10{ }^{\circ} \mathrm{C}$. For SMA using $\mathrm{H}_{2} / \mathrm{CO}_{2}$, biomass concentration was $0.2 \mathrm{~g} \mathrm{VS} / \mathrm{L}$ and serum bottle headspace was charged with $100 \mathrm{~mL}$ of a 4:1 mixture of $\mathrm{H}_{2} / \mathrm{CO}_{2}$ gas that had been previously cooled to $10^{\circ} \mathrm{C}$. Decrease in headspace pressure was monitored for 40 days using a glass syringe with wetted glass barrel to stoichiometrically determine hydrogenotrophic methane production.

\section{Results and discussion}

\subsection{AnMBR organic removal and performance}

Bioresource Technology, Vol 216 (September 2016): pg. 446-452. DOI. This article is @ Elsevier and permission has been granted for this version to appear in e-Publications@Marquette. Elsevier does not grant permission for this article to be further copied/distributed or hosted elsewhere without the express permission from Elsevier. 
All AnMBRs were assumed to achieve quasi-steady state after 320 days of SPE operation, since organic removal varied no more than $\pm 3 \%$ in each system. Organic removal in all four AnMBRs was $>94 \%$ while treating both SPE and PE, with average permeate $\mathrm{BOD}_{5} \leqslant 10 \mathrm{mg} / \mathrm{L}$ in all systems (Table 1). Each AnMBR required a specific bioreactor HRT to achieve low permeate $\mathrm{BOD}_{5}$, with FBR25 and DFF25 both operated at $4.2 \mathrm{~h}$ and FBR10 and DFF10 operated at 5.6 and $9.8 \mathrm{~h}$, respectively. These values correspond to total system HRTs of 6, 6, 8, and $14 \mathrm{~h}$ for the FBR25, DFF25, FBR10, and DFF10 systems, respectively, considering membrane system volumes. Average permeate TCOD was $\leqslant 25 \mathrm{mg} / \mathrm{L}$ in all AnMBRs while treating SPE and $\leqslant 45 \mathrm{mg} / \mathrm{L}$ while treating PE. The increased average effluent TCOD when treating PE was likely due to a combination of higher amount of recalcitrant COD in the PE along with insufficient time for all AnMBRs to acclimate to the PE substrate. Bioreactor bulk liquid total VFA (as acetic acid) concentrations remained low throughout the study, averaging $<40 \mathrm{mg} / \mathrm{L}$ in all AnMBRs during SPE operation and $<15 \mathrm{mg} / \mathrm{L}$ during PE operation.

\subsection{Microbial diversity and community structure}

Diversity indices derived from sequencing analysis of the V4 region of 16S rRNA of biofilm biomass from each bioreactor (Tables S1 and S2) indicate communities dominated by a few OTUs in each AnMBR (Table 2). Analysis revealed greater richness, evenness, and Shannon-Weaver diversity values in the bacterial community of each AnMBR compared to the archaeal community, which is consistent with findings of previous anaerobic studies (Regueiro et al., 2012 and Rivière et al., 2009). All systems contained a similar number of bacterial and archaeal OTUs, with the exception of FBR10, which had fewer bacterial OTUs. Shannon indices were similar among all AnMBRs with an average index for all systems of $1.62 \pm 0.08$ for Bacteria and $0.56 \pm 0.08$ for Archaea. These are lower than values of 1.92 to 3.91 previously reported in mesophilic anaerobic studies treating wastes including swine wastewater and synthetic sulfate-rich wastewater (Briones et al., 2007 and Roy et al., 2009). Evenness scores were higher for bacterial communities compared to archaeal communities. Evenness scores were also similar among AnMBRs, with average scores of $0.27 \pm 0.01$ for Bacteria and $0.20 \pm 0.03$ for Archaea. Evenness scores found in previous mesophilic digestion studies ranged from 0.73 to 0.91 , indicating more even distribution

Bioresource Technology, Vol 216 (September 2016): pg. 446-452. DOI. This article is @ Elsevier and permission has been granted for this version to appear in e-Publications@Marquette. Elsevier does not grant permission for this article to be further copied/distributed or hosted elsewhere without the express permission from Elsevier. 
of OTUs detected in those studies (Briones et al., 2007 and Roy et al., 2009). Diversity index scores for $10^{\circ} \mathrm{C}$ and $25^{\circ} \mathrm{C}$ systems were similar but were lower than scores previously reported for mesophilic systems.

Table 2. Diversity indices for Bacteria and Archaea communities during SPE operation.

\begin{tabular}{llllll} 
& & \multicolumn{1}{c}{ FBR25 } & \multicolumn{1}{c}{ DFF25 } & \multicolumn{1}{c}{ FBR10 } & \multicolumn{1}{c}{ DFF10 } \\
Bacteria & Richness & $384 \pm 30$ & $406 \pm 10$ & $330 \pm 8$ & $403 \pm 18$ \\
& Evenness & $0.28 \pm 0.01$ & $0.27 \pm 0.01$ & $0.27 \pm 0.01$ & $0.28 \pm 0.01$ \\
& Shannon Index & $1.64 \pm 0.08$ & $1.64 \pm 0.05$ & $1.52 \pm 0.05$ & $1.66 \pm 0.09$ \\
\multirow{2}{*}{ Archaea } & Richness & $18 \pm 3$ & $18 \pm 1$ & $15 \pm 1$ & $16 \pm 2$ \\
& Evenness & $0.19 \pm 0.02$ & $0.19 \pm 0.03$ & $0.17 \pm 0.01$ & $0.23 \pm 0.02$ \\
& Shannon Index & $0.56 \pm 0.06$ & $0.55 \pm 0.08$ & $0.47 \pm 0.04$ & $0.64 \pm 0.03$
\end{tabular}

A small group of 5 of over 700 bacterial OTUs identified, including Clostridium, Bacteroides, Cytophaga, Geobacter, and Trichococcus, comprised $31-43 \%$ of the total relative abundance in all reactors while treating SPE. This is consistent with analysis previously conducted on mesophilic anaerobic communities that describe the predominant bacterial composition in anaerobic systems being composed of only a few OTUs ( $\underline{\text { Harb }}$ et al., 2015 and Rivière et al., 2009). This was also observed among Archaea, with only three genera (Methanosaeta, Methanobacterium, and Methanospirillum) accounting for $>80 \%$ of archaeal relative abundance in all AnMBRs while treating SPE.

Despite each reactor containing similar dominant OTUs, unique microbial fingerprints were observed in each system based on the most abundant bacterial OTUs. A comparison of the 20 most abundant OTUs, which represented $>50 \%$ of the relative abundance in each system, showed distinct OTU distributions in all AnMBRs (Fig. S1). During SPE operation, the bacterial community in each AnMBR possessed a unique dominant OTU. For FBR10 and FBR25, an OTU most similar to Clostridium was dominant and accounted for $>20 \%$ of all bacterial relative abundance. For the DFF reactors, an OTU most similar to Geobacter was dominant in DFF25, whereas DFF10 showed higher abundances of OTUs most similar to Cytophaga and Trichococcus. All of these genera are contained within the phyla Proteobacteria, Bacteroidetes, and Firmicuties, which have been described as being dominant in mesophilic anaerobic systems ( McKeown et al., $\underline{2009}$ and Regueiro et al., 2012) and have been shown to account for over

Bioresource Technology, Vol 216 (September 2016): pg. 446-452. DOI. This article is (C Elsevier and permission has been granted for this version to appear in e-Publications@Marquette. Elsevier does not grant permission for this article to be further copied/distributed or hosted elsewhere without the express permission from Elsevier. 
$65 \%$ of relative abundance in a psychrophilic AnMBR treating synthetic domestic wastewater (Smith et al., 2013).

The microbiome within the PE fed to the AnMBRs significantly differed from community structures in the AnMBRs during SPE operation based on Pearson's correlation coefficient and community microbial fingerprint (Fig. S1). Comparison of Pearson's correlation coefficients revealed poor correlation between AnMBR bacterial communities during SPE operation and the PE bacterial community $(r=0.08$ to 0.16$)$. Microbial fingerprint analysis showed that OTUs most similar to Arcobacter represented $30 \%$ of the PE bacterial relative abundance, but these OTUs were $\leqslant 1 \%$ of the relative abundance in all the AnMBRs during SPE operation. Other dominant OTUs in the PE included those most similar to Bacteroides, Parabacteroides, and Aeromonas. These four genera have previously been found to comprise a large portion of the bacterial community in municipal sewage ( Fisher et al., 2014 and McLellan et al., 2011).

Bacterial communities in the AnMBR systems shifted after SPE feeding to AnMBRs ceased and real PE began to be fed (Fig. S1). This was due to introduction of organisms within PE fed to the AnMBRs. Specifically, an OTU most similar to Arcobacter appeared within AnMBRs in higher relative abundance during PE operation with higher increases in the $10^{\circ} \mathrm{C}$ bioreactors.

No significant differences among the AnMBR archaeal populations were observed. A group of 28 unique archaeal OTUs was identified and over $80 \%$ of archaeal relative abundance was accounted for by three OTUs during both SPE and PE operation; these OTUs were most similar to Methanosaeta, Methanobacterium, and Methanospirillum ( Fig. S1). Unlike the bacterial community composition, the archaeal community during PE and SPE feeding were not significantly different.

Hydrogenotrophic methanogen OTUs made up a larger portion of methanogen relative abundance in the $10{ }^{\circ} \mathrm{C}$ AnMBRs, which is consistent with previous observations of methanogen population shifts to favor hydrogen utilization under psychrophilic conditions (Lettinga et al., $\underline{2001}$ and Siggins et al., 2011). OTUs most similar to hydrogenotrophic 
methanogens made up 16-40\% of archaeal relative abundance in the $25^{\circ} \mathrm{C}$ systems, whereas these OTUs accounted for $27-58 \%$ of relative abundance at $10{ }^{\circ} \mathrm{C}$. Among methanogens, the OTU most similar to Methanosaeta was the most dominant, accounting for at least $40 \%$ of archaeal relative abundance in all systems ( Fig. S1). The facts that bioreactor bulk liquid VFA concentrations remained very low, Methanosarcina was virtually absent from all samples, and all AnMBRs were run at temperatures below the mesophilic optimum of $35^{\circ} \mathrm{C}$ indicates that acetoclastic methanogenesis was achieved primarily by Methanosaeta spp. (Bialek et al., 2011).

A decrease in relative abundance of methanogens was seen over time at $10^{\circ} \mathrm{C}$ in this 365 day study, which suggests that biofilms in all AnMBRs primarily contained psychrotolerant mesophilic methanogens as opposed to developing dominant putatively psychrophilic populations. Methanogens comprised $7-12 \%$ of total microbial relative abundance in the $25^{\circ} \mathrm{C}$ AnMBRs, whereas only $2-5 \%$ methanogens were found at $10{ }^{\circ} \mathrm{C}$. Previous psychrophilic anaerobic studies operating up to 300 days have concluded that reactors seeded with mesophilic biomass primarily contained psychrotolerant mesophilic methanogens rather than a population of psychrophilic methanogens (Collins et al., 2006 and Smith et al., 2013). However, putatively psychrophilic microbial populations have been found in long term studies (>1200 days), indicating that psychrophilic organisms are present but require a very long time to establish in significant abundance (McKeown et al., 2009).

\subsection{AnMBR microbial comparisons}

Unique microbial communities existed in each AnMBR based on NMDS, Pearson's correlation, and PCA analysis despite similar values for gross evenness and diversity index. Cluster analysis using NMDS plots revealed distinct differences among the bacterial communities of AnMBRs during SPE operation (Fig. 1). The distinct grouping of bacterial profiles from each AnMBR indicate that selective pressures of bioreactor configuration and operational temperature cause differences in the microbial communities of reactors seeded with the same inoculum and fed identical substrate. This observation was also made by Bialek et al. (2011) who found methanogenic community profiles in different bioreactor configurations clustered using

Bioresource Technology, Vol 216 (September 2016): pg. 446-452. DOI. This article is (c) Elsevier and permission has been granted for this version to appear in e-Publications@Marquette. Elsevier does not grant permission for this article to be further copied/distributed or hosted elsewhere without the express permission from Elsevier. 
NMDS and by O'Reilly et al. (2009) who indicated that microbial community profiles are affected by temperature. However, in contrast to bacterial communities, the archaeal communities in this study did not cluster separately using NMDS (Fig. 1). Results from the archaeal fingerprints confirm this observation and indicates similar archaeal community structures for all AnMBRs during SPE operation (Fig. S1). Analysis using Pearson's correlation coefficient did not indicate that either bioreactor configuration or temperature had a more significant impact on community differences.
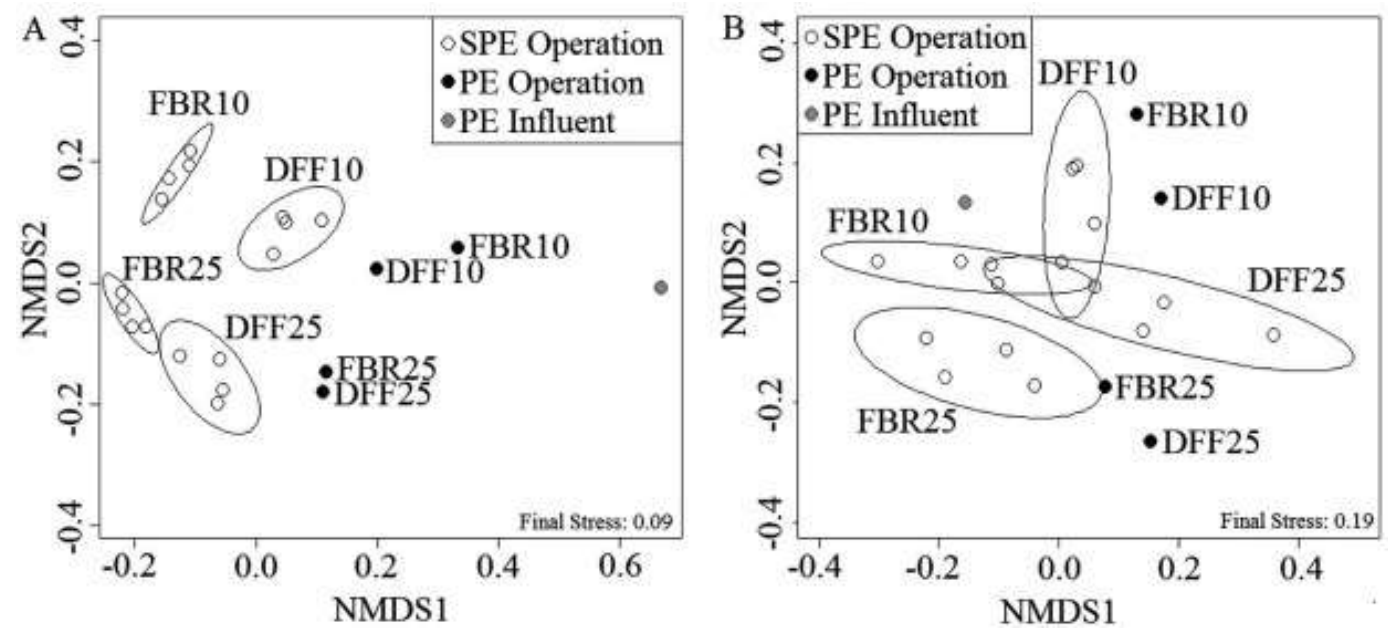

Fig. 1. Non-metric multidimensional scaling (NMDS) analysis of (A) Bacteria and (B) Archaea 16S rRNA sequencing profiles for each AnMBR. Ellipses represent clustering of each AnMBR biomass (95\% confidence). During SPE operation samples were taken on day 180, 200, 230, and 250. Samples were taken during PE operation on day 355.

PCA also helps visualize how the most dominant bacterial and archaeal genera are represented among reactors (Fig. 2). For Bacteria, differences observed among OTUs most similar to the genera Clostridium, Arcobacter, Geobacter, Trichoccous, Acinetobacter, and Cytophaga in each AnMBR explain $73 \%$ of the variance observed within bacterial communities during operation with PE and SPE. Additionally, vectors representing specific bacterial OTUs aligned with the AnMBRs possessing the highest relative abundance of each OTU, indicating the microbial community differences across AnMBRs were attributed to a specific dominant OTU in each AnMBR. For Archaea, Methanosaeta, Methanobacterium, and Methanospirillum explain $99 \%$ of the variance observed among archaeal communities. Unlike results for Bacteria, the vectors representing archaeal OTUs did not align with different AnMBRs, which reinforces observations made with NMDS and 
analysis of community fingerprints that unique archaeal community structures did not emerge in each AnMBR.
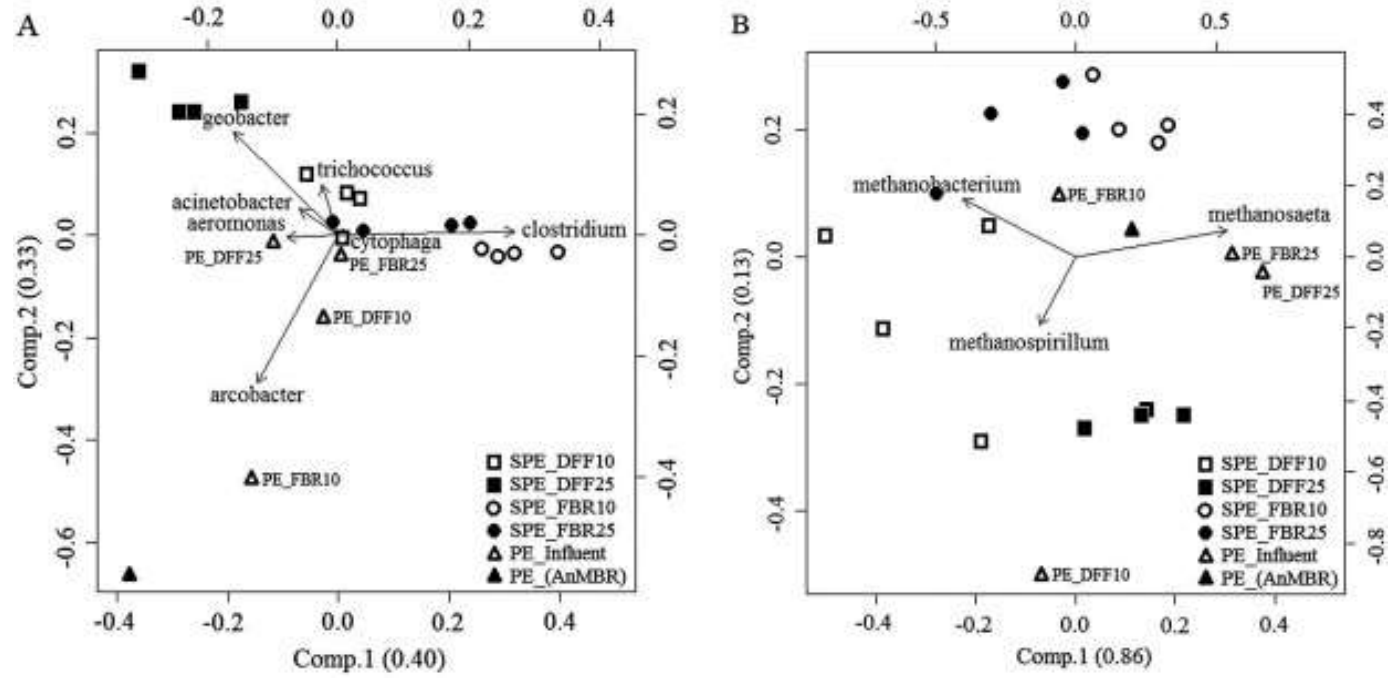

Fig. 2. Principal components analysis (PCA) analysis of (A) Bacteria and (B) Archaea 16S rRNA sequencing profiles for each AnMBR. During SPE operation samples were taken on day 180, 200, 230, and 250. Samples during PE operation were taken on day 355.

\subsection{Impact of continuous inoculation}

Continuous inoculation by PE caused the community to change in each AnMBR. After wastewater containing a high abundance of Arcobacter began to be fed, its relative abundance increased in all bioreactors, ostensibly because reactors were being continuously inoculated ( Fig. S1). During PE feeding, the bacterial community in all AnMBRs did not cluster with communities analyzed during SPE operation (Fig. 1). Additionally, Arcobacter relative abundance was the primary source of community variance among bioreactor biomass during PE operation, especially for the $10{ }^{\circ} \mathrm{C}$ AnMBRs (Fig. 2). Previous work has identified a similar change in microbial community composition within activated sludge systems due to the influent wastewater microbiota (Lee et al., 2015). Influent characteristics are also known to affect microbial community structure (LaPara et al., 2002). The relatively short operation period with PE during this study did not allow time to examine the long term effect of influent continual seeding on AnMBR bioreactor microbial community. Future work should examine the long term 
effect on microbial community structure once a steady state condition has been reached.

\subsection{Methanogenic activity and substrate preference}

Thermodynamically, hydrogen is a more favorable substrate than acetate at lower temperature (Lettinga et al., 2001). In contrast, acetoclastic methanogenesis has been described by some as the primary methanogenic pathway at low temperatures (Metje and Frenzel, 2007). However, hydrogenotrophic methanogenesis has also been observed in low temperature natural (Metje and Frenzel, 2007) and engineered environments (Bialek et al., 2011 and McKeown et al., 2009).

Methanogenic activity assays in this study revealed hydrogenotrophic methanogenesis became the primary methanogenic pathway at lower temperature (Fig. 3). Comparison of SMA at $10^{\circ} \mathrm{C}$ for biomass from all AnMBRs shows hydrogen utilization was similar among all bioreactors during SPE operation but was higher in the FBR10 and DFF10 biomass compared to FBR25 and DFF25 biomass during PE operation. Additionally, while acetate utilization was observed during SPE operation, acetoclastic methanogenesis was not detected during PE operation. These results, combined with the higher relative abundance of hydrogenotrophic methanogens at $10^{\circ} \mathrm{C}$ (Fig. S1) indicate that hydrogen utilization was the primary pathway for methanogenesis at $10^{\circ} \mathrm{C}$ and prolonged low temperature operation increased biomass hydrogen utilization rate compared to biomass at $25^{\circ} \mathrm{C}$. 


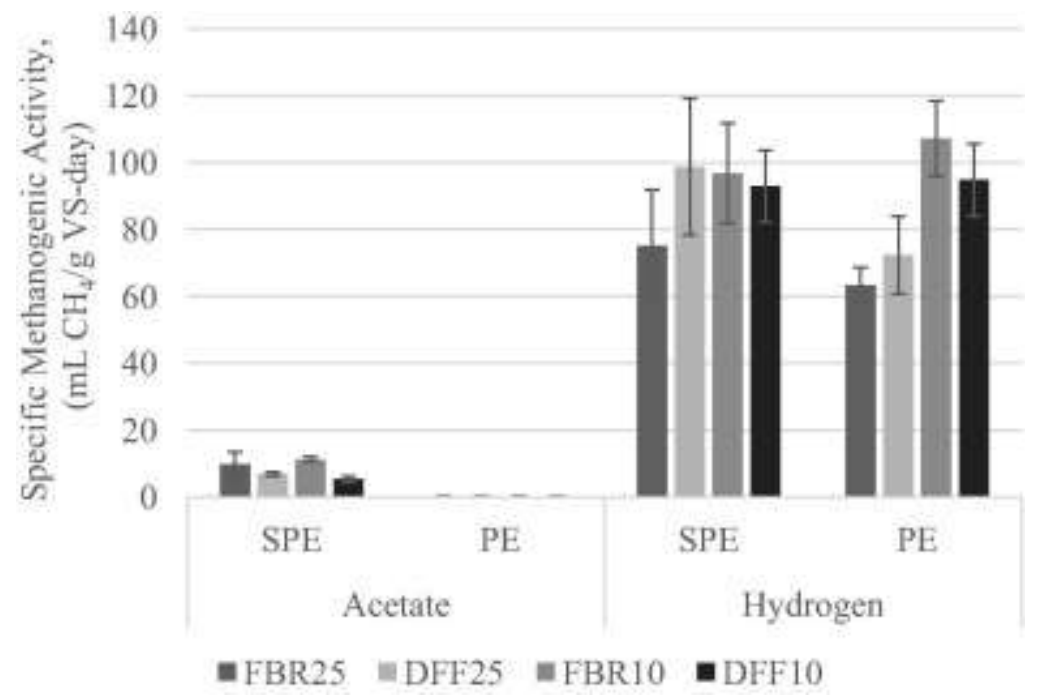

Fig. 3. Specific methanogenic activity (SMA) at $10^{\circ} \mathrm{C}$ using acetate and $\mathrm{H}_{2} / \mathrm{CO}_{2}$ after treating SPE for 300 days $(n=6)$ and after treating PE for 35 days $\left(n=6\right.$ for $\mathrm{H}_{2} / \mathrm{CO}_{2}, n=3-5$ for acetate).

The role of Methanosaeta detected in each AnMBR is unclear. Methanosaeta is commonly found in methanogenic biomass and is known to be important in forming biofilms in bioreactors such as the upflow anaerobic sludge blanket reactor ( Nelson et al., 2012). However, the high relative abundance of Methanosaeta in all systems does not correlate to the extremely low or nonexistent methanogenic activity measured with acetate at $10^{\circ} \mathrm{C}$. The primary explanation for high Methanosaeta detection may stem from the molecular methods used which relied on sequencing analysis of DNA rather than RNA. DNA-based methods can be biased in that intracellular and extracellular DNA may be included from inactive members within a community ( Smith et al., 2015). High detection of Methanosaeta coupled with little acetoclastic methanogenic activity suggests that Methanosaeta was present but may not have been active. Another possibility is that Methanosaeta may have been using a substrate other than acetate. While Methanosaeta spp. have been considered to be exclusively acetoclastic since they are not known to use $\mathrm{H}_{2}$ or formate, a recent study has indicated that Methanosaeta may be able to reduce $\mathrm{CO}_{2}$ to $\mathrm{CH}_{4}$ via direct interspecies electron transfer in conjunction with Geobacter ( Rotaru et al., 2014). In this study, Geobacter bacterial relative abundance in the $25^{\circ} \mathrm{C}$ AnMBRs varied from 5 to $20 \%$, whereas they were only $1.0-2.3 \%$ in the $10^{\circ} \mathrm{C}$ systems. The presence of Geobacter and Methanosaeta coupled with low methanogenic 
acetate utilization suggests that Methanosaeta may play a role other than acetate utilizer in low temperature anaerobic systems. The possibility of functionally significant, cold temperature Methanosaeta- Geobacter direct interspecies electron transfer warrants investigation. Further work utilizing RNA or functional gene-based sequencing methods (such as mcrA) would also be useful to characterize the role of Methanosaeta in similar fixed-film anaerobic systems.

\section{Conclusions}

Unique bacterial communities developed in AnMBRs due to reactor configuration and temperature, but the same was not observed for Archaea. Hydrogenotrophic methanogenesis was dominant at $10^{\circ} \mathrm{C}$, whereas acetoclastic methanogenesis was low or not detected. A shift in AnMBR microbial community occurred when real wastewater was fed due to continuous seeding with influent wastewater microbiota. Future work should determine the influence of long term continuous seeding by wastewater microbiota on bioreactor communities.

\section{Acknowledgements}

The authors thank Xylem, Inc. for assisting with project development and for providing materials, funding, and technical support throughout this study. This article was also developed under STAR Fellowship Assistance Agreement no. FP-917669010 awarded by the U.S. Environmental Protection Agency (EPA). It has not been formally reviewed by EPA. The views expressed in this article are solely those of the authors and EPA does not endorse any products or commercial services mentioned in this article.

\section{References}

APHA et al., 1999. APHA, AWWA, WEF. Standard Methods for the Examination of Water and Wastewater. (20th ed) American Water Works Association (1999)

Bialek et al., 2011. K. Bialek, J. Kim, C. Lee, G. Collins, T. Mahony, V. O'Flaherty. Quantitative and qualitative analyses of methanogenic community development in high-rate anaerobic bioreactors. Water Res., 45 (2011), pp. 1298-1308 http://dx.doi.org/10.1016/j.watres.2010.10.010

Bioresource Technology, Vol 216 (September 2016): pg. 446-452. DOI. This article is (C) Elsevier and permission has been granted for this version to appear in e-Publications@Marquette. Elsevier does not grant permission for this article to be further copied/distributed or hosted elsewhere without the express permission from Elsevier. 
Bocher et al., 2015. B.T.W. Bocher, K. Cherukuri, J.S. Maki, M. Johnson, D.H. Zitomer. Relating methanogen community structure and anaerobic digester function. Water Res., 70 (2015), pp. 425-435 http://dx.doi.org/10.1016/j.watres.2014.12.018

Briones and Raskin, 2003. A. Briones, L. Raskin. Diversity and dynamics of microbial communities in engineered environments and their implications for process stability. Curr. Opin. Biotechnol., 14 (2003), pp. 270-276 http://dx.doi.org/10.1016/S0958-1669(03)00065-X

Briones et al., 2007. A.M. Briones, B.J. Daugherty, L.T. Angenent, K.D. Rausch, M.E. Tumbleson, L. Raskin. Microbial diversity and dynamics in multi- and singlecompartment anaerobic bioreactors processing sulfate-rich waste streams. Environ. Microbiol., 9 (2007), pp. 93-106 http://dx.doi.org/10.1111/j.14622920.2006.01119.x

CME, 2015. CME, 2015. RDP [WWW Document]. URL: <http://rdp.cme.msu.edu>. Collins et al., 2006. G. Collins, S. McHugh, S. Connaughton, A.-M. Enright, A. Kearney, C. Scully, T. Mahony, P. Madden, V. O'Flaherty. New lowtemperature applications of anaerobic wastewater treatment. J. Environ. Sci. Health. A. Tox. Hazard. Subst. Environ. Eng., 41 (2006), pp. 881-895 http://dx.doi.org/10.1080/10934520600614504

DeSantis et al., 2006. T.Z. DeSantis, P. Hugenholtz, N. Larsen, M. Rojas, E.L. Brodie, K. Keller, T. Huber, D. Dalevi, P. Hu, G.L. Andersen. Greengenes, a chimerachecked 16S rRNA gene database and workbench compatible with ARB. Appl. Environ. Microbiol., 72 (2006), pp. 5069-5072 http://dx.doi.org/10.1128/AEM.03006-05

Dowd et al., 2008. S.E. Dowd, T.R. Callaway, R.D. Wolcott, Y. Sun, T. McKeehan, R.G. Hagevoort, T.S. Edrington. Evaluation of the bacterial diversity in the feces of cattle using 16S rDNA bacterial tag-encoded FLX amplicon pyrosequencing (bTEFAP). BMC Microbiol., 8 (2008), p. 125 http://dx.doi.org/10.1186/1471-2180-8-125

Falk et al., 2009. M.W. Falk, K.G. Song, M.G. Matiasek, S. Wuertz. Microbial community dynamics in replicate membrane bioreactors - natural reproducible fluctuations. Water Res., 43 (2009), pp. 842-852 http://dx.doi.org/10.1016/j.watres.2008.11.021

Fernandez et al., 2000. A.S. Fernandez, S.A. Hashsham, S.L. Dollhopf, L. Raskin, O. Glagoleva, F.B. Dazzo, R.F. Hickey, C.S. Criddle, J.M. Tiedje. Flexible community structure correlates with stable community function in methanogenic bioreactor communities perturbed by glucose. Appl. Environ. Microbiol., 66 (2000), pp. 4058-4067 http://dx.doi.org/10.1128/AEM.66.9.4058-4067.2000 
Fisher et al., 2014. J.C. Fisher, A. Levican, M.J. Figueras, S.L. McLellan. Population dynamics and ecology of arcobacter in sewage. Front. Microbiol., 5 (2014), pp. 1-9 http://dx.doi.org/10.3389/fmicb.2014.00525

Harb et al., 2015. M. Harb, Y. Xiong, J. Guest, G. Amy, P.-Y. Hong. Differences in microbial communities and performance between suspended and attached growth anaerobic membrane bioreactors treating synthetic municipal wastewater. Environ. Sci. Water Res. Technol., 1 (2015), pp. 800-813 http://dx.doi.org/10.1039/C5EW00162E

LaPara et al., 2002. T.M. LaPara, C.H. Nakatsu, L.M. Pantea, J.E. Alleman. Stability of the bacterial communities supported by a seven-stage biological process treating pharmaceutical wastewater as revealed by PCR-DGGE. Water Res., 36 (2002), pp. 638-646 http://dx.doi.org/10.1016/S0043-1354(01)00277-9

Lee et al., 2015. S.-H. Lee, H.-J. Kang, H.-D. Park. Influence of influent wastewater communities on temporal variation of activated sludge communities. Water Res., 73 (2015), pp. 132-144 http://dx.doi.org/10.1016/j.watres.2015.01.014

Lettinga et al., 2001. G. Lettinga, S. Rebac, G. Zeeman. Challenge of psychrophilic anaerobic wastewater treatment. Trends Biotechnol., 19 (2001), pp. 363-370 http://dx.doi.org/10.1016/S0167-7799(01)01701-2

McCarty et al., 2011. P.L. McCarty, J. Bae, J. Kim. Domestic wastewater treatment as a net energy producer-can this be achieved? Environ. Sci. Technol., 45 (2011), pp. 7100-7106 http://dx.doi.org/10.1021/es2014264

Mckeown et al., 2009. R.M. McKeown, C. Scully, A.-M. Enright, F.A. Chinalia, C. Lee, T. Mahony, G. Collins, V. O'Flaherty. Psychrophilic methanogenic community development during long-term cultivation of anaerobic granular biofilms. ISME J., 3 (2009), pp. 1231-1242 http://dx.doi.org/10.1038/ismej.2009.67

Mckeown et al., 2012. R.M. McKeown, D. Hughes, G. Collins, T. Mahony, V. O'Flaherty. Low-temperature anaerobic digestion for wastewater treatment. Curr. Opin. Biotechnol., 23 (2012), pp. 444-451 http://dx.doi.org/10.1016/j.copbio.2011.11.025

McLellan et al., 2011. S.L. McLellan, S.M. Huse, S.R. Mueller-Spitz, E.N. Andreihcheva, M.L. Sogin. Diversity and population structure of sewage derived microorganisms in wastewater treatment plant influent. Environ. Microbiol., 12 (2011), pp. 378-392 http://dx.doi.org/10.1111/j.14622920.2009.02075.x.Diversity

Metje and Frenzel, 2007. M. Metje, P. Frenzel. Methanogenesis and methanogenic pathways in a peat from subarctic permafrost. Environ. Microbiol., 9 (2007), pp. 954-964 http://dx.doi.org/10.1111/j.1462-2920.2006.01217.x

NCBI, 2015. NCBI, 2015. National Center for Biotechnology Information [WWW Document]. URL: <http://www.ncbi.nlm.nih.gov/>. 
Nelson et al., 2012. M.C. Nelson, M. Morrison, F. Schanbacher, Z. Yu. Shifts in microbial community structure of granular and liquid biomass in response to changes to infeed and digester design in anaerobic digesters receiving foodprocessing wastes. Bioresour. Technol., 107 (2012), pp. 135-143 http://dx.doi.org/10.1016/j.biortech.2011.12.070

O’Reilly et al., 2009. J. O'Reilly, C. Lee, G. Collins, F. Chinalia, T. Mahony, V. O'Flaherty. Quantitative and qualitative analysis of methanogenic communities in mesophilically and psychrophilically cultivated anaerobic granular biofilims. Water Res., 43 (2009), pp. 3365-3374 http://dx.doi.org/10.1016/j.watres.2009.03.039

Ramette, 2007. A. Ramette. Multivariate analyses in microbial ecology. FEMS Microbiol. Ecol., 62 (2007), pp. 142-160 http://dx.doi.org/10.1111/j.15746941.2007.00375.x

Regueiro et al., 2012. L. Regueiro, P. Veiga, M. Figueroa, J. Alonso-Gutierrez, A.J.M. Stams, J.M. Lema, M. Carballa. Relationship between microbial activity and microbial community structure in six full-scale anaerobic digesters. Microbiol. Res., 167 (2012), pp. 581-589 http://dx.doi.org/10.1016/j.micres.2012.06.002

Rivière et al., 2009. D. Rivière, V. Desvignes, E. Pelletier, S. Chaussonnerie, S. Guermazi, J. Weissenbach, T. Li, P. Camacho, A. Sghir. Towards the definition of a core of microorganisms involved in anaerobic digestion of sludge. ISME J., 3 (2009), pp. 700-714 http://dx.doi.org/10.1038/ismej.2009.2

Rotaru et al., 2014. A.-E. Rotaru, P.M. Shrestha, F. Liu, M. Shrestha, D. Shrestha, M. Embree, K. Zengler, C. Wardman, K.P. Nevin, D.R. Lovley. A new model for electron flow during anaerobic digestion: direct interspecies electron transfer to Methanosaeta for the reduction of carbon dioxide to methane. Energy Environ. Sci., 7 (2014), p. 408 http://dx.doi.org/10.1039/c3ee42189a

Roy et al., 2009. C.S. Roy, G. Talbot, E. Topp, C. Beaulieu, M.F. Palin, D.I. Massé. Bacterial community dynamics in an anaerobic plug-flow type bioreactor treating swine manure. Water Res., 43 (2009), pp. 21-32 http://dx.doi.org/10.1016/j.watres.2008.09.034

Seib et al., 2016a. M.D. Seib, K.J. Berg, D.H. Zitomer. Low energy anaerobic membrane bioreactor for municipal wastewater treatment. J. Membr. Sci., 514 (2016), pp. 450-457 http://dx.doi.org/10.1016/j.memsci.2016.05.007

Seib et al., 2016b. M.D. Seib, K.J. Berg, D.H. Zitomer. Reduced energy demand for municipal wastewater recovery using an anaerobic floating filter membrane bioreactor. Environ. Sci. Water Res. Technol., 2 (2016), pp. 290-297 http://dx.doi.org/10.1039/C5EW00244C

Siggins et al., 2011. A. Siggins, A.M. Enright, V. O’Flaherty. Low-temperature $\left(7^{\circ} \mathrm{C}\right)$ anaerobic treatment of a trichloroethylene-contaminated wastewater: 
NOT THE PUBLISHED VERSION; this is the author's final, peer-reviewed manuscript. The published version may be accessed by following the link in the citation at the bottom of the page.

microbial community development. Water Res., 45 (2011), pp. 4035-4046 http://dx.doi.org/10.1016/j.watres.2011.05.013

Smith et al., 2013. A.L. Smith, S.J. Skerlos, L. Raskin. Psychrophilic anaerobic membrane bioreactor treatment of domestic wastewater. Water Res., 47 (2013), pp. 1655-1665 http://dx.doi.org/10.1016/j.watres.2012.12.028

Smith et al., 2015. A.L. Smith, S.J. Skerlos, L. Raskin. Anaerobic membrane bioreactor treatment of domestic wastewater at psychrophilic temperatures ranging from $15^{\circ} \mathrm{C}$ to $3^{\circ} \mathrm{C}$. Environ. Sci. Water Res. Technol., 1 (2015), pp. 56-64 http://dx.doi.org/10.1039/C4EW00070F

Stirling and Wilsey, 2001. G. Stirling, B. Wilsey. Empirical relationships between species richness, evenness, and proportional diversity. Am. Nat., 158 (2001), pp. 286-299 http://dx.doi.org/10.1086/321317 


\section{Appendix A. Supplementary data}

\section{Influent wastewater microbiota and temperature influence anaerobic membrane bioreactor microbial community}

M.D. Seib ${ }^{a *}$, K.J. Berga ${ }^{a}$ D.H. Zitomera

a Department of Civil, Construction and Environmental Engineering, Marquette University, P.O. Box 1881, Milwaukee, WI 53233, USA

\section{Supporting Materials}

Supporting Figures (Figure S1)

Supporting Tables (Table S1 and S2)

\footnotetext{
* Corresponding author at: Department of Civil, Construction and Environmental Engineering, Marquette University, P.O. Box 1881, Milwaukee, WI 53233, USA

Email address: matthew.seib@marquett.edu 
NOT THE PUBLISHED VERSION; this is the author's final, peer-reviewed manuscript. The published version may be accessed by following the link in the citation at the bottom of the page.

A $80 \%$

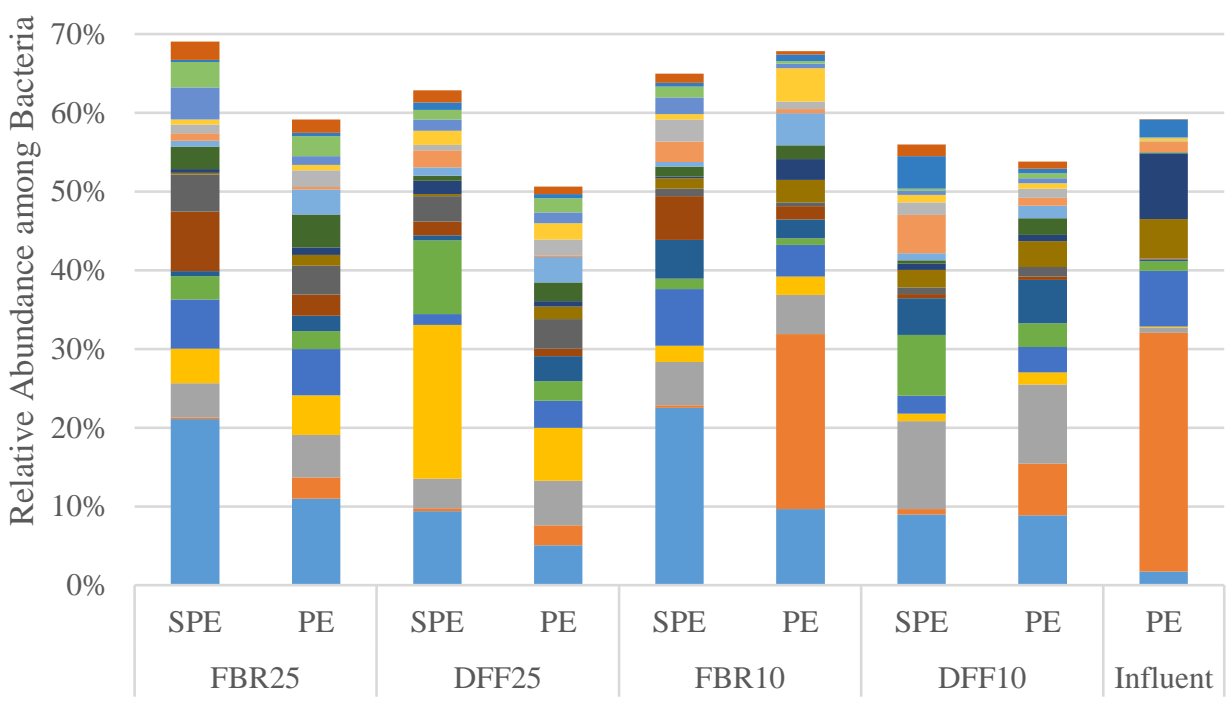

- Levilinea

- Acinetobacter

- Syntrophorhabdus

- Longilinea

Desulfovibrio

Solitalea

- Lactococcus

- Spirochaeta

- Desulfobulbus

- Aeromonas

- Parabacteroides

- Syntrophus

- Bellilinea

- Desulfomicrobium

- Trichococcus

- Bacteroides

- Geobacter

- Cytophaga

Arcobacter

- Clostridium

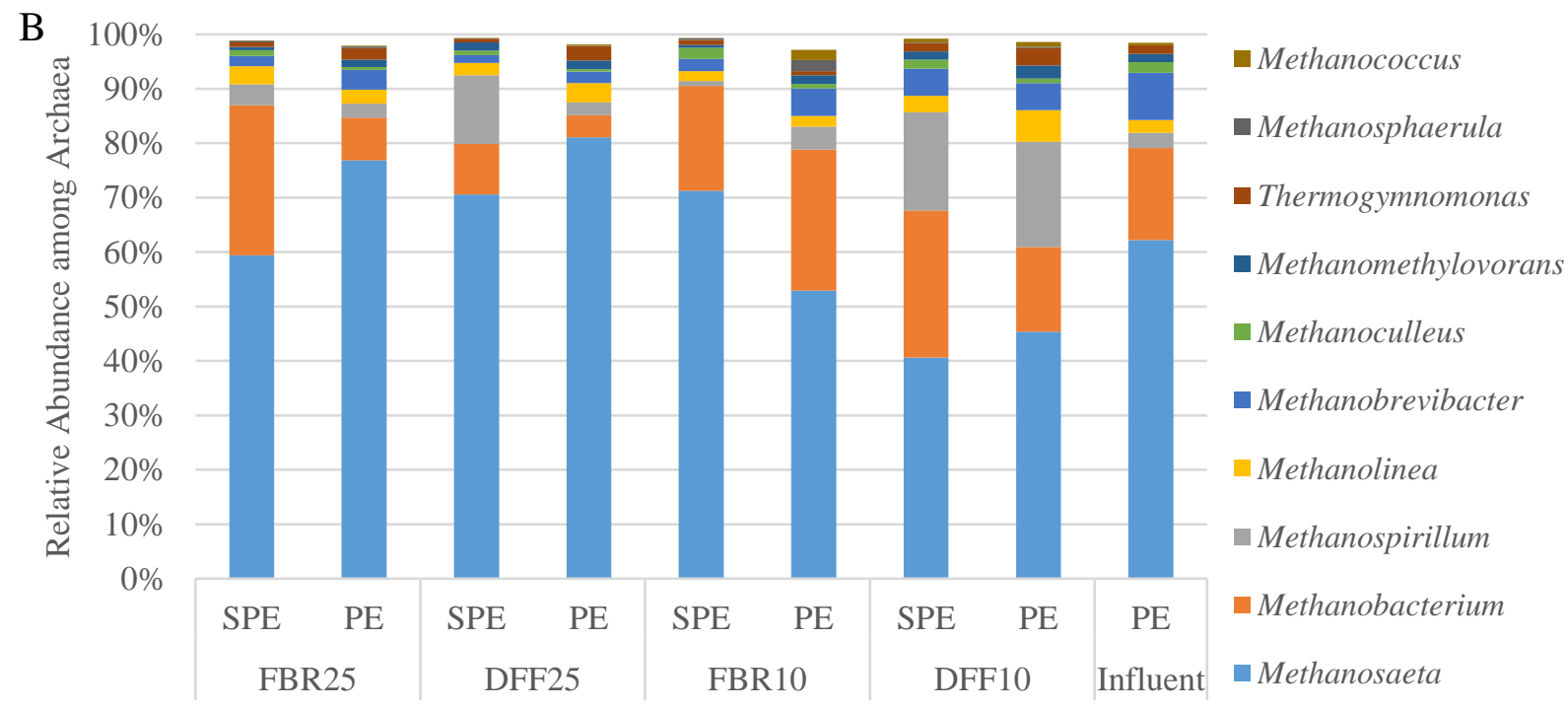

Figure S1: Biofilm community structure at the genus level for A.) Bacteria and B.) Archaea during operation with SPE (day 250) and PE (day 355). Relative abundance is shown for the 20 most abundant genera classified in the domain Bacteria and for the 10 most abundant genera classified in the domain Archaea, respectively. 
Table S1: Relative abundance of the top $98 \%$ most abundant genera in FBR10, FBR25, and the real primary effluent (Real PE) detected across all samples analyzed.

\begin{tabular}{|c|c|c|c|c|c|c|c|c|c|c|c|}
\hline & Real & & & FBR10 & & & & & FBR25 & & \\
\hline Genus & $\begin{array}{c}\text { Real } \\
\text { PE_3 } \\
55\end{array}$ & $\begin{array}{l}\text { FBR } \\
10 \\
180\end{array}$ & $\begin{array}{l}\text { FBR } \\
10 \\
200\end{array}$ & $\begin{array}{l}\text { FBR } \\
10_{-} \\
230\end{array}$ & $\begin{array}{l}\text { FBR } \\
10 \\
250\end{array}$ & $\begin{array}{l}\text { FBR } \\
10 \\
35 \overline{5}\end{array}$ & $\begin{array}{l}\text { FBR } \\
25 \\
180\end{array}$ & $\begin{array}{l}\text { FBR } \\
25 \\
200\end{array}$ & $\begin{array}{l}\text { FBR } \\
25 \\
230\end{array}$ & $\begin{array}{l}\text { FBR } \\
25 \\
250\end{array}$ & $\begin{array}{l}\text { FBR } \\
25 \\
35 \overline{5}\end{array}$ \\
\hline $\begin{array}{l}\text { clostridiu } \\
\mathrm{m}\end{array}$ & $\begin{array}{c}0.01 \\
6967 \\
42\end{array}$ & $\begin{array}{c}0.28 \\
710 \\
2\end{array}$ & $\begin{array}{c}0.10 \\
944 \\
7\end{array}$ & $\begin{array}{c}0.18 \\
375 \\
1\end{array}$ & $\begin{array}{c}0.08 \\
474 \\
9\end{array}$ & $\begin{array}{l}0.21 \\
106\end{array}$ & $\begin{array}{c}0.08 \\
768 \\
8\end{array}$ & $\begin{array}{c}0.09 \\
918 \\
4\end{array}$ & $\begin{array}{c}0.04 \\
228 \\
6\end{array}$ & $\begin{array}{c}0.09 \\
493 \\
4\end{array}$ & $\begin{array}{c}0.08 \\
564 \\
8\end{array}$ \\
\hline geobacter & $\begin{array}{c}0.00 \\
1769 \\
11 \\
\end{array}$ & $\begin{array}{c}0.01 \\
478 \\
7\end{array}$ & $\begin{array}{c}0.01 \\
820 \\
4\end{array}$ & $\begin{array}{c}0.03 \\
834 \\
3\end{array}$ & $\begin{array}{c}0.17 \\
586 \\
8\end{array}$ & $\begin{array}{c}0.01 \\
955 \\
5\end{array}$ & $\begin{array}{c}0.00 \\
923 \\
4\end{array}$ & $\begin{array}{c}0.04 \\
587 \\
6\end{array}$ & $\begin{array}{c}0.05 \\
629 \\
4\end{array}$ & $\begin{array}{c}0.02 \\
279 \\
5\end{array}$ & $\begin{array}{c}0.01 \\
473 \\
7\end{array}$ \\
\hline $\begin{array}{l}\text { trichococc } \\
\text { us }\end{array}$ & $\begin{array}{c}0.01 \\
2222 \\
97\end{array}$ & $\begin{array}{c}0.01 \\
306 \\
5\end{array}$ & $\begin{array}{c}0.16 \\
080 \\
5\end{array}$ & $\begin{array}{c}0.02 \\
587 \\
6\end{array}$ & $\begin{array}{c}0.08 \\
400 \\
7\end{array}$ & $\begin{array}{c}0.01 \\
219 \\
5\end{array}$ & $\begin{array}{l}0.07 \\
539\end{array}$ & $\begin{array}{c}0.02 \\
066 \\
5\end{array}$ & $\begin{array}{c}0.02 \\
044 \\
9\end{array}$ & $\begin{array}{c}0.00 \\
798 \\
1\end{array}$ & $\begin{array}{c}0.02 \\
930 \\
9\end{array}$ \\
\hline cytophaga & $\begin{array}{c}0.00 \\
6304 \\
48\end{array}$ & $\begin{array}{c}0.03 \\
868 \\
2\end{array}$ & $\begin{array}{c}0.05 \\
160 \\
5\end{array}$ & $\begin{array}{c}0.03 \\
766 \\
4\end{array}$ & $\begin{array}{c}0.03 \\
358 \\
9\end{array}$ & $\begin{array}{l}0.05 \\
165\end{array}$ & $\begin{array}{c}0.10 \\
924 \\
8\end{array}$ & $\begin{array}{c}0.04 \\
886 \\
4\end{array}$ & $\begin{array}{c}0.04 \\
763 \\
1\end{array}$ & $\begin{array}{c}0.04 \\
837 \\
7\end{array}$ & $\begin{array}{c}0.09 \\
754 \\
2\end{array}$ \\
\hline $\begin{array}{l}\text { methanos } \\
\text { aeta }\end{array}$ & $\begin{array}{c}0.00 \\
2541 \\
09\end{array}$ & $\begin{array}{c}0.03 \\
414 \\
7\end{array}$ & $\begin{array}{c}0.02 \\
332 \\
7\end{array}$ & $\begin{array}{c}0.07 \\
586 \\
9\end{array}$ & $\begin{array}{c}0.07 \\
087 \\
4\end{array}$ & $\begin{array}{c}0.04 \\
534 \\
4\end{array}$ & $\begin{array}{l}0.00 \\
842\end{array}$ & $\begin{array}{c}0.07 \\
295 \\
7\end{array}$ & $\begin{array}{c}0.13 \\
217 \\
6\end{array}$ & $\begin{array}{c}0.00 \\
977 \\
3\end{array}$ & $\begin{array}{c}0.01 \\
425 \\
6\end{array}$ \\
\hline $\begin{array}{l}\text { bacteroide } \\
\mathrm{s}\end{array}$ & $\begin{array}{c}0.07 \\
0748 \\
5 \\
\end{array}$ & $\begin{array}{c}0.06 \\
287 \\
3 \\
\end{array}$ & $\begin{array}{c}0.02 \\
540 \\
7\end{array}$ & $\begin{array}{c}0.05 \\
453 \\
7\end{array}$ & $\begin{array}{c}0.01 \\
237 \\
7 \\
\end{array}$ & $\begin{array}{c}0.06 \\
725 \\
1 \\
\end{array}$ & $\begin{array}{c}0.02 \\
244 \\
3\end{array}$ & $\begin{array}{c}0.05 \\
308 \\
2\end{array}$ & $\begin{array}{c}0.02 \\
883 \\
4\end{array}$ & $\begin{array}{c}0.03 \\
990 \\
6\end{array}$ & $\begin{array}{c}0.03 \\
090 \\
2 \\
\end{array}$ \\
\hline arcobacter & $\begin{array}{c}0.30 \\
1923 \\
51\end{array}$ & $\begin{array}{c}0.00 \\
235 \\
1\end{array}$ & $\begin{array}{c}0.00 \\
346 \\
5\end{array}$ & $\begin{array}{c}0.00 \\
227 \\
2\end{array}$ & $\begin{array}{c}0.00 \\
333 \\
2\end{array}$ & $\begin{array}{c}0.00 \\
264 \\
1\end{array}$ & $\begin{array}{c}0.00 \\
716 \\
4\end{array}$ & $\begin{array}{c}0.02 \\
441 \\
9\end{array}$ & $\begin{array}{c}0.02 \\
114 \\
3\end{array}$ & $\begin{array}{c}0.21 \\
826 \\
4\end{array}$ & $\begin{array}{c}0.06 \\
385 \\
1\end{array}$ \\
\hline bellilinea & $\begin{array}{c}0.00 \\
0788 \\
06\end{array}$ & $\begin{array}{c}0.05 \\
941 \\
7\end{array}$ & $\begin{array}{c}0.01 \\
855 \\
1\end{array}$ & $\begin{array}{c}0.06 \\
618 \\
6\end{array}$ & $\begin{array}{c}0.01 \\
575 \\
1\end{array}$ & $\begin{array}{c}0.05 \\
201 \\
1\end{array}$ & $\begin{array}{c}0.00 \\
534 \\
2\end{array}$ & $\begin{array}{c}0.02 \\
436 \\
9\end{array}$ & $\begin{array}{c}0.00 \\
773 \\
3\end{array}$ & $\begin{array}{c}0.01 \\
699 \\
9\end{array}$ & $\begin{array}{c}0.00 \\
453 \\
2\end{array}$ \\
\hline $\begin{array}{l}\text { acinetobac } \\
\text { ter }\end{array}$ & $\begin{array}{c}0.02 \\
2869 \\
83\end{array}$ & $\begin{array}{c}0.00 \\
308 \\
3\end{array}$ & $\begin{array}{c}0.01 \\
264 \\
8\end{array}$ & $\begin{array}{l}0.00 \\
259\end{array}$ & $\begin{array}{c}0.00 \\
820 \\
5\end{array}$ & $\begin{array}{c}0.00 \\
445 \\
9\end{array}$ & $\begin{array}{c}0.04 \\
073 \\
2\end{array}$ & $\begin{array}{c}0.00 \\
355 \\
3\end{array}$ & $\begin{array}{l}0.00 \\
429\end{array}$ & $\begin{array}{c}0.00 \\
842 \\
9\end{array}$ & $\begin{array}{c}0.00 \\
567 \\
2\end{array}$ \\
\hline $\begin{array}{l}\text { lactococcu } \\
\mathrm{s}\end{array}$ & $\begin{array}{c}0.01 \\
2801 \\
96\end{array}$ & $\begin{array}{c}0.03 \\
613 \\
8\end{array}$ & $\begin{array}{c}0.04 \\
978 \\
6\end{array}$ & $\begin{array}{c}0.00 \\
860 \\
2\end{array}$ & $\begin{array}{l}0.01 \\
963\end{array}$ & $\begin{array}{c}0.02 \\
433 \\
1\end{array}$ & $\begin{array}{c}0.04 \\
772 \\
9\end{array}$ & $\begin{array}{c}0.00 \\
267 \\
4\end{array}$ & $\begin{array}{c}0.00 \\
209 \\
6\end{array}$ & $\begin{array}{c}0.00 \\
504 \\
1\end{array}$ & $\begin{array}{c}0.00 \\
954 \\
5\end{array}$ \\
\hline $\begin{array}{l}\text { desulfomic } \\
\text { robium }\end{array}$ & $\begin{array}{c}0.00 \\
2090 \\
77\end{array}$ & $\begin{array}{c}0.03 \\
812 \\
9\end{array}$ & $\begin{array}{c}0.03 \\
195 \\
3\end{array}$ & $\begin{array}{c}0.00 \\
526 \\
4\end{array}$ & $\begin{array}{c}0.00 \\
562 \\
8\end{array}$ & $\begin{array}{c}0.04 \\
612 \\
3\end{array}$ & $\begin{array}{c}0.04 \\
560 \\
4\end{array}$ & $\begin{array}{c}0.01 \\
740 \\
1\end{array}$ & $\begin{array}{c}0.02 \\
682 \\
1\end{array}$ & $\begin{array}{c}0.02 \\
334 \\
1\end{array}$ & $\begin{array}{c}0.05 \\
323 \\
4\end{array}$ \\
\hline $\begin{array}{l}\text { aeromona } \\
\text { s }\end{array}$ & $\begin{array}{c}0.08 \\
3019 \\
72\end{array}$ & $\begin{array}{c}0.00 \\
169 \\
6\end{array}$ & $\begin{array}{c}0.00 \\
365 \\
1\end{array}$ & $\begin{array}{c}0.00 \\
398 \\
9\end{array}$ & $\begin{array}{c}0.01 \\
534 \\
5\end{array}$ & $\begin{array}{c}0.00 \\
207 \\
8\end{array}$ & $\begin{array}{c}0.00 \\
764 \\
7\end{array}$ & $\begin{array}{c}0.00 \\
821 \\
1\end{array}$ & $\begin{array}{c}0.00 \\
555 \\
3\end{array}$ & $\begin{array}{c}0.02 \\
589\end{array}$ & $\begin{array}{c}0.00 \\
807 \\
6\end{array}$ \\
\hline $\begin{array}{l}\text { syntrophu } \\
\text { s }\end{array}$ & $\begin{array}{c}0.00 \\
0546 \\
82\end{array}$ & $\begin{array}{l}0.00 \\
925\end{array}$ & $\begin{array}{c}0.01 \\
716 \\
5\end{array}$ & $\begin{array}{c}0.04 \\
104 \\
4\end{array}$ & $\begin{array}{c}0.02 \\
905 \\
2\end{array}$ & $\begin{array}{c}0.00 \\
904 \\
9\end{array}$ & $\begin{array}{c}0.00 \\
821 \\
3\end{array}$ & $\begin{array}{c}0.03 \\
347 \\
1\end{array}$ & $\begin{array}{c}0.03 \\
169 \\
4\end{array}$ & $\begin{array}{c}0.00 \\
459 \\
3\end{array}$ & $\begin{array}{c}0.01 \\
138 \\
6\end{array}$ \\
\hline Iongilinea & $\begin{array}{c}0.00 \\
0546 \\
82\end{array}$ & $\begin{array}{c}0.02 \\
311 \\
2\end{array}$ & $\begin{array}{c}0.01 \\
715 \\
2\end{array}$ & $\begin{array}{c}0.03 \\
580 \\
8\end{array}$ & $\begin{array}{c}0.01 \\
260 \\
1\end{array}$ & $\begin{array}{c}0.01 \\
964 \\
1\end{array}$ & $\begin{array}{c}0.00 \\
524 \\
5\end{array}$ & $\begin{array}{c}0.01 \\
013 \\
2\end{array}$ & $\begin{array}{c}0.01 \\
114 \\
8\end{array}$ & $\begin{array}{c}0.00 \\
565 \\
7\end{array}$ & $\begin{array}{c}0.00 \\
597 \\
4\end{array}$ \\
\hline
\end{tabular}


NOT THE PUBLISHED VERSION; this is the author's final, peer-reviewed manuscript. The published version may be accessed by following the link in the citation at the bottom of the page.

\begin{tabular}{|c|c|c|c|c|c|c|c|c|c|c|c|}
\hline levilinea & $\begin{array}{c}0.00 \\
0385 \\
99\end{array}$ & $\begin{array}{c}0.01 \\
415 \\
7\end{array}$ & $\begin{array}{c}0.02 \\
473 \\
8\end{array}$ & $\begin{array}{l}0.02 \\
003\end{array}$ & $\begin{array}{c}0.01 \\
377 \\
7\end{array}$ & $\begin{array}{c}0.01 \\
088 \\
1\end{array}$ & $\begin{array}{c}0.01 \\
413 \\
4\end{array}$ & $\begin{array}{c}0.01 \\
531 \\
7\end{array}$ & $\begin{array}{c}0.00 \\
830 \\
2\end{array}$ & $\begin{array}{c}0.00 \\
403 \\
3\end{array}$ & $\begin{array}{c}0.00 \\
883 \\
1\end{array}$ \\
\hline solitalea & $\begin{array}{c}0.00 \\
0627 \\
23\end{array}$ & $\begin{array}{c}0.02 \\
004 \\
1\end{array}$ & $\begin{array}{c}0.01 \\
403 \\
4\end{array}$ & $\begin{array}{c}0.00 \\
958 \\
6\end{array}$ & $\begin{array}{c}0.00 \\
613 \\
2\end{array}$ & $\begin{array}{c}0.02 \\
649 \\
6\end{array}$ & $\begin{array}{c}0.01 \\
541 \\
8\end{array}$ & $\begin{array}{l}0.01 \\
941\end{array}$ & $\begin{array}{c}0.01 \\
667 \\
3\end{array}$ & $\begin{array}{c}0.00 \\
945 \\
1\end{array}$ & $\begin{array}{c}0.01 \\
144 \\
1\end{array}$ \\
\hline $\begin{array}{l}\text { methanob } \\
\text { acterium }\end{array}$ & $\begin{array}{c}0.00 \\
0691 \\
56\end{array}$ & $\begin{array}{c}0.00 \\
945 \\
5\end{array}$ & $\begin{array}{c}0.01 \\
726 \\
4\end{array}$ & $\begin{array}{c}0.03 \\
513\end{array}$ & $\begin{array}{c}0.00 \\
931 \\
1\end{array}$ & $\begin{array}{c}0.01 \\
226 \\
7\end{array}$ & $\begin{array}{c}0.00 \\
560 \\
4\end{array}$ & $\begin{array}{l}0.00 \\
742\end{array}$ & $\begin{array}{c}0.00 \\
655 \\
3\end{array}$ & $\begin{array}{c}0.00 \\
478 \\
9\end{array}$ & $\begin{array}{c}0.00 \\
488 \\
9\end{array}$ \\
\hline $\begin{array}{l}\text { desulfobul } \\
\text { bus }\end{array}$ & $\begin{array}{c}0.00 \\
1511 \\
79\end{array}$ & $\begin{array}{c}0.01 \\
350 \\
2\end{array}$ & $\begin{array}{c}0.00 \\
795 \\
7\end{array}$ & $\begin{array}{c}0.02 \\
512 \\
8\end{array}$ & $\begin{array}{c}0.00 \\
554 \\
4\end{array}$ & $\begin{array}{c}0.01 \\
160 \\
3\end{array}$ & $\begin{array}{c}0.00 \\
425 \\
1\end{array}$ & $\begin{array}{c}0.03 \\
806 \\
7\end{array}$ & $\begin{array}{c}0.01 \\
993 \\
5\end{array}$ & $\begin{array}{c}0.01 \\
701 \\
3\end{array}$ & $\begin{array}{c}0.02 \\
040 \\
9\end{array}$ \\
\hline fusibacter & $\begin{array}{c}0.00 \\
0836 \\
31\end{array}$ & $\begin{array}{c}0.03 \\
405 \\
7\end{array}$ & $\begin{array}{c}0.01 \\
690 \\
5\end{array}$ & $\begin{array}{c}0.00 \\
487 \\
6\end{array}$ & $\begin{array}{c}0.01 \\
005 \\
3\end{array}$ & $\begin{array}{c}0.03 \\
398 \\
6\end{array}$ & $\begin{array}{c}0.02 \\
658 \\
4\end{array}$ & $\begin{array}{c}0.00 \\
227 \\
2\end{array}$ & $\begin{array}{c}0.00 \\
360 \\
9\end{array}$ & $\begin{array}{c}0.00 \\
366 \\
9\end{array}$ & $\begin{array}{c}0.00 \\
961 \\
4\end{array}$ \\
\hline $\begin{array}{l}\text { parabacte } \\
\text { roides }\end{array}$ & $\begin{array}{c}0.04 \\
9374 \\
38 \\
\end{array}$ & $\begin{array}{c}0.00 \\
607 \\
7 \\
\end{array}$ & $\begin{array}{c}0.01 \\
116 \\
3 \\
\end{array}$ & $\begin{array}{c}0.00 \\
191 \\
2 \\
\end{array}$ & $\begin{array}{c}0.00 \\
243 \\
6 \\
\end{array}$ & $\begin{array}{c}0.01 \\
245 \\
4\end{array}$ & $\begin{array}{c}0.02 \\
175 \\
3 \\
\end{array}$ & $\begin{array}{l}0.01 \\
248\end{array}$ & $\begin{array}{c}0.01 \\
324 \\
4 \\
\end{array}$ & $\begin{array}{c}0.02 \\
804 \\
6 \\
\end{array}$ & $\begin{array}{l}0.03 \\
174\end{array}$ \\
\hline $\begin{array}{l}\text { spirochaet } \\
\text { a }\end{array}$ & $\begin{array}{c}0.00 \\
0627 \\
23\end{array}$ & $\begin{array}{c}0.00 \\
702 \\
7\end{array}$ & $\begin{array}{c}0.00 \\
638 \\
6\end{array}$ & $\begin{array}{c}0.00 \\
616 \\
4\end{array}$ & $\begin{array}{c}0.00 \\
956 \\
3\end{array}$ & $\begin{array}{c}0.00 \\
539 \\
7\end{array}$ & $\begin{array}{c}0.00 \\
891 \\
6\end{array}$ & $\begin{array}{c}0.02 \\
875 \\
1\end{array}$ & $\begin{array}{c}0.02 \\
701 \\
5\end{array}$ & $\begin{array}{c}0.04 \\
025 \\
6\end{array}$ & $\begin{array}{c}0.01 \\
546 \\
5\end{array}$ \\
\hline $\begin{array}{l}\text { desulfovib } \\
\text { rio }\end{array}$ & $\begin{array}{c}0.00 \\
3795 \\
55\end{array}$ & $\begin{array}{c}0.00 \\
525 \\
4\end{array}$ & $\begin{array}{c}0.01 \\
221 \\
4\end{array}$ & $\begin{array}{c}0.00 \\
540 \\
2\end{array}$ & $\begin{array}{c}0.01 \\
621 \\
3\end{array}$ & $\begin{array}{c}0.00 \\
640 \\
8\end{array}$ & $\begin{array}{c}0.00 \\
941 \\
3\end{array}$ & $\begin{array}{l}0.00 \\
619\end{array}$ & $\begin{array}{l}0.01 \\
745\end{array}$ & $\begin{array}{c}0.04 \\
147 \\
4\end{array}$ & $\begin{array}{l}0.00 \\
673\end{array}$ \\
\hline $\begin{array}{l}\text { syntropho } \\
\text { rhabdus }\end{array}$ & $\begin{array}{c}0.00 \\
0418 \\
15\end{array}$ & $\begin{array}{c}0.01 \\
283 \\
4\end{array}$ & $\begin{array}{c}0.00 \\
678 \\
2\end{array}$ & $\begin{array}{l}0.02 \\
794\end{array}$ & $\begin{array}{c}0.01 \\
129 \\
9\end{array}$ & $\begin{array}{c}0.01 \\
307 \\
5\end{array}$ & $\begin{array}{c}0.00 \\
227 \\
7\end{array}$ & $\begin{array}{c}0.02 \\
303 \\
8\end{array}$ & $\begin{array}{c}0.01 \\
524 \\
3\end{array}$ & $\begin{array}{c}0.00 \\
299 \\
6\end{array}$ & $\begin{array}{c}0.00 \\
594 \\
7\end{array}$ \\
\hline $\begin{array}{l}\text { dehalococ } \\
\text { coides }\end{array}$ & $\begin{array}{c}0.00 \\
0257 \\
33\end{array}$ & $\begin{array}{c}0.00 \\
824 \\
8\end{array}$ & $\begin{array}{c}0.00 \\
570 \\
5\end{array}$ & $\begin{array}{c}0.02 \\
712 \\
3\end{array}$ & $\begin{array}{c}0.00 \\
798 \\
1\end{array}$ & $\begin{array}{c}0.00 \\
663 \\
8\end{array}$ & $\begin{array}{c}0.00 \\
194 \\
6\end{array}$ & $\begin{array}{l}0.00 \\
742\end{array}$ & $\begin{array}{c}0.00 \\
635 \\
8\end{array}$ & $\begin{array}{c}0.00 \\
166 \\
6\end{array}$ & $\begin{array}{c}0.00 \\
245 \\
8\end{array}$ \\
\hline $\begin{array}{l}\text { shewanell } \\
\text { a }\end{array}$ & $\begin{array}{c}0.01 \\
1161 \\
5\end{array}$ & $\begin{array}{c}0.00 \\
073 \\
2\end{array}$ & $\begin{array}{c}0.00 \\
220 \\
3\end{array}$ & $\begin{array}{c}0.00 \\
332 \\
5\end{array}$ & $\begin{array}{c}0.01 \\
502 \\
3\end{array}$ & $\begin{array}{c}0.00 \\
327 \\
6\end{array}$ & $\begin{array}{l}0.03 \\
245\end{array}$ & $\begin{array}{c}0.00 \\
144 \\
4\end{array}$ & $\begin{array}{c}0.00 \\
112 \\
4\end{array}$ & $\begin{array}{c}0.00 \\
572 \\
7\end{array}$ & $\begin{array}{c}0.00 \\
196 \\
4\end{array}$ \\
\hline $\begin{array}{l}\text { syntropho } \\
\text { monas }\end{array}$ & $\begin{array}{c}0.00 \\
0723 \\
73 \\
\end{array}$ & $\begin{array}{c}0.01 \\
524 \\
9\end{array}$ & $\begin{array}{c}0.00 \\
492 \\
5\end{array}$ & $\begin{array}{c}0.01 \\
160 \\
8 \\
\end{array}$ & $\begin{array}{c}0.01 \\
528 \\
9\end{array}$ & $\begin{array}{c}0.01 \\
480 \\
7\end{array}$ & $\begin{array}{c}0.00 \\
276 \\
1\end{array}$ & $\begin{array}{c}0.00 \\
635 \\
3\end{array}$ & $\begin{array}{c}0.00 \\
524 \\
8 \\
\end{array}$ & $\begin{array}{c}0.00 \\
446 \\
7\end{array}$ & $\begin{array}{c}0.00 \\
214 \\
3\end{array}$ \\
\hline $\begin{array}{l}\text { anaeropha } \\
\text { ga }\end{array}$ & $\begin{array}{c}0.00 \\
0418 \\
15\end{array}$ & $\begin{array}{c}0.00 \\
201 \\
7\end{array}$ & $\begin{array}{c}0.01 \\
018 \\
5\end{array}$ & $\begin{array}{c}0.00 \\
436 \\
3\end{array}$ & $\begin{array}{c}0.00 \\
309 \\
4\end{array}$ & $\begin{array}{c}0.00 \\
232 \\
3\end{array}$ & $\begin{array}{c}0.01 \\
870 \\
3\end{array}$ & $\begin{array}{c}0.01 \\
624 \\
6\end{array}$ & $\begin{array}{l}0.01 \\
069\end{array}$ & $\begin{array}{c}0.00 \\
672 \\
1\end{array}$ & $\begin{array}{c}0.01 \\
093 \\
3\end{array}$ \\
\hline $\begin{array}{l}\text { composti } \\
\text { monas }\end{array}$ & $\begin{array}{c}0.00 \\
0209 \\
08\end{array}$ & $\begin{array}{c}0.01 \\
706 \\
1\end{array}$ & $\begin{array}{c}0.00 \\
874 \\
9\end{array}$ & $\begin{array}{c}0.00 \\
851 \\
9\end{array}$ & $\begin{array}{c}0.00 \\
726 \\
7\end{array}$ & $\begin{array}{c}0.01 \\
583 \\
1\end{array}$ & $\begin{array}{c}0.00 \\
550 \\
7\end{array}$ & $\begin{array}{c}0.00 \\
227 \\
2\end{array}$ & $\begin{array}{c}0.00 \\
202 \\
7\end{array}$ & $\begin{array}{c}0.00 \\
429 \\
9\end{array}$ & $\begin{array}{c}0.00 \\
413 \\
4\end{array}$ \\
\hline $\begin{array}{l}\text { prolixibact } \\
\text { er }\end{array}$ & $\begin{array}{c}0.00 \\
0659 \\
4\end{array}$ & $\begin{array}{c}0.00 \\
644 \\
9\end{array}$ & $\begin{array}{c}0.00 \\
762 \\
3\end{array}$ & $\begin{array}{c}0.00 \\
182 \\
9\end{array}$ & $\begin{array}{c}0.00 \\
28\end{array}$ & $\begin{array}{c}0.00 \\
935 \\
2\end{array}$ & $\begin{array}{c}0.01 \\
533 \\
5\end{array}$ & $\begin{array}{c}0.00 \\
532 \\
3\end{array}$ & $\begin{array}{c}0.00 \\
603 \\
9\end{array}$ & $\begin{array}{c}0.00 \\
889 \\
1\end{array}$ & $\begin{array}{c}0.03 \\
303 \\
1\end{array}$ \\
\hline pelobacter & $\begin{array}{c}0.00 \\
0997 \\
14\end{array}$ & $\begin{array}{c}0.00 \\
283 \\
9\end{array}$ & $\begin{array}{c}0.01 \\
030 \\
9\end{array}$ & $\begin{array}{c}0.00 \\
181 \\
5\end{array}$ & $\begin{array}{c}0.00 \\
331 \\
8\end{array}$ & $\begin{array}{c}0.00 \\
317 \\
5\end{array}$ & $\begin{array}{c}0.00 \\
808 \\
8\end{array}$ & $\begin{array}{c}0.01 \\
505 \\
3\end{array}$ & $\begin{array}{c}0.01 \\
277 \\
2\end{array}$ & $\begin{array}{c}0.00 \\
418 \\
7\end{array}$ & $\begin{array}{c}0.01 \\
583 \\
6\end{array}$ \\
\hline $\begin{array}{l}\text { phascolarc } \\
\text { tobacteriu } \\
\text { m }\end{array}$ & $\begin{array}{c}0.00 \\
1785 \\
2\end{array}$ & $\begin{array}{c}0.00 \\
485 \\
6\end{array}$ & $\begin{array}{c}0.00 \\
529 \\
7\end{array}$ & $\begin{array}{c}0.00 \\
405 \\
9\end{array}$ & $\begin{array}{c}0.00 \\
228 \\
2\end{array}$ & $\begin{array}{c}0.00 \\
796 \\
6\end{array}$ & $\begin{array}{c}0.00 \\
826 \\
8\end{array}$ & $\begin{array}{c}0.00 \\
839 \\
9\end{array}$ & $\begin{array}{c}0.00 \\
465 \\
1\end{array}$ & $\begin{array}{l}0.01 \\
172\end{array}$ & $\begin{array}{c}0.00 \\
756 \\
8\end{array}$ \\
\hline
\end{tabular}


NOT THE PUBLISHED VERSION; this is the author's final, peer-reviewed manuscript. The published version may be accessed by following the link in the citation at the bottom of the page.

\begin{tabular}{|c|c|c|c|c|c|c|c|c|c|c|c|}
\hline rikenella & $\begin{array}{c}0.00 \\
1511 \\
79\end{array}$ & $\begin{array}{c}0.00 \\
786 \\
2\end{array}$ & $\begin{array}{c}0.00 \\
628 \\
7\end{array}$ & $\begin{array}{c}0.00 \\
112 \\
2\end{array}$ & $\begin{array}{c}0.00 \\
163 \\
8\end{array}$ & $\begin{array}{c}0.01 \\
788 \\
1\end{array}$ & $\begin{array}{c}0.00 \\
888 \\
9\end{array}$ & $\begin{array}{c}0.00 \\
234 \\
8\end{array}$ & $\begin{array}{c}0.00 \\
483 \\
1\end{array}$ & $\begin{array}{c}0.00 \\
793 \\
9\end{array}$ & $\begin{array}{c}0.00 \\
482 \\
1\end{array}$ \\
\hline $\begin{array}{l}\text { acidobacte } \\
\text { rium }\end{array}$ & $\begin{array}{c}0.00 \\
0257 \\
33 \\
\end{array}$ & $\begin{array}{l}0.00 \\
501\end{array}$ & $\begin{array}{c}0.00 \\
199 \\
2 \\
\end{array}$ & $\begin{array}{c}0.01 \\
644 \\
3 \\
\end{array}$ & $\begin{array}{c}0.00 \\
180 \\
6 \\
\end{array}$ & $\begin{array}{c}0.00 \\
744 \\
7 \\
\end{array}$ & $\begin{array}{c}0.00 \\
158 \\
7 \\
\end{array}$ & $\begin{array}{c}0.01 \\
186 \\
4 \\
\end{array}$ & $\begin{array}{c}0.00 \\
855 \\
2 \\
\end{array}$ & $\begin{array}{c}0.00 \\
372 \\
5\end{array}$ & $\begin{array}{c}0.00 \\
403 \\
8 \\
\end{array}$ \\
\hline caldithrix & $\begin{array}{c}0.00 \\
0402 \\
07\end{array}$ & $\begin{array}{c}0.00 \\
274 \\
9\end{array}$ & $\begin{array}{c}0.00 \\
688 \\
1 \\
\end{array}$ & $\begin{array}{c}0.00 \\
430 \\
8 \\
\end{array}$ & $\begin{array}{l}0.00 \\
182\end{array}$ & $\begin{array}{c}0.00 \\
441 \\
6 \\
\end{array}$ & $\begin{array}{c}0.01 \\
721 \\
2\end{array}$ & $\begin{array}{c}0.01 \\
737 \\
6\end{array}$ & $\begin{array}{l}0.01 \\
652\end{array}$ & $\begin{array}{c}0.00 \\
214 \\
2\end{array}$ & $\begin{array}{c}0.01 \\
161 \\
9 \\
\end{array}$ \\
\hline $\begin{array}{l}\text { sulfurovu } \\
\text { m }\end{array}$ & $\begin{array}{c}0.00 \\
0836 \\
31\end{array}$ & $\begin{array}{c}0.00 \\
457 \\
3\end{array}$ & $\begin{array}{c}0.00 \\
795 \\
7\end{array}$ & $\begin{array}{c}0.00 \\
245 \\
2\end{array}$ & $\begin{array}{c}0.00 \\
781 \\
3\end{array}$ & $\begin{array}{c}0.00 \\
492 \\
1\end{array}$ & $\begin{array}{c}0.00 \\
557 \\
6\end{array}$ & $\begin{array}{l}0.00 \\
231\end{array}$ & $\begin{array}{l}0.00 \\
329\end{array}$ & $\begin{array}{c}0.00 \\
392 \\
1\end{array}$ & $\begin{array}{c}0.00 \\
624 \\
9\end{array}$ \\
\hline $\begin{array}{l}\text { paludibact } \\
\text { er }\end{array}$ & $\begin{array}{c}0.01 \\
5712 \\
95\end{array}$ & $\begin{array}{c}0.00 \\
551 \\
1 \\
\end{array}$ & $\begin{array}{l}0.00 \\
297\end{array}$ & $\begin{array}{c}0.00 \\
426 \\
7\end{array}$ & $\begin{array}{c}0.00 \\
089 \\
6\end{array}$ & $\begin{array}{c}0.01 \\
183 \\
4\end{array}$ & $\begin{array}{l}0.00 \\
588\end{array}$ & $\begin{array}{c}0.00 \\
500 \\
9\end{array}$ & $\begin{array}{c}0.00 \\
240 \\
2\end{array}$ & $\begin{array}{l}0.01 \\
333\end{array}$ & $\begin{array}{c}0.00 \\
855 \\
7\end{array}$ \\
\hline smithella & $\begin{array}{c}0.00 \\
0176 \\
91 \\
\end{array}$ & $\begin{array}{c}0.00 \\
151 \\
6 \\
\end{array}$ & $\begin{array}{c}0.00 \\
509 \\
9\end{array}$ & $\begin{array}{c}0.00 \\
716 \\
2 \\
\end{array}$ & $\begin{array}{c}0.00 \\
428 \\
4 \\
\end{array}$ & $\begin{array}{c}0.00 \\
124 \\
1 \\
\end{array}$ & $\begin{array}{c}0.00 \\
222 \\
2 \\
\end{array}$ & $\begin{array}{l}0.00 \\
565\end{array}$ & $\begin{array}{c}0.01 \\
506 \\
3 \\
\end{array}$ & $\begin{array}{c}0.00 \\
026 \\
6 \\
\end{array}$ & $\begin{array}{c}0.00 \\
256 \\
8 \\
\end{array}$ \\
\hline $\begin{array}{l}\text { methanos } \\
\text { pirillum }\end{array}$ & $\begin{array}{c}0.00 \\
0112 \\
58\end{array}$ & $\begin{array}{c}0.00 \\
073 \\
2\end{array}$ & $\begin{array}{c}0.00 \\
517 \\
3\end{array}$ & $\begin{array}{c}0.00 \\
500 \\
1\end{array}$ & $\begin{array}{c}0.01 \\
269 \\
9\end{array}$ & $\begin{array}{c}0.00 \\
059 \\
2\end{array}$ & $\begin{array}{c}0.00 \\
372 \\
7\end{array}$ & $\begin{array}{c}0.00 \\
243 \\
6\end{array}$ & $\begin{array}{c}0.00 \\
384 \\
5\end{array}$ & $\begin{array}{c}0.00 \\
078 \\
4\end{array}$ & $\begin{array}{c}0.00 \\
609 \\
8\end{array}$ \\
\hline $\begin{array}{l}\text { pedobacte } \\
r\end{array}$ & $\begin{array}{c}0.00 \\
0289 \\
49\end{array}$ & $\begin{array}{l}0.00 \\
492\end{array}$ & $\begin{array}{c}0.01 \\
171 \\
9\end{array}$ & $\begin{array}{c}0.00 \\
037 \\
4\end{array}$ & $\begin{array}{c}0.00 \\
044 \\
8\end{array}$ & $\begin{array}{c}0.01 \\
114 \\
1\end{array}$ & $\begin{array}{c}0.01 \\
432 \\
7\end{array}$ & $\begin{array}{c}0.00 \\
178 \\
3\end{array}$ & $\begin{array}{c}0.00 \\
098 \\
6\end{array}$ & $\begin{array}{c}0.00 \\
819 \\
1\end{array}$ & $\begin{array}{c}0.00 \\
571 \\
4\end{array}$ \\
\hline $\begin{array}{l}\text { eubacteriu } \\
\text { m }\end{array}$ & $\begin{array}{c}0.01 \\
3187 \\
94 \\
\end{array}$ & $\begin{array}{c}0.00 \\
174 \\
7 \\
\end{array}$ & $\begin{array}{c}0.00 \\
616 \\
3 \\
\end{array}$ & $\begin{array}{c}0.00 \\
178 \\
7 \\
\end{array}$ & $\begin{array}{c}0.00 \\
275 \\
8 \\
\end{array}$ & $\begin{array}{c}0.00 \\
301 \\
6 \\
\end{array}$ & $\begin{array}{c}0.00 \\
597 \\
7 \\
\end{array}$ & $\begin{array}{c}0.00 \\
528 \\
6 \\
\end{array}$ & $\begin{array}{c}0.00 \\
885 \\
7 \\
\end{array}$ & $\begin{array}{c}0.00 \\
639 \\
9 \\
\end{array}$ & $\begin{array}{c}0.01 \\
392 \\
7 \\
\end{array}$ \\
\hline $\begin{array}{l}\text { proteocate } \\
\text { Ila }\end{array}$ & $\begin{array}{c}0.00 \\
2734 \\
09\end{array}$ & $\begin{array}{c}0.00 \\
260 \\
8\end{array}$ & $\begin{array}{c}0.00 \\
601 \\
4\end{array}$ & $\begin{array}{c}0.00 \\
347 \\
7\end{array}$ & $\begin{array}{c}0.00 \\
425 \\
6\end{array}$ & $\begin{array}{c}0.00 \\
304 \\
5\end{array}$ & $\begin{array}{c}0.00 \\
634 \\
9\end{array}$ & $\begin{array}{c}0.00 \\
287 \\
5\end{array}$ & $\begin{array}{c}0.00 \\
291 \\
5\end{array}$ & $\begin{array}{c}0.00 \\
113 \\
4\end{array}$ & $\begin{array}{c}0.00 \\
230 \\
7\end{array}$ \\
\hline $\begin{array}{l}\text { ornithiniba } \\
\text { cillus }\end{array}$ & $\begin{array}{c}0.00 \\
0160 \\
83\end{array}$ & $\begin{array}{c}0.00 \\
913 \\
4\end{array}$ & $\begin{array}{c}0.00 \\
471 \\
5\end{array}$ & $\begin{array}{c}0.00 \\
804 \\
8\end{array}$ & $\begin{array}{l}0.00 \\
175\end{array}$ & $\begin{array}{c}0.00 \\
759 \\
1\end{array}$ & $\begin{array}{l}0.00 \\
254\end{array}$ & $\begin{array}{c}0.00 \\
450 \\
7\end{array}$ & $\begin{array}{c}0.00 \\
106 \\
9\end{array}$ & $\begin{array}{c}0.00 \\
138 \\
6\end{array}$ & $\begin{array}{l}0.00 \\
195\end{array}$ \\
\hline leptospira & $\begin{array}{c}0.00 \\
0160 \\
83 \\
\end{array}$ & $\begin{array}{c}0.00 \\
165 \\
7\end{array}$ & $\begin{array}{c}0.00 \\
273 \\
5\end{array}$ & $\begin{array}{c}0.00 \\
146 \\
8 \\
\end{array}$ & $\begin{array}{c}0.00 \\
424 \\
2\end{array}$ & $\begin{array}{c}0.00 \\
282 \\
9 \\
\end{array}$ & $\begin{array}{c}0.00 \\
241 \\
5 \\
\end{array}$ & $\begin{array}{l}0.01 \\
656\end{array}$ & $\begin{array}{c}0.01 \\
060 \\
6\end{array}$ & $\begin{array}{c}0.01 \\
190 \\
2\end{array}$ & $\begin{array}{c}0.00 \\
561 \\
7\end{array}$ \\
\hline $\begin{array}{l}\text { candidatu } \\
\text { s } \\
\text { cloacimon } \\
\text { as }\end{array}$ & $\begin{array}{c}0.00 \\
1190 \\
13\end{array}$ & $\begin{array}{c}0.00 \\
476 \\
6\end{array}$ & $\begin{array}{c}0.00 \\
534 \\
6\end{array}$ & $\begin{array}{l}0.00 \\
356\end{array}$ & $\begin{array}{c}0.00 \\
197 \\
4\end{array}$ & $\begin{array}{c}0.00 \\
398 \\
3\end{array}$ & $\begin{array}{c}0.00 \\
288 \\
5\end{array}$ & $\begin{array}{c}0.00 \\
187 \\
1\end{array}$ & $\begin{array}{c}0.00 \\
537 \\
3\end{array}$ & $\begin{array}{c}0.00 \\
331 \\
8\end{array}$ & $\begin{array}{c}0.00 \\
335 \\
1\end{array}$ \\
\hline $\begin{array}{l}\text { aminobact } \\
\text { erium }\end{array}$ & $\begin{array}{c}0.00 \\
0176 \\
91\end{array}$ & $\begin{array}{c}0.00 \\
635 \\
9\end{array}$ & $\begin{array}{c}0.00 \\
347 \\
7\end{array}$ & $\begin{array}{c}0.00 \\
484 \\
8\end{array}$ & $\begin{array}{c}0.00 \\
449 \\
4\end{array}$ & $\begin{array}{c}0.00 \\
686 \\
9\end{array}$ & $\begin{array}{c}0.00 \\
208 \\
4\end{array}$ & $\begin{array}{c}0.00 \\
244 \\
8\end{array}$ & $\begin{array}{c}0.00 \\
104 \\
1\end{array}$ & $\begin{array}{l}0.00 \\
336\end{array}$ & $\begin{array}{c}0.00 \\
129 \\
1\end{array}$ \\
\hline $\begin{array}{l}\text { guggenhei } \\
\text { mella }\end{array}$ & $\begin{array}{c}0.00 \\
0241 \\
24 \\
\end{array}$ & $\begin{array}{c}0.00 \\
019 \\
3 \\
\end{array}$ & $\begin{array}{c}0.00 \\
013 \\
6 \\
\end{array}$ & $\begin{array}{c}0.01 \\
195 \\
5\end{array}$ & $\begin{array}{l}0.00 \\
021\end{array}$ & $\begin{array}{c}0.00 \\
018 \\
8 \\
\end{array}$ & $\begin{array}{c}0.00 \\
024 \\
8 \\
\end{array}$ & $\begin{array}{c}0.00 \\
337 \\
7\end{array}$ & $\begin{array}{c}0.00 \\
023 \\
6 \\
\end{array}$ & $\begin{array}{c}0.00 \\
011 \\
2\end{array}$ & $\begin{array}{c}0.00 \\
020 \\
6\end{array}$ \\
\hline $\begin{array}{l}\text { treponem } \\
\text { a }\end{array}$ & $\begin{array}{c}0.00 \\
0225 \\
16\end{array}$ & $\begin{array}{l}0.00 \\
158\end{array}$ & $\begin{array}{c}0.00 \\
371 \\
3\end{array}$ & $\begin{array}{c}0.00 \\
279 \\
8\end{array}$ & $\begin{array}{c}0.00 \\
289 \\
8\end{array}$ & $\begin{array}{c}0.00 \\
155 \\
9\end{array}$ & $\begin{array}{c}0.00 \\
574 \\
2\end{array}$ & $\begin{array}{c}0.00 \\
475 \\
8\end{array}$ & $\begin{array}{l}0.00 \\
547\end{array}$ & $\begin{array}{c}0.00 \\
330 \\
4\end{array}$ & $\begin{array}{c}0.00 \\
869 \\
4\end{array}$ \\
\hline
\end{tabular}

Bioresource Technology, Vol 216 (September 2016): pg. 446-452. DOI. This article is @ Elsevier and permission has been granted for this version to appear in e-Publications@Marquette. Elsevier does not grant permission for this article to be further copied/distributed or hosted elsewhere without the express permission from Elsevier. 
NOT THE PUBLISHED VERSION; this is the author's final, peer-reviewed manuscript. The published version may be accessed by following the link in the citation at the bottom of the page.

\begin{tabular}{|c|c|c|c|c|c|c|c|c|c|c|c|}
\hline $\begin{array}{l}\text { acetobact } \\
\text { erium }\end{array}$ & $\begin{array}{c}0.00 \\
1367 \\
04\end{array}$ & $\begin{array}{c}0.00 \\
056 \\
5\end{array}$ & $\begin{array}{c}0.00 \\
670 \\
7\end{array}$ & $\begin{array}{c}0.00 \\
117 \\
7\end{array}$ & $\begin{array}{c}0.00 \\
523 \\
6\end{array}$ & $\begin{array}{c}0.00 \\
034 \\
6\end{array}$ & $\begin{array}{c}0.00 \\
321 \\
6\end{array}$ & $\begin{array}{l}0.00 \\
177\end{array}$ & $\begin{array}{c}0.00 \\
240 \\
2\end{array}$ & $\begin{array}{c}0.00 \\
236 \\
6\end{array}$ & $\begin{array}{c}0.00 \\
281 \\
6\end{array}$ \\
\hline $\begin{array}{l}\text { pelotomac } \\
\text { ulum }\end{array}$ & $\begin{array}{c}0.04 \\
0174 \\
98\end{array}$ & $\begin{array}{c}0.00 \\
050 \\
1\end{array}$ & $\begin{array}{c}0.00 \\
094 \\
1\end{array}$ & $\begin{array}{l}0.00 \\
054\end{array}$ & $\begin{array}{c}0.00 \\
138 \\
6\end{array}$ & $\begin{array}{c}0.00 \\
031 \\
7\end{array}$ & $\begin{array}{c}0.00 \\
063 \\
5\end{array}$ & $\begin{array}{l}0.00 \\
275\end{array}$ & $\begin{array}{c}0.00 \\
294 \\
3\end{array}$ & $\begin{array}{c}0.00 \\
977 \\
3\end{array}$ & $\begin{array}{l}0.00 \\
445\end{array}$ \\
\hline $\begin{array}{l}\text { chlorobiu } \\
\text { m }\end{array}$ & $\begin{array}{c}0.00 \\
0209 \\
08 \\
\end{array}$ & $\begin{array}{c}0.00 \\
092 \\
5\end{array}$ & $\begin{array}{c}0.00 \\
118 \\
8\end{array}$ & $\begin{array}{c}0.00 \\
052 \\
6\end{array}$ & $\begin{array}{c}0.00 \\
382 \\
2\end{array}$ & $\begin{array}{c}0.00 \\
069 \\
3 \\
\end{array}$ & $\begin{array}{c}0.00 \\
136 \\
6\end{array}$ & $\begin{array}{c}0.00 \\
866 \\
3\end{array}$ & $\begin{array}{c}0.01 \\
110 \\
6 \\
\end{array}$ & $\begin{array}{c}0.00 \\
277 \\
2 \\
\end{array}$ & $\begin{array}{c}0.00 \\
508 \\
2\end{array}$ \\
\hline $\begin{array}{l}\text { thermana } \\
\text { erovibrio }\end{array}$ & $\begin{array}{c}0.00 \\
0128 \\
66\end{array}$ & $\begin{array}{c}0.00 \\
014 \\
1\end{array}$ & $\begin{array}{c}0.00 \\
033 \\
4\end{array}$ & $\begin{array}{c}0.00 \\
09\end{array}$ & $\begin{array}{l}0.01 \\
935\end{array}$ & $\begin{array}{c}0.00 \\
015 \\
9\end{array}$ & $\begin{array}{c}0.00 \\
038 \\
6\end{array}$ & $\begin{array}{c}0.00 \\
208 \\
4\end{array}$ & $\begin{array}{c}0.00 \\
438 \\
7\end{array}$ & $\begin{array}{c}0.00 \\
043 \\
4\end{array}$ & $\begin{array}{c}0.00 \\
061 \\
8\end{array}$ \\
\hline $\begin{array}{l}\text { ruminococ } \\
\text { cus }\end{array}$ & $\begin{array}{c}0.00 \\
3345 \\
23\end{array}$ & $\begin{array}{c}0.00 \\
470 \\
2\end{array}$ & $\begin{array}{l}0.00 \\
344\end{array}$ & $\begin{array}{c}0.00 \\
414 \\
2\end{array}$ & $\begin{array}{c}0.00 \\
246 \\
4\end{array}$ & $\begin{array}{c}0.00 \\
386 \\
8\end{array}$ & $\begin{array}{c}0.00 \\
244 \\
3\end{array}$ & $\begin{array}{c}0.00 \\
372 \\
9\end{array}$ & $\begin{array}{c}0.00 \\
417 \\
9\end{array}$ & $\begin{array}{l}0.00 \\
203\end{array}$ & $\begin{array}{c}0.00 \\
366 \\
7\end{array}$ \\
\hline $\begin{array}{l}\text { anaeromy } \\
\text { xobacter }\end{array}$ & $\begin{array}{c}0.00 \\
0128 \\
66\end{array}$ & $\begin{array}{c}0.00 \\
172 \\
1\end{array}$ & $\begin{array}{l}0.00 \\
297\end{array}$ & $\begin{array}{c}0.00 \\
101 \\
1\end{array}$ & $\begin{array}{l}0.00 \\
364\end{array}$ & $\begin{array}{c}0.00 \\
181 \\
8\end{array}$ & $\begin{array}{c}0.00 \\
375 \\
4\end{array}$ & $\begin{array}{l}0.00 \\
162\end{array}$ & $\begin{array}{c}0.00 \\
284 \\
6\end{array}$ & $\begin{array}{c}0.00 \\
086 \\
8\end{array}$ & $\begin{array}{l}0.00 \\
846\end{array}$ \\
\hline $\begin{array}{l}\text { fusobacter } \\
\text { ium }\end{array}$ & $\begin{array}{c}0.00 \\
5178 \\
68\end{array}$ & $\begin{array}{c}0.00 \\
037 \\
3\end{array}$ & $\begin{array}{c}0.00 \\
155 \\
9\end{array}$ & $\begin{array}{c}0.00 \\
048 \\
5\end{array}$ & $\begin{array}{c}0.00 \\
466 \\
2\end{array}$ & $\begin{array}{c}0.00 \\
027 \\
4\end{array}$ & $\begin{array}{c}0.00 \\
335 \\
4\end{array}$ & $\begin{array}{c}0.00 \\
185 \\
8\end{array}$ & $\begin{array}{c}0.00 \\
413 \\
7\end{array}$ & $\begin{array}{c}0.00 \\
065 \\
8\end{array}$ & $\begin{array}{c}0.00 \\
291 \\
2\end{array}$ \\
\hline $\begin{array}{l}\text { paenibacill } \\
\text { us }\end{array}$ & $\begin{array}{c}0.00 \\
0209 \\
08\end{array}$ & $\begin{array}{c}0.00 \\
023 \\
1\end{array}$ & $\begin{array}{l}0.00 \\
297\end{array}$ & $\begin{array}{c}0.00 \\
109 \\
4\end{array}$ & $\begin{array}{c}0.00 \\
63\end{array}$ & $\begin{array}{c}0.00 \\
077 \\
9\end{array}$ & $\begin{array}{c}0.00 \\
496 \\
9\end{array}$ & $\begin{array}{l}0.00 \\
064\end{array}$ & $\begin{array}{c}0.00 \\
045 \\
8\end{array}$ & $\begin{array}{c}0.00 \\
026 \\
6\end{array}$ & $\begin{array}{c}0.00 \\
082 \\
4\end{array}$ \\
\hline $\begin{array}{l}\text { synergiste } \\
\mathrm{s}\end{array}$ & $\begin{array}{c}0.00 \\
1640 \\
45\end{array}$ & $\begin{array}{c}0.00 \\
606 \\
4\end{array}$ & $\begin{array}{c}0.00 \\
529 \\
7\end{array}$ & $\begin{array}{c}0.00 \\
088 \\
7\end{array}$ & $\begin{array}{c}0.00 \\
515 \\
2\end{array}$ & $\begin{array}{l}0.00 \\
534\end{array}$ & $\begin{array}{c}0.00 \\
365 \\
8\end{array}$ & $\begin{array}{c}0.00 \\
096 \\
7\end{array}$ & $\begin{array}{c}0.00 \\
102 \\
7\end{array}$ & $\begin{array}{c}0.00 \\
219 \\
8\end{array}$ & $\begin{array}{c}0.00 \\
280 \\
2\end{array}$ \\
\hline $\begin{array}{l}\text { pedospha } \\
\text { era }\end{array}$ & $\begin{array}{c}9.64 \\
97 \mathrm{E}- \\
05\end{array}$ & $\begin{array}{c}0.00 \\
093 \\
8\end{array}$ & $\begin{array}{c}0.00 \\
311 \\
9\end{array}$ & $\begin{array}{c}0.00 \\
250 \\
7\end{array}$ & $\begin{array}{c}0.00 \\
236 \\
6\end{array}$ & $\begin{array}{l}0.00 \\
101\end{array}$ & $\begin{array}{c}0.00 \\
187 \\
7\end{array}$ & $\begin{array}{c}0.00 \\
606 \\
4\end{array}$ & $\begin{array}{c}0.00 \\
881 \\
5\end{array}$ & $\begin{array}{c}0.00 \\
121 \\
8\end{array}$ & $\begin{array}{c}0.00 \\
432 \\
6\end{array}$ \\
\hline $\begin{array}{l}\text { anaeromu } \\
\text { sa }\end{array}$ & $\begin{array}{c}0.00 \\
6288 \\
4\end{array}$ & $\begin{array}{c}0.00 \\
086 \\
1\end{array}$ & $\begin{array}{c}0.00 \\
384 \\
9\end{array}$ & $\begin{array}{c}0.00 \\
077 \\
6\end{array}$ & $\begin{array}{l}0.00 \\
371\end{array}$ & $\begin{array}{c}0.00 \\
207 \\
8\end{array}$ & $\begin{array}{c}0.01 \\
191 \\
2\end{array}$ & $\begin{array}{c}0.00 \\
072 \\
8\end{array}$ & $\begin{array}{c}0.00 \\
065 \\
2\end{array}$ & $\begin{array}{c}0.00 \\
131 \\
6\end{array}$ & $\begin{array}{c}0.00 \\
134 \\
6\end{array}$ \\
\hline $\begin{array}{l}\text { blastopirel } \\
\text { lula }\end{array}$ & $\begin{array}{c}0.00 \\
0128 \\
66 \\
\end{array}$ & $\begin{array}{c}0.00 \\
024 \\
4\end{array}$ & $\begin{array}{c}0.00 \\
158 \\
4\end{array}$ & $\begin{array}{c}0.00 \\
321 \\
4\end{array}$ & $\begin{array}{c}0.00 \\
890 \\
5 \\
\end{array}$ & $\begin{array}{c}0.00 \\
024 \\
5\end{array}$ & $\begin{array}{c}0.00 \\
110 \\
4\end{array}$ & $\begin{array}{c}0.00 \\
242 \\
3\end{array}$ & $\begin{array}{c}0.00 \\
326 \\
2 \\
\end{array}$ & $\begin{array}{l}0.00 \\
014\end{array}$ & $\begin{array}{c}0.00 \\
140 \\
1 \\
\end{array}$ \\
\hline $\begin{array}{l}\text { syntropho } \\
\text { bacter }\end{array}$ & $\begin{array}{c}0.00 \\
0128 \\
66\end{array}$ & $\begin{array}{l}0.00 \\
167\end{array}$ & $\begin{array}{c}0.00 \\
558 \\
1\end{array}$ & $\begin{array}{c}0.00 \\
440 \\
5\end{array}$ & $\begin{array}{c}0.00 \\
333 \\
2\end{array}$ & $\begin{array}{c}0.00 \\
128 \\
4\end{array}$ & $\begin{array}{c}0.00 \\
168 \\
4\end{array}$ & $\begin{array}{l}0.00 \\
177\end{array}$ & $\begin{array}{c}0.00 \\
54\end{array}$ & $\begin{array}{l}9.8 \mathrm{E} \\
-05\end{array}$ & $\begin{array}{c}0.00 \\
126 \\
4\end{array}$ \\
\hline $\begin{array}{l}\text { anaerovor } \\
\text { ax }\end{array}$ & $\begin{array}{c}0.00 \\
0321 \\
66\end{array}$ & $\begin{array}{l}0.00 \\
158\end{array}$ & $\begin{array}{c}0.00 \\
632 \\
4\end{array}$ & $\begin{array}{c}0.00 \\
081 \\
7\end{array}$ & $\begin{array}{c}0.00 \\
415 \\
8\end{array}$ & $\begin{array}{c}0.00 \\
116 \\
9\end{array}$ & $\begin{array}{c}0.00 \\
528 \\
6\end{array}$ & $\begin{array}{c}0.00 \\
057 \\
8\end{array}$ & $\begin{array}{c}0.00 \\
258 \\
2\end{array}$ & $\begin{array}{c}0.00 \\
127 \\
4\end{array}$ & $\begin{array}{c}0.00 \\
32\end{array}$ \\
\hline zoogloea & $\begin{array}{c}0.00 \\
1785 \\
2\end{array}$ & $\begin{array}{c}0.00 \\
047 \\
5\end{array}$ & $\begin{array}{l}0.00 \\
276\end{array}$ & $\begin{array}{c}0.00 \\
029 \\
1\end{array}$ & $\begin{array}{c}0.00 \\
131 \\
6\end{array}$ & $\begin{array}{c}0.00 \\
030 \\
3\end{array}$ & $\begin{array}{c}0.00 \\
474 \\
8\end{array}$ & $\begin{array}{c}0.00 \\
875 \\
1\end{array}$ & $\begin{array}{c}0.00 \\
653 \\
9\end{array}$ & $\begin{array}{c}0.00 \\
474 \\
7\end{array}$ & $\begin{array}{l}0.00 \\
912\end{array}$ \\
\hline $\begin{array}{l}\text { verrucomi } \\
\text { crobium }\end{array}$ & $\begin{array}{c}0.00 \\
0337 \\
74 \\
\end{array}$ & $\begin{array}{l}0.00 \\
149\end{array}$ & $\begin{array}{c}0.00 \\
252 \\
5\end{array}$ & $\begin{array}{c}0.00 \\
123 \\
3 \\
\end{array}$ & $\begin{array}{c}0.00 \\
07\end{array}$ & $\begin{array}{c}0.00 \\
207 \\
8\end{array}$ & $\begin{array}{c}0.00 \\
147 \\
7\end{array}$ & $\begin{array}{c}0.01 \\
098 \\
6\end{array}$ & $\begin{array}{c}0.00 \\
416 \\
5\end{array}$ & $\begin{array}{c}0.00 \\
365 \\
5\end{array}$ & $\begin{array}{c}0.01 \\
020 \\
5\end{array}$ \\
\hline $\begin{array}{l}\text { flavobacte } \\
\text { rium }\end{array}$ & $\begin{array}{c}0.00 \\
0466 \\
4\end{array}$ & $\begin{array}{c}0.00 \\
165 \\
7\end{array}$ & $\begin{array}{l}0.00 \\
641\end{array}$ & $\begin{array}{c}0.00 \\
055 \\
4\end{array}$ & $\begin{array}{l}0.00 \\
224\end{array}$ & $\begin{array}{c}0.00 \\
203 \\
5\end{array}$ & $\begin{array}{c}0.00 \\
626 \\
6\end{array}$ & $\begin{array}{c}0.00 \\
097 \\
9\end{array}$ & $\begin{array}{l}0.00 \\
447\end{array}$ & $\begin{array}{c}0.00 \\
149 \\
8\end{array}$ & $\begin{array}{c}0.00 \\
293 \\
9\end{array}$ \\
\hline
\end{tabular}

Bioresource Technology, Vol 216 (September 2016): pg. 446-452. DOI. This article is @ Elsevier and permission has been granted for this version to appear in e-Publications@Marquette. Elsevier does not grant permission for this article to be further copied/distributed or hosted elsewhere without the express permission from Elsevier. 
NOT THE PUBLISHED VERSION; this is the author's final, peer-reviewed manuscript. The published version may be accessed by following the link in the citation at the bottom of the page.

\begin{tabular}{|c|c|c|c|c|c|c|c|c|c|c|c|}
\hline $\begin{array}{l}\text { sulfurospir } \\
\text { illum }\end{array}$ & $\begin{array}{c}0.02 \\
5732 \\
57\end{array}$ & $\begin{array}{c}0.00 \\
016 \\
7\end{array}$ & $\begin{array}{c}0.00 \\
065 \\
6\end{array}$ & $\begin{array}{c}0.00 \\
178 \\
7\end{array}$ & $\begin{array}{c}0.00 \\
214 \\
2\end{array}$ & $\begin{array}{c}0.00 \\
020 \\
2\end{array}$ & $\begin{array}{c}0.00 \\
077 \\
3\end{array}$ & $\begin{array}{c}0.00 \\
28\end{array}$ & $\begin{array}{c}0.00 \\
240 \\
2\end{array}$ & $\begin{array}{c}0.00 \\
849 \\
9\end{array}$ & $\begin{array}{l}0.00 \\
342\end{array}$ \\
\hline $\begin{array}{l}\text { acidamino } \\
\text { bacter }\end{array}$ & $\begin{array}{c}0.00 \\
0498 \\
57 \\
\end{array}$ & $\begin{array}{l}0.00 \\
307\end{array}$ & $\begin{array}{c}0.00 \\
561 \\
8 \\
\end{array}$ & $\begin{array}{l}0.00 \\
061\end{array}$ & $\begin{array}{c}0.00 \\
219 \\
8 \\
\end{array}$ & $\begin{array}{c}0.00 \\
307 \\
4\end{array}$ & $\begin{array}{c}0.01 \\
149 \\
8 \\
\end{array}$ & $\begin{array}{c}0.00 \\
052 \\
7 \\
\end{array}$ & $\begin{array}{c}0.00 \\
108 \\
3 \\
\end{array}$ & $\begin{array}{l}0.00 \\
049\end{array}$ & $\begin{array}{c}0.00 \\
166 \\
2\end{array}$ \\
\hline $\begin{array}{l}\text { chondrom } \\
\text { yces }\end{array}$ & $\begin{array}{c}.82 \\
49 \mathrm{E}- \\
05\end{array}$ & $\begin{array}{c}0.00 \\
169 \\
6 \\
\end{array}$ & $\begin{array}{c}0.00 \\
308 \\
1\end{array}$ & $\begin{array}{c}0.00 \\
079\end{array}$ & $\begin{array}{c}0.00 \\
21\end{array}$ & $\begin{array}{c}0.00 \\
154 \\
4\end{array}$ & $\begin{array}{c}0.00 \\
216 \\
7\end{array}$ & $\begin{array}{c}0.00 \\
075 \\
3\end{array}$ & $\begin{array}{c}0.00 \\
206 \\
8\end{array}$ & $\begin{array}{c}0.00 \\
030 \\
8\end{array}$ & $\begin{array}{c}0.00 \\
149 \\
7\end{array}$ \\
\hline $\begin{array}{l}\text { deferribac } \\
\text { ter }\end{array}$ & $\begin{array}{c}8.04 \\
14 \mathrm{E}- \\
05\end{array}$ & $\begin{array}{c}0.00 \\
052 \\
7\end{array}$ & $\begin{array}{c}0.00 \\
048 \\
3\end{array}$ & $\begin{array}{c}0.00 \\
177 \\
3\end{array}$ & $\begin{array}{c}0.01 \\
268 \\
5\end{array}$ & $\begin{array}{c}0.00 \\
054 \\
8\end{array}$ & $\begin{array}{c}0.00 \\
053 \\
8\end{array}$ & $\begin{array}{c}0.00 \\
141 \\
9\end{array}$ & $\begin{array}{c}0.00 \\
462 \\
3\end{array}$ & $\begin{array}{c}0.00 \\
030 \\
8\end{array}$ & $\begin{array}{c}0.00 \\
049 \\
4\end{array}$ \\
\hline $\begin{array}{l}\text { anaeroline } \\
\text { a }\end{array}$ & $\begin{array}{c}3.21 \\
66 \mathrm{E}- \\
05\end{array}$ & $\begin{array}{c}0.00 \\
080 \\
9\end{array}$ & $\begin{array}{c}0.00 \\
257 \\
4\end{array}$ & $\begin{array}{c}0.00 \\
307 \\
5\end{array}$ & $\begin{array}{c}0.00 \\
376 \\
6\end{array}$ & $\begin{array}{c}0.00 \\
056 \\
3\end{array}$ & $\begin{array}{c}0.00 \\
107 \\
7\end{array}$ & $\begin{array}{c}0.00 \\
218 \\
5\end{array}$ & $\begin{array}{c}0.00 \\
367 \\
9\end{array}$ & $\begin{array}{c}0.00 \\
050 \\
4\end{array}$ & $\begin{array}{l}0.00 \\
239\end{array}$ \\
\hline ornatilinea & $\begin{array}{c}3.21 \\
66 \mathrm{E}- \\
05\end{array}$ & $\begin{array}{c}0.00 \\
235 \\
1\end{array}$ & $\begin{array}{c}0.00 \\
231 \\
4\end{array}$ & $\begin{array}{c}0.00 \\
376 \\
8\end{array}$ & $\begin{array}{c}0.00 \\
554 \\
4\end{array}$ & $\begin{array}{c}0.00 \\
187 \\
6\end{array}$ & $\begin{array}{c}0.00 \\
100 \\
8\end{array}$ & $\begin{array}{c}0.00 \\
114 \\
2\end{array}$ & $\begin{array}{c}0.00 \\
180 \\
5\end{array}$ & $\begin{array}{c}0.00 \\
047 \\
6\end{array}$ & $\begin{array}{c}0.00 \\
052 \\
2\end{array}$ \\
\hline leptolinea & $\begin{array}{c}9.64 \\
97 \mathrm{E}- \\
05\end{array}$ & $\begin{array}{c}0.00 \\
152 \\
9\end{array}$ & $\begin{array}{c}0.00 \\
210 \\
4\end{array}$ & $\begin{array}{c}0.00 \\
425 \\
3\end{array}$ & $\begin{array}{l}0.00 \\
364\end{array}$ & $\begin{array}{c}0.00 \\
137 \\
1\end{array}$ & $\begin{array}{c}0.00 \\
113 \\
2\end{array}$ & $\begin{array}{c}0.00 \\
381 \\
7\end{array}$ & $\begin{array}{c}0.00 \\
224 \\
9\end{array}$ & $\begin{array}{c}0.00 \\
050 \\
4\end{array}$ & $\begin{array}{c}0.00 \\
107 \\
1\end{array}$ \\
\hline holophaga & $\begin{array}{c}4.82 \\
49 \mathrm{E}- \\
05\end{array}$ & $\begin{array}{c}0.00 \\
430 \\
4\end{array}$ & $\begin{array}{c}0.00 \\
357 \\
6\end{array}$ & $\begin{array}{c}0.00 \\
040 \\
2\end{array}$ & $\begin{array}{c}0.00 \\
088 \\
2\end{array}$ & $\begin{array}{c}0.00 \\
399 \\
8\end{array}$ & $\begin{array}{l}0.00 \\
421\end{array}$ & $\begin{array}{c}0.00 \\
092 \\
9\end{array}$ & $\begin{array}{c}0.00 \\
165 \\
2\end{array}$ & $\begin{array}{c}0.00 \\
305 \\
2\end{array}$ & $\begin{array}{c}0.00 \\
682 \\
6\end{array}$ \\
\hline $\begin{array}{l}\text { pseudomo } \\
\text { nas }\end{array}$ & $\begin{array}{c}0.01 \\
5519 \\
96\end{array}$ & $\begin{array}{c}0.00 \\
033 \\
4\end{array}$ & $\begin{array}{c}0.00 \\
085 \\
4\end{array}$ & $\begin{array}{c}0.00 \\
031 \\
9\end{array}$ & $\begin{array}{l}0.00 \\
035\end{array}$ & $\begin{array}{c}0.00 \\
059 \\
2 \\
\end{array}$ & $\begin{array}{c}0.00 \\
604 \\
6\end{array}$ & $\begin{array}{c}0.00 \\
198 \\
4\end{array}$ & $\begin{array}{c}0.00 \\
213 \\
8\end{array}$ & $\begin{array}{c}0.00 \\
687 \\
5\end{array}$ & $\begin{array}{c}0.00 \\
527 \\
4\end{array}$ \\
\hline $\begin{array}{l}\text { sulfuricurv } \\
\text { um }\end{array}$ & $\begin{array}{c}0.00 \\
1061 \\
47\end{array}$ & $\begin{array}{l}0.00 \\
122\end{array}$ & $\begin{array}{c}0.00 \\
929 \\
4\end{array}$ & $\begin{array}{c}0.00 \\
031 \\
9\end{array}$ & $\begin{array}{l}0.00 \\
063\end{array}$ & $\begin{array}{l}0.00 \\
202\end{array}$ & $\begin{array}{c}0.01 \\
129 \\
1\end{array}$ & $\begin{array}{c}0.00 \\
100 \\
4\end{array}$ & $\begin{array}{c}0.00 \\
115 \\
2\end{array}$ & $\begin{array}{c}0.00 \\
228 \\
2\end{array}$ & $\begin{array}{c}0.00 \\
611 \\
2\end{array}$ \\
\hline $\begin{array}{l}\text { chitinopha } \\
\text { ga }\end{array}$ & $\begin{array}{c}8.04 \\
14 \mathrm{E}- \\
05\end{array}$ & $\begin{array}{c}0.00 \\
74\end{array}$ & $\begin{array}{c}0.00 \\
082 \\
9\end{array}$ & $\begin{array}{c}0.00 \\
016 \\
6\end{array}$ & $\begin{array}{c}0.00 \\
016 \\
8\end{array}$ & $\begin{array}{c}0.01 \\
121 \\
3\end{array}$ & $\begin{array}{c}0.00 \\
020 \\
7\end{array}$ & $\begin{array}{c}0.00 \\
030 \\
1\end{array}$ & $\begin{array}{l}9.72 \\
E-05\end{array}$ & $\begin{array}{c}0.00 \\
191 \\
8\end{array}$ & $\begin{array}{c}0.00 \\
057 \\
7\end{array}$ \\
\hline $\begin{array}{l}\text { methanoli } \\
\text { nea }\end{array}$ & $\begin{array}{c}9.64 \\
97 \mathrm{E}- \\
05\end{array}$ & $\begin{array}{c}0.00 \\
075 \\
8 \\
\end{array}$ & $\begin{array}{c}0.00 \\
12\end{array}$ & $\begin{array}{l}0.00 \\
417\end{array}$ & $\begin{array}{c}0.00 \\
226 \\
8\end{array}$ & $\begin{array}{c}0.00 \\
111 \\
1 \\
\end{array}$ & $\begin{array}{c}0.00 \\
063 \\
5\end{array}$ & $\begin{array}{c}0.00 \\
242 \\
3\end{array}$ & $\begin{array}{c}0.00 \\
585 \\
8 \\
\end{array}$ & $\begin{array}{l}0.00 \\
035\end{array}$ & $\begin{array}{c}0.00 \\
181 \\
3 \\
\end{array}$ \\
\hline $\begin{array}{l}\text { dehalobac } \\
\text { terium }\end{array}$ & $\begin{array}{c}.82 \\
49 \mathrm{E}- \\
05\end{array}$ & $\begin{array}{c}0.00 \\
303 \\
2\end{array}$ & $\begin{array}{c}0.00 \\
201 \\
7\end{array}$ & $\begin{array}{c}0.00 \\
353 \\
2\end{array}$ & $\begin{array}{c}0.00 \\
359 \\
8\end{array}$ & $\begin{array}{c}0.00 \\
313 \\
2\end{array}$ & $\begin{array}{c}0.00 \\
182 \\
2\end{array}$ & $\begin{array}{c}0.00 \\
267 \\
4\end{array}$ & $\begin{array}{c}0.00 \\
206 \\
8\end{array}$ & $\begin{array}{c}0.00 \\
096 \\
6\end{array}$ & $\begin{array}{c}0.00 \\
120 \\
9\end{array}$ \\
\hline $\begin{array}{l}\text { desulfomo } \\
\text { nile }\end{array}$ & $\begin{array}{c}6.43 \\
31 \mathrm{E}- \\
05\end{array}$ & $\begin{array}{c}0.00 \\
028 \\
3\end{array}$ & $\begin{array}{c}0.00 \\
107 \\
7\end{array}$ & $\begin{array}{c}0.00 \\
238 \\
3\end{array}$ & $\begin{array}{c}0.00 \\
428 \\
4\end{array}$ & $\begin{array}{c}0.00 \\
018 \\
8\end{array}$ & $\begin{array}{c}0.00 \\
075 \\
9\end{array}$ & $\begin{array}{c}0.00 \\
743 \\
3\end{array}$ & $\begin{array}{c}0.00 \\
619 \\
2\end{array}$ & $\begin{array}{c}0.00 \\
085 \\
4\end{array}$ & $\begin{array}{c}0.00 \\
076 \\
9\end{array}$ \\
\hline $\begin{array}{l}\text { rubrobact } \\
\text { er }\end{array}$ & $\begin{array}{c}8.04 \\
14 \mathrm{E}- \\
05\end{array}$ & $\begin{array}{c}0.00 \\
264 \\
6\end{array}$ & $\begin{array}{c}0.00 \\
242 \\
6\end{array}$ & $\begin{array}{c}0.00 \\
315 \\
8\end{array}$ & $\begin{array}{c}0.00 \\
316 \\
4\end{array}$ & $\begin{array}{c}0.00 \\
163 \\
1\end{array}$ & $\begin{array}{c}0.00 \\
114 \\
6\end{array}$ & $\begin{array}{c}0.00 \\
185 \\
8\end{array}$ & $\begin{array}{c}0.00 \\
209 \\
6\end{array}$ & $\begin{array}{c}0.00 \\
029 \\
4\end{array}$ & $\begin{array}{c}0.00 \\
112 \\
6\end{array}$ \\
\hline $\begin{array}{l}\text { pedomicro } \\
\text { bium }\end{array}$ & $\begin{array}{c}8.04 \\
14 \mathrm{E}- \\
05\end{array}$ & $\begin{array}{c}0.00 \\
14\end{array}$ & $\begin{array}{c}0.00 \\
217 \\
8\end{array}$ & $\begin{array}{c}0.00 \\
497 \\
3\end{array}$ & $\begin{array}{c}0.00 \\
453 \\
6\end{array}$ & $\begin{array}{c}0.00 \\
189 \\
1 \\
\end{array}$ & $\begin{array}{c}0.00 \\
117 \\
3 \\
\end{array}$ & $\begin{array}{c}0.00 \\
178 \\
3\end{array}$ & $\begin{array}{c}0.00 \\
209 \\
6\end{array}$ & $\begin{array}{c}0.00 \\
085 \\
4 \\
\end{array}$ & $\begin{array}{c}0.00 \\
175 \\
8 \\
\end{array}$ \\
\hline $\begin{array}{l}\text { terribacillu } \\
\mathrm{s}\end{array}$ & $\begin{array}{c}6.43 \\
31 \mathrm{E}- \\
05\end{array}$ & $\begin{array}{c}0.00 \\
021 \\
8\end{array}$ & $\begin{array}{c}0.00 \\
143 \\
6\end{array}$ & $\begin{array}{c}0.00 \\
033 \\
2\end{array}$ & $\begin{array}{c}0.00 \\
410 \\
2\end{array}$ & $\begin{array}{c}0.00 \\
098 \\
1\end{array}$ & $\begin{array}{c}0.01 \\
514 \\
1\end{array}$ & $\begin{array}{c}0.00 \\
018 \\
8\end{array}$ & $\begin{array}{c}0.00 \\
013 \\
9\end{array}$ & $\begin{array}{c}0.00 \\
050 \\
4\end{array}$ & $\begin{array}{c}0.00 \\
608 \\
4\end{array}$ \\
\hline
\end{tabular}


NOT THE PUBLISHED VERSION; this is the author's final, peer-reviewed manuscript. The published version may be accessed by following the link in the citation at the bottom of the page.

\begin{tabular}{|c|c|c|c|c|c|c|c|c|c|c|c|}
\hline $\begin{array}{l}\text { methanob } \\
\text { revibacter }\end{array}$ & $\begin{array}{c}0.00 \\
0353 \\
82\end{array}$ & $\begin{array}{c}0.00 \\
116 \\
9\end{array}$ & $\begin{array}{c}0.00 \\
136 \\
1\end{array}$ & $\begin{array}{c}0.00 \\
245 \\
2\end{array}$ & $\begin{array}{c}0.00 \\
141 \\
4\end{array}$ & $\begin{array}{c}0.00 \\
147 \\
2\end{array}$ & $\begin{array}{c}0.00 \\
103 \\
5\end{array}$ & $\begin{array}{c}0.00 \\
345 \\
3\end{array}$ & $\begin{array}{c}0.00 \\
342 \\
9\end{array}$ & $\begin{array}{c}0.00 \\
093 \\
8\end{array}$ & $\begin{array}{c}0.00 \\
156 \\
6\end{array}$ \\
\hline thiobacillu & 0.00 & 0.00 & 0.00 & 0.00 & 0.00 & 0.00 & 0.00 & 0.00 & 0.00 & 0.00 & 0.00 \\
\hline $\mathrm{s}$ & $\begin{array}{c}0160 \\
83\end{array}$ & $\begin{array}{c}055 \\
2\end{array}$ & $\begin{array}{c}584 \\
1\end{array}$ & $\begin{array}{c}037 \\
4\end{array}$ & 084 & $\begin{array}{c}144 \\
3\end{array}$ & 726 & $\begin{array}{c}042 \\
7\end{array}$ & 05 & $\begin{array}{c}422 \\
9\end{array}$ & $\begin{array}{c}858 \\
4\end{array}$ \\
\hline $\begin{array}{l}\text { thioalkalib } \\
\text { acter }\end{array}$ & $\begin{array}{c}0.00 \\
0128 \\
66\end{array}$ & $\begin{array}{l}0.00 \\
379\end{array}$ & $\begin{array}{c}0.00 \\
179 \\
4\end{array}$ & $\begin{array}{c}0.00 \\
019 \\
4\end{array}$ & $\begin{array}{l}0.00 \\
035\end{array}$ & $\begin{array}{c}0.00 \\
588 \\
8\end{array}$ & $\begin{array}{c}0.00 \\
274 \\
7\end{array}$ & $\begin{array}{c}0.00 \\
022 \\
6\end{array}$ & $\begin{array}{c}0.00 \\
038 \\
9\end{array}$ & $\begin{array}{l}0.00 \\
112\end{array}$ & $\begin{array}{c}0.00 \\
318 \\
6\end{array}$ \\
\hline hespellia & $\begin{array}{c}0.00 \\
0144 \\
75\end{array}$ & $\begin{array}{c}0.00 \\
236 \\
4\end{array}$ & $\begin{array}{c}0.00 \\
678 \\
2\end{array}$ & $\begin{array}{c}0.00 \\
012 \\
5\end{array}$ & $\begin{array}{l}9.8 \mathrm{E} \\
-05\end{array}$ & $\begin{array}{c}0.00 \\
131 \\
3\end{array}$ & $\begin{array}{c}0.00 \\
346 \\
4\end{array}$ & $\begin{array}{c}0.00 \\
018 \\
8\end{array}$ & $\begin{array}{c}0.00 \\
055 \\
5\end{array}$ & $\begin{array}{c}0.00 \\
061 \\
6\end{array}$ & $\begin{array}{c}0.00 \\
152 \\
5\end{array}$ \\
\hline $\begin{array}{l}\text { cetobacter } \\
\text { ium }\end{array}$ & $\begin{array}{c}0.01 \\
5600 \\
37\end{array}$ & $\begin{array}{l}0.00 \\
045\end{array}$ & $\begin{array}{c}0.00 \\
049 \\
5\end{array}$ & $\begin{array}{c}0.00 \\
015 \\
2\end{array}$ & $\begin{array}{c}0.00 \\
032 \\
2\end{array}$ & $\begin{array}{c}0.00 \\
014 \\
4\end{array}$ & $\begin{array}{c}0.00 \\
114 \\
6\end{array}$ & $\begin{array}{c}0.00 \\
301 \\
3\end{array}$ & $\begin{array}{c}0.00 \\
294 \\
3\end{array}$ & $\begin{array}{c}0.00 \\
519 \\
5\end{array}$ & $\begin{array}{c}0.00 \\
458 \\
7\end{array}$ \\
\hline $\begin{array}{l}\text { methyloph } \\
\text { aga }\end{array}$ & $\begin{array}{c}8.04 \\
14 \mathrm{E}- \\
05\end{array}$ & $\begin{array}{c}0.00 \\
250 \\
5\end{array}$ & $\begin{array}{c}0.00 \\
195 \\
5\end{array}$ & $\begin{array}{l}0.00 \\
374\end{array}$ & $\begin{array}{c}0.00 \\
078 \\
4\end{array}$ & $\begin{array}{c}0.00 \\
193 \\
4\end{array}$ & $\begin{array}{c}0.00 \\
074 \\
5\end{array}$ & $\begin{array}{c}0.00 \\
121 \\
8\end{array}$ & $\begin{array}{c}0.00 \\
111 \\
1\end{array}$ & $\begin{array}{c}0.00 \\
061 \\
6\end{array}$ & $\begin{array}{c}0.00 \\
089 \\
3\end{array}$ \\
\hline $\begin{array}{l}\text { rhodocycl } \\
\text { us }\end{array}$ & $\begin{array}{c}0.00 \\
9231 \\
56\end{array}$ & $\begin{array}{c}0.00 \\
014 \\
1\end{array}$ & $\begin{array}{l}0.00 \\
125\end{array}$ & $\begin{array}{c}0.00 \\
012 \\
5\end{array}$ & $\begin{array}{c}0.00 \\
016 \\
8\end{array}$ & $\begin{array}{c}0.00 \\
024 \\
5\end{array}$ & $\begin{array}{c}0.00 \\
205 \\
7\end{array}$ & $\begin{array}{c}0.00 \\
200 \\
9\end{array}$ & $\begin{array}{c}0.00 \\
238 \\
8\end{array}$ & $\begin{array}{c}0.00 \\
502 \\
7\end{array}$ & $\begin{array}{c}0.00 \\
64\end{array}$ \\
\hline $\begin{array}{l}\text { enterobac } \\
\text { ter }\end{array}$ & $\begin{array}{c}0.01 \\
3959 \\
92\end{array}$ & $\begin{array}{c}0.00 \\
014 \\
1\end{array}$ & $\begin{array}{l}0.00 \\
047\end{array}$ & $\begin{array}{c}0.00 \\
016 \\
6\end{array}$ & $\begin{array}{l}0.00 \\
063\end{array}$ & $\begin{array}{c}0.00 \\
018 \\
8\end{array}$ & $\begin{array}{c}0.00 \\
128 \\
4\end{array}$ & $\begin{array}{c}0.00 \\
090 \\
4\end{array}$ & $\begin{array}{c}0.00 \\
073 \\
6\end{array}$ & $\begin{array}{c}0.00 \\
376 \\
7\end{array}$ & $\begin{array}{c}0.00 \\
115 \\
4\end{array}$ \\
\hline $\begin{array}{l}\text { dechlorom } \\
\text { onas }\end{array}$ & $\begin{array}{c}0.00 \\
4133 \\
29\end{array}$ & $\begin{array}{c}0.00 \\
032 \\
1 \\
\end{array}$ & $\begin{array}{c}0.00 \\
112 \\
6\end{array}$ & $\begin{array}{l}8.31 \\
E-05\end{array}$ & $\begin{array}{c}0.00 \\
025 \\
2\end{array}$ & $\begin{array}{c}0.00 \\
036 \\
1\end{array}$ & $\begin{array}{c}0.00 \\
183 \\
6\end{array}$ & $\begin{array}{c}0.00 \\
311 \\
4\end{array}$ & $\begin{array}{l}0.00 \\
236\end{array}$ & $\begin{array}{c}0.00 \\
614 \\
7\end{array}$ & $\begin{array}{c}0.00 \\
541 \\
1\end{array}$ \\
\hline $\begin{array}{l}\text { streptococ } \\
\text { cus }\end{array}$ & $\begin{array}{c}0.01 \\
0807 \\
68\end{array}$ & $\begin{array}{c}0.00 \\
168 \\
3\end{array}$ & $\begin{array}{c}0.00 \\
148 \\
5\end{array}$ & $\begin{array}{c}0.00 \\
038 \\
8\end{array}$ & $\begin{array}{c}0.00 \\
064 \\
4\end{array}$ & $\begin{array}{l}0.00 \\
101\end{array}$ & $\begin{array}{c}0.00 \\
149 \\
1\end{array}$ & $\begin{array}{c}0.00 \\
091 \\
7\end{array}$ & $\begin{array}{c}0.00 \\
116 \\
6\end{array}$ & $\begin{array}{c}0.00 \\
193 \\
2\end{array}$ & $\begin{array}{c}0.00 \\
181 \\
3\end{array}$ \\
\hline $\begin{array}{l}\text { oscillospir } \\
\text { a }\end{array}$ & $\begin{array}{c}0.00 \\
1994 \\
27\end{array}$ & $\begin{array}{c}0.00 \\
069 \\
4\end{array}$ & $\begin{array}{c}0.00 \\
300 \\
7\end{array}$ & $\begin{array}{c}0.00 \\
031 \\
9\end{array}$ & $\begin{array}{c}0.00 \\
064 \\
4\end{array}$ & $\begin{array}{c}0.00 \\
069 \\
3\end{array}$ & $\begin{array}{c}0.00 \\
263 \\
6\end{array}$ & $\begin{array}{l}0.00 \\
054\end{array}$ & $\begin{array}{l}0.00 \\
118\end{array}$ & $\begin{array}{l}0.00 \\
147\end{array}$ & $\begin{array}{c}0.00 \\
734 \\
8\end{array}$ \\
\hline $\begin{array}{l}\text { solirubrob } \\
\text { acter }\end{array}$ & $\begin{array}{c}9.64 \\
97 \mathrm{E}- \\
05 \\
\end{array}$ & $\begin{array}{c}0.00 \\
074 \\
5\end{array}$ & $\begin{array}{c}0.00 \\
061 \\
9\end{array}$ & $\begin{array}{c}0.00 \\
440 \\
5 \\
\end{array}$ & $\begin{array}{c}0.00 \\
257 \\
6\end{array}$ & $\begin{array}{c}0.00 \\
082 \\
3\end{array}$ & $\begin{array}{c}0.00 \\
017 \\
9\end{array}$ & $\begin{array}{c}0.00 \\
168 \\
2\end{array}$ & $\begin{array}{c}0.00 \\
066 \\
6 \\
\end{array}$ & $\begin{array}{l}0.00 \\
014\end{array}$ & $\begin{array}{c}0.00 \\
017 \\
9\end{array}$ \\
\hline $\begin{array}{l}\text { cloacibacill } \\
\text { us }\end{array}$ & $\begin{array}{c}0.00 \\
0418 \\
15\end{array}$ & $\begin{array}{c}0.00 \\
060 \\
4\end{array}$ & $\begin{array}{c}0.00 \\
454 \\
2\end{array}$ & $\begin{array}{c}0.00 \\
024 \\
9 \\
\end{array}$ & $\begin{array}{c}0.00 \\
060 \\
2\end{array}$ & $\begin{array}{c}0.00 \\
059 \\
2\end{array}$ & $\begin{array}{c}0.00 \\
411 \\
3\end{array}$ & $\begin{array}{c}0.00 \\
021 \\
3\end{array}$ & $\begin{array}{c}0.00 \\
033 \\
3\end{array}$ & $\begin{array}{c}0.00 \\
050 \\
4\end{array}$ & $\begin{array}{c}0.00 \\
421 \\
6\end{array}$ \\
\hline $\begin{array}{l}\text { planctomy } \\
\text { ces }\end{array}$ & $\begin{array}{c}9.64 \\
97 \mathrm{E}- \\
05\end{array}$ & $\begin{array}{c}0.00 \\
024 \\
4\end{array}$ & $\begin{array}{c}0.00 \\
194 \\
3\end{array}$ & $\begin{array}{c}0.00 \\
062 \\
3\end{array}$ & $\begin{array}{c}0.00 \\
093 \\
8\end{array}$ & $\begin{array}{c}0.00 \\
014 \\
4\end{array}$ & $\begin{array}{c}0.00 \\
320 \\
2\end{array}$ & $\begin{array}{l}0.00 \\
349\end{array}$ & $\begin{array}{c}0.00 \\
362 \\
3\end{array}$ & $\begin{array}{l}0.00 \\
056\end{array}$ & $\begin{array}{c}0.00 \\
346 \\
1\end{array}$ \\
\hline $\begin{array}{l}\text { alkalibacte } \\
\mathrm{r}\end{array}$ & $\begin{array}{c}0.00 \\
0128 \\
66 \\
\end{array}$ & $\begin{array}{l}0.00 \\
212\end{array}$ & $\begin{array}{l}0.00 \\
177\end{array}$ & $\begin{array}{c}0.00 \\
288 \\
1 \\
\end{array}$ & $\begin{array}{l}0.00 \\
196\end{array}$ & $\begin{array}{c}0.00 \\
132 \\
8 \\
\end{array}$ & $\begin{array}{c}0.00 \\
084 \\
2\end{array}$ & $\begin{array}{c}0.00 \\
105 \\
5\end{array}$ & $\begin{array}{c}0.00 \\
056 \\
9 \\
\end{array}$ & $\begin{array}{c}0.00 \\
051 \\
8 \\
\end{array}$ & $\begin{array}{c}0.00 \\
071 \\
4\end{array}$ \\
\hline $\begin{array}{l}\text { thermoan } \\
\text { aerobacte } \\
r\end{array}$ & $\begin{array}{c}0.00 \\
0176 \\
91 \\
\end{array}$ & $\begin{array}{c}0.00 \\
046 \\
2\end{array}$ & $\begin{array}{c}0.00 \\
220 \\
3\end{array}$ & $\begin{array}{c}0.00 \\
012 \\
5 \\
\end{array}$ & $\begin{array}{c}0.00 \\
025 \\
2\end{array}$ & $\begin{array}{l}0.00 \\
166\end{array}$ & $\begin{array}{c}0.00 \\
738 \\
4 \\
\end{array}$ & $\begin{array}{c}0.00 \\
150 \\
7 \\
\end{array}$ & $\begin{array}{c}0.00 \\
465 \\
1\end{array}$ & $\begin{array}{l}0.00 \\
084\end{array}$ & $\begin{array}{c}0.00 \\
609 \\
8\end{array}$ \\
\hline acetivibrio & $\begin{array}{c}0.00 \\
0128 \\
66\end{array}$ & $\begin{array}{c}0.00 \\
179 \\
9\end{array}$ & $\begin{array}{c}0.00 \\
086 \\
6\end{array}$ & $\begin{array}{c}0.00 \\
166 \\
2\end{array}$ & $\begin{array}{c}0.00 \\
218 \\
4\end{array}$ & $\begin{array}{c}0.00 \\
155 \\
9\end{array}$ & $\begin{array}{c}0.00 \\
122 \\
8\end{array}$ & $\begin{array}{c}0.00 \\
154 \\
4\end{array}$ & $\begin{array}{l}0.00 \\
211\end{array}$ & $\begin{array}{c}0.00 \\
036 \\
4\end{array}$ & $\begin{array}{l}0.00 \\
239\end{array}$ \\
\hline
\end{tabular}

Bioresource Technology, Vol 216 (September 2016): pg. 446-452. DOI. This article is @ Elsevier and permission has been granted for this version to appear in e-Publications@Marquette. Elsevier does not grant permission for this article to be further copied/distributed or hosted elsewhere without the express permission from Elsevier. 
NOT THE PUBLISHED VERSION; this is the author's final, peer-reviewed manuscript. The published version may be accessed by following the link in the citation at the bottom of the page.

\begin{tabular}{|c|c|c|c|c|c|c|c|c|c|c|c|}
\hline $\begin{array}{l}\text { ruminiclos } \\
\text { tridium }\end{array}$ & $\begin{array}{c}0.00 \\
0932 \\
81\end{array}$ & $\begin{array}{c}0.00 \\
107 \\
9\end{array}$ & $\begin{array}{l}0.00 \\
078\end{array}$ & $\begin{array}{c}0.00 \\
239 \\
6\end{array}$ & $\begin{array}{c}0.00 \\
043 \\
4\end{array}$ & $\begin{array}{c}0.00 \\
106 \\
8\end{array}$ & $\begin{array}{c}0.00 \\
055 \\
2\end{array}$ & $\begin{array}{c}0.00 \\
110 \\
5\end{array}$ & $\begin{array}{c}0.00 \\
062 \\
5\end{array}$ & $\begin{array}{l}0.00 \\
147\end{array}$ & $\begin{array}{c}0.00 \\
120 \\
9\end{array}$ \\
\hline $\begin{array}{l}\text { desulfospo } \\
\text { rosinus }\end{array}$ & $\begin{array}{c}1.60 \\
83 \mathrm{E}- \\
05\end{array}$ & $\begin{array}{c}0.00 \\
281 \\
3 \\
\end{array}$ & $\begin{array}{c}0.00 \\
149 \\
7 \\
\end{array}$ & $\begin{array}{c}0.00 \\
020 \\
8 \\
\end{array}$ & $\begin{array}{c}0.00 \\
058 \\
8 \\
\end{array}$ & $\begin{array}{c}0.00 \\
408 \\
4 \\
\end{array}$ & $\begin{array}{c}0.00 \\
154 \\
6 \\
\end{array}$ & $\begin{array}{c}0.00 \\
051 \\
5 \\
\end{array}$ & $\begin{array}{c}0.00 \\
055 \\
5 \\
\end{array}$ & $\begin{array}{c}0.00 \\
240 \\
8 \\
\end{array}$ & $\begin{array}{c}0.00 \\
233 \\
5 \\
\end{array}$ \\
\hline tolumonas & $\begin{array}{c}0.01 \\
7707 \\
23 \\
\end{array}$ & $\begin{array}{l}1.28 \\
\text { E-05 }\end{array}$ & $\begin{array}{l}8.66 \\
E-05\end{array}$ & $\begin{array}{c}0.00 \\
011 \\
1\end{array}$ & $\begin{array}{c}0.00 \\
051 \\
8 \\
\end{array}$ & $\begin{array}{l}2.89 \\
\text { E-05 }\end{array}$ & $\begin{array}{l}5.52 \\
E-05\end{array}$ & $\begin{array}{c}0.00 \\
066 \\
5\end{array}$ & $\begin{array}{c}0.00 \\
065 \\
2 \\
\end{array}$ & $\begin{array}{c}0.00 \\
375 \\
3 \\
\end{array}$ & $\begin{array}{c}0.00 \\
134 \\
6 \\
\end{array}$ \\
\hline $\begin{array}{l}\text { chloroflex } \\
\text { us }\end{array}$ & $\begin{array}{c}4.82 \\
49 \mathrm{E}- \\
05\end{array}$ & $\begin{array}{c}0.00 \\
030 \\
8\end{array}$ & $\begin{array}{c}0.00 \\
070 \\
5\end{array}$ & $\begin{array}{c}0.00 \\
263 \\
2\end{array}$ & $\begin{array}{l}0.00 \\
231\end{array}$ & $\begin{array}{l}0.00 \\
026\end{array}$ & $\begin{array}{c}0.00 \\
015 \\
2\end{array}$ & $\begin{array}{c}0.00 \\
305 \\
1\end{array}$ & $\begin{array}{c}0.00 \\
215 \\
2\end{array}$ & $\begin{array}{l}\text { 7E- } \\
05\end{array}$ & $\begin{array}{c}0.00 \\
026 \\
1\end{array}$ \\
\hline $\begin{array}{l}\text { faecalibact } \\
\text { erium }\end{array}$ & $\begin{array}{c}0.01 \\
8157 \\
55\end{array}$ & $\begin{array}{l}7.71 \\
\text { E-05 }\end{array}$ & $\begin{array}{l}4.95 \\
E-05\end{array}$ & $\begin{array}{l}4.16 \\
E-05\end{array}$ & $\begin{array}{c}4.2 \mathrm{E} \\
-05\end{array}$ & $\begin{array}{l}2.89 \\
\text { E-05 }\end{array}$ & $\begin{array}{l}4.14 \\
E-05\end{array}$ & $\begin{array}{c}0.00 \\
079 \\
1\end{array}$ & $\begin{array}{c}0.00 \\
112 \\
4\end{array}$ & $\begin{array}{c}0.00 \\
228 \\
2\end{array}$ & $\begin{array}{c}0.00 \\
182 \\
7\end{array}$ \\
\hline $\begin{array}{l}\text { streptomy } \\
\text { ces }\end{array}$ & $\begin{array}{c}6.43 \\
31 \mathrm{E}- \\
05\end{array}$ & $\begin{array}{c}0.00 \\
059 \\
1 \\
\end{array}$ & $\begin{array}{c}0.00 \\
097 \\
8 \\
\end{array}$ & $\begin{array}{c}0.00 \\
196 \\
7 \\
\end{array}$ & $\begin{array}{c}0.00 \\
281 \\
4 \\
\end{array}$ & $\begin{array}{l}0.00 \\
052\end{array}$ & $\begin{array}{c}0.00 \\
052 \\
4\end{array}$ & $\begin{array}{c}0.00 \\
183 \\
3\end{array}$ & $\begin{array}{c}0.00 \\
166 \\
6\end{array}$ & $\begin{array}{l}0.00 \\
021\end{array}$ & $\begin{array}{c}0.00 \\
048 \\
1\end{array}$ \\
\hline $\begin{array}{l}\text { desulfobac } \\
\text { ter }\end{array}$ & $\begin{array}{c}0.00 \\
0273 \\
41\end{array}$ & $\begin{array}{c}0.00 \\
010 \\
3\end{array}$ & $\begin{array}{c}0.00 \\
132 \\
4\end{array}$ & $\begin{array}{c}0.00 \\
013 \\
9\end{array}$ & $\begin{array}{c}0.00 \\
016 \\
8\end{array}$ & $\begin{array}{c}0.00 \\
017 \\
3\end{array}$ & $\begin{array}{c}0.00 \\
111 \\
8\end{array}$ & $\begin{array}{c}0.00 \\
143 \\
1\end{array}$ & $\begin{array}{c}0.00 \\
490 \\
1\end{array}$ & $\begin{array}{c}0.00 \\
218 \\
4\end{array}$ & $\begin{array}{c}0.00 \\
365 \\
3\end{array}$ \\
\hline kushneria & $\begin{array}{c}0.00 \\
0321 \\
66\end{array}$ & $\begin{array}{l}6.42 \\
\text { E-05 }\end{array}$ & $\begin{array}{c}0.00 \\
043 \\
3\end{array}$ & $\begin{array}{c}0.00 \\
013 \\
9\end{array}$ & $\begin{array}{c}0.00 \\
481 \\
6\end{array}$ & $\begin{array}{l}0.00 \\
013\end{array}$ & $\begin{array}{c}0.00 \\
012 \\
4\end{array}$ & $\begin{array}{l}8.79 \\
\text { E-05 }\end{array}$ & $\begin{array}{c}0.00 \\
052 \\
8\end{array}$ & $\begin{array}{c}5.6 \mathrm{E} \\
-05\end{array}$ & $\begin{array}{l}6.87 \\
\text { E-05 }\end{array}$ \\
\hline pelosinus & $\begin{array}{c}0.01 \\
4973 \\
14\end{array}$ & $\begin{array}{c}0.00 \\
068 \\
1\end{array}$ & $\begin{array}{c}0.00 \\
028 \\
5\end{array}$ & $\begin{array}{c}0.00 \\
038 \\
8\end{array}$ & $\begin{array}{l}8.4 \mathrm{E} \\
-05\end{array}$ & $\begin{array}{c}0.00 \\
046 \\
2\end{array}$ & $\begin{array}{c}0.00 \\
015 \\
2 \\
\end{array}$ & $\begin{array}{c}0.00 \\
046 \\
5\end{array}$ & $\begin{array}{c}0.00 \\
034 \\
7\end{array}$ & $\begin{array}{c}0.00 \\
179 \\
2 \\
\end{array}$ & $\begin{array}{c}0.00 \\
072 \\
8\end{array}$ \\
\hline $\begin{array}{l}\text { aminomon } \\
\text { as }\end{array}$ & $\begin{array}{c}3.21 \\
66 \mathrm{E}- \\
05\end{array}$ & $\begin{array}{c}0.00 \\
065 \\
5\end{array}$ & $\begin{array}{l}0.00 \\
021\end{array}$ & $\begin{array}{c}0.00 \\
088 \\
7\end{array}$ & $\begin{array}{c}0.00 \\
491 \\
4\end{array}$ & $\begin{array}{c}0.00 \\
056 \\
3\end{array}$ & $\begin{array}{l}9.66 \\
E-05\end{array}$ & $\begin{array}{c}0.00 \\
060 \\
3\end{array}$ & $\begin{array}{c}0.00 \\
036 \\
1\end{array}$ & $\begin{array}{l}0.00 \\
014\end{array}$ & $\begin{array}{l}5.49 \\
\text { E-05 }\end{array}$ \\
\hline moorella & $\begin{array}{c}4.82 \\
49 \mathrm{E}- \\
05\end{array}$ & $\begin{array}{l}0.00 \\
027\end{array}$ & $\begin{array}{c}0.00 \\
084 \\
2\end{array}$ & $\begin{array}{c}0.00 \\
202 \\
2\end{array}$ & $\begin{array}{c}0.00 \\
085 \\
4\end{array}$ & $\begin{array}{c}0.00 \\
020 \\
2\end{array}$ & $\begin{array}{c}0.00 \\
015 \\
2\end{array}$ & $\begin{array}{l}0.00 \\
334\end{array}$ & $\begin{array}{c}0.00 \\
273 \\
5\end{array}$ & $\begin{array}{l}8.4 \mathrm{E} \\
-05\end{array}$ & $\begin{array}{c}0.00 \\
038 \\
5\end{array}$ \\
\hline $\begin{array}{l}\text { desulfofab } \\
\text { a }\end{array}$ & $\begin{array}{c}0.00 \\
0209 \\
08 \\
\end{array}$ & $\begin{array}{l}6.42 \\
E-05\end{array}$ & $\begin{array}{c}0.00 \\
131 \\
2 \\
\end{array}$ & $\begin{array}{c}0.00 \\
049 \\
9 \\
\end{array}$ & $\begin{array}{c}0.00 \\
099 \\
4\end{array}$ & $\begin{array}{l}7.22 \\
\text { E-05 }\end{array}$ & $\begin{array}{c}0.00 \\
096 \\
6\end{array}$ & $\begin{array}{l}0.00 \\
167\end{array}$ & $\begin{array}{c}0.00 \\
483 \\
1\end{array}$ & $\begin{array}{c}0.00 \\
012 \\
6\end{array}$ & $\begin{array}{c}0.00 \\
087 \\
9 \\
\end{array}$ \\
\hline $\begin{array}{l}\text { symbiobac } \\
\text { terium }\end{array}$ & $\begin{array}{c}8.04 \\
14 \mathrm{E}- \\
05\end{array}$ & $\begin{array}{c}0.00 \\
164 \\
4\end{array}$ & $\begin{array}{c}0.00 \\
076 \\
7\end{array}$ & $\begin{array}{l}0.00 \\
061\end{array}$ & $\begin{array}{c}0.00 \\
067 \\
2\end{array}$ & $\begin{array}{c}0.00 \\
225 \\
1\end{array}$ & $\begin{array}{c}0.00 \\
063 \\
5\end{array}$ & $\begin{array}{c}0.00 \\
189 \\
6\end{array}$ & $\begin{array}{c}0.00 \\
277 \\
7\end{array}$ & $\begin{array}{l}0.00 \\
035\end{array}$ & $\begin{array}{c}0.00 \\
068 \\
7\end{array}$ \\
\hline $\begin{array}{l}\text { anaerofust } \\
\text { is }\end{array}$ & $\begin{array}{c}8.04 \\
14 \mathrm{E}- \\
05\end{array}$ & $\begin{array}{c}0.00 \\
305 \\
8\end{array}$ & $\begin{array}{c}0.00 \\
049 \\
5\end{array}$ & $\begin{array}{c}0.00 \\
148 \\
2\end{array}$ & $\begin{array}{c}0.00 \\
103 \\
6\end{array}$ & $\begin{array}{l}0.00 \\
254\end{array}$ & $\begin{array}{c}0.00 \\
013 \\
8\end{array}$ & $\begin{array}{c}0.00 \\
070 \\
3\end{array}$ & $\begin{array}{c}0.00 \\
076 \\
4\end{array}$ & $\begin{array}{c}0.00 \\
060 \\
2\end{array}$ & $\begin{array}{c}0.00 \\
020 \\
6\end{array}$ \\
\hline $\begin{array}{l}\text { thermogy } \\
\text { mnomona } \\
\text { s }\end{array}$ & $\begin{array}{c}6.43 \\
31 \mathrm{E}- \\
05\end{array}$ & $\begin{array}{c}0.00 \\
082 \\
2\end{array}$ & $\begin{array}{c}0.00 \\
037 \\
1\end{array}$ & $\begin{array}{c}0.00 \\
105 \\
3\end{array}$ & $\begin{array}{c}0.00 \\
067 \\
2\end{array}$ & $\begin{array}{c}0.00 \\
053 \\
4\end{array}$ & $\begin{array}{c}0.00 \\
033 \\
1\end{array}$ & $\begin{array}{c}0.00 \\
199 \\
6\end{array}$ & $\begin{array}{c}0.00 \\
438 \\
7\end{array}$ & $\begin{array}{l}0.00 \\
014\end{array}$ & $\begin{array}{c}0.00 \\
100 \\
3\end{array}$ \\
\hline lutispora & $\begin{array}{c}4.82 \\
49 \mathrm{E}- \\
05\end{array}$ & $\begin{array}{l}0.00 \\
018\end{array}$ & $\begin{array}{c}0.00 \\
179 \\
4\end{array}$ & $\begin{array}{c}0.00 \\
077 \\
6\end{array}$ & $\begin{array}{c}0.00 \\
127 \\
4\end{array}$ & $\begin{array}{c}0.00 \\
023 \\
1\end{array}$ & $\begin{array}{c}0.00 \\
133 \\
9\end{array}$ & $\begin{array}{c}0.00 \\
065 \\
3\end{array}$ & $\begin{array}{c}0.00 \\
101 \\
3\end{array}$ & $\begin{array}{c}0.00 \\
016 \\
8\end{array}$ & $\begin{array}{c}0.00 \\
105 \\
8\end{array}$ \\
\hline serratia & $\begin{array}{c}0.01 \\
2399 \\
88\end{array}$ & $\begin{array}{l}5.14 \\
\text { E-05 }\end{array}$ & $\begin{array}{l}8.66 \\
E-05\end{array}$ & $\begin{array}{l}1.39 \\
E-05\end{array}$ & $\begin{array}{l}2.8 \mathrm{E} \\
-05\end{array}$ & $\begin{array}{l}7.22 \\
E-05\end{array}$ & $\begin{array}{c}0.00 \\
015 \\
2\end{array}$ & $\begin{array}{c}0.00 \\
040 \\
2\end{array}$ & $\begin{array}{l}0.00 \\
068\end{array}$ & $\begin{array}{c}0.00 \\
410 \\
3\end{array}$ & $\begin{array}{c}0.00 \\
162 \\
1\end{array}$ \\
\hline
\end{tabular}

Bioresource Technology, Vol 216 (September 2016): pg. 446-452. DOI. This article is @ Elsevier and permission has been granted for this version to appear in e-Publications@Marquette. Elsevier does not grant permission for this article to be further copied/distributed or hosted elsewhere without the express permission from Elsevier. 
NOT THE PUBLISHED VERSION; this is the author's final, peer-reviewed manuscript. The published version may be accessed by following the link in the citation at the bottom of the page.

\begin{tabular}{|c|c|c|c|c|c|c|c|c|c|c|c|}
\hline $\begin{array}{l}\text { subdoligra } \\
\text { nulum }\end{array}$ & $\begin{array}{c}0.01 \\
2657 \\
21\end{array}$ & $\begin{array}{l}7.71 \\
E-05\end{array}$ & $\begin{array}{l}4.95 \\
E-05\end{array}$ & $\begin{array}{l}6.93 \\
E-05\end{array}$ & $\begin{array}{l}4.2 \mathrm{E} \\
-05\end{array}$ & $\begin{array}{l}4.33 \\
E-05\end{array}$ & $\begin{array}{l}5.52 \\
E-05\end{array}$ & $\begin{array}{c}0.00 \\
077 \\
8\end{array}$ & $\begin{array}{c}0.00 \\
102 \\
7\end{array}$ & $\begin{array}{c}0.00 \\
296 \\
8\end{array}$ & $\begin{array}{c}0.00 \\
173 \\
1\end{array}$ \\
\hline $\begin{array}{l}\text { mycoplas } \\
\text { ma }\end{array}$ & $\begin{array}{c}9.64 \\
97 \mathrm{E}- \\
05 \\
\end{array}$ & $\begin{array}{c}0.00 \\
273 \\
6 \\
\end{array}$ & $\begin{array}{c}0.00 \\
034 \\
7 \\
\end{array}$ & $\begin{array}{c}0.00 \\
029 \\
1 \\
\end{array}$ & $\begin{array}{c}0.00 \\
032 \\
2 \\
\end{array}$ & $\begin{array}{l}0.01 \\
065\end{array}$ & $\begin{array}{c}0.00 \\
019 \\
3 \\
\end{array}$ & $\begin{array}{c}0.00 \\
052 \\
7 \\
\end{array}$ & $\begin{array}{c}0.00 \\
020 \\
8 \\
\end{array}$ & $\begin{array}{c}0.00 \\
156 \\
8 \\
\end{array}$ & $\begin{array}{l}0.00 \\
044\end{array}$ \\
\hline $\begin{array}{l}\text { propionige } \\
\text { nium }\end{array}$ & $\begin{array}{c}0.01 \\
6404 \\
52 \\
\end{array}$ & $\begin{array}{l}7.71 \\
E-05\end{array}$ & $\begin{array}{l}6.19 \\
E-05\end{array}$ & $\begin{array}{l}9.7 \mathrm{E} \\
-05\end{array}$ & $\begin{array}{l}\text { 7E- } \\
05\end{array}$ & 0 & $\begin{array}{l}6.9 E \\
-05\end{array}$ & $\begin{array}{c}0.00 \\
011 \\
3\end{array}$ & $\begin{array}{l}0.00 \\
018\end{array}$ & $\begin{array}{l}0.00 \\
112\end{array}$ & $\begin{array}{l}0.00 \\
033\end{array}$ \\
\hline $\begin{array}{l}\text { ignavibact } \\
\text { erium }\end{array}$ & $\begin{array}{c}6.43 \\
31 \mathrm{E}- \\
05\end{array}$ & $\begin{array}{c}0.00 \\
060 \\
4\end{array}$ & $\begin{array}{l}0.00 \\
078\end{array}$ & $\begin{array}{c}0.00 \\
130 \\
2\end{array}$ & $\begin{array}{c}0.00 \\
095 \\
2\end{array}$ & $\begin{array}{c}0.00 \\
070 \\
7\end{array}$ & $\begin{array}{c}0.00 \\
055 \\
2\end{array}$ & $\begin{array}{c}0.00 \\
219 \\
7\end{array}$ & $\begin{array}{c}0.00 \\
170 \\
8\end{array}$ & $\begin{array}{l}0.00 \\
028\end{array}$ & $\begin{array}{c}0.00 \\
056 \\
3\end{array}$ \\
\hline $\begin{array}{l}\text { methano } \\
\text { methylovo } \\
\text { rans }\end{array}$ & $\begin{array}{c}6.43 \\
31 \mathrm{E}- \\
05\end{array}$ & $\begin{array}{c}0.00 \\
039 \\
8\end{array}$ & $\begin{array}{l}0.00 \\
104\end{array}$ & $\begin{array}{l}0.00 \\
072\end{array}$ & $\begin{array}{c}0.00 \\
155 \\
4\end{array}$ & $\begin{array}{c}0.00 \\
036 \\
1\end{array}$ & $\begin{array}{c}0.00 \\
031 \\
7\end{array}$ & $\begin{array}{c}0.00 \\
129 \\
3\end{array}$ & $\begin{array}{c}0.00 \\
258 \\
2\end{array}$ & $\begin{array}{c}0.00 \\
029 \\
4\end{array}$ & $\begin{array}{c}0.00 \\
076 \\
9\end{array}$ \\
\hline $\begin{array}{l}\text { caloramat } \\
\text { or }\end{array}$ & $\begin{array}{c}3.21 \\
66 \mathrm{E}- \\
05\end{array}$ & $\begin{array}{c}0.00 \\
165 \\
7 \\
\end{array}$ & $\begin{array}{l}0.00 \\
099\end{array}$ & $\begin{array}{c}0.00 \\
095 \\
6 \\
\end{array}$ & $\begin{array}{c}0.00 \\
085 \\
4 \\
\end{array}$ & $\begin{array}{c}0.00 \\
230 \\
9\end{array}$ & $\begin{array}{c}0.00 \\
077 \\
3 \\
\end{array}$ & $\begin{array}{c}0.00 \\
071 \\
6 \\
\end{array}$ & $\begin{array}{c}0.00 \\
081 \\
9 \\
\end{array}$ & $\begin{array}{c}0.00 \\
07\end{array}$ & $\begin{array}{c}0.00 \\
085 \\
2\end{array}$ \\
\hline $\begin{array}{l}\text { methanoc } \\
\text { ulleus }\end{array}$ & $\begin{array}{c}8.04 \\
14 \mathrm{E}- \\
05\end{array}$ & $\begin{array}{c}0.00 \\
134 \\
9\end{array}$ & $\begin{array}{c}0.00 \\
092 \\
8\end{array}$ & $\begin{array}{c}0.00 \\
138 \\
5\end{array}$ & $\begin{array}{c}0.00 \\
081 \\
2\end{array}$ & $\begin{array}{c}0.00 \\
128 \\
4\end{array}$ & $\begin{array}{c}0.00 \\
033 \\
1\end{array}$ & $\begin{array}{l}0.00 \\
054\end{array}$ & $\begin{array}{c}0.00 \\
066 \\
6\end{array}$ & $\begin{array}{c}0.00 \\
015 \\
4\end{array}$ & $\begin{array}{c}0.00 \\
026 \\
1\end{array}$ \\
\hline $\begin{array}{l}\text { desulfuro } \\
\text { monas }\end{array}$ & $\begin{array}{c}3.21 \\
66 \mathrm{E}- \\
05\end{array}$ & $\begin{array}{l}0.00 \\
018\end{array}$ & $\begin{array}{c}0.00 \\
054 \\
5\end{array}$ & $\begin{array}{c}0.00 \\
085 \\
9\end{array}$ & $\begin{array}{l}0.00 \\
049\end{array}$ & $\begin{array}{c}0.00 \\
017 \\
3\end{array}$ & $\begin{array}{c}0.00 \\
034 \\
5\end{array}$ & $\begin{array}{c}0.00 \\
581 \\
3\end{array}$ & $\begin{array}{c}0.00 \\
292 \\
9\end{array}$ & $\begin{array}{c}0.00 \\
088 \\
2\end{array}$ & $\begin{array}{c}0.00 \\
178 \\
5\end{array}$ \\
\hline $\begin{array}{l}\text { arthrobact } \\
\text { er }\end{array}$ & $\begin{array}{c}0.00 \\
0128 \\
66\end{array}$ & $\begin{array}{c}0.00 \\
159 \\
3\end{array}$ & $\begin{array}{c}0.00 \\
061 \\
9\end{array}$ & $\begin{array}{c}0.00 \\
157 \\
9\end{array}$ & $\begin{array}{c}0.00 \\
018 \\
2\end{array}$ & $\begin{array}{c}0.00 \\
109 \\
7\end{array}$ & $\begin{array}{l}0.00 \\
029\end{array}$ & $\begin{array}{c}0.00 \\
164 \\
5\end{array}$ & $\begin{array}{c}0.00 \\
048 \\
6\end{array}$ & $\begin{array}{c}0.00 \\
071 \\
4\end{array}$ & $\begin{array}{c}0.00 \\
031 \\
6\end{array}$ \\
\hline $\begin{array}{l}\text { acholeplas } \\
\text { ma }\end{array}$ & $\begin{array}{c}1.60 \\
83 \mathrm{E}- \\
05\end{array}$ & $\begin{array}{c}0.00 \\
093 \\
8\end{array}$ & $\begin{array}{c}0.00 \\
050 \\
7\end{array}$ & $\begin{array}{c}0.00 \\
031 \\
9\end{array}$ & $\begin{array}{c}0.00 \\
011 \\
2\end{array}$ & $\begin{array}{c}0.00 \\
063 \\
5\end{array}$ & $\begin{array}{c}0.00 \\
017 \\
9\end{array}$ & $\begin{array}{c}0.00 \\
246 \\
1\end{array}$ & $\begin{array}{c}0.00 \\
780 \\
2\end{array}$ & $\begin{array}{c}0.00 \\
016 \\
8\end{array}$ & $\begin{array}{c}0.00 \\
178 \\
5\end{array}$ \\
\hline pirellula & $\begin{array}{c}3.21 \\
66 \mathrm{E}- \\
05\end{array}$ & $\begin{array}{c}0.00 \\
041 \\
1\end{array}$ & $\begin{array}{c}0.00 \\
071 \\
8\end{array}$ & $\begin{array}{c}0.00 \\
084 \\
5\end{array}$ & $\begin{array}{l}0.00 \\
154\end{array}$ & $\begin{array}{c}0.00 \\
047 \\
6\end{array}$ & $\begin{array}{c}0.00 \\
031 \\
7\end{array}$ & $\begin{array}{c}0.00 \\
051 \\
5\end{array}$ & $\begin{array}{c}0.00 \\
123 \\
6\end{array}$ & $\begin{array}{c}0.00 \\
011 \\
2\end{array}$ & $\begin{array}{c}0.00 \\
039 \\
8\end{array}$ \\
\hline ralstonia & $\begin{array}{c}8.04 \\
14 \mathrm{E}- \\
05\end{array}$ & $\begin{array}{c}0.00 \\
015 \\
4\end{array}$ & $\begin{array}{c}0.00 \\
063 \\
1\end{array}$ & $\begin{array}{c}0.00 \\
048 \\
5\end{array}$ & $\begin{array}{c}0.00 \\
298 \\
2\end{array}$ & $\begin{array}{c}0.00 \\
017 \\
3\end{array}$ & $\begin{array}{c}0.00 \\
024 \\
8\end{array}$ & $\begin{array}{c}0.00 \\
072 \\
8\end{array}$ & $\begin{array}{c}0.00 \\
141 \\
6\end{array}$ & $\begin{array}{l}2.8 \mathrm{E} \\
-05\end{array}$ & $\begin{array}{c}0.00 \\
030 \\
2\end{array}$ \\
\hline $\begin{array}{l}\text { caldanaer } \\
\text { obacter }\end{array}$ & $\begin{array}{c}3.21 \\
66 \mathrm{E}- \\
05\end{array}$ & $\begin{array}{c}0.00 \\
059 \\
1\end{array}$ & $\begin{array}{c}0.00 \\
138 \\
6\end{array}$ & $\begin{array}{l}1.39 \\
E-05\end{array}$ & $\begin{array}{c}0.00 \\
022 \\
4\end{array}$ & $\begin{array}{c}0.00 \\
028 \\
9\end{array}$ & $\begin{array}{c}0.00 \\
157 \\
3\end{array}$ & $\begin{array}{c}0.00 \\
017 \\
6\end{array}$ & $\begin{array}{c}0.00 \\
055 \\
5\end{array}$ & $\begin{array}{c}0.00 \\
053 \\
2 \\
\end{array}$ & $\begin{array}{c}0.00 \\
465 \\
6\end{array}$ \\
\hline $\begin{array}{l}\text { thermoan } \\
\text { aerobacul } \\
\text { um }\end{array}$ & $\begin{array}{c}4.82 \\
49 \mathrm{E}- \\
05\end{array}$ & $\begin{array}{l}7.71 \\
\text { E-05 }\end{array}$ & $\begin{array}{c}0.00 \\
055 \\
7\end{array}$ & $\begin{array}{c}0.00 \\
074 \\
8\end{array}$ & $\begin{array}{c}0.00 \\
071 \\
4\end{array}$ & $\begin{array}{c}0.00 \\
010 \\
1\end{array}$ & $\begin{array}{c}0.00 \\
055 \\
2\end{array}$ & $\begin{array}{c}0.00 \\
187 \\
1\end{array}$ & $\begin{array}{c}0.00 \\
187 \\
4\end{array}$ & $\begin{array}{c}0.00 \\
016 \\
8\end{array}$ & $\begin{array}{c}0.00 \\
071 \\
4\end{array}$ \\
\hline $\begin{array}{l}\text { candidatu } \\
\text { s } \\
\text { solibacter }\end{array}$ & $\begin{array}{c}1.60 \\
83 \mathrm{E}- \\
05\end{array}$ & $\begin{array}{l}0.00 \\
045\end{array}$ & $\begin{array}{c}0.00 \\
089 \\
1\end{array}$ & $\begin{array}{c}0.00 \\
044 \\
3\end{array}$ & $\begin{array}{c}0.00 \\
064 \\
4\end{array}$ & $\begin{array}{c}0.00 \\
047 \\
6\end{array}$ & $\begin{array}{c}0.00 \\
089 \\
7\end{array}$ & $\begin{array}{c}0.00 \\
094 \\
2\end{array}$ & $\begin{array}{c}0.00 \\
201 \\
3\end{array}$ & $\begin{array}{c}0.00 \\
030 \\
8\end{array}$ & $\begin{array}{c}0.00 \\
155 \\
2\end{array}$ \\
\hline $\begin{array}{l}\text { acidovora } \\
x\end{array}$ & $\begin{array}{c}0.00 \\
2798 \\
42\end{array}$ & $\begin{array}{c}0.00 \\
012 \\
8\end{array}$ & $\begin{array}{c}0.00 \\
132 \\
4\end{array}$ & $\begin{array}{l}6.93 \\
E-05\end{array}$ & $\begin{array}{l}8.4 \mathrm{E} \\
-05\end{array}$ & $\begin{array}{c}0.00 \\
024 \\
5\end{array}$ & $\begin{array}{c}0.00 \\
299 \\
5\end{array}$ & $\begin{array}{c}0.00 \\
074 \\
1\end{array}$ & $\begin{array}{c}0.00 \\
084 \\
7\end{array}$ & $\begin{array}{l}0.00 \\
266\end{array}$ & $\begin{array}{c}0.00 \\
188 \\
2\end{array}$ \\
\hline $\begin{array}{l}\text { haliangiu } \\
\mathrm{m}\end{array}$ & $\begin{array}{c}3.21 \\
66 \mathrm{E}- \\
05\end{array}$ & $\begin{array}{c}0.00 \\
043 \\
7\end{array}$ & $\begin{array}{c}0.00 \\
065 \\
6\end{array}$ & $\begin{array}{c}0.00 \\
033 \\
2\end{array}$ & $\begin{array}{c}0.00 \\
058 \\
8\end{array}$ & $\begin{array}{c}0.00 \\
054 \\
8\end{array}$ & $\begin{array}{c}0.00 \\
067 \\
6\end{array}$ & $\begin{array}{c}0.00 \\
124 \\
3\end{array}$ & $\begin{array}{c}0.00 \\
145 \\
8\end{array}$ & $\begin{array}{c}0.00 \\
130 \\
2\end{array}$ & $\begin{array}{c}0.00 \\
138 \\
7\end{array}$ \\
\hline
\end{tabular}

Bioresource Technology, Vol 216 (September 2016): pg. 446-452. DOI. This article is @ Elsevier and permission has been granted for this version to appear in e-Publications@Marquette. Elsevier does not grant permission for this article to be further copied/distributed or hosted elsewhere without the express permission from Elsevier. 
NOT THE PUBLISHED VERSION; this is the author's final, peer-reviewed manuscript. The published version may be accessed by following the link in the citation at the bottom of the page.

\begin{tabular}{|c|c|c|c|c|c|c|c|c|c|c|c|}
\hline $\begin{array}{l}\text { azospirillu } \\
\mathrm{m}\end{array}$ & $\begin{array}{c}3.21 \\
66 \mathrm{E}- \\
05\end{array}$ & $\begin{array}{c}0.00 \\
133 \\
6\end{array}$ & $\begin{array}{c}0.00 \\
080 \\
4\end{array}$ & $\begin{array}{c}0.00 \\
031 \\
9\end{array}$ & $\begin{array}{c}0.00 \\
044 \\
8\end{array}$ & $\begin{array}{c}0.00 \\
158 \\
7\end{array}$ & $\begin{array}{c}0.00 \\
075 \\
9\end{array}$ & $\begin{array}{c}0.00 \\
163 \\
2\end{array}$ & $\begin{array}{c}0.00 \\
198 \\
5\end{array}$ & $\begin{array}{c}0.00 \\
030 \\
8\end{array}$ & $\begin{array}{c}0.00 \\
083 \\
8\end{array}$ \\
\hline $\begin{array}{l}\text { leptolyngb } \\
\text { ya }\end{array}$ & $\begin{array}{c}.82 \\
49 \mathrm{E}- \\
05\end{array}$ & $\begin{array}{c}0.00 \\
196 \\
6 \\
\end{array}$ & $\begin{array}{c}0.00 \\
040 \\
8 \\
\end{array}$ & $\begin{array}{c}0.00 \\
020 \\
8 \\
\end{array}$ & $\begin{array}{c}0.00 \\
022 \\
4 \\
\end{array}$ & $\begin{array}{c}0.00 \\
191 \\
9\end{array}$ & $\begin{array}{c}0.00 \\
023 \\
5\end{array}$ & $\begin{array}{c}0.00 \\
202 \\
1\end{array}$ & $\begin{array}{c}0.00 \\
076 \\
4\end{array}$ & $\begin{array}{c}0.00 \\
064 \\
4\end{array}$ & $\begin{array}{c}0.00 \\
145 \\
6\end{array}$ \\
\hline $\begin{array}{l}\text { desulfocal } \\
\text { dus }\end{array}$ & $\begin{array}{c}6.43 \\
31 \mathrm{E}- \\
05\end{array}$ & $\begin{array}{l}3.85 \\
\text { E-05 }\end{array}$ & $\begin{array}{c}0.00 \\
040 \\
8\end{array}$ & $\begin{array}{c}0.00 \\
040 \\
2\end{array}$ & $\begin{array}{c}0.00 \\
439 \\
6\end{array}$ & $\begin{array}{l}4.33 \\
E-05\end{array}$ & $\begin{array}{c}0.00 \\
013 \\
8 \\
\end{array}$ & $\begin{array}{c}0.00 \\
228 \\
5\end{array}$ & $\begin{array}{c}0.00 \\
266 \\
5\end{array}$ & $\begin{array}{l}8.4 \mathrm{E} \\
-05\end{array}$ & $\begin{array}{c}0.00 \\
017 \\
9\end{array}$ \\
\hline $\begin{array}{l}\text { desulfone } \\
\text { ma }\end{array}$ & $\begin{array}{c}.82 \\
49 \mathrm{E}- \\
05\end{array}$ & $\begin{array}{l}2.57 \\
E-05\end{array}$ & 0 & $\begin{array}{l}9.7 \mathrm{E} \\
-05\end{array}$ & $\begin{array}{c}0.00 \\
067 \\
2\end{array}$ & $\begin{array}{l}1.44 \\
\text { E-05 }\end{array}$ & 0 & $\begin{array}{l}6.28 \\
E-05\end{array}$ & $\begin{array}{c}0.00 \\
020 \\
8\end{array}$ & $\begin{array}{l}4.2 \mathrm{E} \\
-05\end{array}$ & $\begin{array}{l}6.87 \\
E-05\end{array}$ \\
\hline $\begin{array}{l}\text { blastomon } \\
\text { as }\end{array}$ & $\begin{array}{c}3.21 \\
66 \mathrm{E}- \\
05\end{array}$ & $\begin{array}{l}0.00 \\
027\end{array}$ & $\begin{array}{c}0.00 \\
048 \\
3\end{array}$ & $\begin{array}{c}0.00 \\
042 \\
9\end{array}$ & $\begin{array}{c}0.00 \\
07\end{array}$ & $\begin{array}{c}0.00 \\
030 \\
3\end{array}$ & $\begin{array}{c}0.00 \\
078 \\
7\end{array}$ & $\begin{array}{c}0.00 \\
069 \\
1\end{array}$ & $\begin{array}{c}0.00 \\
083 \\
3\end{array}$ & $\begin{array}{c}0.00 \\
079 \\
8\end{array}$ & $\begin{array}{c}0.00 \\
304 \\
9\end{array}$ \\
\hline $\begin{array}{l}\text { carboxydo } \\
\text { cella }\end{array}$ & $\begin{array}{c}1.60 \\
83 \mathrm{E}- \\
05\end{array}$ & $\begin{array}{l}0.00 \\
036\end{array}$ & $\begin{array}{c}0.00 \\
225 \\
2 \\
\end{array}$ & $\begin{array}{c}0.00 \\
023 \\
5 \\
\end{array}$ & $\begin{array}{c}0.00 \\
044 \\
8 \\
\end{array}$ & $\begin{array}{c}0.00 \\
057 \\
7 \\
\end{array}$ & $\begin{array}{c}0.00 \\
247 \\
1 \\
\end{array}$ & $\begin{array}{c}0.00 \\
012 \\
6 \\
\end{array}$ & 0 & $\begin{array}{c}0.00 \\
018 \\
2 \\
\end{array}$ & $\begin{array}{c}0.00 \\
119 \\
5 \\
\end{array}$ \\
\hline chlamydia & $\begin{array}{c}3.21 \\
66 \mathrm{E}- \\
05\end{array}$ & $\begin{array}{c}0.00 \\
025 \\
7\end{array}$ & $\begin{array}{c}0.00 \\
092 \\
8\end{array}$ & $\begin{array}{l}0.00 \\
018\end{array}$ & $\begin{array}{c}0.00 \\
039 \\
2\end{array}$ & $\begin{array}{c}0.00 \\
017 \\
3\end{array}$ & $\begin{array}{c}0.00 \\
070 \\
4\end{array}$ & $\begin{array}{c}0.00 \\
203 \\
4\end{array}$ & $\begin{array}{c}0.00 \\
162 \\
4\end{array}$ & $\begin{array}{c}0.00 \\
130 \\
2\end{array}$ & $\begin{array}{c}0.00 \\
144 \\
2\end{array}$ \\
\hline $\begin{array}{l}\text { aminivibri } \\
0\end{array}$ & 0 & $\begin{array}{c}0.00 \\
055 \\
2\end{array}$ & $\begin{array}{c}0.00 \\
030 \\
9\end{array}$ & $\begin{array}{c}0.00 \\
184 \\
2\end{array}$ & $\begin{array}{c}0.00 \\
054 \\
6\end{array}$ & $\begin{array}{c}0.00 \\
072 \\
2\end{array}$ & $\begin{array}{l}0.00 \\
011\end{array}$ & $\begin{array}{c}0.00 \\
043 \\
9\end{array}$ & $\begin{array}{c}0.00 \\
030 \\
5\end{array}$ & $\begin{array}{l}9.8 \mathrm{E} \\
-05\end{array}$ & $\begin{array}{l}6.87 \\
\text { E-05 }\end{array}$ \\
\hline gaiella & $\begin{array}{c}3.21 \\
66 \mathrm{E}- \\
05\end{array}$ & $\begin{array}{c}0.00 \\
107 \\
9\end{array}$ & $\begin{array}{c}0.00 \\
023 \\
5\end{array}$ & $\begin{array}{c}0.00 \\
077 \\
6\end{array}$ & $\begin{array}{c}0.00 \\
033 \\
6\end{array}$ & $\begin{array}{c}0.00 \\
089 \\
5\end{array}$ & $\begin{array}{c}0.00 \\
026 \\
2\end{array}$ & $\begin{array}{c}0.00 \\
046 \\
5\end{array}$ & $\begin{array}{c}0.00 \\
054 \\
1\end{array}$ & $\begin{array}{c}0.00 \\
053 \\
2\end{array}$ & $\begin{array}{c}0.00 \\
028 \\
8\end{array}$ \\
\hline $\begin{array}{l}\text { nitrosovibr } \\
\text { io }\end{array}$ & $\begin{array}{c}0.00 \\
0257 \\
33\end{array}$ & $\begin{array}{c}0.00 \\
046 \\
2\end{array}$ & $\begin{array}{c}0.00 \\
027 \\
2\end{array}$ & $\begin{array}{c}0.00 \\
116 \\
4\end{array}$ & $\begin{array}{c}0.00 \\
071 \\
4\end{array}$ & $\begin{array}{c}0.00 \\
047 \\
6\end{array}$ & $\begin{array}{c}0.00 \\
037 \\
3\end{array}$ & $\begin{array}{c}0.00 \\
075 \\
3\end{array}$ & $\begin{array}{c}0.00 \\
094 \\
4\end{array}$ & $\begin{array}{c}0.00 \\
039 \\
2\end{array}$ & $\begin{array}{c}0.00 \\
083 \\
8\end{array}$ \\
\hline $\begin{array}{l}\text { desulfatife } \\
\text { rula }\end{array}$ & $\begin{array}{c}3.21 \\
66 \mathrm{E}- \\
05\end{array}$ & $\begin{array}{l}1.28 \\
\text { E-05 }\end{array}$ & $\begin{array}{c}0.00 \\
014 \\
9\end{array}$ & $\begin{array}{l}2.77 \\
\text { E-05 }\end{array}$ & $\begin{array}{l}4.2 \mathrm{E} \\
-05\end{array}$ & $\begin{array}{l}1.44 \\
\text { E-05 }\end{array}$ & $\begin{array}{c}0.00 \\
016 \\
6\end{array}$ & $\begin{array}{c}0.00 \\
262 \\
4\end{array}$ & $\begin{array}{c}0.00 \\
358 \\
2\end{array}$ & $\begin{array}{c}0.00 \\
121 \\
8\end{array}$ & $\begin{array}{c}0.00 \\
293 \\
9\end{array}$ \\
\hline $\begin{array}{l}\text { cellulosilyt } \\
\text { icum }\end{array}$ & $\begin{array}{c}8.04 \\
14 \mathrm{E}- \\
05\end{array}$ & $\begin{array}{c}0.00 \\
061 \\
7 \\
\end{array}$ & $\begin{array}{c}0.00 \\
064 \\
4 \\
\end{array}$ & $\begin{array}{l}0.00 \\
115\end{array}$ & $\begin{array}{c}0.00 \\
067 \\
2 \\
\end{array}$ & $\begin{array}{c}0.00 \\
037 \\
5 \\
\end{array}$ & $\begin{array}{c}0.00 \\
060 \\
7\end{array}$ & $\begin{array}{c}0.00 \\
138 \\
1\end{array}$ & $\begin{array}{c}0.00 \\
026 \\
4\end{array}$ & $\begin{array}{l}0.00 \\
021\end{array}$ & $\begin{array}{c}0.00 \\
020 \\
6\end{array}$ \\
\hline veillonella & $\begin{array}{c}0.00 \\
2026 \\
44\end{array}$ & $\begin{array}{c}0.00 \\
070 \\
7\end{array}$ & $\begin{array}{c}0.00 \\
030 \\
9\end{array}$ & $\begin{array}{c}0.00 \\
037 \\
4\end{array}$ & $\begin{array}{l}0.00 \\
028\end{array}$ & $\begin{array}{c}0.00 \\
076 \\
5\end{array}$ & $\begin{array}{c}0.00 \\
030 \\
4\end{array}$ & $\begin{array}{l}0.00 \\
054\end{array}$ & $\begin{array}{c}0.00 \\
023 \\
6\end{array}$ & $\begin{array}{l}0.00 \\
091\end{array}$ & $\begin{array}{c}0.00 \\
037 \\
1\end{array}$ \\
\hline caldilinea & 0 & $\begin{array}{c}0.00 \\
064 \\
2\end{array}$ & $\begin{array}{c}0.00 \\
044 \\
6\end{array}$ & $\begin{array}{c}0.00 \\
119 \\
1\end{array}$ & $\begin{array}{l}0.00 \\
035\end{array}$ & $\begin{array}{c}0.00 \\
053 \\
4\end{array}$ & $\begin{array}{l}6.9 \mathrm{E} \\
-05\end{array}$ & $\begin{array}{c}0.00 \\
042 \\
7\end{array}$ & $\begin{array}{c}0.00 \\
065 \\
2\end{array}$ & $\begin{array}{l}8.4 \mathrm{E} \\
-05\end{array}$ & $\begin{array}{l}0.00 \\
022\end{array}$ \\
\hline $\begin{array}{l}\text { methylote } \\
\text { nera }\end{array}$ & $\begin{array}{c}0.00 \\
0257 \\
33\end{array}$ & $\begin{array}{l}3.85 \\
E-05\end{array}$ & $\begin{array}{c}0.00 \\
084 \\
2\end{array}$ & $\begin{array}{l}2.77 \\
\text { E-05 }\end{array}$ & $\begin{array}{l}5.6 \mathrm{E} \\
-05\end{array}$ & $\begin{array}{c}0.00 \\
021 \\
6\end{array}$ & $\begin{array}{l}0.00 \\
127\end{array}$ & $\begin{array}{c}0.00 \\
071 \\
6\end{array}$ & $\begin{array}{c}0.00 \\
058 \\
3\end{array}$ & $\begin{array}{c}0.00 \\
334 \\
6\end{array}$ & $\begin{array}{c}0.00 \\
207 \\
4\end{array}$ \\
\hline $\begin{array}{l}\text { cloacibact } \\
\text { erium }\end{array}$ & $\begin{array}{c}0.00 \\
2219 \\
43 \\
\end{array}$ & $\begin{array}{l}0.00 \\
018\end{array}$ & $\begin{array}{c}0.00 \\
027 \\
2\end{array}$ & $\begin{array}{l}0.00 \\
018\end{array}$ & $\begin{array}{c}0.00 \\
016 \\
8\end{array}$ & $\begin{array}{c}0.00 \\
014 \\
4\end{array}$ & $\begin{array}{c}0.00 \\
019 \\
3\end{array}$ & $\begin{array}{c}0.00 \\
120 \\
5\end{array}$ & $\begin{array}{c}0.00 \\
102 \\
7\end{array}$ & $\begin{array}{c}0.00 \\
07\end{array}$ & $\begin{array}{c}0.00 \\
065 \\
9\end{array}$ \\
\hline $\begin{array}{l}\text { methano } \\
\text { massiliicoc } \\
\text { cus }\end{array}$ & $\begin{array}{c}1.60 \\
83 \mathrm{E}- \\
05\end{array}$ & $\begin{array}{l}8.99 \\
E-05\end{array}$ & $\begin{array}{c}0.00 \\
018 \\
6\end{array}$ & $\begin{array}{c}0.00 \\
121 \\
9\end{array}$ & $\begin{array}{c}0.00 \\
012 \\
6\end{array}$ & $\begin{array}{c}0.00 \\
021 \\
6\end{array}$ & $\begin{array}{l}2.76 \\
\text { E-05 }\end{array}$ & $\begin{array}{c}0.00 \\
110 \\
5\end{array}$ & $\begin{array}{c}0.00 \\
030 \\
5\end{array}$ & $\begin{array}{l}9.8 \mathrm{E} \\
-05\end{array}$ & $\begin{array}{l}2.75 \\
\text { E-05 }\end{array}$ \\
\hline
\end{tabular}

Bioresource Technology, Vol 216 (September 2016): pg. 446-452. DOI. This article is @ Elsevier and permission has been granted for this version to appear in e-Publications@Marquette. Elsevier does not grant permission for this article to be further copied/distributed or hosted elsewhere without the express permission from Elsevier. 
NOT THE PUBLISHED VERSION; this is the author's final, peer-reviewed manuscript. The published version may be accessed by following the link in the citation at the bottom of the page.

\begin{tabular}{|c|c|c|c|c|c|c|c|c|c|c|c|}
\hline coxiella & $\begin{array}{c}3.21 \\
66 \mathrm{E}- \\
05\end{array}$ & $\begin{array}{c}0.00 \\
048 \\
8\end{array}$ & $\begin{array}{l}0.00 \\
073\end{array}$ & $\begin{array}{c}0.00 \\
040 \\
2\end{array}$ & $\begin{array}{c}0.00 \\
054 \\
6\end{array}$ & $\begin{array}{c}0.00 \\
082 \\
3\end{array}$ & $\begin{array}{c}0.00 \\
042 \\
8\end{array}$ & $\begin{array}{c}0.00 \\
101 \\
7\end{array}$ & $\begin{array}{c}0.00 \\
038 \\
9\end{array}$ & $\begin{array}{l}0.00 \\
014\end{array}$ & $\begin{array}{c}0.00 \\
041 \\
2\end{array}$ \\
\hline $\begin{array}{l}\text { candidatu } \\
\text { s } \\
\text { phytoplas } \\
\text { ma }\end{array}$ & $\begin{array}{c}4.82 \\
49 \mathrm{E}- \\
05\end{array}$ & $\begin{array}{c}0.00 \\
034 \\
7\end{array}$ & $\begin{array}{c}0.00 \\
118 \\
8\end{array}$ & $\begin{array}{c}0.00 \\
016 \\
6\end{array}$ & $\begin{array}{l}7 \mathrm{E}- \\
05\end{array}$ & $\begin{array}{c}0.00 \\
040 \\
4\end{array}$ & $\begin{array}{c}0.00 \\
136 \\
6\end{array}$ & $\begin{array}{l}8.79 \\
\text { E-05 }\end{array}$ & $\begin{array}{l}6.94 \\
E-05\end{array}$ & $\begin{array}{c}0.00 \\
023 \\
8\end{array}$ & $\begin{array}{c}0.00 \\
071 \\
4\end{array}$ \\
\hline $\begin{array}{l}\text { dethiobact } \\
\text { er }\end{array}$ & $\begin{array}{c}3.21 \\
66 \mathrm{E}- \\
05\end{array}$ & $\begin{array}{c}0.00 \\
034 \\
7 \\
\end{array}$ & $\begin{array}{c}0.00 \\
034 \\
7\end{array}$ & $\begin{array}{c}0.00 \\
141 \\
3 \\
\end{array}$ & $\begin{array}{c}0.00 \\
159 \\
6\end{array}$ & $\begin{array}{c}0.00 \\
034 \\
6 \\
\end{array}$ & $\begin{array}{c}0.00 \\
016 \\
6 \\
\end{array}$ & $\begin{array}{c}0.00 \\
036 \\
4\end{array}$ & $\begin{array}{c}0.00 \\
030 \\
5\end{array}$ & $\begin{array}{l}7 \mathrm{E}- \\
05\end{array}$ & $\begin{array}{c}0.00 \\
019 \\
2\end{array}$ \\
\hline $\begin{array}{l}\text { aquabacte } \\
\text { rium }\end{array}$ & $\begin{array}{c}0.00 \\
3280 \\
9 \\
\end{array}$ & $\begin{array}{l}7.71 \\
\text { E-05 }\end{array}$ & $\begin{array}{c}0.00 \\
022 \\
3\end{array}$ & $\begin{array}{l}4.16 \\
\text { E-05 }\end{array}$ & $\begin{array}{l}\text { 7E- } \\
05\end{array}$ & $\begin{array}{c}0.00 \\
010 \\
1 \\
\end{array}$ & $\begin{array}{c}0.00 \\
053 \\
8 \\
\end{array}$ & $\begin{array}{c}0.00 \\
119 \\
3\end{array}$ & $\begin{array}{c}0.00 \\
098 \\
6\end{array}$ & $\begin{array}{c}0.00 \\
119\end{array}$ & $\begin{array}{c}0.00 \\
111 \\
2\end{array}$ \\
\hline $\begin{array}{l}\text { pelagicocc } \\
\text { us }\end{array}$ & $\begin{array}{c}1.60 \\
83 \mathrm{E}- \\
05\end{array}$ & $\begin{array}{l}0.00 \\
176\end{array}$ & $\begin{array}{c}0.00 \\
032 \\
2\end{array}$ & $\begin{array}{c}0.00 \\
015 \\
2\end{array}$ & $\begin{array}{l}0.00 \\
014\end{array}$ & $\begin{array}{c}0.00 \\
134 \\
2\end{array}$ & $\begin{array}{c}0.00 \\
022 \\
1\end{array}$ & $\begin{array}{l}7.53 \\
E-05\end{array}$ & $\begin{array}{c}0.00 \\
026 \\
4\end{array}$ & $\begin{array}{c}0.00 \\
050 \\
4\end{array}$ & $\begin{array}{l}9.61 \\
E-05\end{array}$ \\
\hline $\begin{array}{l}\text { intestinim } \\
\text { onas }\end{array}$ & $\begin{array}{c}4.82 \\
49 \mathrm{E}- \\
05 \\
\end{array}$ & $\begin{array}{l}0.00 \\
018\end{array}$ & $\begin{array}{c}0.00 \\
082 \\
9\end{array}$ & $\begin{array}{c}0.00 \\
023 \\
5 \\
\end{array}$ & $\begin{array}{c}0.00 \\
114 \\
8 \\
\end{array}$ & $\begin{array}{l}7.22 \\
\text { E-05 }\end{array}$ & $\begin{array}{c}0.00 \\
146 \\
3 \\
\end{array}$ & $\begin{array}{l}6.28 \\
E-05\end{array}$ & $\begin{array}{c}0.00 \\
020 \\
8 \\
\end{array}$ & $\begin{array}{l}5.6 \mathrm{E} \\
-05\end{array}$ & $\begin{array}{c}0.00 \\
108 \\
5 \\
\end{array}$ \\
\hline $\begin{array}{l}\text { sedimenti } \\
\text { bacter }\end{array}$ & $\begin{array}{c}0.00 \\
0128 \\
66\end{array}$ & $\begin{array}{c}0.00 \\
087 \\
4 \\
\end{array}$ & $\begin{array}{c}0.00 \\
064 \\
4\end{array}$ & $\begin{array}{l}2.77 \\
\text { E-05 }\end{array}$ & $\begin{array}{l}5.6 \mathrm{E} \\
-05\end{array}$ & $\begin{array}{c}0.00 \\
093 \\
8 \\
\end{array}$ & $\begin{array}{c}0.00 \\
153 \\
2 \\
\end{array}$ & $\begin{array}{c}0.00 \\
012 \\
6\end{array}$ & $\begin{array}{l}0.00 \\
018\end{array}$ & $\begin{array}{l}0.00 \\
042\end{array}$ & $\begin{array}{c}0.00 \\
061 \\
8\end{array}$ \\
\hline blautia & $\begin{array}{c}0.00 \\
6288 \\
4\end{array}$ & $\begin{array}{l}6.42 \\
E-05\end{array}$ & $\begin{array}{l}3.71 \\
E-05\end{array}$ & $\begin{array}{l}2.77 \\
E-05\end{array}$ & $\begin{array}{l}5.6 \mathrm{E} \\
-05\end{array}$ & $\begin{array}{c}0.00 \\
010 \\
1\end{array}$ & $\begin{array}{l}5.52 \\
E-05\end{array}$ & $\begin{array}{c}0.00 \\
023 \\
9\end{array}$ & $\begin{array}{c}0.00 \\
034 \\
7\end{array}$ & $\begin{array}{c}0.00 \\
086 \\
8 \\
\end{array}$ & $\begin{array}{c}0.00 \\
079 \\
7\end{array}$ \\
\hline $\begin{array}{l}\text { fibrobacte } \\
r\end{array}$ & $\begin{array}{c}9.64 \\
97 \mathrm{E}- \\
05 \\
\end{array}$ & $\begin{array}{c}0.00 \\
066 \\
8 \\
\end{array}$ & $\begin{array}{c}0.00 \\
032 \\
2\end{array}$ & $\begin{array}{c}0.00 \\
027 \\
7\end{array}$ & $\begin{array}{c}0.00 \\
022 \\
4\end{array}$ & $\begin{array}{c}0.00 \\
043 \\
3\end{array}$ & $\begin{array}{c}0.00 \\
038 \\
6\end{array}$ & $\begin{array}{c}0.00 \\
013 \\
8\end{array}$ & $\begin{array}{c}0.00 \\
026 \\
4\end{array}$ & $\begin{array}{c}0.00 \\
116 \\
2\end{array}$ & $\begin{array}{c}0.00 \\
133 \\
2\end{array}$ \\
\hline $\begin{array}{l}\text { desulforeg } \\
\text { ula }\end{array}$ & $\begin{array}{c}8.04 \\
14 \mathrm{E}- \\
05\end{array}$ & $\begin{array}{l}6.42 \\
E-05\end{array}$ & $\begin{array}{c}0.00 \\
017 \\
3\end{array}$ & $\begin{array}{l}5.54 \\
E-05\end{array}$ & $\begin{array}{c}0.00 \\
015 \\
4\end{array}$ & $\begin{array}{l}5.77 \\
E-05\end{array}$ & $\begin{array}{c}0.00 \\
013 \\
8 \\
\end{array}$ & $\begin{array}{c}0.00 \\
052 \\
7 \\
\end{array}$ & $\begin{array}{c}0.00 \\
195 \\
7\end{array}$ & $\begin{array}{c}0.00 \\
270 \\
2\end{array}$ & $\begin{array}{c}0.00 \\
223 \\
9\end{array}$ \\
\hline $\begin{array}{l}\text { halothioba } \\
\text { cillus }\end{array}$ & $\begin{array}{c}6.43 \\
31 \mathrm{E}- \\
05\end{array}$ & $\begin{array}{c}0.00 \\
025 \\
7\end{array}$ & $\begin{array}{l}0.00 \\
078\end{array}$ & $\begin{array}{l}9.7 \mathrm{E} \\
-05\end{array}$ & $\begin{array}{c}0.00 \\
019 \\
6\end{array}$ & $\begin{array}{c}0.00 \\
024 \\
5\end{array}$ & $\begin{array}{c}0.00 \\
234 \\
6\end{array}$ & $\begin{array}{c}0.00 \\
028 \\
9\end{array}$ & $\begin{array}{c}0.00 \\
031 \\
9\end{array}$ & $\begin{array}{c}0.00 \\
015 \\
4\end{array}$ & $\begin{array}{c}0.00 \\
054 \\
9\end{array}$ \\
\hline beggiatoa & 0 & $\begin{array}{c}0.00 \\
025 \\
7\end{array}$ & $\begin{array}{c}0.00 \\
043 \\
3\end{array}$ & $\begin{array}{c}0.00 \\
052 \\
6\end{array}$ & $\begin{array}{c}0.00 \\
165 \\
2\end{array}$ & $\begin{array}{c}0.00 \\
023 \\
1 \\
\end{array}$ & $\begin{array}{c}0.00 \\
030 \\
4\end{array}$ & $\begin{array}{c}0.00 \\
026 \\
4\end{array}$ & $\begin{array}{c}0.00 \\
019 \\
4\end{array}$ & $\begin{array}{l}4.2 \mathrm{E} \\
-05\end{array}$ & $\begin{array}{c}0.00 \\
027 \\
5\end{array}$ \\
\hline lysobacter & $\begin{array}{c}8.04 \\
14 \mathrm{E}- \\
05 \\
\end{array}$ & $\begin{array}{c}0.00 \\
010 \\
3 \\
\end{array}$ & $\begin{array}{c}0.00 \\
016 \\
1 \\
\end{array}$ & $\begin{array}{l}6.93 \\
E-05\end{array}$ & $\begin{array}{c}0.00 \\
058 \\
8 \\
\end{array}$ & $\begin{array}{l}0.00 \\
013\end{array}$ & $\begin{array}{l}9.66 \\
E-05\end{array}$ & $\begin{array}{c}0.00 \\
013 \\
8\end{array}$ & $\begin{array}{c}0.00 \\
027 \\
8\end{array}$ & $\begin{array}{c}0.00 \\
28\end{array}$ & $\begin{array}{l}0.00 \\
044\end{array}$ \\
\hline $\begin{array}{l}\text { acidithiob } \\
\text { acillus }\end{array}$ & 0 & $\begin{array}{l}0.00 \\
018\end{array}$ & $\begin{array}{l}0.00 \\
099\end{array}$ & $\begin{array}{c}0.00 \\
048 \\
5\end{array}$ & $\begin{array}{c}0.00 \\
019 \\
6\end{array}$ & $\begin{array}{c}0.00 \\
021 \\
6\end{array}$ & $\begin{array}{c}0.00 \\
017 \\
9 \\
\end{array}$ & $\begin{array}{c}0.00 \\
011 \\
3\end{array}$ & $\begin{array}{c}0.00 \\
047 \\
2\end{array}$ & $\begin{array}{l}2.8 \mathrm{E} \\
-05\end{array}$ & $\begin{array}{c}0.00 \\
035 \\
7\end{array}$ \\
\hline $\begin{array}{l}\text { robinsonie } \\
\text { Ila }\end{array}$ & $\begin{array}{c}3.21 \\
66 \mathrm{E}- \\
05 \\
\end{array}$ & $\begin{array}{c}0.00 \\
057 \\
8 \\
\end{array}$ & $\begin{array}{c}0.00 \\
032 \\
2\end{array}$ & $\begin{array}{c}0.00 \\
023 \\
5\end{array}$ & $\begin{array}{l}0.00 \\
021\end{array}$ & $\begin{array}{c}0.00 \\
056 \\
3 \\
\end{array}$ & $\begin{array}{c}0.00 \\
048 \\
3 \\
\end{array}$ & $\begin{array}{c}0.00 \\
070 \\
3\end{array}$ & $\begin{array}{c}0.00 \\
030 \\
5\end{array}$ & $\begin{array}{c}0.00 \\
061 \\
6\end{array}$ & $\begin{array}{c}0.00 \\
038 \\
5\end{array}$ \\
\hline $\begin{array}{l}\text { gracilibact } \\
\text { er }\end{array}$ & $\begin{array}{c}.82 \\
49 \mathrm{E}- \\
05\end{array}$ & $\begin{array}{c}0.00 \\
025 \\
7\end{array}$ & $\begin{array}{c}0.00 \\
027 \\
2\end{array}$ & $\begin{array}{c}0.00 \\
088 \\
7\end{array}$ & $\begin{array}{l}0.00 \\
063\end{array}$ & $\begin{array}{c}0.00 \\
010 \\
1 \\
\end{array}$ & $\begin{array}{c}0.00 \\
042 \\
8\end{array}$ & $\begin{array}{l}0.00 \\
113\end{array}$ & $\begin{array}{c}0.00 \\
062 \\
5\end{array}$ & $\begin{array}{c}0.00 \\
012 \\
6\end{array}$ & $\begin{array}{c}0.00 \\
017 \\
9\end{array}$ \\
\hline
\end{tabular}

Bioresource Technology, Vol 216 (September 2016): pg. 446-452. DOI. This article is @ Elsevier and permission has been granted for this version to appear in e-Publications@Marquette. Elsevier does not grant permission for this article to be further copied/distributed or hosted elsewhere without the express permission from Elsevier. 


\begin{tabular}{|c|c|c|c|c|c|c|c|c|c|c|c|}
\hline lactivibrio & $\begin{array}{c}1.60 \\
83 \mathrm{E}- \\
05\end{array}$ & $\begin{array}{c}0.00 \\
033 \\
4\end{array}$ & $\begin{array}{c}0.00 \\
018 \\
6\end{array}$ & $\begin{array}{c}0.00 \\
109 \\
4\end{array}$ & $\begin{array}{l}0.00 \\
091\end{array}$ & $\begin{array}{l}0.00 \\
026\end{array}$ & $\begin{array}{l}0.00 \\
011\end{array}$ & $\begin{array}{c}0.00 \\
051 \\
5\end{array}$ & $\begin{array}{c}0.00 \\
016 \\
7\end{array}$ & $\begin{array}{l}0.00 \\
021\end{array}$ & $\begin{array}{c}0.00 \\
015 \\
1\end{array}$ \\
\hline $\begin{array}{l}\text { sacchariba } \\
\text { cter }\end{array}$ & 0 & $\begin{array}{c}0.00 \\
016 \\
7\end{array}$ & $\begin{array}{l}3.71 \\
\text { E-05 }\end{array}$ & $\begin{array}{c}0.00 \\
315 \\
8\end{array}$ & $\begin{array}{l}5.6 \mathrm{E} \\
-05\end{array}$ & $\begin{array}{l}5.77 \\
\text { E-05 }\end{array}$ & $\begin{array}{l}2.76 \\
\text { E-05 }\end{array}$ & $\begin{array}{l}7.53 \\
E-05\end{array}$ & $\begin{array}{l}2.78 \\
\text { E-05 }\end{array}$ & $\begin{array}{l}7 \mathrm{E}- \\
05\end{array}$ & $\begin{array}{l}2.75 \\
\text { E-05 }\end{array}$ \\
\hline $\begin{array}{l}\text { peredibact } \\
\text { er }\end{array}$ & $\begin{array}{c}9.64 \\
97 \mathrm{E}- \\
05\end{array}$ & $\begin{array}{c}0.00 \\
098 \\
9\end{array}$ & $\begin{array}{c}0.00 \\
034 \\
7\end{array}$ & $\begin{array}{l}0.00 \\
036\end{array}$ & $\begin{array}{c}0.00 \\
071 \\
4\end{array}$ & $\begin{array}{c}0.00 \\
070 \\
7\end{array}$ & $\begin{array}{c}0.00 \\
031 \\
7\end{array}$ & $\begin{array}{c}0.00 \\
047 \\
7\end{array}$ & $\begin{array}{c}0.00 \\
020 \\
8\end{array}$ & $\begin{array}{c}0.00 \\
019 \\
6\end{array}$ & $\begin{array}{c}0.00 \\
023 \\
3\end{array}$ \\
\hline $\begin{array}{l}\text { microbulbi } \\
\text { fer }\end{array}$ & 0 & $\begin{array}{l}1.28 \\
\text { E-05 }\end{array}$ & 0 & $\begin{array}{c}0.00 \\
026 \\
3\end{array}$ & $\begin{array}{c}0.00 \\
081 \\
2\end{array}$ & 0 & $\begin{array}{l}1.38 \\
\text { E-05 }\end{array}$ & $\begin{array}{c}0.00 \\
057 \\
8\end{array}$ & $\begin{array}{c}0.00 \\
290 \\
1\end{array}$ & $\begin{array}{l}1.4 \mathrm{E} \\
-05\end{array}$ & $\begin{array}{l}1.37 \\
\text { E-05 }\end{array}$ \\
\hline $\begin{array}{l}\text { desulfotig } \\
\text { num }\end{array}$ & $\begin{array}{c}9.64 \\
97 \mathrm{E}- \\
05\end{array}$ & 0 & $\begin{array}{l}1.24 \\
E-05\end{array}$ & $\begin{array}{l}1.39 \\
E-05\end{array}$ & $\begin{array}{l}2.8 \mathrm{E} \\
-05\end{array}$ & 0 & $\begin{array}{l}5.52 \\
E-05\end{array}$ & $\begin{array}{c}0.00 \\
013 \\
8\end{array}$ & $\begin{array}{c}0.00 \\
427 \\
6\end{array}$ & $\begin{array}{c}0.00 \\
025 \\
2\end{array}$ & $\begin{array}{c}0.00 \\
324 \\
1\end{array}$ \\
\hline maricaulis & 0 & $\begin{array}{c}0.00 \\
164 \\
4\end{array}$ & $\begin{array}{l}0.00 \\
052\end{array}$ & $\begin{array}{l}2.77 \\
\text { E-05 }\end{array}$ & $\begin{array}{l}5.6 \mathrm{E} \\
-05\end{array}$ & $\begin{array}{c}0.00 \\
160 \\
2\end{array}$ & $\begin{array}{c}0.00 \\
031 \\
7\end{array}$ & 0 & $\begin{array}{l}4.16 \\
E-05\end{array}$ & $\begin{array}{c}0.00 \\
032 \\
2\end{array}$ & $\begin{array}{c}0.00 \\
015 \\
1\end{array}$ \\
\hline rhizobium & $\begin{array}{c}0.00 \\
0144 \\
75\end{array}$ & $\begin{array}{c}0.00 \\
020 \\
6\end{array}$ & $\begin{array}{l}0.00 \\
078\end{array}$ & $\begin{array}{c}0.00 \\
011 \\
1\end{array}$ & $\begin{array}{c}0.00 \\
050 \\
4\end{array}$ & $\begin{array}{c}0.00 \\
011 \\
5\end{array}$ & $\begin{array}{c}0.00 \\
107 \\
7\end{array}$ & $\begin{array}{c}0.00 \\
011 \\
3\end{array}$ & $\begin{array}{c}0.00 \\
019 \\
4\end{array}$ & $\begin{array}{l}0.00 \\
014\end{array}$ & $\begin{array}{c}0.00 \\
053 \\
6\end{array}$ \\
\hline $\begin{array}{l}\text { acidamino } \\
\text { coccus }\end{array}$ & $\begin{array}{c}0.00 \\
4278 \\
04\end{array}$ & 0 & $\begin{array}{l}6.19 \\
E-05\end{array}$ & 0 & $\begin{array}{l}\text { 7E- } \\
05\end{array}$ & $\begin{array}{l}2.89 \\
\text { E-05 }\end{array}$ & $\begin{array}{l}5.52 \\
E-05\end{array}$ & $\begin{array}{c}0.00 \\
041 \\
4\end{array}$ & $\begin{array}{c}0.00 \\
059 \\
7\end{array}$ & $\begin{array}{c}0.00 \\
124 \\
6\end{array}$ & $\begin{array}{c}0.00 \\
072 \\
8\end{array}$ \\
\hline $\begin{array}{l}\text { thermaero } \\
\text { bacter }\end{array}$ & $\begin{array}{c}1.60 \\
83 \mathrm{E}- \\
05\end{array}$ & 0 & $\begin{array}{l}1.24 \\
\text { E-05 }\end{array}$ & $\begin{array}{c}0.00 \\
016 \\
6\end{array}$ & $\begin{array}{c}0.00 \\
051 \\
8\end{array}$ & $\begin{array}{l}1.44 \\
\text { E-05 }\end{array}$ & 0 & $\begin{array}{c}0.00 \\
425 \\
6\end{array}$ & $\begin{array}{c}0.00 \\
058 \\
3\end{array}$ & $\begin{array}{l}4.2 \mathrm{E} \\
-05\end{array}$ & $\begin{array}{l}4.12 \\
\text { E-05 }\end{array}$ \\
\hline $\begin{array}{l}\text { simplicispi } \\
\text { ra }\end{array}$ & $\begin{array}{c}0.00 \\
2090 \\
77\end{array}$ & $\begin{array}{l}6.42 \\
\text { E-05 }\end{array}$ & $\begin{array}{c}0.00 \\
022 \\
3\end{array}$ & $\begin{array}{l}8.31 \\
\text { E-05 }\end{array}$ & $\begin{array}{c}0.00 \\
012 \\
6\end{array}$ & $\begin{array}{l}4.33 \\
\text { E-05 }\end{array}$ & $\begin{array}{c}0.00 \\
045 \\
5\end{array}$ & $\begin{array}{c}0.00 \\
046 \\
5\end{array}$ & $\begin{array}{c}0.00 \\
063 \\
9\end{array}$ & $\begin{array}{c}0.00 \\
120 \\
4\end{array}$ & $\begin{array}{c}0.00 \\
112 \\
6\end{array}$ \\
\hline $\begin{array}{l}\text { turicibacte } \\
r\end{array}$ & $\begin{array}{c}0.00 \\
0498 \\
57\end{array}$ & $\begin{array}{c}0.00 \\
127 \\
2\end{array}$ & $\begin{array}{c}0.00 \\
030 \\
9\end{array}$ & $\begin{array}{l}0.00 \\
018\end{array}$ & $\begin{array}{c}0.00 \\
011 \\
2\end{array}$ & $\begin{array}{c}0.00 \\
106 \\
8\end{array}$ & $\begin{array}{c}0.00 \\
015 \\
2\end{array}$ & $\begin{array}{c}0.00 \\
016 \\
3\end{array}$ & $\begin{array}{c}0.00 \\
016 \\
7\end{array}$ & $\begin{array}{c}0.00 \\
065 \\
8\end{array}$ & $\begin{array}{c}0.00 \\
012 \\
4\end{array}$ \\
\hline $\begin{array}{l}\text { helicobact } \\
\text { er }\end{array}$ & $\begin{array}{c}0.00 \\
0128 \\
66 \\
\end{array}$ & $\begin{array}{c}0.00 \\
077 \\
1\end{array}$ & $\begin{array}{c}0.00 \\
014 \\
9 \\
\end{array}$ & $\begin{array}{c}0.00 \\
027 \\
7\end{array}$ & $\begin{array}{l}0.00 \\
042\end{array}$ & $\begin{array}{c}0.00 \\
067 \\
8 \\
\end{array}$ & $\begin{array}{l}0.00 \\
011\end{array}$ & $\begin{array}{c}0.00 \\
032 \\
6\end{array}$ & $\begin{array}{c}0.00 \\
034 \\
7\end{array}$ & $\begin{array}{l}0.00 \\
056\end{array}$ & $\begin{array}{l}0.00 \\
022\end{array}$ \\
\hline $\begin{array}{l}\text { rhodopirell } \\
\text { ula }\end{array}$ & $\begin{array}{c}1.60 \\
83 \mathrm{E}- \\
05\end{array}$ & $\begin{array}{l}6.42 \\
E-05\end{array}$ & $\begin{array}{c}0.00 \\
032 \\
2\end{array}$ & $\begin{array}{c}0.00 \\
047 \\
1\end{array}$ & $\begin{array}{c}0.00 \\
100 \\
8\end{array}$ & $\begin{array}{l}1.44 \\
\text { E-05 }\end{array}$ & $\begin{array}{c}0.00 \\
015 \\
2\end{array}$ & $\begin{array}{c}0.00 \\
016 \\
3\end{array}$ & $\begin{array}{c}0.00 \\
070 \\
8\end{array}$ & 0 & $\begin{array}{l}0.00 \\
022\end{array}$ \\
\hline $\begin{array}{l}\text { desulfatigl } \\
\text { ans }\end{array}$ & $\begin{array}{c}1.60 \\
83 \mathrm{E}- \\
05\end{array}$ & $\begin{array}{l}1.28 \\
E-05\end{array}$ & $\begin{array}{l}7.43 \\
E-05\end{array}$ & $\begin{array}{l}6.93 \\
E-05\end{array}$ & $\begin{array}{c}0.00 \\
180 \\
6\end{array}$ & 0 & $\begin{array}{c}0.00 \\
022 \\
1\end{array}$ & $\begin{array}{l}5.02 \\
E-05\end{array}$ & $\begin{array}{c}0.00 \\
094 \\
4\end{array}$ & $\begin{array}{l}4.2 \mathrm{E} \\
-05\end{array}$ & $\begin{array}{l}4.12 \\
\text { E-05 }\end{array}$ \\
\hline $\begin{array}{l}\text { pseudoxa } \\
\text { nthomona } \\
\text { s }\end{array}$ & $\begin{array}{c}0.00 \\
0112 \\
58\end{array}$ & $\begin{array}{l}3.85 \\
E-05\end{array}$ & $\begin{array}{c}0.00 \\
068 \\
1\end{array}$ & $\begin{array}{l}5.54 \\
\text { E-05 }\end{array}$ & $\begin{array}{c}0.00 \\
054 \\
6\end{array}$ & $\begin{array}{l}7.22 \\
\text { E-05 }\end{array}$ & $\begin{array}{c}0.00 \\
106 \\
3\end{array}$ & $\begin{array}{c}0.00 \\
012 \\
6\end{array}$ & $\begin{array}{c}0.00 \\
05\end{array}$ & $\begin{array}{c}0.00 \\
026 \\
6\end{array}$ & $\begin{array}{c}0.00 \\
129 \\
1\end{array}$ \\
\hline $\begin{array}{l}\text { polyangiu } \\
\mathrm{m}\end{array}$ & 0 & 0 & 0 & $\begin{array}{c}0.00 \\
024 \\
9\end{array}$ & $\begin{array}{c}0.00 \\
029 \\
4\end{array}$ & 0 & 0 & $\begin{array}{l}0.00 \\
172\end{array}$ & $\begin{array}{c}0.00 \\
423 \\
4\end{array}$ & $\begin{array}{l}2.8 \mathrm{E} \\
-05\end{array}$ & $\begin{array}{l}2.75 \\
\text { E-05 }\end{array}$ \\
\hline $\begin{array}{l}\text { barnesiell } \\
\text { a }\end{array}$ & $\begin{array}{c}0.00 \\
0884 \\
56\end{array}$ & $\begin{array}{c}0.00 \\
024 \\
4\end{array}$ & $\begin{array}{c}0.00 \\
027 \\
2\end{array}$ & $\begin{array}{l}.54 \\
E-05\end{array}$ & $\begin{array}{c}0.00 \\
030 \\
8\end{array}$ & $\begin{array}{c}0.00 \\
033 \\
2\end{array}$ & $\begin{array}{l}0.00 \\
138\end{array}$ & $\begin{array}{c}0.00 \\
01\end{array}$ & $\begin{array}{c}0.00 \\
013 \\
9\end{array}$ & $\begin{array}{c}0.00 \\
037 \\
8\end{array}$ & $\begin{array}{c}0.00 \\
024 \\
7\end{array}$ \\
\hline
\end{tabular}




\begin{tabular}{|c|c|c|c|c|c|c|c|c|c|c|c|}
\hline $\begin{array}{l}\text { byssovora } \\
x\end{array}$ & 0 & $\begin{array}{l}5.14 \\
\text { E-05 }\end{array}$ & $\begin{array}{l}0.00 \\
026\end{array}$ & $\begin{array}{c}0.00 \\
037 \\
4\end{array}$ & $\begin{array}{c}0.00 \\
030 \\
8\end{array}$ & $\begin{array}{c}0.00 \\
021 \\
6\end{array}$ & $\begin{array}{c}0.00 \\
034 \\
5\end{array}$ & $\begin{array}{l}2.51 \\
E-05\end{array}$ & $\begin{array}{l}5.55 \\
E-05\end{array}$ & $\begin{array}{l}5.6 \mathrm{E} \\
-05\end{array}$ & $\begin{array}{c}0.00 \\
024 \\
7\end{array}$ \\
\hline $\begin{array}{l}\text { anaerovibr } \\
\text { io }\end{array}$ & $\begin{array}{c}4.82 \\
49 \mathrm{E}- \\
05\end{array}$ & $\begin{array}{c}0.00 \\
084 \\
8 \\
\end{array}$ & $\begin{array}{c}0.00 \\
033 \\
4 \\
\end{array}$ & $\begin{array}{c}0.00 \\
041 \\
6 \\
\end{array}$ & $\begin{array}{c}0.00 \\
019 \\
6 \\
\end{array}$ & $\begin{array}{c}0.00 \\
059 \\
2 \\
\end{array}$ & $\begin{array}{c}0.00 \\
031 \\
7 \\
\end{array}$ & $\begin{array}{c}0.00 \\
021 \\
3 \\
\end{array}$ & $\begin{array}{l}6.94 \\
E-05\end{array}$ & $\begin{array}{c}0.00 \\
023 \\
8 \\
\end{array}$ & $\begin{array}{c}0.00 \\
016 \\
5 \\
\end{array}$ \\
\hline $\begin{array}{l}\text { comamon } \\
\text { as }\end{array}$ & $\begin{array}{c}0.00 \\
1238 \\
38\end{array}$ & $\begin{array}{c}0.00 \\
011 \\
6\end{array}$ & $\begin{array}{c}0.00 \\
023 \\
5\end{array}$ & $\begin{array}{l}4.16 \\
E-05\end{array}$ & $\begin{array}{c}0.00 \\
026 \\
6\end{array}$ & $\begin{array}{c}0.00 \\
011 \\
5\end{array}$ & $\begin{array}{c}0.00 \\
056 \\
6\end{array}$ & $\begin{array}{c}0.00 \\
030 \\
1\end{array}$ & $\begin{array}{c}0.00 \\
045 \\
8 \\
\end{array}$ & $\begin{array}{l}0.00 \\
042\end{array}$ & $\begin{array}{c}0.00 \\
034 \\
3\end{array}$ \\
\hline dyella & $\begin{array}{c}6.43 \\
31 \mathrm{E}- \\
05\end{array}$ & $\begin{array}{l}2.57 \\
E-05\end{array}$ & $\begin{array}{l}7.43 \\
E-05\end{array}$ & $\begin{array}{c}0.00 \\
022 \\
2\end{array}$ & $\begin{array}{c}0.00 \\
065 \\
8\end{array}$ & $\begin{array}{l}1.44 \\
\text { E-05 }\end{array}$ & $\begin{array}{l}5.52 \\
E-05\end{array}$ & $\begin{array}{c}0.00 \\
023 \\
9\end{array}$ & $\begin{array}{c}0.00 \\
05\end{array}$ & $\begin{array}{l}2.8 \mathrm{E} \\
-05\end{array}$ & $\begin{array}{l}4.12 \\
E-05\end{array}$ \\
\hline $\begin{array}{l}\text { solobacter } \\
\text { ium }\end{array}$ & $\begin{array}{c}1.60 \\
83 \mathrm{E}- \\
05\end{array}$ & $\begin{array}{c}0.00 \\
028 \\
3\end{array}$ & $\begin{array}{c}0.00 \\
016 \\
1\end{array}$ & $\begin{array}{c}0.00 \\
034 \\
6\end{array}$ & $\begin{array}{c}0.00 \\
033 \\
6\end{array}$ & $\begin{array}{c}0.00 \\
031 \\
7\end{array}$ & $\begin{array}{c}0.00 \\
012 \\
4\end{array}$ & $\begin{array}{l}2.51 \\
E-05\end{array}$ & $\begin{array}{c}0.00 \\
015 \\
3\end{array}$ & $\begin{array}{l}4.2 \mathrm{E} \\
-05\end{array}$ & $\begin{array}{l}4.12 \\
E-05\end{array}$ \\
\hline dialister & $\begin{array}{c}0.00 \\
1495 \\
71 \\
\end{array}$ & $\begin{array}{c}0.00 \\
050 \\
1 \\
\end{array}$ & $\begin{array}{c}0.00 \\
019 \\
8 \\
\end{array}$ & $\begin{array}{l}0.00 \\
018\end{array}$ & $\begin{array}{c}0.00 \\
016 \\
8 \\
\end{array}$ & $\begin{array}{c}0.00 \\
030 \\
3\end{array}$ & $\begin{array}{c}0.00 \\
020 \\
7 \\
\end{array}$ & $\begin{array}{c}0.00 \\
057 \\
8 \\
\end{array}$ & $\begin{array}{c}0.00 \\
027 \\
8 \\
\end{array}$ & $\begin{array}{c}0.00 \\
061 \\
6 \\
\end{array}$ & $\begin{array}{c}0.00 \\
046 \\
7 \\
\end{array}$ \\
\hline alistipes & $\begin{array}{c}0.00 \\
3924 \\
22\end{array}$ & $\begin{array}{l}2.57 \\
E-05\end{array}$ & $\begin{array}{l}2.48 \\
E-05\end{array}$ & $\begin{array}{l}5.54 \\
E-05\end{array}$ & $\begin{array}{l}7 \mathrm{CE}- \\
05\end{array}$ & $\begin{array}{l}2.89 \\
E-05\end{array}$ & $\begin{array}{l}1.38 \\
E-05\end{array}$ & $\begin{array}{c}0.00 \\
023 \\
9\end{array}$ & $\begin{array}{c}0.00 \\
033 \\
3\end{array}$ & $\begin{array}{c}0.00 \\
095 \\
2\end{array}$ & $\begin{array}{c}0.00 \\
063 \\
2\end{array}$ \\
\hline devosia & $\begin{array}{c}1.60 \\
83 \mathrm{E}- \\
05\end{array}$ & $\begin{array}{l}3.85 \\
E-05\end{array}$ & $\begin{array}{c}0.00 \\
045 \\
8\end{array}$ & 0 & $\begin{array}{c}0.00 \\
036 \\
4\end{array}$ & $\begin{array}{l}4.33 \\
E-05\end{array}$ & $\begin{array}{c}0.00 \\
078 \\
7\end{array}$ & $\begin{array}{l}1.26 \\
E-05\end{array}$ & $\begin{array}{c}0.00 \\
019 \\
4\end{array}$ & $\begin{array}{l}4.2 \mathrm{E} \\
-05\end{array}$ & $\begin{array}{c}0.00 \\
098 \\
9\end{array}$ \\
\hline $\begin{array}{l}\text { bifidobact } \\
\text { erium }\end{array}$ & $\begin{array}{c}0.00 \\
3457 \\
81\end{array}$ & $\begin{array}{l}1.28 \\
\text { E-05 }\end{array}$ & $\begin{array}{l}1.24 \\
\text { E-05 }\end{array}$ & $\begin{array}{l}1.39 \\
E-05\end{array}$ & 0 & $\begin{array}{l}4.33 \\
\text { E-05 }\end{array}$ & 0 & $\begin{array}{c}0.00 \\
047 \\
7\end{array}$ & $\begin{array}{c}0.00 \\
073 \\
6\end{array}$ & $\begin{array}{l}0.00 \\
084\end{array}$ & $\begin{array}{c}0.00 \\
072 \\
8\end{array}$ \\
\hline $\begin{array}{l}\text { alkaliflexu } \\
\text { s }\end{array}$ & 0 & $\begin{array}{c}0.00 \\
019 \\
3\end{array}$ & $\begin{array}{l}8.66 \\
E-05\end{array}$ & $\begin{array}{c}0.00 \\
022 \\
2\end{array}$ & $\begin{array}{c}0.00 \\
053 \\
2\end{array}$ & $\begin{array}{l}0.00 \\
026\end{array}$ & $\begin{array}{c}0.00 \\
030 \\
4\end{array}$ & $\begin{array}{c}0.00 \\
033 \\
9\end{array}$ & $\begin{array}{c}0.00 \\
122 \\
2\end{array}$ & $\begin{array}{l}5.6 \mathrm{E} \\
-05\end{array}$ & $\begin{array}{l}0.00 \\
044\end{array}$ \\
\hline $\begin{array}{l}\text { prochloroc } \\
\text { occus }\end{array}$ & $\begin{array}{c}4.82 \\
49 \mathrm{E}- \\
05\end{array}$ & $\begin{array}{c}0.00 \\
056 \\
5\end{array}$ & $\begin{array}{c}0.00 \\
087 \\
9\end{array}$ & $\begin{array}{c}0.00 \\
013 \\
9\end{array}$ & $\begin{array}{l}\text { 7E- } \\
05\end{array}$ & $\begin{array}{l}0.00 \\
039\end{array}$ & $\begin{array}{c}0.00 \\
030 \\
4\end{array}$ & $\begin{array}{c}0.00 \\
016 \\
3\end{array}$ & $\begin{array}{l}0.00 \\
018\end{array}$ & $\begin{array}{c}0.00 \\
011 \\
2\end{array}$ & $\begin{array}{c}0.00 \\
037 \\
1\end{array}$ \\
\hline $\begin{array}{l}\text { methylom } \\
\text { onas }\end{array}$ & $\begin{array}{c}4.82 \\
49 \mathrm{E}- \\
05\end{array}$ & $\begin{array}{l}3.85 \\
\text { E-05 }\end{array}$ & $\begin{array}{l}8.66 \\
E-05\end{array}$ & $\begin{array}{l}1.39 \\
E-05\end{array}$ & $\begin{array}{l}5.6 \mathrm{E} \\
-05\end{array}$ & $\begin{array}{l}2.89 \\
E-05\end{array}$ & $\begin{array}{c}0.00 \\
04\end{array}$ & $\begin{array}{c}0.00 \\
023 \\
9\end{array}$ & $\begin{array}{c}0.00 \\
026 \\
4\end{array}$ & $\begin{array}{l}0.00 \\
287\end{array}$ & $\begin{array}{c}0.00 \\
170 \\
3\end{array}$ \\
\hline fluviicola & 0 & $\begin{array}{c}0.00 \\
051 \\
4\end{array}$ & $\begin{array}{c}0.00 \\
048 \\
3\end{array}$ & $\begin{array}{l}8.31 \\
E-05\end{array}$ & $\begin{array}{l}4.2 \mathrm{E} \\
-05\end{array}$ & $\begin{array}{c}0.00 \\
033 \\
2\end{array}$ & $\begin{array}{l}0.00 \\
069\end{array}$ & $\begin{array}{c}0.00 \\
016 \\
3\end{array}$ & $\begin{array}{c}0.00 \\
016 \\
7\end{array}$ & $\begin{array}{c}0.00 \\
032 \\
2\end{array}$ & $\begin{array}{c}0.00 \\
046 \\
7\end{array}$ \\
\hline $\begin{array}{l}\text { haliscome } \\
\text { nobacter }\end{array}$ & $\begin{array}{c}1.60 \\
83 \mathrm{E}- \\
05\end{array}$ & $\begin{array}{l}3.85 \\
\text { E-05 }\end{array}$ & $\begin{array}{l}3.71 \\
E-05\end{array}$ & $\begin{array}{l}9.7 \mathrm{E} \\
-05\end{array}$ & $\begin{array}{c}0.00 \\
067 \\
2\end{array}$ & $\begin{array}{l}2.89 \\
E-05\end{array}$ & $\begin{array}{l}6.9 \mathrm{E} \\
-05\end{array}$ & $\begin{array}{l}5.02 \\
E-05\end{array}$ & $\begin{array}{c}0.00 \\
012 \\
5\end{array}$ & $\begin{array}{l}4.2 \mathrm{E} \\
-05\end{array}$ & $\begin{array}{c}0.00 \\
015 \\
1\end{array}$ \\
\hline $\begin{array}{l}\text { sterolibact } \\
\text { erium }\end{array}$ & 0 & $\begin{array}{l}3.85 \\
E-05\end{array}$ & $\begin{array}{c}0.00 \\
012 \\
4\end{array}$ & $\begin{array}{l}8.31 \\
\text { E-05 }\end{array}$ & $\begin{array}{c}0.00 \\
018 \\
2\end{array}$ & 0 & $\begin{array}{c}0.00 \\
026 \\
2\end{array}$ & $\begin{array}{c}0.00 \\
045 \\
2\end{array}$ & $\begin{array}{c}0.00 \\
038 \\
9\end{array}$ & $\begin{array}{l}4.2 \mathrm{E} \\
-05\end{array}$ & $\begin{array}{c}0.00 \\
026 \\
1\end{array}$ \\
\hline $\begin{array}{l}\text { desulfitob } \\
\text { acterium }\end{array}$ & $\begin{array}{c}3.21 \\
66 \mathrm{E}- \\
05\end{array}$ & $\begin{array}{l}3.85 \\
\text { E-05 }\end{array}$ & $\begin{array}{l}3.71 \\
E-05\end{array}$ & $\begin{array}{c}0.00 \\
012 \\
5\end{array}$ & $\begin{array}{c}0.00 \\
015 \\
4\end{array}$ & $\begin{array}{l}2.89 \\
E-05\end{array}$ & $\begin{array}{l}4.14 \\
E-05\end{array}$ & $\begin{array}{c}0.00 \\
170 \\
7\end{array}$ & $\begin{array}{c}0.00 \\
197 \\
1\end{array}$ & $\begin{array}{l}0.00 \\
035\end{array}$ & $\begin{array}{c}0.00 \\
039 \\
8\end{array}$ \\
\hline $\begin{array}{l}\text { calditerric } \\
\text { ola }\end{array}$ & $\begin{array}{c}3.21 \\
66 \mathrm{E}- \\
05\end{array}$ & $\begin{array}{c}0.00 \\
030 \\
8\end{array}$ & $\begin{array}{c}0.00 \\
060 \\
6\end{array}$ & $\begin{array}{c}0.00 \\
030 \\
5\end{array}$ & $\begin{array}{c}0.00 \\
029 \\
4\end{array}$ & $\begin{array}{l}0.00 \\
026\end{array}$ & $\begin{array}{c}0.00 \\
063 \\
5\end{array}$ & $\begin{array}{c}0.00 \\
031 \\
4\end{array}$ & $\begin{array}{c}0.00 \\
015 \\
3\end{array}$ & $\begin{array}{c}0.00 \\
012 \\
6\end{array}$ & $\begin{array}{c}0.00 \\
030 \\
2\end{array}$ \\
\hline
\end{tabular}




\begin{tabular}{|c|c|c|c|c|c|c|c|c|c|c|c|}
\hline waddlia & 0 & $\begin{array}{l}2.57 \\
\text { E-05 }\end{array}$ & $\begin{array}{l}8.66 \\
E-05\end{array}$ & $\begin{array}{l}8.31 \\
\text { E-05 }\end{array}$ & $\begin{array}{c}0.00 \\
144 \\
2\end{array}$ & $\begin{array}{l}1.44 \\
\text { E-05 }\end{array}$ & $\begin{array}{l}4.14 \\
E-05\end{array}$ & $\begin{array}{c}0.00 \\
041 \\
4\end{array}$ & $\begin{array}{c}0.00 \\
081 \\
9\end{array}$ & $\begin{array}{l}1.4 \mathrm{E} \\
-05\end{array}$ & $\begin{array}{l}4.12 \\
E-05\end{array}$ \\
\hline lachnoclos & 0.00 & 0.00 & 0.00 & 0.00 & $8.4 \mathrm{E}$ & 5.77 & 0.00 & 0.00 & 0.00 & 0.00 & 0.00 \\
\hline tridium & $\begin{array}{c}2846 \\
67\end{array}$ & $\begin{array}{c}012 \\
8\end{array}$ & $\begin{array}{c}011 \\
1\end{array}$ & $\begin{array}{c}011 \\
1\end{array}$ & -05 & E-05 & $\begin{array}{c}019 \\
3\end{array}$ & $\begin{array}{c}023 \\
9\end{array}$ & $\begin{array}{c}029 \\
2\end{array}$ & $\begin{array}{c}060 \\
2\end{array}$ & $\begin{array}{c}035 \\
7\end{array}$ \\
\hline prevotella & $\begin{array}{c}0.00 \\
5001 \\
77\end{array}$ & $\begin{array}{l}1.28 \\
\text { E-05 }\end{array}$ & $\begin{array}{l}4.95 \\
E-05\end{array}$ & 0 & $\begin{array}{c}1.4 \mathrm{E} \\
-05\end{array}$ & $\begin{array}{l}2.89 \\
\text { E-05 }\end{array}$ & $\begin{array}{l}2.76 \\
\text { E-05 }\end{array}$ & $\begin{array}{l}7.53 \\
E-05\end{array}$ & $\begin{array}{l}4.16 \\
\text { E-05 }\end{array}$ & $\begin{array}{c}0.00 \\
040 \\
6\end{array}$ & $\begin{array}{c}0.00 \\
013 \\
7\end{array}$ \\
\hline $\begin{array}{l}\text { sphingoba } \\
\text { cterium }\end{array}$ & $\begin{array}{c}0.00 \\
0739 \\
81\end{array}$ & $\begin{array}{c}0.00 \\
024 \\
4\end{array}$ & $\begin{array}{c}0.00 \\
023 \\
5\end{array}$ & $\begin{array}{l}6.93 \\
E-05\end{array}$ & $\begin{array}{l}0.00 \\
035\end{array}$ & $\begin{array}{c}0.00 \\
033 \\
2\end{array}$ & $\begin{array}{l}8.28 \\
E-05\end{array}$ & $\begin{array}{c}0.00 \\
013 \\
8\end{array}$ & $\begin{array}{c}0.00 \\
086 \\
1\end{array}$ & $\begin{array}{c}0.00 \\
032 \\
2\end{array}$ & $\begin{array}{c}0.00 \\
034 \\
3\end{array}$ \\
\hline $\begin{array}{l}\text { phycispha } \\
\text { era }\end{array}$ & $\begin{array}{c}1.60 \\
83 \mathrm{E}- \\
05\end{array}$ & $\begin{array}{l}1.28 \\
\text { E-05 }\end{array}$ & $\begin{array}{l}7.43 \\
\text { E-05 }\end{array}$ & $\begin{array}{l}8.31 \\
\text { E-05 }\end{array}$ & $\begin{array}{c}0.00 \\
067 \\
2\end{array}$ & 0 & $\begin{array}{c}0.00 \\
016 \\
6\end{array}$ & $\begin{array}{c}0.00 \\
070 \\
3\end{array}$ & $\begin{array}{l}0.00 \\
043\end{array}$ & $\begin{array}{c}0.00 \\
011 \\
2\end{array}$ & $\begin{array}{c}0.00 \\
188 \\
2\end{array}$ \\
\hline $\begin{array}{l}\text { desulfocap } \\
\text { sa }\end{array}$ & 0 & $\begin{array}{l}5.14 \\
\text { E-05 }\end{array}$ & $\begin{array}{c}0.00 \\
038 \\
4\end{array}$ & 0 & $\begin{array}{c}0.00 \\
026 \\
6\end{array}$ & $\begin{array}{l}1.44 \\
\text { E-05 }\end{array}$ & $\begin{array}{c}0.00 \\
037 \\
3\end{array}$ & $\begin{array}{c}0.00 \\
042 \\
7\end{array}$ & $\begin{array}{c}0.00 \\
088 \\
8\end{array}$ & $\begin{array}{c}0.00 \\
018 \\
2\end{array}$ & $\begin{array}{c}0.00 \\
097 \\
5\end{array}$ \\
\hline thauera & $\begin{array}{c}0.00 \\
0788 \\
06\end{array}$ & $\begin{array}{l}1.28 \\
E-05\end{array}$ & $\begin{array}{l}1.24 \\
\text { E-05 }\end{array}$ & 0 & 0 & 0 & $\begin{array}{l}1.38 \\
E-05\end{array}$ & $\begin{array}{l}0.00 \\
182\end{array}$ & $\begin{array}{c}0.00 \\
149 \\
9\end{array}$ & $\begin{array}{l}0.00 \\
063\end{array}$ & $\begin{array}{c}0.00 \\
060 \\
4\end{array}$ \\
\hline
\end{tabular}

Bioresource Technology, Vol 216 (September 2016): pg. 446-452. DOI. This article is @ Elsevier and permission has been granted for this version to appear in e-Publications@Marquette. Elsevier does not grant permission for this article to be further copied/distributed or hosted elsewhere without the express permission from Elsevier. 
NOT THE PUBLISHED VERSION; this is the author's final, peer-reviewed manuscript. The published version may be accessed by following the link in the citation at the bottom of the page.

Table S2: Relative abundance of the top $98 \%$ most abundant genera in DFF10 and DFF25 detected across all samples analyzed.

\begin{tabular}{|c|c|c|c|c|c|c|c|c|c|c|}
\hline & \multicolumn{5}{|c|}{ DFF10 } & \multicolumn{5}{|c|}{ DFF25 } \\
\hline Genus & $\begin{array}{l}\text { DFF } \\
10 \\
180\end{array}$ & $\begin{array}{l}\text { DFF } \\
10 \\
200\end{array}$ & $\begin{array}{l}\text { DFF } \\
10 \\
230\end{array}$ & $\begin{array}{l}\text { DFF } \\
10 \\
250\end{array}$ & $\begin{array}{l}\text { DFF } \\
10 \\
35 \overline{5}\end{array}$ & $\begin{array}{l}\text { DFF } \\
25 \\
180\end{array}$ & $\begin{array}{l}\text { DFF } \\
25 \\
200\end{array}$ & $\begin{array}{l}\text { DFF } \\
25 \\
230\end{array}$ & $\begin{array}{l}\text { DFF } \\
25 \\
250\end{array}$ & $\begin{array}{l}\text { DFF } \\
25 \\
355\end{array}$ \\
\hline $\begin{array}{l}\text { clostridiu } \\
\text { m }\end{array}$ & $\begin{array}{c}0.10 \\
283 \\
5\end{array}$ & $\begin{array}{l}0.04 \\
844\end{array}$ & $\begin{array}{c}0.22 \\
753 \\
1\end{array}$ & $\begin{array}{c}0.10 \\
027 \\
6\end{array}$ & $\begin{array}{c}0.08 \\
194 \\
3 \\
\end{array}$ & $\begin{array}{c}0.04 \\
876 \\
3\end{array}$ & $\begin{array}{c}0.24 \\
310 \\
5\end{array}$ & $\begin{array}{c}0.07 \\
967 \\
4 \\
\end{array}$ & $\begin{array}{l}0.20 \\
153\end{array}$ & $\begin{array}{l}0.06 \\
545\end{array}$ \\
\hline geobacter & $\begin{array}{c}0.03 \\
243 \\
9 \\
\end{array}$ & $\begin{array}{l}0.17 \\
151\end{array}$ & $\begin{array}{c}0.01 \\
619 \\
7 \\
\end{array}$ & $\begin{array}{c}0.01 \\
763 \\
8 \\
\end{array}$ & $\begin{array}{c}0.04 \\
687 \\
4 \\
\end{array}$ & $\begin{array}{c}0.22 \\
691 \\
5 \\
\end{array}$ & $\begin{array}{c}0.01 \\
235 \\
4\end{array}$ & $\begin{array}{c}0.00 \\
884 \\
9\end{array}$ & $\begin{array}{c}0.03 \\
026 \\
8\end{array}$ & $\begin{array}{l}0.19 \\
685\end{array}$ \\
\hline $\begin{array}{l}\text { trichococc } \\
\text { us }\end{array}$ & $\begin{array}{c}0.03 \\
551 \\
5\end{array}$ & $\begin{array}{c}0.04 \\
317 \\
7\end{array}$ & $\begin{array}{c}0.01 \\
401 \\
8\end{array}$ & $\begin{array}{l}0.18 \\
195\end{array}$ & $\begin{array}{c}0.02 \\
511 \\
5\end{array}$ & $\begin{array}{c}0.05 \\
356 \\
4\end{array}$ & $\begin{array}{c}0.01 \\
782 \\
2\end{array}$ & $\begin{array}{c}0.20 \\
924 \\
6\end{array}$ & $\begin{array}{c}0.05 \\
570 \\
6\end{array}$ & $\begin{array}{l}0.04 \\
402\end{array}$ \\
\hline cytophaga & $\begin{array}{c}0.05 \\
734 \\
7 \\
\end{array}$ & $\begin{array}{c}0.03 \\
180 \\
4 \\
\end{array}$ & $\begin{array}{c}0.04 \\
423 \\
3 \\
\end{array}$ & $\begin{array}{c}0.04 \\
186 \\
1\end{array}$ & $\begin{array}{c}0.05 \\
574 \\
3 \\
\end{array}$ & $\begin{array}{c}0.02 \\
692 \\
2 \\
\end{array}$ & $\begin{array}{c}0.04 \\
618 \\
6\end{array}$ & $\begin{array}{c}0.05 \\
692 \\
1\end{array}$ & $\begin{array}{c}0.02 \\
178 \\
9 \\
\end{array}$ & $\begin{array}{c}0.02 \\
497 \\
7\end{array}$ \\
\hline $\begin{array}{l}\text { methanos } \\
\text { aeta }\end{array}$ & $\begin{array}{c}0.07 \\
505 \\
7\end{array}$ & & $\begin{array}{c}0.04 \\
125 \\
4\end{array}$ & $\begin{array}{c}0.01 \\
074 \\
6\end{array}$ & $\begin{array}{c}0.05 \\
886 \\
7\end{array}$ & $\begin{array}{c}713 \\
9 \\
\end{array}$ & $\begin{array}{c}0.02 \\
795 \\
6\end{array}$ & $\begin{array}{c}0.00 \\
670 \\
8 \\
\end{array}$ & $\begin{array}{c}0.04 \\
730 \\
5\end{array}$ & $\begin{array}{c}0.04 \\
550 \\
4\end{array}$ \\
\hline $\begin{array}{l}\text { bacte } \\
s\end{array}$ & $\begin{array}{c}0.04 \\
001 \\
8\end{array}$ & $\begin{array}{c}0.00 \\
816 \\
6\end{array}$ & $\begin{array}{c}0.06 \\
852 \\
1\end{array}$ & $\begin{array}{c}0.02 \\
799 \\
6\end{array}$ & $\begin{array}{c}0.06 \\
627 \\
9\end{array}$ & $\begin{array}{c}0.00 \\
844 \\
1\end{array}$ & $\begin{array}{c}0.08 \\
324 \\
9\end{array}$ & $\begin{array}{c}0.02 \\
407 \\
5\end{array}$ & $\begin{array}{c}0.02 \\
498 \\
3\end{array}$ & $\begin{array}{l}0.01 \\
354\end{array}$ \\
\hline arcol & $\begin{array}{c}0.00 \\
448 \\
7 \\
\end{array}$ & $\begin{array}{c}740 \\
1 \\
\end{array}$ & & $\begin{array}{c}0.00 \\
406 \\
8\end{array}$ & $\begin{array}{c}0.00 \\
186 \\
3 \\
\end{array}$ & $\begin{array}{c}0.00 \\
411 \\
5\end{array}$ & $\begin{array}{c}0.00 \\
233 \\
4\end{array}$ & $\begin{array}{c}0.00 \\
585 \\
7 \\
\end{array}$ & $\begin{array}{c}0.00 \\
223 \\
3\end{array}$ & $\begin{array}{c}0.01 \\
041 \\
2\end{array}$ \\
\hline bellili & $\begin{array}{c}0.06 \\
368 \\
9\end{array}$ & & $\begin{array}{c}0.07 \\
703 \\
5 \\
\end{array}$ & $\begin{array}{c}0.01 \\
062 \\
6 \\
\end{array}$ & $\begin{array}{c}0.06 \\
190 \\
1 \\
\end{array}$ & $\begin{array}{c}0.01 \\
371 \\
6\end{array}$ & $\begin{array}{c}0.05 \\
743 \\
1 \\
\end{array}$ & $\begin{array}{l}0.00 \\
907\end{array}$ & $\begin{array}{c}0.06 \\
921 \\
1 \\
\end{array}$ & $\begin{array}{c}0.01 \\
169 \\
3 \\
\end{array}$ \\
\hline $\begin{array}{l}\text { acinetobac } \\
\text { ter }\end{array}$ & $\begin{array}{c}0.01 \\
127 \\
3\end{array}$ & & $\begin{array}{c}0.00 \\
636 \\
6\end{array}$ & $\begin{array}{c}034 \\
5\end{array}$ & $\begin{array}{c}0.00 \\
675 \\
3\end{array}$ & $\begin{array}{c}0.07 \\
447 \\
2\end{array}$ & $\begin{array}{c}776 \\
8\end{array}$ & $\begin{array}{c}0.10 \\
823 \\
7\end{array}$ & $\begin{array}{c}0.00 \\
323 \\
3\end{array}$ & $\begin{array}{c}0.01 \\
513 \\
2\end{array}$ \\
\hline & $\begin{array}{c}0.01 \\
211 \\
3 \\
\end{array}$ & $\begin{array}{c}0.01 \\
472 \\
2\end{array}$ & $\begin{array}{c}0.01 \\
213 \\
6\end{array}$ & $\begin{array}{c}0.02 \\
775 \\
5 \\
\end{array}$ & $\begin{array}{c}0.00 \\
460 \\
3 \\
\end{array}$ & $\begin{array}{c}0.00 \\
436 \\
1\end{array}$ & $\begin{array}{c}0.04 \\
453 \\
8 \\
\end{array}$ & $\begin{array}{c}0.05 \\
547 \\
2 \\
\end{array}$ & $\begin{array}{c}0.01 \\
885 \\
4\end{array}$ & $\begin{array}{c}0.05 \\
130 \\
3 \\
\end{array}$ \\
\hline $\begin{array}{l}\text { desulfomic } \\
\text { robium }\end{array}$ & $\begin{array}{c}0.00 \\
550 \\
2 \\
\end{array}$ & $\begin{array}{c}0.00 \\
690 \\
6 \\
\end{array}$ & $\begin{array}{c}0.02 \\
646 \\
8 \\
\end{array}$ & $\begin{array}{l}0.02 \\
888\end{array}$ & $\begin{array}{c}0.00 \\
508 \\
6 \\
\end{array}$ & $\begin{array}{c}0.00 \\
576 \\
8 \\
\end{array}$ & $\begin{array}{c}0.04 \\
207 \\
3 \\
\end{array}$ & $\begin{array}{c}0.02 \\
183 \\
9 \\
\end{array}$ & $\begin{array}{c}0.00 \\
311 \\
6\end{array}$ & $\begin{array}{c}0.00 \\
739 \\
1 \\
\end{array}$ \\
\hline $\begin{array}{l}\text { aeror } \\
\mathrm{s}\end{array}$ & $\begin{array}{c}0.00 \\
672 \\
2 \\
\end{array}$ & $\begin{array}{c}0.04 \\
327 \\
2\end{array}$ & $\begin{array}{c}0.00 \\
355 \\
9\end{array}$ & $\begin{array}{c}382 \\
7\end{array}$ & $\begin{array}{c}0.00 \\
914 \\
2 \\
\end{array}$ & $\begin{array}{c}0.09 \\
272 \\
5\end{array}$ & $\begin{array}{c}0.00 \\
166 \\
5 \\
\end{array}$ & $\begin{array}{l}0.00 \\
981\end{array}$ & $\begin{array}{c}0.00 \\
564 \\
9 \\
\end{array}$ & $\begin{array}{c}0.05 \\
760 \\
1 \\
\end{array}$ \\
\hline $\begin{array}{l}\text { syntr } \\
\text { s }\end{array}$ & $\begin{array}{c}0.03 \\
947 \\
9\end{array}$ & $\begin{array}{l}0.01 \\
737\end{array}$ & $\begin{array}{c}0.01 \\
367 \\
3\end{array}$ & $\begin{array}{c}0.00 \\
952 \\
8\end{array}$ & $\begin{array}{c}0.03 \\
189 \\
6\end{array}$ & $\begin{array}{c}0.01 \\
396 \\
2\end{array}$ & $\begin{array}{c}0.00 \\
687 \\
1\end{array}$ & $\begin{array}{c}0.00 \\
661 \\
3\end{array}$ & $\begin{array}{c}0.03 \\
135 \\
9\end{array}$ & $\begin{array}{l}0.01 \\
528\end{array}$ \\
\hline Iongilinea & $\begin{array}{c}0.05 \\
133 \\
8\end{array}$ & $\begin{array}{c}0.01 \\
143 \\
6\end{array}$ & $\begin{array}{c}0.02 \\
723 \\
6\end{array}$ & $\begin{array}{c}0.01 \\
043 \\
8\end{array}$ & $\begin{array}{c}0.04 \\
206 \\
8\end{array}$ & $\begin{array}{c}0.00 \\
798 \\
4\end{array}$ & $\begin{array}{c}0.01 \\
945 \\
4\end{array}$ & $\begin{array}{c}0.00 \\
741 \\
6\end{array}$ & $\begin{array}{c}0.04 \\
042 \\
3\end{array}$ & $\begin{array}{c}0.01 \\
124 \\
8 \\
\end{array}$ \\
\hline levilinea & $\begin{array}{c}0.02 \\
338 \\
6\end{array}$ & $\begin{array}{c}0.01 \\
631 \\
7 \\
\end{array}$ & $\begin{array}{c}0.02 \\
105 \\
8 \\
\end{array}$ & $\begin{array}{c}0.03 \\
745 \\
8 \\
\end{array}$ & $\begin{array}{l}0.02 \\
054\end{array}$ & $\begin{array}{c}0.01 \\
396 \\
2\end{array}$ & $\begin{array}{c}0.01 \\
356 \\
2\end{array}$ & $\begin{array}{c}0.03 \\
470 \\
4 \\
\end{array}$ & $\begin{array}{c}0.02 \\
565 \\
9 \\
\end{array}$ & $\begin{array}{c}0.01 \\
014 \\
2 \\
\end{array}$ \\
\hline
\end{tabular}

Bioresource Technology, Vol 216 (September 2016): pg. 446-452. DOI. This article is C Elsevier and permission has been granted for this version to appear in e-Publications@Marquette. Elsevier does not grant permission for this article to be further copied/distributed or hosted elsewhere without the express permission from Elsevier. 
NOT THE PUBLISHED VERSION; this is the author's final, peer-reviewed manuscript. The published version may be accessed by following the link in the citation at the bottom of the page.

\begin{tabular}{|c|c|c|c|c|c|c|c|c|c|c|}
\hline solitalea & $\begin{array}{c}0.01 \\
331 \\
8\end{array}$ & $\begin{array}{c}0.02 \\
261 \\
7\end{array}$ & $\begin{array}{c}0.03 \\
531 \\
1\end{array}$ & $\begin{array}{c}0.02 \\
028 \\
8\end{array}$ & $\begin{array}{c}0.02 \\
064 \\
5\end{array}$ & $\begin{array}{c}0.01 \\
049 \\
8\end{array}$ & $\begin{array}{c}0.03 \\
335 \\
8\end{array}$ & $\begin{array}{c}0.01 \\
456 \\
5\end{array}$ & $\begin{array}{c}0.00 \\
586 \\
9\end{array}$ & $\begin{array}{c}0.00 \\
875 \\
3\end{array}$ \\
\hline $\begin{array}{l}\text { methanob } \\
\text { acterium }\end{array}$ & $\begin{array}{c}0.04 \\
033 \\
5 \\
\end{array}$ & $\begin{array}{c}0.00 \\
939 \\
5 \\
\end{array}$ & $\begin{array}{c}0.01 \\
502 \\
1 \\
\end{array}$ & $\begin{array}{c}0.01 \\
513 \\
6 \\
\end{array}$ & $\begin{array}{c}0.04 \\
538 \\
9 \\
\end{array}$ & $\begin{array}{c}0.00 \\
724 \\
5 \\
\end{array}$ & $\begin{array}{c}0.01 \\
266 \\
4 \\
\end{array}$ & $\begin{array}{c}0.01 \\
467 \\
5 \\
\end{array}$ & $\begin{array}{c}0.04 \\
903 \\
2 \\
\end{array}$ & $\begin{array}{c}0.00 \\
900 \\
9 \\
\end{array}$ \\
\hline $\begin{array}{l}\text { desulfobul } \\
\text { bus }\end{array}$ & $\begin{array}{c}0.02 \\
351 \\
3 \\
\end{array}$ & $\begin{array}{c}0.00 \\
808 \\
7 \\
\end{array}$ & $\begin{array}{c}0.01 \\
020 \\
8 \\
\end{array}$ & $\begin{array}{c}0.01 \\
014 \\
4 \\
\end{array}$ & $\begin{array}{c}0.02 \\
348 \\
2 \\
\end{array}$ & $\begin{array}{c}0.00 \\
655 \\
9 \\
\end{array}$ & $\begin{array}{c}0.00 \\
881 \\
3 \\
\end{array}$ & $\begin{array}{c}0.00 \\
681 \\
8 \\
\end{array}$ & $\begin{array}{c}0.02 \\
498 \\
3 \\
\end{array}$ & $\begin{array}{c}0.00 \\
366 \\
8\end{array}$ \\
\hline fusibacter & $\begin{array}{c}0.00 \\
312 \\
3\end{array}$ & $\begin{array}{c}0.00 \\
625 \\
2\end{array}$ & $\begin{array}{c}0.01 \\
161 \\
9\end{array}$ & $\begin{array}{c}0.01 \\
148 \\
2\end{array}$ & $\begin{array}{c}0.00 \\
189 \\
8\end{array}$ & $\begin{array}{l}0.00 \\
779\end{array}$ & $\begin{array}{c}0.02 \\
854 \\
4\end{array}$ & $\begin{array}{c}0.01 \\
106 \\
9\end{array}$ & $\begin{array}{l}0.00 \\
535\end{array}$ & $\begin{array}{c}0.01 \\
506 \\
4\end{array}$ \\
\hline $\begin{array}{l}\text { parab } \\
\text { roide }\end{array}$ & $\begin{array}{c}0.00 \\
206 \\
1\end{array}$ & $\begin{array}{c}0.00 \\
539 \\
1 \\
\end{array}$ & $\begin{array}{c}0.00 \\
393 \\
6 \\
\end{array}$ & $\begin{array}{c}0.01 \\
191\end{array}$ & $\begin{array}{c}0.00 \\
418 \\
2 \\
\end{array}$ & $\begin{array}{c}0.00 \\
429 \\
1\end{array}$ & $\begin{array}{c}0.00 \\
726 \\
2\end{array}$ & $\begin{array}{c}0.01 \\
004 \\
6\end{array}$ & $\begin{array}{c}0.00 \\
137 \\
6\end{array}$ & $\begin{array}{c}0.00 \\
407 \\
3\end{array}$ \\
\hline $\begin{array}{l}\text { spiroc } \\
\text { a }\end{array}$ & $\begin{array}{c}0.01 \\
176 \\
4 \\
\end{array}$ & $\begin{array}{c}0.01 \\
159 \\
6\end{array}$ & $\begin{array}{c}0.01 \\
099 \\
2 \\
\end{array}$ & $\begin{array}{c}0.00 \\
608 \\
9 \\
\end{array}$ & $\begin{array}{c}0.01 \\
236 \\
5\end{array}$ & $\begin{array}{c}0.00 \\
914 \\
4 \\
\end{array}$ & $\begin{array}{c}0.00 \\
538 \\
6 \\
\end{array}$ & $\begin{array}{c}0.00 \\
401 \\
5\end{array}$ & $\begin{array}{c}0.00 \\
649 \\
3\end{array}$ & $\begin{array}{c}0.01 \\
000 \\
7\end{array}$ \\
\hline $\begin{array}{l}\text { desulfovib } \\
\text { rio }\end{array}$ & $\begin{array}{c}0.00 \\
534 \\
3\end{array}$ & $\begin{array}{c}0.01 \\
963 \\
4\end{array}$ & $\begin{array}{c}0.00 \\
820 \\
1\end{array}$ & $\begin{array}{c}0.01 \\
893 \\
6\end{array}$ & $\begin{array}{c}0.00 \\
574 \\
5\end{array}$ & $\begin{array}{c}0.01 \\
612 \\
5\end{array}$ & $\begin{array}{c}582 \\
6\end{array}$ & $\begin{array}{c}0.01 \\
199 \\
8\end{array}$ & $\begin{array}{c}453 \\
2\end{array}$ & $\begin{array}{c}0.01 \\
177 \\
4\end{array}$ \\
\hline & $\begin{array}{c}0.01 \\
837 \\
6\end{array}$ & $\begin{array}{c}331 \\
8\end{array}$ & $\begin{array}{c}0.01 \\
299 \\
9\end{array}$ & $\begin{array}{c}0.00 \\
247 \\
6\end{array}$ & $\begin{array}{c}957 \\
3\end{array}$ & $\begin{array}{c}0.01 \\
088 \\
5\end{array}$ & 488 & $\begin{array}{c}0.00 \\
135 \\
4\end{array}$ & & $\begin{array}{l}.01 \\
06\end{array}$ \\
\hline $\begin{array}{l}\text { deha } \\
\text { coide }\end{array}$ & $\begin{array}{c}0.02 \\
433 \\
7\end{array}$ & $\begin{array}{c}0.00 \\
653 \\
9\end{array}$ & $\begin{array}{c}0.00 \\
870 \\
2\end{array}$ & $\begin{array}{c}0.00 \\
305 \\
1\end{array}$ & & $\begin{array}{c}0.00 \\
573 \\
3\end{array}$ & $\begin{array}{c}641 \\
4 \\
\end{array}$ & $\begin{array}{c}0.00 \\
214 \\
1\end{array}$ & $\begin{array}{c}190 \\
5\end{array}$ & $\begin{array}{c}0.00 \\
613 \\
6\end{array}$ \\
\hline $\begin{array}{l}\text { shew } \\
\text { a }\end{array}$ & $\begin{array}{c}0.00 \\
253 \\
7\end{array}$ & $\begin{array}{c}0.02 \\
355 \\
8\end{array}$ & $\begin{array}{c}0.00 \\
189 \\
7\end{array}$ & $\begin{array}{c}202 \\
1\end{array}$ & 0.00 & $\begin{array}{c}0.01 \\
591 \\
4\end{array}$ & $\begin{array}{c}084 \\
9\end{array}$ & $\begin{array}{c}0.00 \\
341 \\
7\end{array}$ & $\begin{array}{c}366 \\
2\end{array}$ & $\begin{array}{c}0.04 \\
218 \\
6\end{array}$ \\
\hline & $\begin{array}{c}0.00 \\
956 \\
1\end{array}$ & $\begin{array}{c}328 \\
6\end{array}$ & $\begin{array}{c}113 \\
6\end{array}$ & $\begin{array}{c}298 \\
4\end{array}$ & $\begin{array}{c}373 \\
8\end{array}$ & $\begin{array}{c}0.00 \\
395 \\
7\end{array}$ & $\begin{array}{c}147 \\
3\end{array}$ & 222 & $\begin{array}{c}258 \\
3\end{array}$ & $\begin{array}{c}0.00 \\
547 \\
6\end{array}$ \\
\hline ropha & $\begin{array}{c}0.00 \\
645 \\
3 \\
\end{array}$ & $\begin{array}{c}0.00 \\
491 \\
3\end{array}$ & $\begin{array}{l}0.00 \\
519\end{array}$ & $\begin{array}{c}0.02 \\
408 \\
9\end{array}$ & $\begin{array}{c}605 \\
3 \\
\end{array}$ & $\begin{array}{c}0.00 \\
348 \\
2 \\
\end{array}$ & $\begin{array}{c}0.00 \\
406 \\
4\end{array}$ & $\begin{array}{c}0.00 \\
984 \\
1\end{array}$ & $\begin{array}{c}325 \\
9 \\
\end{array}$ & $\begin{array}{c}0.00 \\
470 \\
7\end{array}$ \\
\hline & $\begin{array}{l}0.00 \\
899\end{array}$ & $\begin{array}{c}0.00 \\
400 \\
3\end{array}$ & $\begin{array}{l}0.01 \\
096\end{array}$ & $\begin{array}{c}0.00 \\
798 \\
9 \\
\end{array}$ & $\begin{array}{c}088 \\
7\end{array}$ & $\begin{array}{c}0.00 \\
469 \\
5\end{array}$ & $\begin{array}{c}245 \\
2\end{array}$ & $\begin{array}{c}0.00 \\
850 \\
3\end{array}$ & & $\begin{array}{c}0.00 \\
400 \\
6\end{array}$ \\
\hline $\begin{array}{l}\text { prol } \\
\text { er }\end{array}$ & $\begin{array}{c}0.00 \\
342 \\
5\end{array}$ & & $\begin{array}{c}774 \\
6\end{array}$ & $\begin{array}{c}0.01 \\
047 \\
9\end{array}$ & $\begin{array}{c}259 \\
2\end{array}$ & $\begin{array}{c}0.00 \\
318 \\
3\end{array}$ & $\begin{array}{c}897 \\
6\end{array}$ & $\begin{array}{c}0.00 \\
858 \\
1\end{array}$ & $\begin{array}{c}149 \\
3\end{array}$ & $\begin{array}{c}0.00 \\
401 \\
9\end{array}$ \\
\hline & $\begin{array}{c}0.00 \\
242 \\
6\end{array}$ & $\begin{array}{c}0.00 \\
425 \\
9\end{array}$ & $\begin{array}{l}0.00 \\
392\end{array}$ & $\begin{array}{c}0.02 \\
388 \\
8\end{array}$ & $\begin{array}{c}0.00 \\
250 \\
8\end{array}$ & $\begin{array}{c}0.00 \\
297 \\
2\end{array}$ & $\begin{array}{c}0.00 \\
403 \\
1\end{array}$ & $\begin{array}{c}0.01 \\
391 \\
9\end{array}$ & $\begin{array}{c}0.00 \\
144 \\
1\end{array}$ & $\begin{array}{c}0.00 \\
298 \\
1\end{array}$ \\
\hline $\begin{array}{l}\text { phascolarc } \\
\text { tobacteriu } \\
\text { m }\end{array}$ & $\begin{array}{l}0.00 \\
658\end{array}$ & $\begin{array}{c}0.00 \\
328 \\
6 \\
\end{array}$ & $\begin{array}{c}0.01 \\
437 \\
8 \\
\end{array}$ & $\begin{array}{c}0.00 \\
701 \\
2\end{array}$ & $\begin{array}{c}0.00 \\
595 \\
5\end{array}$ & $\begin{array}{l}0.00 \\
211\end{array}$ & $\begin{array}{c}0.01 \\
047 \\
8\end{array}$ & $\begin{array}{c}0.00 \\
661 \\
3\end{array}$ & $\begin{array}{c}188 \\
3\end{array}$ & $\begin{array}{c}0.00 \\
316 \\
9\end{array}$ \\
\hline rikenella & $\begin{array}{c}0.00 \\
152 \\
2\end{array}$ & $\begin{array}{c}0.00 \\
121 \\
2\end{array}$ & $\begin{array}{c}0.01 \\
792 \\
2\end{array}$ & $\begin{array}{c}0.01 \\
021 \\
1\end{array}$ & $\begin{array}{l}0.00 \\
131\end{array}$ & $\begin{array}{c}0.00 \\
098 \\
5\end{array}$ & $\begin{array}{l}0.01 \\
694\end{array}$ & $\begin{array}{c}0.00 \\
788 \\
9\end{array}$ & $\begin{array}{c}0.00 \\
3\end{array}$ & $\begin{array}{c}0.00 \\
183 \\
4\end{array}$ \\
\hline & $\begin{array}{c}0.01 \\
266 \\
8\end{array}$ & $\begin{array}{c}0.00 \\
312 \\
6\end{array}$ & $\begin{array}{c}0.00 \\
633 \\
5\end{array}$ & $\begin{array}{c}0.00 \\
167 \\
3\end{array}$ & $\begin{array}{c}198 \\
3\end{array}$ & $\begin{array}{c}0.00 \\
242 \\
7\end{array}$ & & $\begin{array}{c}0.00 \\
094 \\
5\end{array}$ & $\begin{array}{c}488 \\
2\end{array}$ & $\begin{array}{c}0.00 \\
248 \\
2\end{array}$ \\
\hline
\end{tabular}

Bioresource Technology, Vol 216 (September 2016): pg. 446-452. DOI. This article is (C) Elsevier and permission has been granted for this version to appear in e-Publications@Marquette. Elsevier does not grant permission for this article to be further copied/distributed or hosted elsewhere without the express permission from Elsevier. 
NOT THE PUBLISHED VERSION; this is the author's final, peer-reviewed manuscript. The published version may be accessed by following the link in the citation at the bottom of the page.

\begin{tabular}{|c|c|c|c|c|c|c|c|c|c|c|}
\hline caldithrix & $\begin{array}{c}0.00 \\
359 \\
9\end{array}$ & $\begin{array}{c}0.00 \\
334 \\
9\end{array}$ & $\begin{array}{c}0.00 \\
166 \\
2\end{array}$ & $\begin{array}{l}0.00 \\
985\end{array}$ & $\begin{array}{l}0.00 \\
337\end{array}$ & $\begin{array}{c}0.00 \\
228 \\
6\end{array}$ & $\begin{array}{c}0.00 \\
210 \\
5\end{array}$ & $\begin{array}{c}0.00 \\
492 \\
8\end{array}$ & $\begin{array}{c}0.00 \\
194 \\
8\end{array}$ & $\begin{array}{c}0.00 \\
285 \\
9\end{array}$ \\
\hline $\begin{array}{l}\text { sulfurovu } \\
\mathrm{m}\end{array}$ & $\begin{array}{c}0.00 \\
326 \\
6\end{array}$ & $\begin{array}{c}0.00 \\
569 \\
4\end{array}$ & $\begin{array}{c}0.00 \\
301 \\
1\end{array}$ & $\begin{array}{c}0.01 \\
018 \\
4\end{array}$ & $\begin{array}{c}0.00 \\
245 \\
2\end{array}$ & $\begin{array}{c}0.00 \\
532 \\
8\end{array}$ & $\begin{array}{c}0.00 \\
448 \\
8\end{array}$ & $\begin{array}{c}0.00 \\
719 \\
6\end{array}$ & $\begin{array}{c}0.00 \\
925 \\
8\end{array}$ & $\begin{array}{c}0.00 \\
490 \\
9\end{array}$ \\
\hline $\begin{array}{l}\text { paludibact } \\
\text { er }\end{array}$ & $\begin{array}{c}0.00 \\
104 \\
6\end{array}$ & $\begin{array}{c}0.00 \\
224 \\
9\end{array}$ & $\begin{array}{c}0.00 \\
282 \\
2\end{array}$ & $\begin{array}{c}0.00 \\
216 \\
8\end{array}$ & $\begin{array}{c}0.00 \\
235 \\
4\end{array}$ & $\begin{array}{c}0.00 \\
167 \\
1\end{array}$ & $\begin{array}{c}0.00 \\
533 \\
7\end{array}$ & $\begin{array}{c}0.00 \\
414 \\
1\end{array}$ & $\begin{array}{c}0.00 \\
229 \\
8\end{array}$ & $\begin{array}{c}0.00 \\
273 \\
8\end{array}$ \\
\hline smithella & $\begin{array}{c}0.00 \\
753 \\
1\end{array}$ & $\begin{array}{c}0.01 \\
146 \\
8\end{array}$ & $\begin{array}{c}0.00 \\
304 \\
2\end{array}$ & $\begin{array}{c}0.00 \\
258 \\
3\end{array}$ & $\begin{array}{c}0.00 \\
838 \\
6\end{array}$ & $\begin{array}{c}0.00 \\
67\end{array}$ & $\begin{array}{c}0.00 \\
101 \\
2\end{array}$ & $\begin{array}{c}0.00 \\
176 \\
4\end{array}$ & $\begin{array}{c}0.00 \\
3\end{array}$ & $\begin{array}{c}0.00 \\
732 \\
3\end{array}$ \\
\hline $\begin{array}{l}\text { methanos } \\
\text { pirillum }\end{array}$ & $\begin{array}{c}0.00 \\
274 \\
3\end{array}$ & $\begin{array}{c}0.00 \\
749 \\
6\end{array}$ & $\begin{array}{c}0.00 \\
092 \\
5\end{array}$ & $\begin{array}{l}0.00 \\
645\end{array}$ & $\begin{array}{c}0.00 \\
348 \\
2\end{array}$ & $\begin{array}{c}0.00 \\
733 \\
3\end{array}$ & $\begin{array}{c}0.00 \\
044 \\
1\end{array}$ & $\begin{array}{c}0.00 \\
470 \\
8\end{array}$ & $\begin{array}{c}0.01 \\
368 \\
6\end{array}$ & $\begin{array}{c}0.00 \\
907 \\
6\end{array}$ \\
\hline $\begin{array}{l}\text { pedobacte } \\
\mathrm{r}\end{array}$ & $\begin{array}{c}0.00 \\
042 \\
8 \\
\end{array}$ & $\begin{array}{c}0.00 \\
236 \\
1 \\
\end{array}$ & $\begin{array}{l}0.00 \\
218\end{array}$ & $\begin{array}{c}0.01 \\
557 \\
7 \\
\end{array}$ & $\begin{array}{c}0.00 \\
038 \\
5 \\
\end{array}$ & $\begin{array}{c}0.00 \\
098 \\
5 \\
\end{array}$ & $\begin{array}{c}0.00 \\
347 \\
6 \\
\end{array}$ & $\begin{array}{c}0.01 \\
053 \\
4 \\
\end{array}$ & $\begin{array}{c}0.00 \\
033 \\
8 \\
\end{array}$ & $\begin{array}{c}0.00 \\
075 \\
5 \\
\end{array}$ \\
\hline $\begin{array}{l}\text { eubacteriu } \\
\mathrm{m}\end{array}$ & $\begin{array}{c}0.00 \\
107 \\
8\end{array}$ & $\begin{array}{c}0.00 \\
052 \\
6\end{array}$ & $\begin{array}{c}0.00 \\
147 \\
4\end{array}$ & $\begin{array}{c}0.00 \\
659 \\
8\end{array}$ & $\begin{array}{c}0.00 \\
112 \\
8\end{array}$ & $\begin{array}{c}0.00 \\
079 \\
1\end{array}$ & $\begin{array}{c}0.00 \\
189 \\
3\end{array}$ & $\begin{array}{l}0.00 \\
411\end{array}$ & $\begin{array}{l}0.00 \\
361\end{array}$ & $\begin{array}{c}0.00 \\
272 \\
4\end{array}$ \\
\hline $\begin{array}{l}\text { proteocate } \\
\text { lla }\end{array}$ & $\begin{array}{c}0.00 \\
889 \\
5\end{array}$ & $\begin{array}{l}0.00 \\
689\end{array}$ & $\begin{array}{l}0.00 \\
149\end{array}$ & $\begin{array}{c}0.00 \\
333 \\
2\end{array}$ & $\begin{array}{c}0.00 \\
371 \\
3\end{array}$ & $\begin{array}{c}0.00 \\
427 \\
3\end{array}$ & $\begin{array}{c}0.00 \\
233 \\
4\end{array}$ & $\begin{array}{c}0.00 \\
448 \\
8\end{array}$ & $\begin{array}{c}0.00 \\
554 \\
5\end{array}$ & $\begin{array}{c}0.00 \\
775 \\
5\end{array}$ \\
\hline $\begin{array}{l}\text { ornithiniba } \\
\text { cillus }\end{array}$ & $\begin{array}{c}0.00 \\
554 \\
9\end{array}$ & $\begin{array}{c}0.00 \\
114 \\
8\end{array}$ & $\begin{array}{c}0.00 \\
912 \\
6\end{array}$ & $\begin{array}{c}0.00 \\
385 \\
4\end{array}$ & $\begin{array}{c}0.00 \\
322 \\
3\end{array}$ & $\begin{array}{c}0.00 \\
131 \\
9\end{array}$ & $\begin{array}{c}0.00 \\
667 \\
5\end{array}$ & $\begin{array}{c}0.00 \\
305 \\
5\end{array}$ & $\begin{array}{c}0.00 \\
807 \\
7\end{array}$ & $\begin{array}{l}0.00 \\
151\end{array}$ \\
\hline leptospira & $\begin{array}{c}0.00 \\
242 \\
6\end{array}$ & $\begin{array}{c}0.00 \\
381 \\
2\end{array}$ & $\begin{array}{c}0.00 \\
199 \\
1\end{array}$ & $\begin{array}{c}0.00 \\
286 \\
4\end{array}$ & $\begin{array}{c}0.00 \\
217 \\
9\end{array}$ & $\begin{array}{c}0.00 \\
247 \\
9\end{array}$ & $\begin{array}{c}0.00 \\
163 \\
2\end{array}$ & $\begin{array}{l}0.00 \\
148\end{array}$ & $\begin{array}{l}0.00 \\
148\end{array}$ & $\begin{array}{c}0.00 \\
296 \\
7\end{array}$ \\
\hline $\begin{array}{l}\text { candidatu } \\
\text { s } \\
\text { cloacimon } \\
\text { as }\end{array}$ & $\begin{array}{c}0.00 \\
669 \\
1\end{array}$ & $\begin{array}{c}0.00 \\
266 \\
4\end{array}$ & $\begin{array}{l}0.00 \\
508\end{array}$ & $\begin{array}{c}0.00 \\
623 \\
6\end{array}$ & $\begin{array}{c}0.01 \\
036 \\
8\end{array}$ & $\begin{array}{c}0.00 \\
156 \\
5\end{array}$ & $\begin{array}{c}0.00 \\
352 \\
5\end{array}$ & $\begin{array}{c}0.00 \\
259 \\
8\end{array}$ & $\begin{array}{c}0.00 \\
181 \\
8\end{array}$ & $\begin{array}{c}0.00 \\
163 \\
2\end{array}$ \\
\hline $\begin{array}{l}\text { aminobact } \\
\text { erium }\end{array}$ & $\begin{array}{c}0.00 \\
326 \\
6\end{array}$ & $\begin{array}{c}0.00 \\
245 \\
6\end{array}$ & $\begin{array}{c}0.01 \\
580 \\
5\end{array}$ & $\begin{array}{c}0.00 \\
231 \\
5\end{array}$ & $\begin{array}{c}0.00 \\
280 \\
9\end{array}$ & $\begin{array}{c}0.00 \\
283 \\
1\end{array}$ & $\begin{array}{l}0.00 \\
488\end{array}$ & $\begin{array}{c}0.00 \\
193 \\
7\end{array}$ & $\begin{array}{c}0.00 \\
394 \\
7\end{array}$ & $\begin{array}{c}0.00 \\
256 \\
2\end{array}$ \\
\hline $\begin{array}{l}\text { guggenhei } \\
\text { mella }\end{array}$ & $\begin{array}{c}0.02 \\
216 \\
5\end{array}$ & $\begin{array}{l}7.97 \\
E-05\end{array}$ & $\begin{array}{c}0.00 \\
017 \\
2\end{array}$ & $\begin{array}{c}0.00 \\
017 \\
4\end{array}$ & $\begin{array}{c}0.01 \\
959 \\
4\end{array}$ & $\begin{array}{c}0.00 \\
010 \\
6\end{array}$ & $\begin{array}{c}0.00 \\
022 \\
8\end{array}$ & $\begin{array}{c}0.00 \\
029 \\
9\end{array}$ & $\begin{array}{c}0.01 \\
733 \\
5\end{array}$ & $\begin{array}{c}0.00 \\
016 \\
2\end{array}$ \\
\hline $\begin{array}{l}\text { treponem } \\
\text { a }\end{array}$ & $\begin{array}{c}0.00 \\
448 \\
7\end{array}$ & $\begin{array}{c}0.00 \\
354 \\
1\end{array}$ & $\begin{array}{c}0.00 \\
299 \\
5\end{array}$ & $\begin{array}{c}0.00 \\
335 \\
9\end{array}$ & $\begin{array}{l}0.00 \\
648\end{array}$ & $\begin{array}{c}0.00 \\
321 \\
8\end{array}$ & $\begin{array}{c}0.00 \\
190 \\
9\end{array}$ & $\begin{array}{c}0.00 \\
201 \\
5\end{array}$ & $\begin{array}{c}0.00 \\
188 \\
3\end{array}$ & $\begin{array}{c}0.00 \\
484 \\
2\end{array}$ \\
\hline $\begin{array}{l}\text { acetobact } \\
\text { erium }\end{array}$ & $\begin{array}{l}0.00 \\
157\end{array}$ & $\begin{array}{c}0.00 \\
153 \\
1\end{array}$ & $\begin{array}{c}0.00 \\
083 \\
1\end{array}$ & $\begin{array}{c}0.01 \\
288 \\
7\end{array}$ & $\begin{array}{c}0.00 \\
142 \\
9\end{array}$ & $\begin{array}{c}0.00 \\
307 \\
7\end{array}$ & $\begin{array}{c}0.00 \\
070 \\
2\end{array}$ & $\begin{array}{c}0.01 \\
281 \\
7\end{array}$ & $\begin{array}{c}0.00 \\
699 \\
9\end{array}$ & $\begin{array}{c}0.00 \\
366 \\
8\end{array}$ \\
\hline $\begin{array}{l}\text { pelotomac } \\
\text { ulum }\end{array}$ & $\begin{array}{c}0.00 \\
099 \\
9\end{array}$ & $\begin{array}{c}0.00 \\
079 \\
7\end{array}$ & $\begin{array}{c}0.00 \\
042 \\
3\end{array}$ & $\begin{array}{c}0.00 \\
053 \\
5\end{array}$ & $\begin{array}{c}0.00 \\
150 \\
6\end{array}$ & $\begin{array}{c}0.00 \\
119 \\
6\end{array}$ & $\begin{array}{c}0.00 \\
050 \\
6\end{array}$ & $\begin{array}{c}0.00 \\
023 \\
6\end{array}$ & $\begin{array}{c}0.00 \\
085 \\
7\end{array}$ & $\begin{array}{l}0.00 \\
147\end{array}$ \\
\hline $\begin{array}{l}\text { chlorobiu } \\
\mathrm{m}\end{array}$ & $\begin{array}{c}0.00 \\
212 \\
5\end{array}$ & $\begin{array}{c}0.01 \\
271 \\
2\end{array}$ & $\begin{array}{c}0.00 \\
023 \\
5\end{array}$ & $\begin{array}{c}0.00 \\
085 \\
6\end{array}$ & $\begin{array}{c}0.00 \\
204 \\
6\end{array}$ & $\begin{array}{c}0.00 \\
961 \\
9\end{array}$ & $\begin{array}{l}0.00 \\
093\end{array}$ & $\begin{array}{c}0.00 \\
066 \\
1\end{array}$ & $\begin{array}{c}0.00 \\
063 \\
6\end{array}$ & $\begin{array}{c}0.00 \\
586 \\
7\end{array}$ \\
\hline $\begin{array}{l}\text { thermana } \\
\text { erovibrio }\end{array}$ & $\begin{array}{c}0.00 \\
017 \\
4\end{array}$ & $\begin{array}{c}0.00 \\
792 \\
7\end{array}$ & $\begin{array}{c}0.00 \\
020 \\
4\end{array}$ & $\begin{array}{c}0.00 \\
018 \\
7\end{array}$ & $\begin{array}{c}0.00 \\
019 \\
6\end{array}$ & $\begin{array}{c}0.01 \\
489 \\
4\end{array}$ & $\begin{array}{c}0.00 \\
024 \\
5\end{array}$ & $\begin{array}{c}0.00 \\
033 \\
1\end{array}$ & $\begin{array}{c}0.00 \\
059 \\
7\end{array}$ & $\begin{array}{c}0.01 \\
530 \\
7\end{array}$ \\
\hline
\end{tabular}

Bioresource Technology, Vol 216 (September 2016): pg. 446-452. DOI. This article is (C) Elsevier and permission has been granted for this version to appear in e-Publications@Marquette. Elsevier does not grant permission for this article to be further copied/distributed or hosted elsewhere without the express permission from Elsevier. 
NOT THE PUBLISHED VERSION; this is the author's final, peer-reviewed manuscript. The published version may be accessed by following the link in the citation at the bottom of the page.

\begin{tabular}{|c|c|c|c|c|c|c|c|c|c|c|}
\hline $\begin{array}{l}\text { ruminococ } \\
\text { cus }\end{array}$ & $\begin{array}{c}0.00 \\
290 \\
1 \\
\end{array}$ & $\begin{array}{c}0.00 \\
173 \\
9 \\
\end{array}$ & $\begin{array}{c}0.00 \\
492 \\
3 \\
\end{array}$ & $\begin{array}{c}0.00 \\
353 \\
3 \\
\end{array}$ & $\begin{array}{c}0.00 \\
204 \\
6\end{array}$ & $\begin{array}{c}0.00 \\
170 \\
6 \\
\end{array}$ & $\begin{array}{c}0.00 \\
473 \\
3 \\
\end{array}$ & $\begin{array}{c}0.00 \\
198 \\
4 \\
\end{array}$ & $\begin{array}{c}0.00 \\
497 \\
3 \\
\end{array}$ & $\begin{array}{l}0.00 \\
236\end{array}$ \\
\hline $\begin{array}{l}\text { anaeromy } \\
\text { xobacter }\end{array}$ & $\begin{array}{c}0.00 \\
277 \\
5 \\
\end{array}$ & $\begin{array}{c}0.00 \\
655 \\
5 \\
\end{array}$ & $\begin{array}{c}0.00 \\
316 \\
7\end{array}$ & $\begin{array}{c}0.00 \\
327 \\
9\end{array}$ & $\begin{array}{l}0.00 \\
482\end{array}$ & $\begin{array}{c}0.00 \\
545 \\
1 \\
\end{array}$ & $\begin{array}{c}0.00 \\
215 \\
4\end{array}$ & $\begin{array}{c}0.00 \\
141 \\
7 \\
\end{array}$ & $\begin{array}{c}0.00 \\
164 \\
9 \\
\end{array}$ & $\begin{array}{c}0.00 \\
716 \\
1 \\
\end{array}$ \\
\hline $\begin{array}{l}\text { fusobacter } \\
\text { ium }\end{array}$ & $\begin{array}{c}0.00 \\
114 \\
2\end{array}$ & $\begin{array}{l}0.01 \\
134\end{array}$ & $\begin{array}{c}0.00 \\
037 \\
6\end{array}$ & $\begin{array}{c}0.00 \\
165 \\
9\end{array}$ & $\begin{array}{c}0.00 \\
226 \\
3\end{array}$ & $\begin{array}{c}0.00 \\
99\end{array}$ & $\begin{array}{c}0.00 \\
034 \\
3\end{array}$ & $\begin{array}{c}0.00 \\
560 \\
6\end{array}$ & $\begin{array}{c}0.00 \\
128 \\
6\end{array}$ & $\begin{array}{c}0.00 \\
770 \\
1\end{array}$ \\
\hline $\begin{array}{l}\text { paenibacill } \\
\text { us }\end{array}$ & $\begin{array}{c}0.00 \\
469 \\
3\end{array}$ & $\begin{array}{c}0.00 \\
221 \\
7\end{array}$ & $\begin{array}{c}0.00 \\
061 \\
2\end{array}$ & $\begin{array}{c}0.00 \\
892 \\
6\end{array}$ & $\begin{array}{c}0.00 \\
423 \\
1\end{array}$ & $\begin{array}{c}0.00 \\
274 \\
3\end{array}$ & $\begin{array}{c}0.00 \\
088 \\
1\end{array}$ & $\begin{array}{c}0.00 \\
858 \\
1\end{array}$ & $\begin{array}{c}0.00 \\
544 \\
1\end{array}$ & $\begin{array}{c}0.00 \\
915 \\
7\end{array}$ \\
\hline $\begin{array}{l}\text { synergiste } \\
\text { s }\end{array}$ & $\begin{array}{c}0.00 \\
069 \\
8 \\
\end{array}$ & $\begin{array}{c}0.00 \\
266 \\
4\end{array}$ & $\begin{array}{c}0.00 \\
780 \\
9\end{array}$ & $\begin{array}{c}0.00 \\
507 \\
2\end{array}$ & $\begin{array}{c}0.00 \\
079 \\
2\end{array}$ & $\begin{array}{c}0.00 \\
170 \\
6\end{array}$ & $\begin{array}{c}0.00 \\
448 \\
8\end{array}$ & $\begin{array}{c}0.00 \\
492 \\
8\end{array}$ & $\begin{array}{c}0.00 \\
122 \\
1\end{array}$ & $\begin{array}{c}0.00 \\
145 \\
7\end{array}$ \\
\hline $\begin{array}{l}\text { pedospha } \\
\text { era }\end{array}$ & $\begin{array}{c}0.00 \\
394 \\
8 \\
\end{array}$ & $\begin{array}{c}0.00 \\
480 \\
1 \\
\end{array}$ & $\begin{array}{c}0.00 \\
156 \\
8 \\
\end{array}$ & $\begin{array}{l}0.00 \\
265\end{array}$ & $\begin{array}{c}0.00 \\
624 \\
9 \\
\end{array}$ & $\begin{array}{c}0.00 \\
327 \\
1 \\
\end{array}$ & $\begin{array}{c}0.00 \\
146 \\
9\end{array}$ & $\begin{array}{c}0.00 \\
168 \\
5\end{array}$ & $\begin{array}{c}0.00 \\
181 \\
8 \\
\end{array}$ & $\begin{array}{c}0.00 \\
323 \\
7 \\
\end{array}$ \\
\hline $\begin{array}{l}\text { anaeromu } \\
\text { sa }\end{array}$ & $\begin{array}{c}0.00 \\
123 \\
7\end{array}$ & $\begin{array}{c}0.00 \\
231 \\
3\end{array}$ & $\begin{array}{c}0.00 \\
065 \\
9\end{array}$ & $\begin{array}{c}0.00 \\
405 \\
5\end{array}$ & $\begin{array}{c}0.00 \\
072 \\
2\end{array}$ & $\begin{array}{l}0.00 \\
211\end{array}$ & $\begin{array}{c}0.00 \\
122 \\
4\end{array}$ & $\begin{array}{c}0.00 \\
647 \\
2\end{array}$ & $\begin{array}{c}0.00 \\
312 \\
9\end{array}$ & $\begin{array}{c}0.00 \\
745 \\
8\end{array}$ \\
\hline $\begin{array}{l}\text { blastopirel } \\
\text { lula }\end{array}$ & $\begin{array}{c}0.00 \\
765 \\
8\end{array}$ & $\begin{array}{c}0.00 \\
507 \\
2\end{array}$ & $\begin{array}{c}0.00 \\
026 \\
7\end{array}$ & $\begin{array}{l}0.00 \\
103\end{array}$ & $\begin{array}{c}0.00 \\
596 \\
9\end{array}$ & $\begin{array}{c}0.00 \\
471 \\
3\end{array}$ & $\begin{array}{c}0.00 \\
027 \\
7\end{array}$ & $\begin{array}{l}0.00 \\
096\end{array}$ & $\begin{array}{c}0.00 \\
834 \\
9\end{array}$ & $\begin{array}{c}0.00 \\
397 \\
9\end{array}$ \\
\hline $\begin{array}{l}\text { syntropho } \\
\text { bacter }\end{array}$ & $\begin{array}{c}0.00 \\
540 \\
7 \\
\end{array}$ & $\begin{array}{l}0.00 \\
496\end{array}$ & $\begin{array}{l}0.00 \\
276\end{array}$ & $\begin{array}{l}0.00 \\
285\end{array}$ & $\begin{array}{c}0.00 \\
488 \\
3\end{array}$ & $\begin{array}{c}0.00 \\
307 \\
7\end{array}$ & $\begin{array}{c}0.00 \\
102 \\
8\end{array}$ & $\begin{array}{c}0.00 \\
173 \\
2\end{array}$ & $\begin{array}{c}0.00 \\
394 \\
7\end{array}$ & $\begin{array}{c}0.00 \\
264 \\
3\end{array}$ \\
\hline $\begin{array}{l}\text { anaerovor } \\
\text { ax }\end{array}$ & $\begin{array}{c}0.00 \\
150 \\
6\end{array}$ & $\begin{array}{c}0.00 \\
373 \\
2\end{array}$ & $\begin{array}{c}0.00 \\
211 \\
7\end{array}$ & $\begin{array}{c}0.00 \\
869 \\
9\end{array}$ & $\begin{array}{c}0.00 \\
097 \\
4\end{array}$ & $\begin{array}{c}0.00 \\
304 \\
2\end{array}$ & $\begin{array}{c}0.00 \\
151 \\
8\end{array}$ & $\begin{array}{c}0.00 \\
637 \\
7\end{array}$ & $\begin{array}{c}0.00 \\
153 \\
2\end{array}$ & $\begin{array}{c}0.00 \\
261 \\
6\end{array}$ \\
\hline zoogloea & $\begin{array}{c}0.00 \\
057 \\
1\end{array}$ & $\begin{array}{c}0.00 \\
228 \\
1\end{array}$ & $\begin{array}{c}0.00 \\
056 \\
4\end{array}$ & $\begin{array}{c}0.00 \\
481 \\
8\end{array}$ & $\begin{array}{c}0.00 \\
086 \\
2\end{array}$ & $\begin{array}{c}0.00 \\
165 \\
3\end{array}$ & $\begin{array}{c}0.00 \\
060 \\
4\end{array}$ & $\begin{array}{l}0.00 \\
263\end{array}$ & $\begin{array}{c}0.00 \\
096 \\
1\end{array}$ & $\begin{array}{c}0.00 \\
335 \\
8\end{array}$ \\
\hline $\begin{array}{l}\text { verrucomi } \\
\text { crobium }\end{array}$ & $\begin{array}{c}0.00 \\
383 \\
7\end{array}$ & $\begin{array}{l}0.00 \\
142\end{array}$ & $\begin{array}{c}0.00 \\
233 \\
6\end{array}$ & $\begin{array}{c}0.00 \\
266 \\
3\end{array}$ & $\begin{array}{c}0.00 \\
244 \\
5\end{array}$ & $\begin{array}{l}0.00 \\
095\end{array}$ & $\begin{array}{c}0.00 \\
228 \\
5\end{array}$ & $\begin{array}{c}0.00 \\
143 \\
3\end{array}$ & $\begin{array}{c}0.00 \\
176 \\
6\end{array}$ & $\begin{array}{c}0.00 \\
094 \\
4\end{array}$ \\
\hline $\begin{array}{l}\text { flavobacte } \\
\text { rium }\end{array}$ & $\begin{array}{c}0.00 \\
093 \\
5\end{array}$ & $\begin{array}{c}0.00 \\
342 \\
9\end{array}$ & $\begin{array}{c}0.00 \\
189 \\
7\end{array}$ & $\begin{array}{c}0.00 \\
891 \\
3\end{array}$ & $\begin{array}{c}0.00 \\
060 \\
2\end{array}$ & $\begin{array}{c}0.00 \\
298 \\
9\end{array}$ & $\begin{array}{c}0.00 \\
199 \\
1\end{array}$ & $\begin{array}{c}0.00 \\
514 \\
9\end{array}$ & $\begin{array}{c}0.00 \\
042 \\
9\end{array}$ & $\begin{array}{c}0.00 \\
256 \\
2\end{array}$ \\
\hline $\begin{array}{l}\text { sulfurospir } \\
\text { illum }\end{array}$ & $\begin{array}{c}0.00 \\
141 \\
1\end{array}$ & $\begin{array}{c}0.00 \\
089 \\
3\end{array}$ & $\begin{array}{c}0.00 \\
031 \\
4\end{array}$ & $\begin{array}{c}0.00 \\
056 \\
2\end{array}$ & $\begin{array}{c}0.00 \\
168 \\
8\end{array}$ & $\begin{array}{c}0.00 \\
105 \\
5\end{array}$ & $\begin{array}{c}0.00 \\
021 \\
2\end{array}$ & $\begin{array}{c}0.00 \\
025 \\
2\end{array}$ & $\begin{array}{c}0.00 \\
128 \\
6\end{array}$ & $\begin{array}{c}0.00 \\
144 \\
3\end{array}$ \\
\hline $\begin{array}{l}\text { acidamino } \\
\text { bacter }\end{array}$ & $\begin{array}{l}0.00 \\
065\end{array}$ & $\begin{array}{c}0.00 \\
296 \\
7\end{array}$ & $\begin{array}{c}0.00 \\
161 \\
5\end{array}$ & $\begin{array}{c}0.00 \\
377 \\
4\end{array}$ & $\begin{array}{c}0.00 \\
039 \\
9\end{array}$ & $\begin{array}{c}0.00 \\
232 \\
1 \\
\end{array}$ & $\begin{array}{c}0.00 \\
403 \\
1\end{array}$ & $\begin{array}{l}0.00 \\
444\end{array}$ & $\begin{array}{c}0.00 \\
063 \\
6\end{array}$ & $\begin{array}{c}0.00 \\
446 \\
4\end{array}$ \\
\hline $\begin{array}{l}\text { chondrom } \\
\text { yces }\end{array}$ & $\begin{array}{c}0.00 \\
242 \\
6\end{array}$ & $\begin{array}{c}0.00 \\
542 \\
3\end{array}$ & $\begin{array}{c}0.00 \\
442 \\
2\end{array}$ & $\begin{array}{c}0.00 \\
880 \\
6\end{array}$ & $\begin{array}{c}0.00 \\
253 \\
6\end{array}$ & $\begin{array}{l}0.00 \\
357\end{array}$ & $\begin{array}{c}0.00 \\
161 \\
6\end{array}$ & $\begin{array}{c}0.00 \\
472 \\
4\end{array}$ & $\begin{array}{c}0.00 \\
123 \\
4\end{array}$ & $\begin{array}{c}0.00 \\
345 \\
3\end{array}$ \\
\hline $\begin{array}{l}\text { deferribac } \\
\text { ter }\end{array}$ & $\begin{array}{c}0.00 \\
258 \\
4\end{array}$ & $\begin{array}{c}0.00 \\
591 \\
7\end{array}$ & $\begin{array}{c}0.00 \\
042 \\
3\end{array}$ & $\begin{array}{c}0.00 \\
064 \\
2\end{array}$ & $\begin{array}{l}0.00 \\
152\end{array}$ & $\begin{array}{c}0.00 \\
902 \\
1\end{array}$ & $\begin{array}{c}0.00 \\
08\end{array}$ & $\begin{array}{c}0.00 \\
042 \\
5\end{array}$ & $\begin{array}{c}0.00 \\
146 \\
7\end{array}$ & $\begin{array}{l}0.00 \\
646\end{array}$ \\
\hline $\begin{array}{l}\text { anaeroline } \\
\text { a }\end{array}$ & $\begin{array}{c}0.00 \\
415 \\
4\end{array}$ & $\begin{array}{c}0.00 \\
354 \\
1\end{array}$ & $\begin{array}{l}0.00 \\
149\end{array}$ & $\begin{array}{c}0.00 \\
137 \\
8\end{array}$ & $\begin{array}{l}0.00 \\
482\end{array}$ & $\begin{array}{c}0.00 \\
571 \\
5\end{array}$ & $\begin{array}{c}0.00 \\
097 \\
9\end{array}$ & $\begin{array}{c}0.00 \\
116 \\
5\end{array}$ & $\begin{array}{c}0.00 \\
272 \\
7\end{array}$ & $\begin{array}{c}0.00 \\
565 \\
1 \\
\end{array}$ \\
\hline
\end{tabular}

Bioresource Technology, Vol 216 (September 2016): pg. 446-452. DOI. This article is (C) Elsevier and permission has been granted for this version to appear in e-Publications@Marquette. Elsevier does not grant permission for this article to be further copied/distributed or hosted elsewhere without the express permission from Elsevier. 
NOT THE PUBLISHED VERSION; this is the author's final, peer-reviewed manuscript. The published version may be accessed by following the link in the citation at the bottom of the page.

\begin{tabular}{|c|c|c|c|c|c|c|c|c|c|c|}
\hline ornat & $\begin{array}{c}0.00 \\
320 \\
3\end{array}$ & $\begin{array}{l}0.00 \\
303\end{array}$ & $\begin{array}{c}0.00 \\
274 \\
4\end{array}$ & $\begin{array}{c}0.00 \\
144 \\
5\end{array}$ & $\begin{array}{c}0.00 \\
333 \\
5\end{array}$ & $\begin{array}{l}0.00 \\
313\end{array}$ & $\begin{array}{c}0.00 \\
176 \\
3\end{array}$ & $\begin{array}{c}0.00 \\
140 \\
1\end{array}$ & $\begin{array}{c}0.00 \\
596\end{array}$ & $\begin{array}{c}0.00 \\
276 \\
5\end{array}$ \\
\hline leptolinea & $\begin{array}{c}0.00 \\
304 \\
4\end{array}$ & $\begin{array}{c}0.00 \\
216 \\
9\end{array}$ & $\begin{array}{c}0.00 \\
189 \\
7\end{array}$ & $\begin{array}{c}0.00 \\
180 \\
7\end{array}$ & $\begin{array}{c}0.00 \\
421 \\
7\end{array}$ & $\begin{array}{c}0.00 \\
240 \\
9\end{array}$ & $\begin{array}{c}0.00 \\
125 \\
7\end{array}$ & $\begin{array}{c}0.00 \\
198 \\
4\end{array}$ & $\begin{array}{c}0.00 \\
564 \\
9\end{array}$ & $\begin{array}{c}0.00 \\
244 \\
1\end{array}$ \\
\hline holophaga & $\begin{array}{l}0.00 \\
084\end{array}$ & $\begin{array}{c}0.00 \\
154 \\
7 \\
\end{array}$ & $\begin{array}{l}0.00 \\
472\end{array}$ & $\begin{array}{c}0.00 \\
279 \\
7\end{array}$ & $\begin{array}{c}0.00 \\
085 \\
5\end{array}$ & $\begin{array}{c}0.00 \\
068 \\
6 \\
\end{array}$ & $\begin{array}{c}0.00 \\
349 \\
3 \\
\end{array}$ & $\begin{array}{c}0.00 \\
244 \\
1 \\
\end{array}$ & $\begin{array}{c}0.00 \\
024 \\
7 \\
\end{array}$ & $\begin{array}{c}0.00 \\
074 \\
2 \\
\end{array}$ \\
\hline $\begin{array}{l}\text { pseuc } \\
\text { nas }\end{array}$ & $\begin{array}{c}0.00 \\
033 \\
3\end{array}$ & & $\begin{array}{c}0.00 \\
017 \\
2\end{array}$ & $\begin{array}{c}0.00 \\
119 \\
1\end{array}$ & $\begin{array}{c}0.00 \\
025 \\
2\end{array}$ & $\begin{array}{c}0.00 \\
174 \\
1\end{array}$ & $\begin{array}{l}0.00 \\
018\end{array}$ & $\begin{array}{c}0.00 \\
168 \\
5\end{array}$ & $\begin{array}{c}0.00 \\
023 \\
4\end{array}$ & $\begin{array}{c}0.00 \\
087 \\
7\end{array}$ \\
\hline & $\begin{array}{l}0.00 \\
019\end{array}$ & $\begin{array}{c}0.00 \\
062 \\
2\end{array}$ & $\begin{array}{c}0.00 \\
087 \\
8 \\
\end{array}$ & $\begin{array}{c}0.00 \\
301 \\
1\end{array}$ & $\begin{array}{c}0.00 \\
025 \\
2\end{array}$ & $\begin{array}{c}0.00 \\
091 \\
4 \\
\end{array}$ & $\begin{array}{c}0.00 \\
130 \\
6\end{array}$ & $\begin{array}{c}0.00 \\
292 \\
9\end{array}$ & $\begin{array}{c}0.00 \\
031 \\
2\end{array}$ & $\begin{array}{c}0.00 \\
095 \\
8 \\
\end{array}$ \\
\hline $\begin{array}{l}\text { chitinopha } \\
\text { ga }\end{array}$ & & & $\begin{array}{c}0.00 \\
644 \\
4\end{array}$ & $\begin{array}{c}0.00 \\
013 \\
4\end{array}$ & $\begin{array}{l}7.71 \\
\text { E-05 }\end{array}$ & 5.28 & $\begin{array}{c}0.01 \\
728 \\
3\end{array}$ & $\begin{array}{c}012 \\
6\end{array}$ & $\begin{array}{c}0.00 \\
015 \\
6\end{array}$ & $\begin{array}{l}5.39 \\
\text { E-05 }\end{array}$ \\
\hline & $\begin{array}{c}0.00 \\
561 \\
3\end{array}$ & $\begin{array}{c}339 \\
7\end{array}$ & $\begin{array}{c}0.00 \\
177 \\
2\end{array}$ & $\begin{array}{c}060 \\
2\end{array}$ & $\begin{array}{c}0.00 \\
750 \\
3\end{array}$ & $\begin{array}{c}184 \\
6 \\
\end{array}$ & $\begin{array}{c}0.00 \\
066 \\
9\end{array}$ & $\begin{array}{c}044 \\
1\end{array}$ & $\begin{array}{c}0.00 \\
272 \\
7\end{array}$ & $\begin{array}{c}0.00 \\
207 \\
7\end{array}$ \\
\hline & $\begin{array}{c}0.00 \\
266 \\
4\end{array}$ & $\begin{array}{c}137 \\
2\end{array}$ & & $\begin{array}{c}121 \\
8\end{array}$ & $\begin{array}{c}0.00 \\
145 \\
7\end{array}$ & $\begin{array}{c}219 \\
8\end{array}$ & $\begin{array}{c}0.00 \\
251 \\
3\end{array}$ & 8 & $\begin{array}{c}0.00 \\
486 \\
9\end{array}$ & $\begin{array}{c}0.00 \\
240 \\
1\end{array}$ \\
\hline & $\begin{array}{c}0.00 \\
466 \\
1\end{array}$ & 8 & $\begin{array}{c}0.00 \\
015 \\
7\end{array}$ & 4 & $\begin{array}{c}0.00 \\
217 \\
9\end{array}$ & $\begin{array}{c}365 \\
8\end{array}$ & $\begin{array}{c}021 \\
2\end{array}$ & 9 & $\begin{array}{c}411 \\
6\end{array}$ & $\begin{array}{c}0.00 \\
213 \\
1\end{array}$ \\
\hline & $\begin{array}{c}0.00 \\
320 \\
3\end{array}$ & & $\begin{array}{c}0.00 \\
349 \\
7 \\
\end{array}$ & $\begin{array}{c}117 \\
8\end{array}$ & $\begin{array}{c}0.00 \\
293 \\
5 \\
\end{array}$ & $\begin{array}{c}267 \\
3 \\
\end{array}$ & $\begin{array}{c}0.00 \\
192 \\
6 \\
\end{array}$ & $\begin{array}{c}099 \\
2 \\
\end{array}$ & $\begin{array}{c}0.00 \\
380 \\
5\end{array}$ & $\begin{array}{c}.00 \\
191 \\
5 \\
\end{array}$ \\
\hline & $\begin{array}{c}0.00 \\
293 \\
3\end{array}$ & $\begin{array}{c}151 \\
5\end{array}$ & $\begin{array}{c}0.00 \\
224 \\
2\end{array}$ & & $\begin{array}{c}0.00 \\
408 \\
4\end{array}$ & $\begin{array}{c}0.00 \\
16\end{array}$ & 0.00 & $\begin{array}{c}069 \\
3\end{array}$ & $\begin{array}{c}0.00 \\
416 \\
8\end{array}$ & $\begin{array}{c}0.00 \\
165 \\
9\end{array}$ \\
\hline & $\begin{array}{c}0.00 \\
087 \\
2 \\
\end{array}$ & $\begin{array}{c}078 \\
2\end{array}$ & $\begin{array}{c}0.00 \\
025 \\
1\end{array}$ & $\begin{array}{c}0 / 4 \\
9\end{array}$ & $\begin{array}{c}0.00 \\
326 \\
5\end{array}$ & $\begin{array}{c}049 \\
2 \\
\end{array}$ & $\begin{array}{c}070 \\
2 \\
\end{array}$ & $\begin{array}{c}094 \\
5\end{array}$ & $\begin{array}{c}0.00 \\
159 \\
7 \\
\end{array}$ & $\begin{array}{c}0.00 \\
434 \\
3\end{array}$ \\
\hline & $\begin{array}{c}0.00 \\
269 \\
5\end{array}$ & & $\begin{array}{c}0.00 \\
145 \\
8\end{array}$ & $\begin{array}{c}115 \\
1\end{array}$ & $\begin{array}{c}0.00 \\
694 \\
2\end{array}$ & $\begin{array}{c}200 \\
5\end{array}$ & $\begin{array}{c}101 \\
2\end{array}$ & $\begin{array}{c}100 \\
8\end{array}$ & $\begin{array}{c}153 \\
2\end{array}$ & $\begin{array}{c}0.00 \\
160 \\
5\end{array}$ \\
\hline & $\begin{array}{c}0.00 \\
030 \\
1\end{array}$ & & $\begin{array}{c}0.00 \\
025 \\
1\end{array}$ & $\begin{array}{c}298 \\
4\end{array}$ & $\begin{array}{c}0.00 \\
058 \\
8\end{array}$ & $\begin{array}{c}0.00 \\
103 \\
8 \\
\end{array}$ & & $\begin{array}{c}0.00 \\
259 \\
8\end{array}$ & $\begin{array}{c}0.00 \\
081 \\
8\end{array}$ & $\begin{array}{c}0.00 \\
080 \\
9\end{array}$ \\
\hline & $\begin{array}{c}0.00 \\
014 \\
3\end{array}$ & $\begin{array}{c}054 \\
2\end{array}$ & $\begin{array}{c}0.00 \\
125 \\
4\end{array}$ & $\begin{array}{c}380 \\
1\end{array}$ & $\begin{array}{c}0.00 \\
010 \\
5\end{array}$ & $\begin{array}{c}045 \\
7\end{array}$ & $\begin{array}{c}044 \\
5\end{array}$ & $\begin{array}{c}195 \\
2\end{array}$ & $\begin{array}{c}0.00 \\
015 \\
6\end{array}$ & $\begin{array}{c}0.00 \\
028 \\
3\end{array}$ \\
\hline hespe & $\begin{array}{c}0.00 \\
011 \\
1\end{array}$ & & $\begin{array}{c}0.00 \\
301 \\
1\end{array}$ & $\begin{array}{c}0.00 \\
706 \\
6\end{array}$ & $\begin{array}{l}4.9 E \\
-05\end{array}$ & $\begin{array}{l}1.76 \\
\text { E-05 }\end{array}$ & $\begin{array}{c}0.00 \\
272 \\
5\end{array}$ & $\begin{array}{c}0.00 \\
656 \\
6\end{array}$ & E-05 & $\begin{array}{c}0.00 \\
010 \\
8\end{array}$ \\
\hline & $\begin{array}{c}0.00 \\
012 \\
7\end{array}$ & $\begin{array}{c}019 \\
1\end{array}$ & $\begin{array}{c}0.00 \\
014 \\
1\end{array}$ & $\begin{array}{c}014 \\
7\end{array}$ & & $\begin{array}{c}012 \\
3\end{array}$ & $\begin{array}{c}0.00 \\
026 \\
1\end{array}$ & $\begin{array}{c}0.00 \\
031 \\
5\end{array}$ & $\begin{array}{c}0.00 \\
033 \\
8\end{array}$ & $\begin{array}{c}0.00 \\
036 \\
4\end{array}$ \\
\hline & $\begin{array}{c}0.00 \\
439 \\
2 \\
\end{array}$ & $\begin{array}{c}0.00 \\
095 \\
7 \\
\end{array}$ & $\begin{array}{c}0.00 \\
224 \\
2 \\
\end{array}$ & $\begin{array}{c}088 \\
3\end{array}$ & $\begin{array}{c}0.00 \\
373 \\
4\end{array}$ & $\begin{array}{c}0.00 \\
075 \\
6\end{array}$ & $\begin{array}{c}0.00 \\
128 \\
9 \\
\end{array}$ & $\begin{array}{c}0.00 \\
059 \\
8 \\
\end{array}$ & $\begin{array}{c}0.00 \\
341 \\
5 \\
\end{array}$ & $\begin{array}{c}0.00 \\
113 \\
3 \\
\end{array}$ \\
\hline
\end{tabular}

Bioresource Technology, Vol 216 (September 2016): pg. 446-452. DOI. This article is (C) Elsevier and permission has been granted for this version to appear in e-Publications@Marquette. Elsevier does not grant permission for this article to be further copied/distributed or hosted elsewhere without the express permission from Elsevier. 
NOT THE PUBLISHED VERSION; this is the author's final, peer-reviewed manuscript. The published version may be accessed by following the link in the citation at the bottom of the page.

\begin{tabular}{|c|c|c|c|c|c|c|c|c|c|c|}
\hline $\begin{array}{l}\text { rhodocycl } \\
\text { us }\end{array}$ & $\begin{array}{c}0.00 \\
017 \\
4\end{array}$ & $\begin{array}{c}0.00 \\
027 \\
1\end{array}$ & $\begin{array}{c}0.00 \\
026 \\
7\end{array}$ & $\begin{array}{c}0.00 \\
156 \\
6\end{array}$ & $\begin{array}{c}0.00 \\
022 \\
4\end{array}$ & $\begin{array}{c}0.00 \\
028 \\
1\end{array}$ & $\begin{array}{c}0.00 \\
019 \\
6\end{array}$ & $\begin{array}{l}0.00 \\
137\end{array}$ & $\begin{array}{l}2.6 \mathrm{E} \\
-05\end{array}$ & $\begin{array}{c}0.00 \\
041 \\
8\end{array}$ \\
\hline $\begin{array}{l}\text { enterobact } \\
\text { er }\end{array}$ & $\begin{array}{l}0.00 \\
046\end{array}$ & $\begin{array}{c}0.00 \\
180 \\
2 \\
\end{array}$ & $\begin{array}{c}0.00 \\
040 \\
8 \\
\end{array}$ & $\begin{array}{c}0.00 \\
034 \\
8 \\
\end{array}$ & $\begin{array}{c}0.00 \\
022 \\
4 \\
\end{array}$ & $\begin{array}{l}0.00 \\
262\end{array}$ & $\begin{array}{c}0.00 \\
011 \\
4\end{array}$ & $\begin{array}{c}0.00 \\
042 \\
5\end{array}$ & $\begin{array}{c}0.00 \\
018 \\
2\end{array}$ & $\begin{array}{l}0.00 \\
379\end{array}$ \\
\hline $\begin{array}{l}\text { dechlorom } \\
\text { onas }\end{array}$ & $\begin{array}{c}0.00 \\
014 \\
3\end{array}$ & $\begin{array}{c}0.00 \\
068 \\
6\end{array}$ & $\begin{array}{c}0.00 \\
048 \\
6\end{array}$ & $\begin{array}{c}0.00 \\
242 \\
2\end{array}$ & $\begin{array}{l}0.00 \\
014\end{array}$ & $\begin{array}{c}0.00 \\
047 \\
5\end{array}$ & $\begin{array}{c}0.00 \\
029 \\
4\end{array}$ & $\begin{array}{c}0.00 \\
105 \\
5\end{array}$ & $\begin{array}{l}9.09 \\
\text { E-05 }\end{array}$ & $\begin{array}{c}0.00 \\
035 \\
1\end{array}$ \\
\hline $\begin{array}{l}\text { streptococ } \\
\text { cus }\end{array}$ & $\begin{array}{c}0.00 \\
058 \\
7\end{array}$ & $\begin{array}{c}0.00 \\
038 \\
3\end{array}$ & $\begin{array}{c}0.00 \\
045 \\
5\end{array}$ & $\begin{array}{l}0.00 \\
091\end{array}$ & $\begin{array}{c}0.00 \\
039 \\
2\end{array}$ & $\begin{array}{c}0.00 \\
047 \\
5\end{array}$ & $\begin{array}{c}0.00 \\
169 \\
7\end{array}$ & $\begin{array}{c}0.00 \\
102 \\
3\end{array}$ & $\begin{array}{c}0.00 \\
070 \\
1\end{array}$ & $\begin{array}{c}0.00 \\
124 \\
1\end{array}$ \\
\hline $\begin{array}{l}\text { oscillospir } \\
\text { a }\end{array}$ & $\begin{array}{c}0.00 \\
044 \\
4\end{array}$ & $\begin{array}{c}0.00 \\
079 \\
7\end{array}$ & $\begin{array}{c}0.00 \\
050 \\
2\end{array}$ & $\begin{array}{c}0.00 \\
374 \\
7\end{array}$ & $\begin{array}{c}0.00 \\
016 \\
1\end{array}$ & $\begin{array}{c}0.00 \\
068 \\
6\end{array}$ & $\begin{array}{c}0.00 \\
083 \\
2\end{array}$ & $\begin{array}{c}0.00 \\
196 \\
8\end{array}$ & $\begin{array}{c}0.00 \\
022 \\
1\end{array}$ & $\begin{array}{c}0.00 \\
067 \\
4\end{array}$ \\
\hline $\begin{array}{l}\text { soliru } \\
\text { acter }\end{array}$ & $\begin{array}{c}0.00 \\
451 \\
9\end{array}$ & $\begin{array}{c}0.00 \\
070 \\
2\end{array}$ & $\begin{array}{c}0.00 \\
141 \\
1\end{array}$ & $\begin{array}{c}0.00 \\
028 \\
1\end{array}$ & $\begin{array}{c}0.00 \\
425 \\
2 \\
\end{array}$ & $\begin{array}{l}0.00 \\
109\end{array}$ & $\begin{array}{c}0.00 \\
083 \\
2\end{array}$ & $\begin{array}{c}0.00 \\
048 \\
8\end{array}$ & $\begin{array}{c}0.00 \\
316 \\
8\end{array}$ & $\begin{array}{c}0.00 \\
134 \\
9\end{array}$ \\
\hline $\begin{array}{l}\text { cloacibacill } \\
\text { us }\end{array}$ & $\begin{array}{c}0.00 \\
014 \\
3\end{array}$ & $\begin{array}{c}0.00 \\
030 \\
3\end{array}$ & $\begin{array}{c}0.00 \\
084 \\
7\end{array}$ & $\begin{array}{c}0.00 \\
559 \\
4\end{array}$ & $\begin{array}{c}0.00 \\
015 \\
4\end{array}$ & $\begin{array}{c}0.00 \\
026 \\
4\end{array}$ & $\begin{array}{c}0.00 \\
060 \\
4\end{array}$ & $\begin{array}{c}0.00 \\
519 \\
6\end{array}$ & $\begin{array}{c}044 \\
1\end{array}$ & $\begin{array}{c}0.00 \\
022 \\
9\end{array}$ \\
\hline $\begin{array}{l}\text { plan } \\
\text { ces }\end{array}$ & $\begin{array}{c}0.00 \\
104 \\
6\end{array}$ & $\begin{array}{c}0.00 \\
156 \\
3\end{array}$ & $\begin{array}{c}0.00 \\
051 \\
7\end{array}$ & $\begin{array}{c}0.00 \\
314 \\
5\end{array}$ & $\begin{array}{l}0.00 \\
131\end{array}$ & $\begin{array}{c}0.00 \\
093 \\
2\end{array}$ & $\begin{array}{c}0.00 \\
014 \\
7\end{array}$ & $\begin{array}{c}0.00 \\
130 \\
7\end{array}$ & $\begin{array}{c}027 \\
3\end{array}$ & $\begin{array}{c}0.00 \\
091 \\
7\end{array}$ \\
\hline & $\begin{array}{c}0.00 \\
114 \\
2\end{array}$ & $\begin{array}{c}0.00 \\
092 \\
5\end{array}$ & $\begin{array}{c}0.00 \\
235 \\
2\end{array}$ & $\begin{array}{c}139 \\
2\end{array}$ & $\begin{array}{c}096 \\
7\end{array}$ & $\begin{array}{c}0.00 \\
135 \\
4\end{array}$ & & $\begin{array}{c}0.00 \\
122 \\
8\end{array}$ & & $\begin{array}{c}0.00 \\
110 \\
6\end{array}$ \\
\hline & $\begin{array}{c}0.00 \\
020 \\
6\end{array}$ & & $\begin{array}{c}0.00 \\
025 \\
1\end{array}$ & $\begin{array}{c}032 \\
1\end{array}$ & $\begin{array}{c}015 \\
4\end{array}$ & $\begin{array}{l}0.00 \\
051\end{array}$ & $\begin{array}{l}9.79 \\
E-05\end{array}$ & $\begin{array}{c}0.00 \\
018 \\
9\end{array}$ & $\begin{array}{c}010 \\
4\end{array}$ & $\begin{array}{c}0.00 \\
064 \\
7\end{array}$ \\
\hline & $\begin{array}{c}0.00 \\
158 \\
5\end{array}$ & $\begin{array}{c}0.00 \\
148 \\
3\end{array}$ & $\begin{array}{c}0.00 \\
097 \\
2\end{array}$ & $\begin{array}{c}066 \\
9\end{array}$ & $\begin{array}{c}0.00 \\
101 \\
6\end{array}$ & $\begin{array}{c}0.00 \\
165 \\
3\end{array}$ & $\begin{array}{c}179 \\
5\end{array}$ & 052 & $\begin{array}{c}097 \\
4\end{array}$ & $\begin{array}{c}0.00 \\
195 \\
6\end{array}$ \\
\hline & $\begin{array}{l}0.00 \\
398\end{array}$ & $\begin{array}{c}0.00 \\
017 \\
5 \\
\end{array}$ & $\begin{array}{l}0.00 \\
058\end{array}$ & $\begin{array}{c}0.00 \\
064 \\
2 \\
\end{array}$ & $\begin{array}{l}0.00 \\
573\end{array}$ & $\begin{array}{c}0.00 \\
047 \\
5\end{array}$ & $\begin{array}{c}0.00 \\
133 \\
8 \\
\end{array}$ & $\begin{array}{c}0.00 \\
047 \\
2 \\
\end{array}$ & $\begin{array}{c}0.00 \\
093 \\
5\end{array}$ & $\begin{array}{c}0.00 \\
056 \\
6\end{array}$ \\
\hline $\begin{array}{l}\text { desulfospo } \\
\text { rosinus }\end{array}$ & $\begin{array}{c}0.00 \\
015 \\
9 \\
\end{array}$ & $\begin{array}{c}0.00 \\
041 \\
5 \\
\end{array}$ & $\begin{array}{c}0.00 \\
076 \\
8\end{array}$ & $\begin{array}{c}115 \\
1\end{array}$ & $\begin{array}{c}0.00 \\
010 \\
5\end{array}$ & $\begin{array}{c}0.00 \\
087 \\
9\end{array}$ & $\begin{array}{c}0.00 \\
430 \\
9 \\
\end{array}$ & $\begin{array}{c}0.00 \\
116 \\
5\end{array}$ & $\begin{array}{c}0.00 \\
014 \\
3\end{array}$ & $\begin{array}{c}0.00 \\
087 \\
7\end{array}$ \\
\hline tolumonas & $\begin{array}{c}0.00 \\
012 \\
7\end{array}$ & $\begin{array}{l}6.38 \\
E-05\end{array}$ & $\begin{array}{l}6.27 \\
\text { E-05 }\end{array}$ & & $\begin{array}{l}4.2 \mathrm{E} \\
-05\end{array}$ & $\begin{array}{c}0.00 \\
014 \\
1\end{array}$ & E-05 & $\begin{array}{l}6.3 \mathrm{E} \\
-05\end{array}$ & 6.49 & $\begin{array}{c}0.00 \\
044 \\
5\end{array}$ \\
\hline & $\begin{array}{l}0.00 \\
206\end{array}$ & 134 & $\begin{array}{c}043 \\
9\end{array}$ & $\begin{array}{c}033 \\
5\end{array}$ & $\begin{array}{c}344 \\
7\end{array}$ & $\begin{array}{c}137 \\
2\end{array}$ & $\begin{array}{c}019 \\
6\end{array}$ & 017 & $\begin{array}{c}263 \\
6\end{array}$ & $\begin{array}{c}0.00 \\
178\end{array}$ \\
\hline $\begin{array}{l}\text { faecalibact } \\
\text { erium }\end{array}$ & $\begin{array}{l}4.76 \\
E-05\end{array}$ & $\begin{array}{l}3.19 \\
E-05\end{array}$ & $\begin{array}{l}4.7 E \\
-05\end{array}$ & $\begin{array}{c}0.00 \\
013 \\
4\end{array}$ & $\begin{array}{l}3.5 \mathrm{E} \\
-05\end{array}$ & $\begin{array}{l}8.79 \\
E-05\end{array}$ & $\begin{array}{l}4.9 \mathrm{E} \\
-05\end{array}$ & $\begin{array}{l}6.3 \mathrm{E} \\
-05\end{array}$ & $\begin{array}{l}3.9 \mathrm{E} \\
-05\end{array}$ & $\begin{array}{l}2.7 \mathrm{E} \\
-05\end{array}$ \\
\hline & $\begin{array}{c}0.00 \\
220 \\
4\end{array}$ & $\begin{array}{c}0.00 \\
105 \\
3\end{array}$ & $\begin{array}{c}084 \\
7\end{array}$ & $\begin{array}{c}0.00 \\
042 \\
8\end{array}$ & $\begin{array}{c}231 \\
2\end{array}$ & $\begin{array}{c}100 \\
2\end{array}$ & $\begin{array}{c}045 \\
7\end{array}$ & $\begin{array}{c}0.00 \\
045 \\
7\end{array}$ & $\begin{array}{c}0.00 \\
270 \\
1\end{array}$ & $\begin{array}{c}0.00 \\
144 \\
3\end{array}$ \\
\hline & $\begin{array}{c}0.00 \\
022 \\
2\end{array}$ & $\begin{array}{c}031 \\
9\end{array}$ & $\begin{array}{l}0.00 \\
022\end{array}$ & $\begin{array}{c}444 \\
3\end{array}$ & 021 & $\begin{array}{c}0.00 \\
019 \\
3\end{array}$ & $\begin{array}{c}0.00 \\
016 \\
3\end{array}$ & $\begin{array}{c}0.00 \\
297 \\
6\end{array}$ & E-05 & $\begin{array}{c}0.00 \\
016 \\
2\end{array}$ \\
\hline
\end{tabular}

Bioresource Technology, Vol 216 (September 2016): pg. 446-452. DOI. This article is (C) Elsevier and permission has been granted for this version to appear in e-Publications@Marquette. Elsevier does not grant permission for this article to be further copied/distributed or hosted elsewhere without the express permission from Elsevier. 
NOT THE PUBLISHED VERSION; this is the author's final, peer-reviewed manuscript. The published version may be accessed by following the link in the citation at the bottom of the page.

\begin{tabular}{|c|c|c|c|c|c|c|c|c|c|c|}
\hline kush & $\begin{array}{c}0.00 \\
011 \\
1\end{array}$ & $\begin{array}{l}0.00 \\
453\end{array}$ & $\begin{array}{l}6.27 \\
\text { E-05 }\end{array}$ & $\begin{array}{c}0.00 \\
069 \\
6\end{array}$ & $\begin{array}{c}0.00 \\
035 \\
7\end{array}$ & $\begin{array}{c}0.00 \\
559 \\
2\end{array}$ & $\begin{array}{c}0.00 \\
013 \\
1\end{array}$ & $\begin{array}{c}0.00 \\
018 \\
9\end{array}$ & $\begin{array}{c}0.00 \\
014 \\
3\end{array}$ & $\begin{array}{c}0.00 \\
53\end{array}$ \\
\hline pelosinus & $\begin{array}{c}0.00 \\
036 \\
5 \\
\end{array}$ & $\begin{array}{c}0.00 \\
011 \\
2\end{array}$ & $\begin{array}{l}0.00 \\
047\end{array}$ & $\begin{array}{c}0.00 \\
025 \\
4\end{array}$ & $\begin{array}{c}0.00 \\
027 \\
3 \\
\end{array}$ & $\begin{array}{c}0.00 \\
019 \\
3 \\
\end{array}$ & $\begin{array}{c}0.00 \\
055 \\
5 \\
\end{array}$ & $\begin{array}{c}0.00 \\
034 \\
6 \\
\end{array}$ & $\begin{array}{c}0.00 \\
033 \\
8 \\
\end{array}$ & $\begin{array}{c}0.00 \\
010 \\
8\end{array}$ \\
\hline $\begin{array}{l}\text { aminomon } \\
\text { as }\end{array}$ & $\begin{array}{c}0.00 \\
072 \\
9 \\
\end{array}$ & $\begin{array}{c}0.00 \\
279 \\
1\end{array}$ & $\begin{array}{c}0.00 \\
089 \\
4\end{array}$ & $\begin{array}{c}0.00 \\
016 \\
1\end{array}$ & $\begin{array}{c}0.00 \\
083 \\
4 \\
\end{array}$ & $\begin{array}{c}0.00 \\
332 \\
4\end{array}$ & $\begin{array}{c}0.00 \\
071 \\
8 \\
\end{array}$ & $\begin{array}{l}7.87 \\
E-05\end{array}$ & $\begin{array}{l}0.00 \\
074\end{array}$ & $\begin{array}{c}0.00 \\
362 \\
8 \\
\end{array}$ \\
\hline moorella & $\begin{array}{c}0.00 \\
201 \\
4\end{array}$ & $\begin{array}{c}0.00 \\
122 \\
8\end{array}$ & $\begin{array}{c}0.00 \\
059 \\
6\end{array}$ & $\begin{array}{c}0.00 \\
070 \\
9\end{array}$ & $\begin{array}{c}0.00 \\
378 \\
3\end{array}$ & $\begin{array}{l}0.00 \\
058\end{array}$ & $\begin{array}{c}0.00 \\
034 \\
3\end{array}$ & $\begin{array}{c}025 \\
2\end{array}$ & $\begin{array}{c}0.00 \\
107 \\
8\end{array}$ & $\begin{array}{c}0.00 \\
076 \\
9\end{array}$ \\
\hline $\begin{array}{l}\text { desulfofab } \\
\text { a }\end{array}$ & $\begin{array}{c}0.00 \\
079 \\
3\end{array}$ & $\begin{array}{c}0.00 \\
309 \\
4\end{array}$ & $\begin{array}{c}0.00 \\
014 \\
1\end{array}$ & $\begin{array}{c}0.00 \\
077 \\
6\end{array}$ & $\begin{array}{c}0.00 \\
107 \\
9 \\
\end{array}$ & $\begin{array}{c}0.00 \\
158 \\
3\end{array}$ & $\begin{array}{l}8.16 \\
E-05\end{array}$ & $\begin{array}{l}0.00 \\
063\end{array}$ & $\begin{array}{l}0.00 \\
061\end{array}$ & $\begin{array}{c}0.00 \\
141 \\
6 \\
\end{array}$ \\
\hline & $\begin{array}{c}0.00 \\
095 \\
1 \\
\end{array}$ & $\begin{array}{c}0.00 \\
092 \\
5 \\
\end{array}$ & $\begin{array}{l}0.00 \\
127\end{array}$ & $\begin{array}{c}0.00 \\
056 \\
2\end{array}$ & $\begin{array}{c}0.00 \\
069 \\
4 \\
\end{array}$ & $\begin{array}{c}0.00 \\
093 \\
2 \\
\end{array}$ & $\begin{array}{c}0.00 \\
189 \\
3 \\
\end{array}$ & $\begin{array}{c}01 \\
4\end{array}$ & $\begin{array}{c}0.00 \\
045 \\
4\end{array}$ & $\begin{array}{l}0.00 \\
085\end{array}$ \\
\hline $\begin{array}{l}\text { anaer } \\
\text { is }\end{array}$ & $\begin{array}{c}0.00 \\
155 \\
4\end{array}$ & & $\begin{array}{c}0.00 \\
200 \\
7\end{array}$ & $\begin{array}{c}0.00 \\
028 \\
1\end{array}$ & $\begin{array}{c}0.00 \\
084 \\
1\end{array}$ & $\begin{array}{c}0.00 \\
024 \\
6\end{array}$ & $\begin{array}{c}0.00 \\
243 \\
2\end{array}$ & $\begin{array}{c}034 \\
6\end{array}$ & $\begin{array}{c}0.00 \\
172 \\
7\end{array}$ & 0.00 \\
\hline & $\begin{array}{c}0.00 \\
103 \\
1\end{array}$ & & $\begin{array}{c}0.00 \\
161 \\
5\end{array}$ & $\begin{array}{c}034 \\
8\end{array}$ & $\begin{array}{c}0.00 \\
272 \\
5\end{array}$ & $\begin{array}{c}061 \\
5\end{array}$ & $\begin{array}{c}0.00 \\
024 \\
5\end{array}$ & $\begin{array}{c}023 \\
6\end{array}$ & $\begin{array}{l}0.00 \\
087\end{array}$ & $\begin{array}{c}0.00 \\
067 \\
4\end{array}$ \\
\hline & & $\begin{array}{c}0.00 \\
153 \\
1\end{array}$ & $\begin{array}{l}0.00 \\
022\end{array}$ & 0.00 & $\begin{array}{c}0.00 \\
038 \\
5\end{array}$ & $\begin{array}{c}0.00 \\
147 \\
7 \\
\end{array}$ & 0.00 & $\begin{array}{c}0.00 \\
165 \\
3\end{array}$ & $\begin{array}{c}0.00 \\
277 \\
9\end{array}$ & $\begin{array}{c}0.00 \\
152 \\
4 \\
\end{array}$ \\
\hline serra & $\begin{array}{c}0.00 \\
015 \\
9\end{array}$ & & & $\begin{array}{c}0.00 \\
013 \\
4\end{array}$ & $\begin{array}{l}7.01 \\
\text { E-05 }\end{array}$ & 8.79 & $\begin{array}{l}4.9 \mathrm{E} \\
-05\end{array}$ & 0.00 & 7.79 & $\begin{array}{c}0.00 \\
013 \\
5\end{array}$ \\
\hline & & & 0 & & -05 & & & & & $\begin{array}{l}2.7 \mathrm{E} \\
-05\end{array}$ \\
\hline $\begin{array}{l}\text { myco } \\
\text { ma }\end{array}$ & $\begin{array}{c}0.00 \\
011 \\
1 \\
\end{array}$ & $\begin{array}{c}0.00 \\
011 \\
2 \\
\end{array}$ & $\begin{array}{c}0.00 \\
023 \\
5\end{array}$ & $\begin{array}{c}032 \\
1 \\
\end{array}$ & $\begin{array}{l}9.81 \\
\text { E-05 }\end{array}$ & $\begin{array}{c}038 \\
7 \\
\end{array}$ & $\begin{array}{c}081 \\
6\end{array}$ & $\begin{array}{c}017 \\
3 \\
\end{array}$ & 7.79 & $\begin{array}{c}0.00 \\
012 \\
1\end{array}$ \\
\hline hige & $\begin{array}{l}7.93 \\
E-05\end{array}$ & $\begin{array}{c}033 \\
5\end{array}$ & $\begin{array}{l}9.41 \\
E-05\end{array}$ & & $\begin{array}{l}6.3 E \\
-05\end{array}$ & & E-05 & $\begin{array}{l}6.3 \mathrm{E} \\
-05\end{array}$ & & $\begin{array}{c}0.00 \\
032 \\
4\end{array}$ \\
\hline & $\begin{array}{c}0.00 \\
118 \\
9\end{array}$ & $\begin{array}{c}0.00 \\
121 \\
2\end{array}$ & & $\begin{array}{c}111 \\
1 \\
\end{array}$ & $\begin{array}{c}0.00 \\
142 \\
9 \\
\end{array}$ & $\begin{array}{c}093 \\
2\end{array}$ & $\begin{array}{c}063 \\
6\end{array}$ & $\begin{array}{c}050 \\
4\end{array}$ & $\begin{array}{c}0.00 \\
105 \\
2\end{array}$ & $\begin{array}{c}0.00 \\
071 \\
5\end{array}$ \\
\hline & $\begin{array}{c}0.00 \\
069 \\
8\end{array}$ & & 050 & & $\begin{array}{c}0.00 \\
108 \\
6\end{array}$ & $\begin{array}{c}131 \\
9\end{array}$ & 0.00 & $\begin{array}{c}058 \\
3\end{array}$ & $\begin{array}{c}0.00 \\
059 \\
7\end{array}$ & $\begin{array}{c}0.00 \\
176 \\
7\end{array}$ \\
\hline $\begin{array}{l}\text { calc } \\
\text { or }\end{array}$ & $\begin{array}{c}0.00 \\
076 \\
1\end{array}$ & $\begin{array}{c}0.00 \\
079 \\
7\end{array}$ & $\begin{array}{c}0.00 \\
087 \\
8\end{array}$ & $\begin{array}{c}0.00 \\
080 \\
3\end{array}$ & $\begin{array}{c}0.00 \\
059 \\
5\end{array}$ & $\begin{array}{c}0.00 \\
066 \\
8\end{array}$ & $\begin{array}{c}0.00 \\
197 \\
5\end{array}$ & $\begin{array}{c}0.00 \\
047 \\
2\end{array}$ & $\begin{array}{c}0.00 \\
051 \\
9\end{array}$ & $\begin{array}{c}0.00 \\
068 \\
8\end{array}$ \\
\hline & $\begin{array}{c}0.00 \\
126 \\
8\end{array}$ & $\begin{array}{c}047 \\
8\end{array}$ & $\begin{array}{c}0.00 \\
122 \\
3\end{array}$ & $\begin{array}{c}048 \\
2\end{array}$ & $\begin{array}{c}0.00 \\
154 \\
1\end{array}$ & $\begin{array}{c}0.00 \\
036 \\
9\end{array}$ & $\begin{array}{c}0.00 \\
130 \\
6\end{array}$ & $\begin{array}{c}037 \\
8\end{array}$ & $\begin{array}{c}0.00 \\
290 \\
9\end{array}$ & $\begin{array}{c}0.00 \\
033 \\
7\end{array}$ \\
\hline & $\begin{array}{c}0.00 \\
053 \\
9\end{array}$ & $\begin{array}{c}0.00 \\
060 \\
6\end{array}$ & $\begin{array}{c}0.00 \\
048 \\
6\end{array}$ & $\begin{array}{l}0.00 \\
025\end{array}$ & $\begin{array}{l}0.00 \\
060\end{array}$ & $\begin{array}{l}0.00 \\
047\end{array}$ & $\begin{array}{c}0.00 \\
016 \\
3\end{array}$ & $\begin{array}{c}0.00 \\
017 \\
3\end{array}$ & $\begin{array}{l}0.00 \\
022\end{array}$ & $\begin{array}{l}0.00 \\
047\end{array}$ \\
\hline
\end{tabular}

Bioresource Technology, Vol 216 (September 2016): pg. 446-452. DOI. This article is (C) Elsevier and permission has been granted for this version to appear in e-Publications@Marquette. Elsevier does not grant permission for this article to be further copied/distributed or hosted elsewhere without the express permission from Elsevier. 
NOT THE PUBLISHED VERSION; this is the author's final, peer-reviewed manuscript. The published version may be accessed by following the link in the citation at the bottom of the page.

\begin{tabular}{|c|c|c|c|c|c|c|c|c|c|c|}
\hline $\begin{array}{l}\text { arthrobact } \\
\text { er }\end{array}$ & $\begin{array}{c}0.00 \\
212 \\
5 \\
\end{array}$ & $\begin{array}{c}0.00 \\
081 \\
3 \\
\end{array}$ & $\begin{array}{c}0.00 \\
103 \\
5\end{array}$ & $\begin{array}{c}0.00 \\
058 \\
9\end{array}$ & $\begin{array}{l}0.00 \\
213\end{array}$ & $\begin{array}{c}0.00 \\
033 \\
4 \\
\end{array}$ & $\begin{array}{l}0.00 \\
062\end{array}$ & $\begin{array}{c}0.00 \\
015 \\
7\end{array}$ & $\begin{array}{c}0.00 \\
081 \\
8 \\
\end{array}$ & $\begin{array}{c}0.00 \\
039 \\
1\end{array}$ \\
\hline $\begin{array}{l}\text { acholeplas } \\
\text { ma }\end{array}$ & $\begin{array}{c}0.00 \\
036 \\
5\end{array}$ & $\begin{array}{l}9.57 \\
\text { E-05 }\end{array}$ & $\begin{array}{c}0.00 \\
053 \\
3\end{array}$ & $\begin{array}{c}0.00 \\
022 \\
8\end{array}$ & $\begin{array}{c}0.00 \\
048 \\
3\end{array}$ & $\begin{array}{l}7.03 \\
\text { E-05 }\end{array}$ & $\begin{array}{l}0.00 \\
049\end{array}$ & $\begin{array}{c}0.00 \\
020 \\
5\end{array}$ & $\begin{array}{l}0.00 \\
013\end{array}$ & $\begin{array}{l}9.44 \\
\text { E-05 }\end{array}$ \\
\hline pirellula & $\begin{array}{c}0.00 \\
209 \\
3\end{array}$ & $\begin{array}{c}0.00 \\
161 \\
1\end{array}$ & $\begin{array}{l}0.00 \\
022\end{array}$ & $\begin{array}{c}0.00 \\
038 \\
8\end{array}$ & $\begin{array}{c}0.00 \\
177 \\
9\end{array}$ & $\begin{array}{c}0.00 \\
130 \\
1\end{array}$ & $\begin{array}{c}0.00 \\
073 \\
4\end{array}$ & $\begin{array}{c}0.00 \\
025 \\
2\end{array}$ & $\begin{array}{l}0.00 \\
135\end{array}$ & $\begin{array}{c}0.00 \\
091 \\
7\end{array}$ \\
\hline ralstonia & $\begin{array}{c}0.00 \\
093 \\
5\end{array}$ & $\begin{array}{c}0.00 \\
132 \\
4 \\
\end{array}$ & $\begin{array}{c}0.00 \\
025 \\
1\end{array}$ & $\begin{array}{c}0.00 \\
073 \\
6\end{array}$ & $\begin{array}{c}0.00 \\
117 \\
7 \\
\end{array}$ & $\begin{array}{c}0.00 \\
116 \\
1 \\
\end{array}$ & $\begin{array}{c}0.00 \\
022 \\
8\end{array}$ & $\begin{array}{c}0.00 \\
034 \\
6\end{array}$ & $\begin{array}{c}0.00 \\
159 \\
7\end{array}$ & $\begin{array}{c}0.00 \\
126 \\
8 \\
\end{array}$ \\
\hline $\begin{array}{l}\text { caldanaer } \\
\text { obacter }\end{array}$ & $\begin{array}{l}7.93 \\
E-05\end{array}$ & $\begin{array}{c}0.00 \\
035 \\
1 \\
\end{array}$ & $\begin{array}{c}0.00 \\
056 \\
4 \\
\end{array}$ & $\begin{array}{c}0.00 \\
311 \\
8 \\
\end{array}$ & $\begin{array}{l}4.2 \mathrm{E} \\
-05\end{array}$ & $\begin{array}{c}0.00 \\
017 \\
6 \\
\end{array}$ & $\begin{array}{c}0.00 \\
029 \\
4 \\
\end{array}$ & $\begin{array}{c}0.00 \\
116 \\
5 \\
\end{array}$ & $\begin{array}{l}9.09 \\
\text { E-05 }\end{array}$ & $\begin{array}{l}0.00 \\
027\end{array}$ \\
\hline $\begin{array}{l}\text { thermoan } \\
\text { aerobacul } \\
\text { um }\end{array}$ & $\begin{array}{c}0.00 \\
179 \\
2 \\
\end{array}$ & $\begin{array}{c}0.00 \\
129 \\
2\end{array}$ & $\begin{array}{l}9.41 \\
\text { E-05 }\end{array}$ & $\begin{array}{c}0.00 \\
028 \\
1\end{array}$ & $\begin{array}{c}0.00 \\
228 \\
4 \\
\end{array}$ & $\begin{array}{c}0.00 \\
068 \\
6\end{array}$ & $\begin{array}{c}0.00 \\
019 \\
6 \\
\end{array}$ & $\begin{array}{c}0.00 \\
028 \\
3 \\
\end{array}$ & $\begin{array}{c}0.00 \\
075 \\
3\end{array}$ & $\begin{array}{c}0.00 \\
106 \\
5\end{array}$ \\
\hline $\begin{array}{l}\text { candidatu } \\
\text { s } \\
\text { solibacter }\end{array}$ & $\begin{array}{c}0.00 \\
061 \\
8\end{array}$ & $\begin{array}{c}0.00 \\
132 \\
4\end{array}$ & $\begin{array}{c}0.00 \\
042 \\
3\end{array}$ & $\begin{array}{c}0.00 \\
097 \\
7\end{array}$ & $\begin{array}{c}0.00 \\
064 \\
5\end{array}$ & $\begin{array}{c}0.00 \\
080 \\
9\end{array}$ & $\begin{array}{c}0.00 \\
066 \\
9\end{array}$ & $\begin{array}{l}0.00 \\
074\end{array}$ & $\begin{array}{c}0.00 \\
033 \\
8\end{array}$ & $\begin{array}{c}0.00 \\
086 \\
3\end{array}$ \\
\hline $\begin{array}{l}\text { acidovora } \\
\mathrm{x}\end{array}$ & $\begin{array}{l}9.51 \\
\text { E-05 }\end{array}$ & $\begin{array}{c}0.00 \\
022 \\
3\end{array}$ & $\begin{array}{l}7.84 \\
E-05\end{array}$ & $\begin{array}{c}0.00 \\
029 \\
4\end{array}$ & $\begin{array}{l}7.71 \\
\text { E-05 }\end{array}$ & $\begin{array}{c}0.00 \\
019 \\
3\end{array}$ & $\begin{array}{c}0.00 \\
011 \\
4\end{array}$ & $\begin{array}{c}0.00 \\
039 \\
4\end{array}$ & $\begin{array}{l}6.49 \\
E-05\end{array}$ & $\begin{array}{c}0.00 \\
022 \\
9\end{array}$ \\
\hline $\begin{array}{l}\text { haliangiu } \\
\text { m }\end{array}$ & $\begin{array}{l}0.00 \\
092\end{array}$ & $\begin{array}{c}0.00 \\
090 \\
9 \\
\end{array}$ & $\begin{array}{c}0.00 \\
083 \\
1 \\
\end{array}$ & $\begin{array}{c}0.00 \\
097 \\
7 \\
\end{array}$ & $\begin{array}{c}0.00 \\
108 \\
6 \\
\end{array}$ & $\begin{array}{c}0.00 \\
035 \\
2 \\
\end{array}$ & $\begin{array}{c}0.00 \\
019 \\
6 \\
\end{array}$ & $\begin{array}{c}0.00 \\
033 \\
1 \\
\end{array}$ & $\begin{array}{c}0.00 \\
040 \\
3 \\
\end{array}$ & $\begin{array}{c}0.00 \\
079 \\
6 \\
\end{array}$ \\
\hline $\begin{array}{l}\text { azospirillu } \\
\text { m }\end{array}$ & $\begin{array}{c}0.00 \\
039 \\
6\end{array}$ & $\begin{array}{c}0.00 \\
079 \\
7\end{array}$ & $\begin{array}{l}0.00 \\
058\end{array}$ & $\begin{array}{c}0.00 \\
042 \\
8\end{array}$ & $\begin{array}{c}0.00 \\
034 \\
3\end{array}$ & $\begin{array}{c}0.00 \\
056 \\
3\end{array}$ & $\begin{array}{c}0.00 \\
096 \\
3\end{array}$ & $\begin{array}{c}0.00 \\
029 \\
9\end{array}$ & $\begin{array}{c}0.00 \\
020 \\
8\end{array}$ & $\begin{array}{c}0.00 \\
079 \\
6\end{array}$ \\
\hline $\begin{array}{l}\text { leptolyngb } \\
\text { ya }\end{array}$ & $\begin{array}{c}0.00 \\
023 \\
8 \\
\end{array}$ & $\begin{array}{l}0.00 \\
051\end{array}$ & $\begin{array}{l}0.00 \\
185\end{array}$ & $\begin{array}{c}0.00 \\
042 \\
8 \\
\end{array}$ & $\begin{array}{c}0.00 \\
013 \\
3\end{array}$ & $\begin{array}{c}0.00 \\
021 \\
1\end{array}$ & $\begin{array}{c}0.00 \\
138 \\
7\end{array}$ & $\begin{array}{c}0.00 \\
020 \\
5\end{array}$ & $\begin{array}{c}0.00 \\
010 \\
4\end{array}$ & $\begin{array}{c}0.00 \\
018 \\
9\end{array}$ \\
\hline $\begin{array}{l}\text { desulfocal } \\
\text { dus }\end{array}$ & $\begin{array}{c}0.00 \\
020 \\
6 \\
\end{array}$ & $\begin{array}{c}0.00 \\
079 \\
7 \\
\end{array}$ & $\begin{array}{l}1.57 \\
\text { E-05 }\end{array}$ & $\begin{array}{c}0.00 \\
020 \\
1\end{array}$ & $\begin{array}{c}0.00 \\
051 \\
8 \\
\end{array}$ & $\begin{array}{l}0.00 \\
044\end{array}$ & $\begin{array}{l}6.53 \\
\text { E-05 }\end{array}$ & $\begin{array}{c}0.00 \\
015 \\
7 \\
\end{array}$ & $\begin{array}{c}0.00 \\
071 \\
4 \\
\end{array}$ & $\begin{array}{c}0.00 \\
070 \\
1 \\
\end{array}$ \\
\hline $\begin{array}{l}\text { desulfone } \\
\text { ma }\end{array}$ & $\begin{array}{l}7.93 \\
\text { E-05 }\end{array}$ & $\begin{array}{c}0.00 \\
435 \\
4\end{array}$ & 0 & 0 & $\begin{array}{l}2.1 \mathrm{E} \\
-05\end{array}$ & $\begin{array}{c}0.00 \\
543 \\
4\end{array}$ & $\begin{array}{l}3.26 \\
E-05\end{array}$ & $\begin{array}{l}3.15 \\
\text { E-05 }\end{array}$ & $\begin{array}{l}5.19 \\
\text { E-05 }\end{array}$ & $\begin{array}{c}0.00 \\
315 \\
6\end{array}$ \\
\hline $\begin{array}{l}\text { blastomon } \\
\text { as }\end{array}$ & $\begin{array}{c}0.00 \\
063 \\
4\end{array}$ & $\begin{array}{c}0.00 \\
076 \\
6\end{array}$ & $\begin{array}{l}0.00 \\
022\end{array}$ & $\begin{array}{c}0.00 \\
119 \\
1\end{array}$ & $\begin{array}{c}0.00 \\
044 \\
1\end{array}$ & $\begin{array}{c}0.00 \\
047 \\
5\end{array}$ & $\begin{array}{c}0.00 \\
014 \\
7\end{array}$ & $\begin{array}{c}0.00 \\
045 \\
7\end{array}$ & $\begin{array}{c}0.00 \\
081 \\
8\end{array}$ & $\begin{array}{c}0.00 \\
040 \\
5\end{array}$ \\
\hline $\begin{array}{l}\text { carboxydo } \\
\text { cella }\end{array}$ & $\begin{array}{c}0.00 \\
017 \\
4\end{array}$ & $\begin{array}{c}0.00 \\
030 \\
3\end{array}$ & $\begin{array}{l}0.00 \\
022\end{array}$ & $\begin{array}{c}0.00 \\
219 \\
5\end{array}$ & $\begin{array}{l}9.81 \\
\text { E-05 }\end{array}$ & $\begin{array}{c}0.00 \\
052 \\
8\end{array}$ & $\begin{array}{c}0.00 \\
016 \\
3\end{array}$ & $\begin{array}{c}0.00 \\
151 \\
2\end{array}$ & $\begin{array}{c}0.00 \\
019 \\
5\end{array}$ & $\begin{array}{c}0.00 \\
048 \\
6\end{array}$ \\
\hline chlamydia & $\begin{array}{c}0.00 \\
023 \\
8\end{array}$ & $\begin{array}{c}0.00 \\
087 \\
7\end{array}$ & $\begin{array}{c}0.00 \\
015 \\
7\end{array}$ & $\begin{array}{l}0.00 \\
087\end{array}$ & $\begin{array}{c}0.00 \\
047 \\
6\end{array}$ & $\begin{array}{c}0.00 \\
036 \\
9\end{array}$ & $\begin{array}{c}0.00 \\
022 \\
8\end{array}$ & $\begin{array}{c}0.00 \\
039 \\
4\end{array}$ & $\begin{array}{c}0.00 \\
041 \\
6\end{array}$ & $\begin{array}{c}0.00 \\
041 \\
8\end{array}$ \\
\hline $\begin{array}{l}\text { aminivibri } \\
\text { o }\end{array}$ & $\begin{array}{c}0.00 \\
196 \\
6\end{array}$ & $\begin{array}{c}0.00 \\
020 \\
7\end{array}$ & $\begin{array}{c}0.00 \\
122 \\
3\end{array}$ & $\begin{array}{c}0.00 \\
013 \\
4\end{array}$ & $\begin{array}{c}0.00 \\
208 \\
1\end{array}$ & $\begin{array}{c}0.00 \\
026 \\
4\end{array}$ & $\begin{array}{c}0.00 \\
044 \\
1\end{array}$ & $\begin{array}{l}9.45 \\
\text { E-05 }\end{array}$ & $\begin{array}{c}0.00 \\
114 \\
3\end{array}$ & $\begin{array}{c}0.00 \\
021 \\
6\end{array}$ \\
\hline gaiella & $\begin{array}{c}0.00 \\
185 \\
5 \\
\end{array}$ & $\begin{array}{c}0.00 \\
020 \\
7 \\
\end{array}$ & $\begin{array}{c}0.00 \\
076 \\
8 \\
\end{array}$ & $\begin{array}{c}0.00 \\
014 \\
7 \\
\end{array}$ & $\begin{array}{c}0.00 \\
151 \\
3 \\
\end{array}$ & $\begin{array}{c}0.00 \\
022 \\
9\end{array}$ & $\begin{array}{c}0.00 \\
109 \\
3 \\
\end{array}$ & $\begin{array}{c}0.00 \\
017 \\
3 \\
\end{array}$ & $\begin{array}{l}0.00 \\
087\end{array}$ & $\begin{array}{l}0.00 \\
027\end{array}$ \\
\hline
\end{tabular}

Bioresource Technology, Vol 216 (September 2016): pg. 446-452. DOI. This article is (C) Elsevier and permission has been granted for this version to appear in e-Publications@Marquette. Elsevier does not grant permission for this article to be further copied/distributed or hosted elsewhere without the express permission from Elsevier. 
NOT THE PUBLISHED VERSION; this is the author's final, peer-reviewed manuscript. The published version may be accessed by following the link in the citation at the bottom of the page.

\begin{tabular}{|c|c|c|c|c|c|c|c|c|c|c|}
\hline $\begin{array}{l}\text { nitrosovibr } \\
\text { io }\end{array}$ & $\begin{array}{c}0.00 \\
069 \\
8\end{array}$ & $\begin{array}{c}0.00 \\
038 \\
3\end{array}$ & $\begin{array}{c}0.00 \\
032 \\
9\end{array}$ & $\begin{array}{c}0.00 \\
024 \\
1\end{array}$ & $\begin{array}{c}0.00 \\
114 \\
9\end{array}$ & $\begin{array}{c}0.00 \\
040 \\
4\end{array}$ & $\begin{array}{c}0.00 \\
039 \\
2\end{array}$ & $\begin{array}{c}0.00 \\
017 \\
3\end{array}$ & $\begin{array}{c}0.00 \\
033 \\
8\end{array}$ & $\begin{array}{c}0.00 \\
078 \\
2\end{array}$ \\
\hline $\begin{array}{l}\text { desulfatife } \\
\text { rula }\end{array}$ & $\begin{array}{c}0.00 \\
011 \\
1\end{array}$ & $\begin{array}{l}4.78 \\
E-05\end{array}$ & $\begin{array}{l}4.7 \mathrm{E} \\
-05\end{array}$ & $\begin{array}{c}0.00 \\
020 \\
1\end{array}$ & $\begin{array}{l}4.2 \mathrm{E} \\
-05\end{array}$ & $\begin{array}{l}5.28 \\
\text { E-05 }\end{array}$ & $\begin{array}{l}1.63 \\
E-05\end{array}$ & $\begin{array}{l}7.87 \\
\text { E-05 }\end{array}$ & $\begin{array}{l}1.3 \mathrm{E} \\
-05\end{array}$ & $\begin{array}{l}1.35 \\
\text { E-05 }\end{array}$ \\
\hline $\begin{array}{l}\text { cellulosilyt } \\
\text { icum }\end{array}$ & $\begin{array}{c}0.00 \\
079 \\
3 \\
\end{array}$ & $\begin{array}{c}0.00 \\
031 \\
9\end{array}$ & $\begin{array}{l}0.00 \\
047\end{array}$ & $\begin{array}{c}0.00 \\
036 \\
1\end{array}$ & $\begin{array}{c}0.00 \\
094 \\
6\end{array}$ & $\begin{array}{c}0.00 \\
031 \\
7\end{array}$ & $\begin{array}{c}0.00 \\
022 \\
8\end{array}$ & $\begin{array}{c}0.00 \\
031 \\
5\end{array}$ & $\begin{array}{c}0.00 \\
071 \\
4\end{array}$ & $\begin{array}{l}0.00 \\
058\end{array}$ \\
\hline veillonella & $\begin{array}{c}0.00 \\
034 \\
9\end{array}$ & $\begin{array}{c}0.00 \\
012 \\
8\end{array}$ & $\begin{array}{c}0.00 \\
062 \\
7\end{array}$ & $\begin{array}{l}0.00 \\
091\end{array}$ & $\begin{array}{c}0.00 \\
038 \\
5\end{array}$ & $\begin{array}{c}0.00 \\
015 \\
8\end{array}$ & $\begin{array}{c}0.00 \\
078 \\
3\end{array}$ & $\begin{array}{c}0.00 \\
034 \\
6\end{array}$ & $\begin{array}{c}0.00 \\
059 \\
7\end{array}$ & $\begin{array}{l}9.44 \\
\text { E-05 }\end{array}$ \\
\hline caldilinea & $\begin{array}{c}0.00 \\
104 \\
6\end{array}$ & $\begin{array}{c}0.00 \\
055 \\
8\end{array}$ & $\begin{array}{c}0.00 \\
070 \\
6\end{array}$ & $\begin{array}{c}0.00 \\
020 \\
1\end{array}$ & $\begin{array}{c}0.00 \\
212 \\
3\end{array}$ & $\begin{array}{c}0.00 \\
029 \\
9\end{array}$ & $\begin{array}{c}0.00 \\
034 \\
3\end{array}$ & $\begin{array}{l}6.3 E \\
-05\end{array}$ & $\begin{array}{c}0.00 \\
079 \\
2\end{array}$ & $\begin{array}{c}0.00 \\
036 \\
4\end{array}$ \\
\hline $\begin{array}{l}\text { methylote } \\
\text { nera }\end{array}$ & $\begin{array}{l}6.34 \\
E-05\end{array}$ & $\begin{array}{c}0.00 \\
015 \\
9\end{array}$ & $\begin{array}{c}0.00 \\
014 \\
1\end{array}$ & $\begin{array}{c}0.00 \\
021 \\
4\end{array}$ & $\begin{array}{c}0.00 \\
012 \\
6\end{array}$ & $\begin{array}{c}0.00 \\
029 \\
9\end{array}$ & $\begin{array}{c}0.00 \\
016 \\
3\end{array}$ & $\begin{array}{l}0.00 \\
022\end{array}$ & 0 & $\begin{array}{c}0.00 \\
014 \\
8 \\
\end{array}$ \\
\hline $\begin{array}{l}\text { cloacibact } \\
\text { erium }\end{array}$ & $\begin{array}{c}0.00 \\
020 \\
6\end{array}$ & $\begin{array}{c}0.00 \\
039 \\
9\end{array}$ & $\begin{array}{c}0.00 \\
015 \\
7\end{array}$ & $\begin{array}{c}0.00 \\
038 \\
8\end{array}$ & $\begin{array}{c}0.00 \\
018 \\
9\end{array}$ & $\begin{array}{c}0.00 \\
065 \\
1\end{array}$ & $\begin{array}{c}0.00 \\
029 \\
4\end{array}$ & $\begin{array}{l}0.00 \\
022\end{array}$ & $\begin{array}{l}9.09 \\
E-05\end{array}$ & $\begin{array}{c}0.00 \\
099 \\
8\end{array}$ \\
\hline $\begin{array}{l}\text { methano } \\
\text { massiliicoc } \\
\text { cus }\end{array}$ & $\begin{array}{c}0.00 \\
142 \\
7\end{array}$ & $\begin{array}{c}0.00 \\
017 \\
5\end{array}$ & $\begin{array}{c}0.00 \\
051 \\
7\end{array}$ & $\begin{array}{l}9.37 \\
E-05\end{array}$ & $\begin{array}{c}0.00 \\
307 \\
5\end{array}$ & $\begin{array}{l}5.28 \\
\text { E-05 }\end{array}$ & $\begin{array}{c}0.00 \\
022 \\
8\end{array}$ & 0 & $\begin{array}{c}0.00 \\
136 \\
3\end{array}$ & $\begin{array}{c}0.00 \\
013 \\
5\end{array}$ \\
\hline coxiella & $\begin{array}{l}0.00 \\
027\end{array}$ & $\begin{array}{c}0.00 \\
023 \\
9\end{array}$ & $\begin{array}{c}0.00 \\
032 \\
9\end{array}$ & $\begin{array}{c}0.00 \\
101 \\
7\end{array}$ & $\begin{array}{c}0.00 \\
039 \\
9\end{array}$ & $\begin{array}{c}0.00 \\
022 \\
9\end{array}$ & $\begin{array}{c}0.00 \\
078 \\
3\end{array}$ & $\begin{array}{c}0.00 \\
080 \\
3\end{array}$ & $\begin{array}{c}0.00 \\
068 \\
8\end{array}$ & $\begin{array}{c}0.00 \\
014 \\
8\end{array}$ \\
\hline $\begin{array}{l}\text { candidatu } \\
\text { s } \\
\text { phytoplas } \\
\text { ma }\end{array}$ & $\begin{array}{c}0.00 \\
031 \\
7\end{array}$ & $\begin{array}{l}4.78 \\
E-05\end{array}$ & $\begin{array}{c}0.00 \\
032 \\
9\end{array}$ & $\begin{array}{c}0.00 \\
215 \\
5\end{array}$ & $\begin{array}{c}0.00 \\
064 \\
5\end{array}$ & $\begin{array}{l}8.79 \\
\text { E-05 }\end{array}$ & $\begin{array}{c}0.00 \\
044 \\
1\end{array}$ & $\begin{array}{c}0.00 \\
108 \\
6\end{array}$ & $\begin{array}{l}7.79 \\
\text { E-05 }\end{array}$ & $\begin{array}{l}9.44 \\
\text { E-05 }\end{array}$ \\
\hline $\begin{array}{l}\text { dethiobact } \\
\text { er }\end{array}$ & $\begin{array}{c}0.00 \\
066 \\
6\end{array}$ & $\begin{array}{c}0.00 \\
015 \\
9\end{array}$ & $\begin{array}{c}0.00 \\
045 \\
5\end{array}$ & $\begin{array}{c}0.00 \\
016 \\
1\end{array}$ & $\begin{array}{c}0.00 \\
046 \\
9\end{array}$ & $\begin{array}{c}0.00 \\
047 \\
5\end{array}$ & $\begin{array}{c}0.00 \\
045 \\
7\end{array}$ & $\begin{array}{c}0.00 \\
014 \\
2\end{array}$ & $\begin{array}{l}0.00 \\
126\end{array}$ & $\begin{array}{c}0.00 \\
052 \\
6\end{array}$ \\
\hline $\begin{array}{l}\text { aquabacte } \\
\text { rium }\end{array}$ & $\begin{array}{l}4.76 \\
E-05\end{array}$ & $\begin{array}{c}0.00 \\
022 \\
3\end{array}$ & $\begin{array}{l}3.14 \\
\text { E-05 }\end{array}$ & $\begin{array}{c}0.00 \\
022 \\
8\end{array}$ & $\begin{array}{l}3.5 \mathrm{E} \\
-05\end{array}$ & $\begin{array}{c}0.00 \\
010 \\
6\end{array}$ & $\begin{array}{l}4.9 E \\
-05\end{array}$ & $\begin{array}{c}0.00 \\
028 \\
3\end{array}$ & $\begin{array}{l}2.6 \mathrm{E} \\
-05\end{array}$ & $\begin{array}{l}9.44 \\
\text { E-05 }\end{array}$ \\
\hline $\begin{array}{l}\text { pelagicocc } \\
\text { us }\end{array}$ & $\begin{array}{c}0.00 \\
012 \\
7\end{array}$ & $\begin{array}{c}0.00 \\
041 \\
5\end{array}$ & $\begin{array}{c}0.00 \\
158 \\
4\end{array}$ & $\begin{array}{c}0.00 \\
070 \\
9\end{array}$ & $\begin{array}{c}0.00 \\
012 \\
6\end{array}$ & $\begin{array}{c}0.00 \\
021 \\
1\end{array}$ & $\begin{array}{c}0.00 \\
140 \\
4\end{array}$ & $\begin{array}{l}0.00 \\
022\end{array}$ & $\begin{array}{l}1.3 \mathrm{E} \\
-05\end{array}$ & $\begin{array}{l}9.44 \\
\text { E-05 }\end{array}$ \\
\hline $\begin{array}{l}\text { intestinim } \\
\text { onas }\end{array}$ & $\begin{array}{l}0.00 \\
046\end{array}$ & $\begin{array}{c}0.00 \\
082 \\
9\end{array}$ & $\begin{array}{l}6.27 \\
E-05\end{array}$ & $\begin{array}{c}0.00 \\
058 \\
9\end{array}$ & $\begin{array}{c}0.00 \\
025 \\
2\end{array}$ & $\begin{array}{c}0.00 \\
077 \\
4\end{array}$ & $\begin{array}{c}0.00 \\
019 \\
6\end{array}$ & $\begin{array}{c}0.00 \\
017 \\
3\end{array}$ & $\begin{array}{c}0.00 \\
031 \\
2\end{array}$ & $\begin{array}{c}0.00 \\
074 \\
2\end{array}$ \\
\hline $\begin{array}{l}\text { sedimenti } \\
\text { bacter }\end{array}$ & $\begin{array}{l}1.59 \\
\text { E-05 }\end{array}$ & $\begin{array}{c}0.00 \\
011 \\
2\end{array}$ & $\begin{array}{c}0.00 \\
050 \\
2\end{array}$ & $\begin{array}{l}0.00 \\
095\end{array}$ & $\begin{array}{l}5.6 \mathrm{E} \\
-05\end{array}$ & $\begin{array}{c}0.00 \\
017 \\
6\end{array}$ & $\begin{array}{c}0.00 \\
135 \\
5\end{array}$ & $\begin{array}{c}0.00 \\
058 \\
3\end{array}$ & $\begin{array}{l}5.19 \\
E-05\end{array}$ & $\begin{array}{l}8.09 \\
\text { E-05 }\end{array}$ \\
\hline blautia & $\begin{array}{l}3.17 \\
E-05\end{array}$ & $\begin{array}{l}1.59 \\
E-05\end{array}$ & $\begin{array}{l}7.84 \\
E-05\end{array}$ & $\begin{array}{l}5.35 \\
E-05\end{array}$ & $\begin{array}{l}1.4 \mathrm{E} \\
-05\end{array}$ & 0 & $\begin{array}{l}3.26 \\
E-05\end{array}$ & $\begin{array}{l}6.3 \mathrm{E} \\
-05\end{array}$ & $\begin{array}{l}1.3 \mathrm{E} \\
-05\end{array}$ & $\begin{array}{l}1.35 \\
E-05\end{array}$ \\
\hline $\begin{array}{l}\text { fibrobacte } \\
r\end{array}$ & $\begin{array}{c}0.00 \\
044 \\
4\end{array}$ & $\begin{array}{c}0.00 \\
012 \\
8\end{array}$ & $\begin{array}{c}0.00 \\
056 \\
4\end{array}$ & $\begin{array}{c}0.00 \\
033 \\
5\end{array}$ & $\begin{array}{c}0.00 \\
053 \\
9\end{array}$ & $\begin{array}{c}0.00 \\
019 \\
3\end{array}$ & $\begin{array}{c}0.00 \\
088 \\
1\end{array}$ & $\begin{array}{l}9.45 \\
\text { E-05 }\end{array}$ & $\begin{array}{c}0.00 \\
027 \\
3\end{array}$ & $\begin{array}{c}0.00 \\
039 \\
1\end{array}$ \\
\hline $\begin{array}{l}\text { desulforeg } \\
\text { ula }\end{array}$ & $\begin{array}{l}6.34 \\
\text { E-05 }\end{array}$ & $\begin{array}{c}0.00 \\
019 \\
1\end{array}$ & $\begin{array}{l}3.14 \\
E-05\end{array}$ & $\begin{array}{c}0.00 \\
014 \\
7\end{array}$ & $\begin{array}{l}9.11 \\
\text { E-05 }\end{array}$ & $\begin{array}{c}0.00 \\
019 \\
3\end{array}$ & $\begin{array}{l}1.63 \\
E-05\end{array}$ & $\begin{array}{l}1.57 \\
\text { E-05 }\end{array}$ & $\begin{array}{l}7.79 \\
\text { E-05 }\end{array}$ & $\begin{array}{c}0.00 \\
010 \\
8\end{array}$ \\
\hline
\end{tabular}

Bioresource Technology, Vol 216 (September 2016): pg. 446-452. DOI. This article is (C) Elsevier and permission has been granted for this version to appear in e-Publications@Marquette. Elsevier does not grant permission for this article to be further copied/distributed or hosted elsewhere without the express permission from Elsevier. 
NOT THE PUBLISHED VERSION; this is the author's final, peer-reviewed manuscript. The published version may be accessed by following the link in the citation at the bottom of the page.

\begin{tabular}{|c|c|c|c|c|c|c|c|c|c|c|}
\hline $\begin{array}{l}\text { halothioba } \\
\text { cillus }\end{array}$ & $\begin{array}{c}0.00 \\
017 \\
4 \\
\end{array}$ & $\begin{array}{c}0.00 \\
043 \\
1 \\
\end{array}$ & $\begin{array}{c}0.00 \\
012 \\
5 \\
\end{array}$ & $\begin{array}{c}0.00 \\
109 \\
7 \\
\end{array}$ & $\begin{array}{c}0.00 \\
034 \\
3 \\
\end{array}$ & $\begin{array}{c}0.00 \\
022 \\
9 \\
\end{array}$ & $\begin{array}{c}0.00 \\
042 \\
4 \\
\end{array}$ & $\begin{array}{l}0.00 \\
063\end{array}$ & $\begin{array}{c}0.00 \\
010 \\
4 \\
\end{array}$ & $\begin{array}{c}0.00 \\
013 \\
5 \\
\end{array}$ \\
\hline beggiatoa & $\begin{array}{c}0.00 \\
055 \\
5\end{array}$ & $\begin{array}{c}0.00 \\
057 \\
4 \\
\end{array}$ & $\begin{array}{c}0.00 \\
040 \\
8\end{array}$ & $\begin{array}{c}0.00 \\
033 \\
5\end{array}$ & $\begin{array}{c}0.00 \\
044 \\
1\end{array}$ & $\begin{array}{c}0.00 \\
054 \\
5\end{array}$ & $\begin{array}{c}0.00 \\
014 \\
7\end{array}$ & $\begin{array}{c}0.00 \\
028 \\
3\end{array}$ & $\begin{array}{c}0.00 \\
071 \\
4\end{array}$ & $\begin{array}{c}0.00 \\
079 \\
6\end{array}$ \\
\hline lysobacter & $\begin{array}{c}0.00 \\
031 \\
7\end{array}$ & $\begin{array}{c}0.00 \\
041 \\
5\end{array}$ & $\begin{array}{l}6.27 \\
\text { E-05 }\end{array}$ & $\begin{array}{c}0.00 \\
014 \\
7\end{array}$ & $\begin{array}{c}0.00 \\
125 \\
4\end{array}$ & $\begin{array}{c}0.00 \\
077 \\
4\end{array}$ & $\begin{array}{c}0.00 \\
011 \\
4\end{array}$ & $\begin{array}{l}4.72 \\
E-05\end{array}$ & $\begin{array}{c}0.00 \\
016 \\
9\end{array}$ & $\begin{array}{c}0.00 \\
059 \\
3\end{array}$ \\
\hline $\begin{array}{l}\text { acidithiob } \\
\text { acillus }\end{array}$ & $\begin{array}{c}0.00 \\
107 \\
8\end{array}$ & $\begin{array}{c}0.00 \\
049 \\
4\end{array}$ & $\begin{array}{c}0.00 \\
029 \\
8 \\
\end{array}$ & $\begin{array}{c}0.00 \\
042 \\
8\end{array}$ & $\begin{array}{c}0.00 \\
156 \\
2\end{array}$ & $\begin{array}{c}0.00 \\
015 \\
8\end{array}$ & $\begin{array}{c}0.00 \\
016 \\
3\end{array}$ & $\begin{array}{c}0.00 \\
029 \\
9\end{array}$ & $\begin{array}{c}0.00 \\
077 \\
9\end{array}$ & $\begin{array}{c}0.00 \\
029 \\
7\end{array}$ \\
\hline $\begin{array}{l}\text { robinsonie } \\
\text { lla }\end{array}$ & $\begin{array}{c}0.00 \\
036 \\
5\end{array}$ & $\begin{array}{c}0.00 \\
017 \\
5\end{array}$ & $\begin{array}{c}0.00 \\
108 \\
2\end{array}$ & $\begin{array}{c}0.00 \\
054 \\
9\end{array}$ & $\begin{array}{c}0.00 \\
028 \\
7\end{array}$ & $\begin{array}{c}0.00 \\
024 \\
6\end{array}$ & $\begin{array}{c}0.00 \\
088 \\
1\end{array}$ & $\begin{array}{c}0.00 \\
040 \\
9\end{array}$ & $\begin{array}{l}5.19 \\
\text { E-05 }\end{array}$ & $\begin{array}{c}0.00 \\
028 \\
3\end{array}$ \\
\hline $\begin{array}{l}\text { gracilibact } \\
\text { er }\end{array}$ & $\begin{array}{c}0.00 \\
068 \\
2\end{array}$ & $\begin{array}{c}0.00 \\
030 \\
3\end{array}$ & $\begin{array}{c}0.00 \\
028 \\
2\end{array}$ & $\begin{array}{c}0.00 \\
022 \\
8\end{array}$ & $\begin{array}{c}0.00 \\
043 \\
4\end{array}$ & $\begin{array}{c}0.00 \\
063 \\
3\end{array}$ & $\begin{array}{c}0.00 \\
029 \\
4\end{array}$ & $\begin{array}{c}0.00 \\
015 \\
7\end{array}$ & $\begin{array}{c}0.00 \\
064 \\
9\end{array}$ & $\begin{array}{c}0.00 \\
036 \\
4\end{array}$ \\
\hline lactivibrio & $\begin{array}{c}0.00 \\
042 \\
8\end{array}$ & $\begin{array}{c}0.00 \\
038 \\
3\end{array}$ & $\begin{array}{c}0.00 \\
070 \\
6\end{array}$ & $\begin{array}{c}0.00 \\
028 \\
1\end{array}$ & $\begin{array}{c}0.00 \\
046 \\
2\end{array}$ & $\begin{array}{c}0.00 \\
059 \\
8\end{array}$ & $\begin{array}{c}0.00 \\
040 \\
8\end{array}$ & $\begin{array}{c}0.00 \\
025 \\
2\end{array}$ & $\begin{array}{c}0.00 \\
079 \\
2\end{array}$ & $\begin{array}{c}0.00 \\
041 \\
8\end{array}$ \\
\hline $\begin{array}{l}\text { sacchariba } \\
\text { cter }\end{array}$ & $\begin{array}{c}0.00 \\
217 \\
2\end{array}$ & $\begin{array}{l}4.78 \\
E-05\end{array}$ & $\begin{array}{l}9.41 \\
\text { E-05 }\end{array}$ & 0 & $\begin{array}{c}0.00 \\
083 \\
4\end{array}$ & $\begin{array}{l}5.28 \\
\text { E-05 }\end{array}$ & $\begin{array}{l}8.16 \\
\text { E-05 }\end{array}$ & $\begin{array}{l}3.15 \\
\text { E-05 }\end{array}$ & $\begin{array}{c}0.00 \\
157 \\
1\end{array}$ & $\begin{array}{l}2.7 \mathrm{E} \\
-05\end{array}$ \\
\hline $\begin{array}{l}\text { peredibact } \\
\text { er }\end{array}$ & $\begin{array}{c}0.00 \\
039 \\
6\end{array}$ & $\begin{array}{c}0.00 \\
022 \\
3\end{array}$ & $\begin{array}{c}0.00 \\
040 \\
8 \\
\end{array}$ & $\begin{array}{c}0.00 \\
041 \\
5\end{array}$ & $\begin{array}{c}0.00 \\
055 \\
3\end{array}$ & $\begin{array}{c}0.00 \\
022 \\
9 \\
\end{array}$ & $\begin{array}{c}0.00 \\
068 \\
5 \\
\end{array}$ & $\begin{array}{c}0.00 \\
028 \\
3 \\
\end{array}$ & $\begin{array}{c}0.00 \\
028 \\
6\end{array}$ & $\begin{array}{c}0.00 \\
035 \\
1\end{array}$ \\
\hline $\begin{array}{l}\text { microbulbi } \\
\text { fer }\end{array}$ & $\begin{array}{c}0.00 \\
063 \\
4\end{array}$ & $\begin{array}{c}0.00 \\
121 \\
2\end{array}$ & 0 & $\begin{array}{l}2.68 \\
E-05\end{array}$ & $\begin{array}{c}0.00 \\
074 \\
3\end{array}$ & $\begin{array}{c}0.00 \\
061 \\
5\end{array}$ & 0 & 0 & $\begin{array}{c}0.00 \\
010 \\
4\end{array}$ & $\begin{array}{c}0.00 \\
052 \\
6\end{array}$ \\
\hline $\begin{array}{l}\text { desulfotig } \\
\text { num }\end{array}$ & $\begin{array}{l}3.17 \\
\text { E-05 }\end{array}$ & $\begin{array}{l}1.59 \\
\text { E-05 }\end{array}$ & 0 & .34 & $\begin{array}{l}7.01 \\
\text { E-06 }\end{array}$ & $\begin{array}{l}1.76 \\
\text { E-05 }\end{array}$ & 0 & $\begin{array}{l}3.15 \\
\text { E-05 }\end{array}$ & $\begin{array}{l}2.6 \mathrm{E} \\
-05 \\
\end{array}$ & $\begin{array}{l}8.09 \\
\text { E-05 }\end{array}$ \\
\hline maricaulis & $\begin{array}{l}9.51 \\
\text { E-05 }\end{array}$ & $\begin{array}{l}1.59 \\
\text { E-05 }\end{array}$ & $\begin{array}{c}0.00 \\
189 \\
7\end{array}$ & $\begin{array}{c}0.00 \\
038 \\
8\end{array}$ & $\begin{array}{l}5.6 \mathrm{E} \\
-05\end{array}$ & $\begin{array}{l}5.28 \\
\text { E-05 }\end{array}$ & $\begin{array}{c}0.00 \\
081 \\
6\end{array}$ & $\begin{array}{c}0.00 \\
020 \\
5\end{array}$ & $\begin{array}{l}3.9 \mathrm{E} \\
-05\end{array}$ & $\begin{array}{l}4.05 \\
\text { E-05 }\end{array}$ \\
\hline rhizo & $\begin{array}{c}0.00 \\
022 \\
2\end{array}$ & $\begin{array}{c}0.00 \\
039 \\
9\end{array}$ & $\begin{array}{l}9.41 \\
\text { E-05 }\end{array}$ & $\begin{array}{c}0.00 \\
088 \\
3\end{array}$ & $\begin{array}{c}0.00 \\
015 \\
4\end{array}$ & $\begin{array}{c}0.00 \\
065 \\
1\end{array}$ & $\begin{array}{c}0.00 \\
024 \\
5\end{array}$ & $\begin{array}{c}0.00 \\
088 \\
2\end{array}$ & $\begin{array}{c}0.00 \\
044 \\
1\end{array}$ & $\begin{array}{c}0.00 \\
036 \\
4\end{array}$ \\
\hline $\begin{array}{l}\text { acidamino } \\
\text { coccus }\end{array}$ & $\begin{array}{c}0.00 \\
012 \\
7\end{array}$ & $\begin{array}{c}0.00 \\
015 \\
9\end{array}$ & $\begin{array}{l}4.7 E \\
-05\end{array}$ & $\begin{array}{l}4.01 \\
E-05\end{array}$ & $\begin{array}{l}6.3 \mathrm{E} \\
-05\end{array}$ & $\begin{array}{l}5.28 \\
\text { E-05 }\end{array}$ & $\begin{array}{l}1.63 \\
E-05\end{array}$ & $\begin{array}{l}7.87 \\
\text { E-05 }\end{array}$ & $\begin{array}{l}6.49 \\
E-05\end{array}$ & $\begin{array}{l}6.74 \\
\text { E-05 }\end{array}$ \\
\hline $\begin{array}{l}\text { thermaero } \\
\text { bacter }\end{array}$ & $\begin{array}{c}0.00 \\
022 \\
2\end{array}$ & $\begin{array}{c}0.00 \\
030 \\
3\end{array}$ & $\begin{array}{l}3.14 \\
E-05\end{array}$ & 0 & $\begin{array}{l}0.00 \\
021\end{array}$ & $\begin{array}{c}0.00 \\
054 \\
5\end{array}$ & 0 & $\begin{array}{l}1.57 \\
E-05\end{array}$ & $\begin{array}{l}0.00 \\
048\end{array}$ & $\begin{array}{c}0.00 \\
033 \\
7\end{array}$ \\
\hline $\begin{array}{l}\text { simplic } \\
\text { ra }\end{array}$ & $\begin{array}{l}3.17 \\
\text { E-05 }\end{array}$ & $\begin{array}{c}0.00 \\
017 \\
5\end{array}$ & $\begin{array}{l}3.14 \\
\text { E-05 }\end{array}$ & $\begin{array}{c}0.00 \\
029 \\
4\end{array}$ & $\begin{array}{l}2.1 \mathrm{E} \\
-05\end{array}$ & $\begin{array}{c}0.00 \\
024 \\
6\end{array}$ & $\begin{array}{l}3.26 \\
\text { E-05 }\end{array}$ & $\begin{array}{c}0.00 \\
015 \\
7\end{array}$ & $\begin{array}{l}3.9 \mathrm{E} \\
-05\end{array}$ & $\begin{array}{c}0.00 \\
017 \\
5\end{array}$ \\
\hline $\begin{array}{l}\text { turicibacte } \\
r\end{array}$ & $\begin{array}{l}6.34 \\
E-05\end{array}$ & $\begin{array}{l}9.57 \\
\text { E-05 }\end{array}$ & $\begin{array}{c}0.00 \\
098 \\
8\end{array}$ & $\begin{array}{c}0.00 \\
016 \\
1\end{array}$ & $\begin{array}{l}4.2 E \\
-05\end{array}$ & $\begin{array}{l}5.28 \\
\text { E-05 }\end{array}$ & $\begin{array}{c}0.00 \\
135 \\
5\end{array}$ & $\begin{array}{l}0.00 \\
011\end{array}$ & $\begin{array}{l}7.79 \\
\text { E-05 }\end{array}$ & $\begin{array}{l}4.05 \\
\text { E-05 }\end{array}$ \\
\hline $\begin{array}{l}\text { helic } \\
\text { er }\end{array}$ & $\begin{array}{c}0.00 \\
014 \\
3\end{array}$ & $\begin{array}{c}0.00 \\
015 \\
9\end{array}$ & $\begin{array}{c}0.00 \\
097 \\
2\end{array}$ & $\begin{array}{c}0.00 \\
020 \\
1\end{array}$ & $\begin{array}{c}0.00 \\
041 \\
3\end{array}$ & $\begin{array}{c}0.00 \\
022 \\
9\end{array}$ & $\begin{array}{c}0.00 \\
081 \\
6\end{array}$ & $\begin{array}{c}0.00 \\
017 \\
3\end{array}$ & $\begin{array}{c}0.00 \\
027 \\
3\end{array}$ & $\begin{array}{c}0.00 \\
017 \\
5\end{array}$ \\
\hline
\end{tabular}

Bioresource Technology, Vol 216 (September 2016): pg. 446-452. DOI. This article is (C) Elsevier and permission has been granted for this version to appear in e-Publications@Marquette. Elsevier does not grant permission for this article to be further copied/distributed or hosted elsewhere without the express permission from Elsevier. 
NOT THE PUBLISHED VERSION; this is the author's final, peer-reviewed manuscript. The published version may be accessed by following the link in the citation at the bottom of the page.

\begin{tabular}{|c|c|c|c|c|c|c|c|c|c|c|}
\hline $\begin{array}{l}\text { rhodopirell } \\
\text { ula }\end{array}$ & $\begin{array}{c}0.00 \\
058 \\
7\end{array}$ & $\begin{array}{c}0.00 \\
062 \\
2\end{array}$ & $\begin{array}{l}7.84 \\
E-05\end{array}$ & $\begin{array}{c}0.00 \\
025 \\
4\end{array}$ & $\begin{array}{c}0.00 \\
061 \\
6\end{array}$ & $\begin{array}{c}0.00 \\
035 \\
2\end{array}$ & $\begin{array}{l}8.16 \\
E-05\end{array}$ & $\begin{array}{c}0.00 \\
018 \\
9\end{array}$ & $\begin{array}{c}0.00 \\
111 \\
7\end{array}$ & $\begin{array}{c}0.00 \\
047 \\
2\end{array}$ \\
\hline $\begin{array}{l}\text { desulfatigl } \\
\text { ans }\end{array}$ & $\begin{array}{l}1.59 \\
E-05\end{array}$ & $\begin{array}{c}0.00 \\
124 \\
4\end{array}$ & $\begin{array}{l}1.57 \\
\text { E-05 }\end{array}$ & $\begin{array}{c}0.00 \\
030 \\
8\end{array}$ & $\begin{array}{l}4.2 \mathrm{E} \\
-05\end{array}$ & $\begin{array}{l}0.00 \\
095\end{array}$ & 0 & $\begin{array}{l}9.45 \\
\text { E-05 }\end{array}$ & $\begin{array}{c}0.00 \\
010 \\
4\end{array}$ & $\begin{array}{c}0.00 \\
144 \\
3\end{array}$ \\
\hline $\begin{array}{l}\text { pseudoxa } \\
\text { nthomona } \\
\text { s }\end{array}$ & $\begin{array}{l}4.76 \\
E-05\end{array}$ & $\begin{array}{c}0.00 \\
022 \\
3\end{array}$ & $\begin{array}{l}3.14 \\
E-05\end{array}$ & $\begin{array}{l}9.37 \\
E-05\end{array}$ & $\begin{array}{c}0.00 \\
030 \\
8\end{array}$ & $\begin{array}{c}0.00 \\
128 \\
4\end{array}$ & $\begin{array}{l}4.9 E \\
-05\end{array}$ & $\begin{array}{c}0.00 \\
028 \\
3\end{array}$ & $\begin{array}{l}9.09 \\
\text { E-05 }\end{array}$ & $\begin{array}{l}0.00 \\
031\end{array}$ \\
\hline $\begin{array}{l}\text { polyangiu } \\
\mathrm{m}\end{array}$ & $\begin{array}{l}6.34 \\
E-05\end{array}$ & $\begin{array}{l}6.38 \\
E-05\end{array}$ & $\begin{array}{l}1.57 \\
\text { E-05 }\end{array}$ & 0 & $\begin{array}{c}0.00 \\
019 \\
6\end{array}$ & $\begin{array}{c}0.00 \\
015 \\
8\end{array}$ & $\begin{array}{l}1.63 \\
E-05\end{array}$ & $\begin{array}{l}1.57 \\
\text { E-05 }\end{array}$ & $\begin{array}{l}9.09 \\
E-05\end{array}$ & $\begin{array}{c}0.00 \\
024 \\
3\end{array}$ \\
\hline $\begin{array}{l}\text { barnesiell } \\
\text { a }\end{array}$ & $\begin{array}{l}6.34 \\
E-05\end{array}$ & $\begin{array}{c}0.00 \\
063 \\
8\end{array}$ & $\begin{array}{l}3.14 \\
\text { E-05 }\end{array}$ & $\begin{array}{l}9.37 \\
E-05\end{array}$ & $\begin{array}{l}9.81 \\
\text { E-05 }\end{array}$ & $\begin{array}{c}0.00 \\
049 \\
2\end{array}$ & $\begin{array}{c}0.00 \\
032 \\
6\end{array}$ & $\begin{array}{l}0.00 \\
022\end{array}$ & $\begin{array}{l}9.09 \\
\text { E-05 }\end{array}$ & $\begin{array}{l}0.00 \\
089\end{array}$ \\
\hline $\begin{array}{l}\text { byssovora } \\
x\end{array}$ & $\begin{array}{c}0.00 \\
020 \\
6 \\
\end{array}$ & $\begin{array}{c}0.00 \\
063 \\
8 \\
\end{array}$ & $\begin{array}{c}0.00 \\
020 \\
4 \\
\end{array}$ & $\begin{array}{c}0.00 \\
107 \\
1 \\
\end{array}$ & $\begin{array}{c}0.00 \\
038 \\
5\end{array}$ & $\begin{array}{c}0.00 \\
045 \\
7\end{array}$ & $\begin{array}{c}0.00 \\
016 \\
3\end{array}$ & $\begin{array}{c}0.00 \\
058 \\
3\end{array}$ & $\begin{array}{c}0.00 \\
046 \\
7\end{array}$ & $\begin{array}{c}0.00 \\
111 \\
9\end{array}$ \\
\hline $\begin{array}{l}\text { anaerovibr } \\
\text { io }\end{array}$ & $\begin{array}{c}0.00 \\
034 \\
9\end{array}$ & $\begin{array}{l}6.38 \\
E-05\end{array}$ & $\begin{array}{c}0.00 \\
059 \\
6\end{array}$ & $\begin{array}{c}0.00 \\
074 \\
9\end{array}$ & $\begin{array}{c}0.00 \\
022 \\
4\end{array}$ & $\begin{array}{c}0.00 \\
012 \\
3\end{array}$ & $\begin{array}{c}0.00 \\
060 \\
4\end{array}$ & $\begin{array}{c}0.00 \\
045 \\
7\end{array}$ & $\begin{array}{c}0.00 \\
050 \\
6\end{array}$ & $\begin{array}{l}5.39 \\
E-05\end{array}$ \\
\hline $\begin{array}{l}\text { comamon } \\
\text { as }\end{array}$ & $\begin{array}{c}0.00 \\
014 \\
3\end{array}$ & $\begin{array}{c}0.00 \\
057 \\
4\end{array}$ & $\begin{array}{c}0.00 \\
017 \\
2\end{array}$ & $\begin{array}{c}0.00 \\
024 \\
1\end{array}$ & $\begin{array}{l}0.00 \\
021\end{array}$ & $\begin{array}{c}0.00 \\
061 \\
5\end{array}$ & $\begin{array}{l}3.26 \\
E-05\end{array}$ & $\begin{array}{c}0.00 \\
026 \\
8\end{array}$ & $\begin{array}{c}0.00 \\
014 \\
3\end{array}$ & $\begin{array}{c}0.00 \\
053 \\
9\end{array}$ \\
\hline dyella & $\begin{array}{c}0.00 \\
039 \\
6\end{array}$ & $\begin{array}{c}0.00 \\
076 \\
6\end{array}$ & $\begin{array}{l}3.14 \\
E-05\end{array}$ & $\begin{array}{c}0.00 \\
010 \\
7\end{array}$ & $\begin{array}{c}0.00 \\
084 \\
8\end{array}$ & $\begin{array}{c}0.00 \\
107 \\
3\end{array}$ & 0 & $\begin{array}{l}9.45 \\
E-05\end{array}$ & $\begin{array}{c}0.00 \\
070 \\
1\end{array}$ & $\begin{array}{c}0.00 \\
101 \\
1\end{array}$ \\
\hline $\begin{array}{l}\text { solobacter } \\
\text { ium }\end{array}$ & $\begin{array}{l}0.00 \\
092\end{array}$ & $\begin{array}{c}0.00 \\
065 \\
4\end{array}$ & $\begin{array}{c}0.00 \\
043 \\
9\end{array}$ & $\begin{array}{c}0.00 \\
028 \\
1\end{array}$ & $\begin{array}{c}0.00 \\
080 \\
6\end{array}$ & $\begin{array}{l}0.00 \\
058\end{array}$ & $\begin{array}{c}0.00 \\
029 \\
4\end{array}$ & $\begin{array}{c}0.00 \\
026 \\
8\end{array}$ & $\begin{array}{c}0.00 \\
024 \\
7\end{array}$ & $\begin{array}{c}0.00 \\
040 \\
5\end{array}$ \\
\hline dialister & $\begin{array}{c}0.00 \\
017 \\
4\end{array}$ & $\begin{array}{l}1.59 \\
E-05\end{array}$ & $\begin{array}{c}0.00 \\
028 \\
2\end{array}$ & $\begin{array}{c}0.00 \\
028 \\
1\end{array}$ & $\begin{array}{l}9.11 \\
\text { E-05 }\end{array}$ & $\begin{array}{l}3.52 \\
E-05\end{array}$ & $\begin{array}{c}0.00 \\
040 \\
8\end{array}$ & $\begin{array}{c}0.00 \\
018 \\
9\end{array}$ & $\begin{array}{c}0.00 \\
016 \\
9\end{array}$ & $\begin{array}{l}6.74 \\
E-05\end{array}$ \\
\hline alistipes & $\begin{array}{l}4.76 \\
E-05\end{array}$ & $\begin{array}{l}3.19 \\
E-05\end{array}$ & $\begin{array}{l}1.57 \\
E-05\end{array}$ & $\begin{array}{l}2.68 \\
E-05\end{array}$ & $\begin{array}{l}2.8 \mathrm{E} \\
-05\end{array}$ & 0 & $\begin{array}{l}4.9 \mathrm{E} \\
-05\end{array}$ & $\begin{array}{l}6.3 \mathrm{E} \\
-05\end{array}$ & $\begin{array}{l}1.3 \mathrm{E} \\
-05\end{array}$ & $\begin{array}{l}1.35 \\
E-05\end{array}$ \\
\hline devosia & $\begin{array}{l}3.17 \\
\text { E-05 }\end{array}$ & $\begin{array}{l}0.00 \\
051\end{array}$ & $\begin{array}{l}9.41 \\
\text { E-05 }\end{array}$ & $\begin{array}{l}0.00 \\
091\end{array}$ & $\begin{array}{l}1.4 \mathrm{E} \\
-05\end{array}$ & $\begin{array}{c}0.00 \\
086 \\
2\end{array}$ & $\begin{array}{l}4.9 \mathrm{E} \\
-05\end{array}$ & $\begin{array}{c}0.00 \\
045 \\
7\end{array}$ & $\begin{array}{c}2.6 \mathrm{E} \\
-05\end{array}$ & $\begin{array}{l}0.00 \\
062\end{array}$ \\
\hline $\begin{array}{l}\text { bifidobact } \\
\text { erium }\end{array}$ & $\begin{array}{l}1.59 \\
E-05\end{array}$ & $\begin{array}{l}3.19 \\
E-05\end{array}$ & 0 & 0 & $\begin{array}{l}3.5 \mathrm{E} \\
-05\end{array}$ & $\begin{array}{l}1.76 \\
E-05\end{array}$ & $\begin{array}{l}1.63 \\
E-05\end{array}$ & $\begin{array}{l}1.57 \\
E-05\end{array}$ & $\begin{array}{l}1.3 \mathrm{E} \\
-05\end{array}$ & $\begin{array}{l}4.05 \\
E-05\end{array}$ \\
\hline $\begin{array}{l}\text { alkaliflexu } \\
\mathrm{s}\end{array}$ & $\begin{array}{l}7.93 \\
E-05\end{array}$ & $\begin{array}{c}0.00 \\
055 \\
8\end{array}$ & $\begin{array}{c}0.00 \\
054 \\
9\end{array}$ & $\begin{array}{c}0.00 \\
026 \\
8\end{array}$ & $\begin{array}{c}0.00 \\
020 \\
3\end{array}$ & $\begin{array}{c}0.00 \\
040 \\
4\end{array}$ & $\begin{array}{l}8.16 \\
E-05\end{array}$ & $\begin{array}{l}0.00 \\
022\end{array}$ & $\begin{array}{c}2.6 \mathrm{E} \\
-05\end{array}$ & $\begin{array}{c}0.00 \\
043 \\
2\end{array}$ \\
\hline $\begin{array}{l}\text { prochloroc } \\
\text { occus }\end{array}$ & $\begin{array}{c}0.00 \\
014 \\
3\end{array}$ & $\begin{array}{c}0.00 \\
025 \\
5\end{array}$ & $\begin{array}{c}0.00 \\
034 \\
5\end{array}$ & $\begin{array}{c}0.00 \\
058 \\
9\end{array}$ & $\begin{array}{l}0.00 \\
014\end{array}$ & $\begin{array}{l}5.28 \\
E-05\end{array}$ & $\begin{array}{c}0.00 \\
075 \\
1\end{array}$ & $\begin{array}{c}0.00 \\
045 \\
7\end{array}$ & $\begin{array}{c}0.00 \\
014 \\
3\end{array}$ & $\begin{array}{c}0.00 \\
020 \\
2\end{array}$ \\
\hline $\begin{array}{l}\text { methylom } \\
\text { onas }\end{array}$ & $\begin{array}{l}4.76 \\
E-05\end{array}$ & $\begin{array}{l}1.59 \\
E-05\end{array}$ & $\begin{array}{l}4.7 \mathrm{E} \\
-05\end{array}$ & $\begin{array}{c}0.00 \\
020 \\
1\end{array}$ & $\begin{array}{l}1.4 \mathrm{E} \\
-05\end{array}$ & $\begin{array}{l}1.76 \\
\text { E-05 }\end{array}$ & 0 & $\begin{array}{c}0.00 \\
012 \\
6\end{array}$ & $\begin{array}{l}2.6 \mathrm{E} \\
-05\end{array}$ & $\begin{array}{l}2.7 \mathrm{E} \\
-05\end{array}$ \\
\hline fluviicola & $\begin{array}{c}0.00 \\
022 \\
2\end{array}$ & $\begin{array}{l}7.97 \\
\text { E-05 }\end{array}$ & $\begin{array}{c}0.00 \\
065 \\
9\end{array}$ & $\begin{array}{c}0.00 \\
052 \\
2\end{array}$ & $\begin{array}{l}0.00 \\
021\end{array}$ & $\begin{array}{c}0.00 \\
014 \\
1\end{array}$ & $\begin{array}{c}0.00 \\
068 \\
5\end{array}$ & $\begin{array}{c}0.00 \\
023 \\
6\end{array}$ & $\begin{array}{l}5.19 \\
\text { E-05 }\end{array}$ & $\begin{array}{c}0.00 \\
018 \\
9\end{array}$ \\
\hline $\begin{array}{l}\text { haliscome } \\
\text { nobacter }\end{array}$ & $\begin{array}{l}6.34 \\
E-05\end{array}$ & $\begin{array}{c}0.00 \\
111 \\
6\end{array}$ & $\begin{array}{l}1.57 \\
\text { E-05 }\end{array}$ & $\begin{array}{l}4.01 \\
E-05\end{array}$ & $\begin{array}{l}1.4 \mathrm{E} \\
-05\end{array}$ & $\begin{array}{c}0.00 \\
133 \\
6\end{array}$ & 0 & $\begin{array}{l}3.15 \\
\text { E-05 }\end{array}$ & $\begin{array}{c}2.6 \mathrm{E} \\
-05\end{array}$ & $\begin{array}{c}0.00 \\
213 \\
1\end{array}$ \\
\hline
\end{tabular}

Bioresource Technology, Vol 216 (September 2016): pg. 446-452. DOI. This article is (C) Elsevier and permission has been granted for this version to appear in e-Publications@Marquette. Elsevier does not grant permission for this article to be further copied/distributed or hosted elsewhere without the express permission from Elsevier. 
NOT THE PUBLISHED VERSION; this is the author's final, peer-reviewed manuscript. The published version may be accessed by following the link in the citation at the bottom of the page.

\begin{tabular}{|c|c|c|c|c|c|c|c|c|c|c|}
\hline $\begin{array}{l}\text { sterolibact } \\
\text { erium }\end{array}$ & $\begin{array}{c}0.00 \\
012 \\
7 \\
\end{array}$ & $\begin{array}{c}0.00 \\
078 \\
2 \\
\end{array}$ & $\begin{array}{l}9.41 \\
\text { E-05 }\end{array}$ & $\begin{array}{c}0.00 \\
081 \\
6 \\
\end{array}$ & $\begin{array}{c}0.00 \\
119 \\
1 \\
\end{array}$ & $\begin{array}{c}0.00 \\
070 \\
3 \\
\end{array}$ & $\begin{array}{l}6.53 \\
E-05\end{array}$ & $\begin{array}{c}0.00 \\
025 \\
2 \\
\end{array}$ & $\begin{array}{l}1.3 \mathrm{E} \\
-05\end{array}$ & $\begin{array}{c}0.00 \\
021 \\
6 \\
\end{array}$ \\
\hline $\begin{array}{l}\text { desulfitob } \\
\text { acterium }\end{array}$ & $\begin{array}{l}4.76 \\
E-05\end{array}$ & $\begin{array}{c}0.00 \\
014 \\
4\end{array}$ & $\begin{array}{c}0.00 \\
018 \\
8\end{array}$ & $\begin{array}{l}2.68 \\
E-05\end{array}$ & $\begin{array}{l}4.2 \mathrm{E} \\
-05\end{array}$ & $\begin{array}{c}0.00 \\
022 \\
9\end{array}$ & $\begin{array}{c}0.00 \\
011 \\
4\end{array}$ & $\begin{array}{l}1.57 \\
E-05\end{array}$ & $\begin{array}{l}5.19 \\
\text { E-05 }\end{array}$ & $\begin{array}{c}0.00 \\
024 \\
3\end{array}$ \\
\hline $\begin{array}{l}\text { calditerric } \\
\text { ola }\end{array}$ & $\begin{array}{c}0.00 \\
028 \\
5\end{array}$ & $\begin{array}{c}0.00 \\
028 \\
7\end{array}$ & $\begin{array}{c}0.00 \\
025 \\
1\end{array}$ & $\begin{array}{c}0.00 \\
032 \\
1\end{array}$ & $\begin{array}{c}0.00 \\
014\end{array}$ & $\begin{array}{c}0.00 \\
035 \\
2\end{array}$ & $\begin{array}{c}0.00 \\
018\end{array}$ & $\begin{array}{c}0.00 \\
018 \\
9\end{array}$ & $\begin{array}{c}0.00 \\
026\end{array}$ & $\begin{array}{c}0.00 \\
032 \\
4\end{array}$ \\
\hline waddlia & $\begin{array}{c}0.00 \\
017 \\
4\end{array}$ & $\begin{array}{c}0.00 \\
102 \\
1\end{array}$ & 0 & $\begin{array}{l}1.34 \\
E-05\end{array}$ & $\begin{array}{c}0.00 \\
016 \\
1\end{array}$ & $\begin{array}{c}0.00 \\
072 \\
1\end{array}$ & $\begin{array}{l}9.79 \\
E-05\end{array}$ & 0 & $\begin{array}{c}0.00 \\
015 \\
6\end{array}$ & $\begin{array}{c}0.00 \\
059 \\
3\end{array}$ \\
\hline $\begin{array}{l}\text { lachnoclos } \\
\text { tridium }\end{array}$ & $\begin{array}{c}0.00 \\
011 \\
1\end{array}$ & $\begin{array}{l}9.57 \\
E-05\end{array}$ & $\begin{array}{l}6.27 \\
E-05\end{array}$ & $\begin{array}{l}6.69 \\
E-05\end{array}$ & $\begin{array}{l}8.41 \\
E-05\end{array}$ & $\begin{array}{c}0.00 \\
015 \\
8\end{array}$ & $\begin{array}{l}0.00 \\
018\end{array}$ & $\begin{array}{l}6.3 E \\
-05\end{array}$ & $\begin{array}{l}3.9 E \\
-05\end{array}$ & $\begin{array}{l}2.7 \mathrm{E} \\
-05\end{array}$ \\
\hline prevotella & $\begin{array}{l}1.59 \\
\text { E-05 } \\
\end{array}$ & 0 & 0 & $\begin{array}{l}1.34 \\
\text { E-05 }\end{array}$ & $\begin{array}{l}7.01 \\
\text { E-06 }\end{array}$ & 0 & $\begin{array}{l}1.63 \\
\text { E-05 } \\
\end{array}$ & 0 & $\begin{array}{l}1.3 \mathrm{E} \\
-05 \\
\end{array}$ & 0 \\
\hline $\begin{array}{l}\text { sphingoba } \\
\text { cterium }\end{array}$ & $\begin{array}{l}4.76 \\
E-05\end{array}$ & $\begin{array}{c}0.00 \\
025 \\
5 \\
\end{array}$ & $\begin{array}{c}0.00 \\
031 \\
4\end{array}$ & $\begin{array}{l}0.00 \\
012\end{array}$ & $\begin{array}{c}0.00 \\
011 \\
2\end{array}$ & $\begin{array}{c}0.00 \\
022 \\
9\end{array}$ & $\begin{array}{c}0.00 \\
035 \\
9\end{array}$ & $\begin{array}{c}0.00 \\
014 \\
2 \\
\end{array}$ & $\begin{array}{l}1.3 \mathrm{E} \\
-05\end{array}$ & $\begin{array}{c}0.00 \\
037 \\
8 \\
\end{array}$ \\
\hline $\begin{array}{l}\text { phycispha } \\
\text { era }\end{array}$ & $\begin{array}{l}9.51 \\
E-05\end{array}$ & $\begin{array}{c}0.00 \\
049 \\
4\end{array}$ & 0 & $\begin{array}{l}4.01 \\
\text { E-05 }\end{array}$ & $\begin{array}{c}0.00 \\
014 \\
7\end{array}$ & $\begin{array}{c}0.00 \\
029 \\
9\end{array}$ & 0 & 0 & $\begin{array}{l}7.79 \\
\text { E-05 }\end{array}$ & $\begin{array}{c}0.00 \\
036 \\
4\end{array}$ \\
\hline $\begin{array}{l}\text { desulfocap } \\
\text { sa }\end{array}$ & $\begin{array}{c}0.00 \\
020 \\
6 \\
\end{array}$ & $\begin{array}{c}0.00 \\
023 \\
9 \\
\end{array}$ & $\begin{array}{c}0.00 \\
012 \\
5 \\
\end{array}$ & $\begin{array}{c}0.00 \\
034 \\
8 \\
\end{array}$ & $\begin{array}{c}0.00 \\
018 \\
2 \\
\end{array}$ & $\begin{array}{c}0.00 \\
036 \\
9 \\
\end{array}$ & $\begin{array}{l}3.26 \\
E-05\end{array}$ & $\begin{array}{c}0.00 \\
023 \\
6 \\
\end{array}$ & $\begin{array}{l}7.79 \\
\text { E-05 }\end{array}$ & $\begin{array}{c}0.00 \\
028 \\
3 \\
\end{array}$ \\
\hline thauera & $\begin{array}{l}3.17 \\
\mathrm{E}-05 \\
\end{array}$ & $\begin{array}{l}3.19 \\
\mathrm{E}-05 \\
\end{array}$ & 0 & $\begin{array}{l}2.68 \\
E-05 \\
\end{array}$ & $\begin{array}{l}7.01 \\
\text { E-06 } \\
\end{array}$ & 0 & 0 & $\begin{array}{l}1.57 \\
\text { E-05 } \\
\end{array}$ & 0 & $\begin{array}{l}1.35 \\
E-05 \\
\end{array}$ \\
\hline
\end{tabular}

Bioresource Technology, Vol 216 (September 2016): pg. 446-452. DOI. This article is C Elsevier and permission has been granted for this version to appear in e-Publications@Marquette. Elsevier does not grant permission for this article to be further copied/distributed or hosted elsewhere without the express permission from Elsevier. 